\title{
LESSONS FROM BIOMINERALISATION: THE ROLE OF POST-TRANSLATIONAL MODIFICATION
}

\author{
Benjamin Matthewson
}

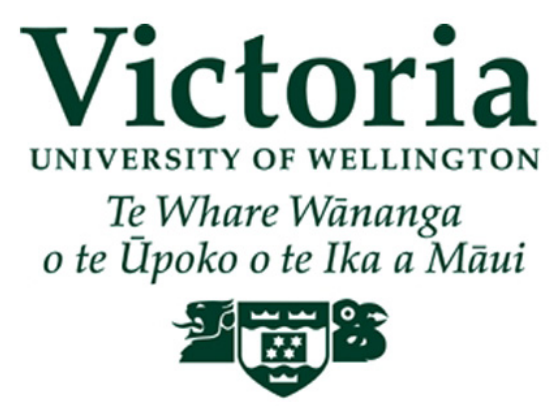

A thesis

submitted to the Victoria University of Wellington

in fulfilment of the requirements for the degree of

Doctor of Philosophy

in Chemistry

Victoria University of Wellington 


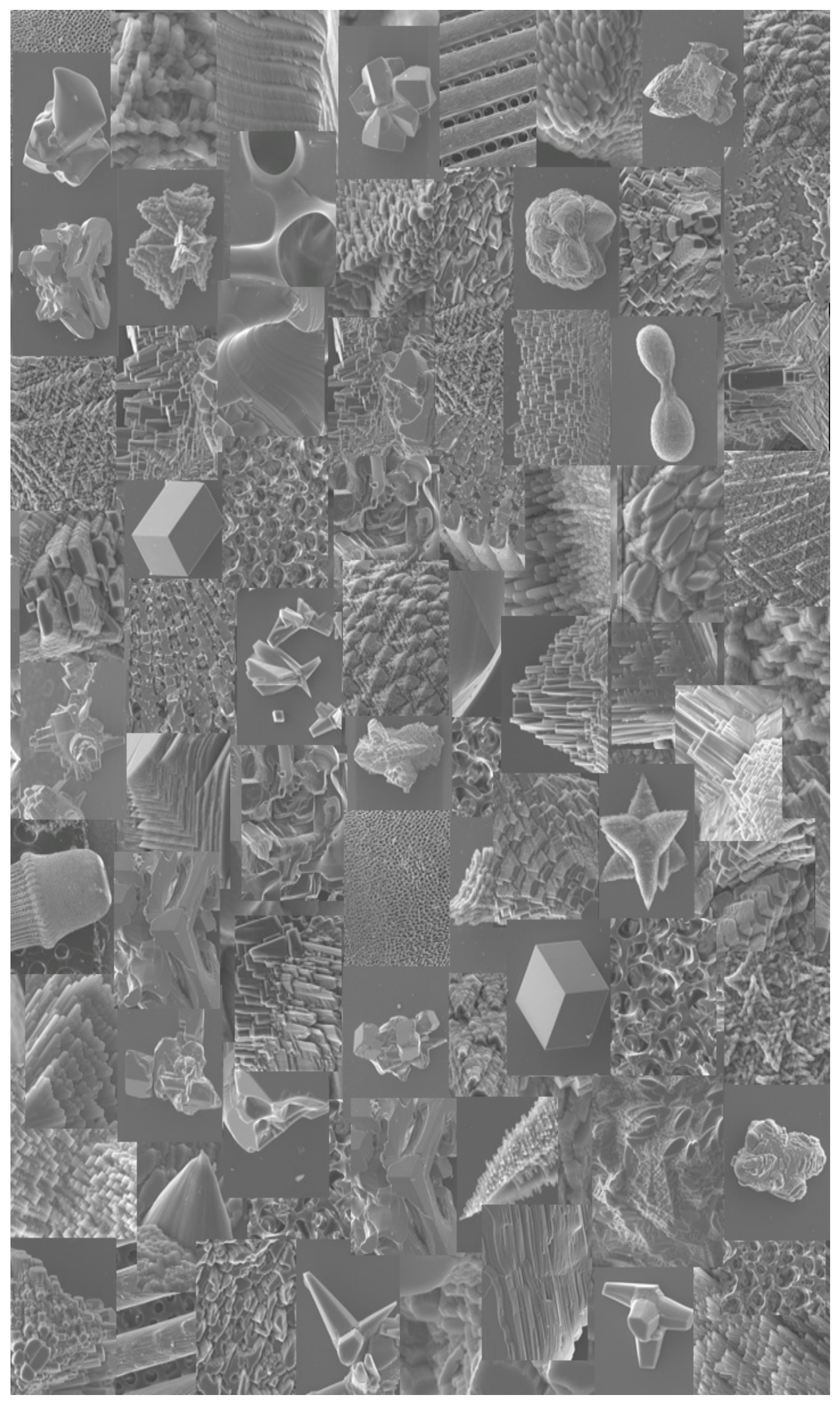




\section{ABSTRACT}

In this thesis we present our findings following analysis of the acidic organic matrix (SMP) occluded in the calcite spines of the New Zealand sea urchin Evechinus chloroticus. The main focus involves correlation of the structure and function of the post-translational modifications (PTMs). The experimental framework developed to achieve this involved mapping the structure of the PTMs throughout SMP based on molecular weight (MW) followed by selective removal of each of the identified PTMs. The functional analysis involved the use of SMP, and its derivatives, as additives in an in vitro calcium carbonate crystallisation assay. The adoption of in vitro methods was considered appropriate as the focus of this work was to develop strategies towards programmable crystal growth in vitro.

From analysis of the PTMs we have shown that there is extensive protein glycosylation, sulfation, and phosphorylation; all are involved in rendering the isoelectric point (pl) of the SMP macromolecules. The sulfates are exclusively housed on the glycan framework whereas the phosphate is protein bound. The majority of the SMP glycone is charged with O-glycosylation accounting for $80.0 \pm$ $4.0 \mathrm{wt} \%$.

The structure of the glycans includes sulfated HexNAc oligomers, and potentially mucin-like/keratan sulfate and/or carrageenan structures. Using Stains-All we have shown that the desulfated HexNAc oligomers have the ability to bind calcium which signals relevance in the formation of calcium carbonate.

SMP was fractionated by MW across a series of spin-filters. Use of the various fractions in the crystallisation assay showed that the species in the greater than $30 \mathrm{kDa}$ fraction held the ability to increase the number of crystals nucleated. In contrast, the macromolecules in the 10 to $30 \mathrm{kDa}$ range contained the full complement of morphologically active species. The result that these functions can be isolated demonstrates that they are independently controlled. 
The structure-function relationships determined include: the protein and the acidic glycans are jointly sufficient to generate the nucleating function; deglycosylated SMP holds the complete morphological activity, however, the glycans contribute by increasing reproducibility presumably through regulatory influences; and the sterically hindered phosphate residues make a slight contribution to this morphological activity.

These results indicate that analyses which involve characterisation of the morphological function of cloned biomineral proteins may indeed correspond to their native counterparts. The observation that the morphologically active species are phosphorylated identifies them as the calcium-binding phosphoproteins. The morphological activity of SMP stripped of all PTMs is equivalent to the proteins extracted from the aragonitic layer of Haliotis iris.

Characterisation of SMP demonstrated similarities with the OMs of other sea urchin species. For example, SMP appears to include SM30. In addition, the overall structure of SMP includes abundant acidic glycosylation with a relatively neutral protein component. This structural make-up is in contrast to the highly acidic proteins which are barely post-translationally modified. 


\section{ACKNOWLEDGEMENTS}

To the people who brought me to where I am today:

First and foremost I would like to thank my supervisor and mentor Kate McGrath. For inventing this project, and securing the funds to pay for it. Because of your willingness to engage in commercially-focused research I now find myself employed. Most of all though, for being there.

The people in the Biochemistry Department at the University of Otago. My co-supervisor Sigurd Wilbanks, thank you for your patience as I orientated myself in a new field. Alan Carne who completed the 2D SDS-PAGE experiments while I watched and asked questions. And Törsten Kleffman who completed a series of proteomics analyses on SMP.

lan Simms who generously provided time and expertise guiding me through the sugar work. This was a one-way relationship - I asked for help and he gave it.

Frédérick Marin for providing the soluble matrix extracted from the calcitic prisms of Pinna nobilis. Also for writing a paper that was so enjoyable that I only read it a page at a time.

Catherine Davis for the SEM images of the crystals grown in the presence of the organic matrix extracted from the aragonitic layer of Haliotis iris.

The workshops at the Complex Carbohydrate Research Center and Imperial College of London. Special mention to Parastoo Azadi, Mark Sutton-Smith, and Anne Dell.

For emphasising the importance of the work in science which goes on outside the laboratory, such as communication and commercialisation: Paul Callaghan.

I am very grateful for the leadership provided by John Spencer; I felt that my contribution to the School was valued.

Keith Gordon, my honours supervisor. Constructing organic light-emitting diodes was the beginning of my interest in micromachines and their potential role in controlled templation.

Sally Brooker told me in a second year laboratory that I was a capable student. I then became a capable student.

My $3^{\text {rd }}$ form Chemistry teacher who demonstrated a passion for chemistry, thank you Robert Wellington.

The taxpayers who paid for this work.

Funding Agencies: the MacDiarmid Institute for Advanced Materials and Nanotechnology and Victoria University of Wellington.

The staff who get things done: Darren Alexander, David Flynn, Margaret Brown, Alan Rennie, Manu, Liza Wilson, Sally Wisheart, Lisa Meredith, Helen Rowly, and Scott Forbes.

Friends: Jade Mackay, Amar Flood, Jihua Yang, Conrad Lendrum, and Evan Blackie.

Family: Claire Matthewson, Clive Matthewson, Gail Birt, Lisa Matthewson, John Matthewson, Mavora Watson, Roland Watson, Felix Page,

and Ellie Gray - we made it. 


\section{LIST OF ABBREVI ATI ONS}

\begin{tabular}{|c|c|}
\hline Abbreviated & Expanded \\
\hline A280 & UV absorption at $280 \mathrm{~nm}$ \\
\hline AAA & Amino acid analysis \\
\hline ACC & Amorphous calcium carbonate \\
\hline Asp-rich & Aspartic acid-rich \\
\hline GAGs & Glycosaminoglycans \\
\hline Gal & Galactose \\
\hline GalNAc & $N$-acetylgalactosamine \\
\hline GC & Gas chromatography \\
\hline GC-MS & Gas chromatography-mass spectrometry \\
\hline GlcNAc & $\mathrm{N}$-acetylglucosamine \\
\hline HexNAcs & $\mathrm{N}$-acetylgalactosamine and $\mathrm{N}$-acetylglucosamine \\
\hline HPAEC & High-pressure Anion Exchange Chromatography \\
\hline HPLC & High-pressure liquid chromatography \\
\hline MALDI TOF/TOF & Matrix-Assisted Laser Desorption Ionisation Time of flight spectrometry \\
\hline Man & Mannose \\
\hline MS & Mass spectrometry \\
\hline MSA & Monosaccharide analysis \\
\hline $\mathrm{MQ}$ & Ultrapure water \\
\hline MW & Molecular weight \\
\hline MWCO & Molecular weight cut-off \\
\hline NANA & $\mathrm{N}$-acetylneuraminic acid \\
\hline OM & Organic matrix \\
\hline $\mathrm{pl}$ & Isoelectric point \\
\hline PNGase $\mathrm{F}$ & peptide-N4-(acetyl-b-glucosaminyl) asparagine amidase \\
\hline PTM(s) & Post-translational modification(s) \\
\hline SDS-PAGE & Sodium dodecyl sulfate polyacrylamide gel electrophoresis \\
\hline SMP & Spine matrix glycoproteins \\
\hline $\mathrm{SMP}<10 \mathrm{kDa}$ & The eluant of SMP which has been fractionated over a $10 \mathrm{kDa}$ spin-filter \\
\hline SMP10-30kDa & The retentate of $S M P>30 \mathrm{kDa}$ which has been fractionated over a $10 \mathrm{kDa}$ spin-filter \\
\hline $\mathrm{SMP}>30 \mathrm{kDa}$ & The retentate of SMP which has been fractionated over a $30 \mathrm{kDa}$ spin-filter \\
\hline SMPDeGly & $\begin{array}{l}\text { SMP which has been treated with acid to remove the glycans and therefore the } \\
\text { associated sulfates }\end{array}$ \\
\hline SMPDeN-g & SMP which has been treated enzymatically to remove the $\mathrm{N}$-glycosylation \\
\hline SMPDePO & SMP which has been treated with a phosphatase \\
\hline SMPDePTM & SMP which has all of the post-translational modifications removed \\
\hline SMPDeSia & SMP which has been treated with acetic acid to remove the sialic acids \\
\hline SMPDeSOxhr & $\begin{array}{l}\text { SMP which has been treated with methanolic } \mathrm{HCl} \text { to remove the sulfates (where ' } \mathrm{x} \text { ' } \\
\text { represents the time in hours that the sample was incubated in acid) }\end{array}$ \\
\hline TFA & Trifluoroacetic acid \\
\hline TFMS & Trifluoromethane sulfonic acid \\
\hline TMS & Trimethylsilane \\
\hline Tris & Tris(hydroxymethyl)aminomethane \\
\hline
\end{tabular}




\section{Table Of Contents}

Abstract

Acknowledgements

List of Abbreviations

Table of Contents

List of Figures

xiii

List of Tables

xvii

Chapter 1 : Introduction

$\begin{array}{lll}1.1 & \text { Calcium Carbonate } & 1\end{array}$

1.2 Biomineralisation 2

1.3 Biomineral Construction 3

1.3.1 The Organic Matrix 5

1.3.1.1 Composition: Individual Chemical Moieties 6

1.3.1.1.1 Acidic Amino Acids $\quad 7$

1.3.1.1.2 Glycosylation and Sulfation 8

$\begin{array}{lll}\text { 1.3.1.1.3 Phosphoproteins } & 10\end{array}$

1.3.1.2 Macromolecular Structure: Meccano 11

1.3.1.3 3D Assemblies: Macromolecular Architectures 12

$\begin{array}{lll}1.4 & \text { Sea Urchin } & 14\end{array}$

$\begin{array}{lll}\text { 1.4.1 The Spine Mineral } & 14\end{array}$

1.4.1.1 Amorphous Calcium Carbonate 16

$\begin{array}{lll}\text { 1.4.2 Sea Urchin Organic Matrix } & 16\end{array}$

1.5 Chapter Outline 22

$\begin{array}{lll}1.6 & \text { References } & 25\end{array}$

Chapter 2 : Experimental Framework 31

$\begin{array}{lll}2.1 & \text { Isolation of SMP } & 31\end{array}$

2.1.1 Preparation of Spines 31

2.1.2 Spine Decalcification $\quad 32$ 
$\begin{array}{lll}2.1 .3 & \text { Ultrafiltration } & 32\end{array}$

2.1.4 Protein Isolation 32

2.2 Structural Methods 33

2.2.1 Spectroscopic Assays 33

2.2.1.1 Protein Quantitation 33

2.2.1.1.1 Bicinchoninic Acid Assay 34

2.2.1.1.2 Absorption at $280 \mathrm{~nm} \quad 34$

2.2.1.2 Other Detection 35

2.2.1.2.1 Phenol-Sulfuric Acid Assay 35

2.2.1.2.2 Ferric-Orcinol Assay 35

2.2.1.2.3 Malachite Green Assay 35

2.2.2 Monomer Analyses 36

2.2.2.1 Amino Acid Analysis 36

2.2.2.2 Monosaccharide Analysis $\quad 37$

2.2.2.2.1 Standardisation of the Spectra 39

$\begin{array}{lll}2.2 .3 & \text { SDS-PAGE } & 40\end{array}$

2.2.3.1 Coomassie Blue $\quad 41$

2.2.3.2 Silver Stain $\quad 41$

2.2.3.3 Periodic acid-Schiff Base Stain 42

2.2.3.4 Alcian Blue Stain 43

2.2.3.5 Stains-All Stain $\quad 44$

2.2.3.6 2D SDS-PAGE 46

$\begin{array}{lll}2.2 .4 & H P L C & 46\end{array}$

$\begin{array}{lll}\text { 2.2.5 Glycan Structure Determination } & 47\end{array}$

2.2.5.1 Chemical Preparation 47

2.2.5.2 Mass Spectrometry 48

2.2.5.3 Linkage Analysis 49

2.2.5.4 Glycan Profiling 50

2.3 Functional Methods 51

2.3.1 Crystallisation Assay $\quad 51$

2.3.1.1 Optimisation of the Crystal Growth Conditions 54

2.4 SMP Ensemble Manipulation 57

2.4.1 SMP Fractionation (Chapter 5) 57

2.4.2 Specific Digestion of SMP (Chapter 6) 59 
2.4.2.1 Glycosylation $\quad 60$

2.4.2.1.1 N-Glycans and SMPDeN-g $\quad 60$

2.4.2.1.2 Sugar and Sulfate Removed (SMPDeGly) 63

2.4.2.2 Acidic Glycosylation $\quad 65$

2.4.2.2.1 Sialic Acid Removed (SMPDeSia) 65

2.4.2.2.2 Sulfate Removed (SMPDeSO) 65

2.4.2.3 Phosphate Removed (SMPDePO and SMPDePTM) 66

$\begin{array}{lll}2.5 & \text { References } & 67\end{array}$

Chapter 3 : Experimental protocols 73

$\begin{array}{lll}3.1 & \text { Isolation of SMP } & 73\end{array}$

$\begin{array}{lll}3.1 .1 & \text { Preparation of Spines } & 73\end{array}$

$\begin{array}{lll}\text { 3.1.2 Spine Decalcification } & 74\end{array}$

$\begin{array}{lll}\text { 3.1.3 Ultrafiltration } & 74\end{array}$

$\begin{array}{lll}\text { 3.1.4 Protein Isolation } & 74\end{array}$

3.2 Fractionation of the SMP Ensemble 75

$\begin{array}{lll}3.3 & \text { Specific Digestion of SMP } & 75\end{array}$

$\begin{array}{lll}\text { 3.3.1 N-Glycans and SMPDeN-G } & 75\end{array}$

$\begin{array}{lll}3.3 .2 & \text { O-Glycans } & 76\end{array}$

3.3.3 Sugar and Sulfate Removed (SMPDeGly) 76

3.3.4 Sialic Acid Removed (SMPDeSia) 77

3.3.5 Sulfate Removed (SMPDeSO) 77

3.3.6 Phosphate Removed (SMPDePO and SMPDePTM) 78

$\begin{array}{lll}3.4 & \text { Structural Protocols } & 78\end{array}$

$\begin{array}{lll}3.4 .1 & \text { Absorption at } 280 \mathrm{~nm} & 78\end{array}$

$\begin{array}{lll}3.4 .2 & \text { Colorimetric Assays } & 78\end{array}$

3.4.2.1 Bicinchoninic Acid Assay 78

$\begin{array}{lll}\text { 3.4.2.2 Phenol-Sulfuric Acid Assay } & 78\end{array}$

$\begin{array}{lll}\text { 3.4.2.3 Malachite Green Assay } & 79\end{array}$

$\begin{array}{lll}\text { 3.4.2.4 Ferric-Orcinol Assay } & 79\end{array}$

3.4.3 Gel Electrophoresis (SDS-PAGE) 80

$\begin{array}{lll}\text { 3.4.3.1 Gel Electrophoresis Stains } & 81\end{array}$

3.4.3.1.1 Silver Stain $\quad 81$

3.4.3.1.2 Alcian Blue Stain $\quad 82$

3.4.3.1.3 Stains-All Stain $\quad 82$ 
3.4.3.2 2D Gel Electrophoresis 83

$\begin{array}{lll}3.4 .4 & \text { HPLC } & 84\end{array}$

3.4.5 Monomer Analyses $\quad 84$

3.4.5.1 Amino Acid Analysis $\quad 84$

3.4.5.2 Monosaccharide Analysis $\quad 85$

3.4.5.2.1 Acid digestion with Alditol Acetate Derivatisation 85

3.4.5.2.2 Methanolysis with Trimethylsilane (TMS) Derivatisation 86

3.4.6 Glycan Profiling 86

3.4.6.1 Cleavage and Blocking of Disulfide Bridges 87

3.4.6.2 Cleavage into Glycopeptides 87

3.4.6.3 Release of Glycans from Glycopeptides 88

3.4.6.3.1 N-Glycans 88

3.4.6.3.2 O-Glycans 88

3.4.6.4 NaOH Permethylation 88

3.4.6.5 MALDI TOF/TOF 89

3.4.7 Glycosyl Linkage Analysis $\quad 89$

$\begin{array}{lll}3.5 & \text { Functional Protocols } & 90\end{array}$

$\begin{array}{lll}3.5 .1 & \text { Crystallisation } & 90\end{array}$

3.5.1.1 Crystal Growth 90

3.5.1.2 Scanning Electron Microscopy 90

$\begin{array}{lll}3.6 & \text { References } & 93\end{array}$

Chapter 4 : Results and Discussion Native Ensemble 95

4.1 Spectroscopic Methods $\quad 95$

$\begin{array}{lll}4.1 .1 & \text { Absorption at } 280 \mathrm{~nm} & 95\end{array}$

4.1.2 Phenol-Sulfuric Acid Assay 96

$\begin{array}{lll}\text { 4.1.3 Ferric-Orcinol Assay } & 98\end{array}$

4.1.4 Malachite Green Assay 100

$\begin{array}{lll}4.2 & \text { Amino Acid Analysis } & 101\end{array}$

$\begin{array}{lll}4.3 & \text { Monosaccharide Analysis } & 105\end{array}$

$\begin{array}{lll}4.4 & \text { SDS-PAGE } & 110\end{array}$

$\begin{array}{lll}\text { 4.4.1 Silver Stain } & 111\end{array}$

4.4.2 Alcian Blue Stain 112

$\begin{array}{lll}\text { 4.4.3 Periodic Acid-Schiff Stain } & 113\end{array}$ 
$\begin{array}{lll}\text { 4.4.4 Stains-All Stain } & 114\end{array}$

$\begin{array}{lll}\text { 4.4.5 2D SDS-PAGE } & 117\end{array}$

$\begin{array}{lll}4.5 & \text { Crystallisation } & 120\end{array}$

4.6 Chapter 4: Native Ensemble Summary 122

$\begin{array}{lll}4.7 & \text { References } & 125\end{array}$

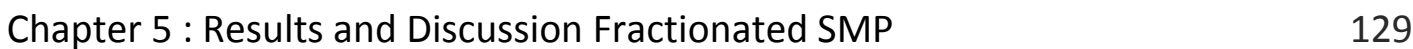

$\begin{array}{lll}5.1 & \text { Crystallisation } & 129\end{array}$

5.2 Compositional Analysis of SMP Fractions 133

5.2.1 Absorption at $280 \mathrm{~nm} \quad 133$

5.2.2 Amino Acid Analysis 134

$\begin{array}{ll}\text { 5.2.3 Monosaccharide Analysis } & 136\end{array}$

5.2.4 Malachite Green Assay 138

$\begin{array}{lll}\text { 5.2.5 SDS-PAGE } & 139\end{array}$

5.3 Chapter Five Fractionated SMP Summary 144

$\begin{array}{lll}5.4 & \text { References } & 147\end{array}$

$\begin{array}{ll}\text { Chapter } 6 \text { : Results and Discussion Specific Digestion of SMP } & 149\end{array}$

$\begin{array}{lll}6.1 & \text { Glycosylation } & 149\end{array}$

6.1.1 Amino Acid Analysis 150

6.1.2 Monosaccharide Analysis 151

6.1.3 Malachite Green Assay 154

$\begin{array}{lll}\text { 6.1.4 SDS-PAGE } & 155\end{array}$

$\begin{array}{ll}\text { 6.1.5 Linkage Analysis } & 159\end{array}$

6.1.6 Glycan Profiling 160

$\begin{array}{lll}\text { 6.1.7 Crystallisation } & 164\end{array}$

$\begin{array}{lll}6.2 & \text { Acidic Glycosylation } & 170\end{array}$

6.2.1 Amino Acid Analysis 171

6.2.2 Monosaccharide Analysis 172

6.2.3 Malachite Green Assay 174

$\begin{array}{lll}\text { 6.2.4 SDS-PAGE } & 174\end{array}$

$\begin{array}{lll}\text { 6.2.5 Crystallisation } & 178\end{array}$

$\begin{array}{lll}6.3 & \text { Phosphate } & 181\end{array}$

6.3.1 Malachite Green Assay 182 
$\begin{array}{lll}\text { 6.3.2 } & \text { SDS-PAGE } & 183\end{array}$

$\begin{array}{lll}\text { 6.3.3 Crystallisation } & 184\end{array}$

6.4 2D SDS-PAGE of Specific Digestion Products 189

6.5 Chapter Six: Selective Digestion Summary 192

$\begin{array}{lll}6.6 & \text { References } & 195\end{array}$

$\begin{array}{ll}\text { Chapter } 7 \text { : Conclusions } & 199\end{array}$

7.1 Future Directions 202

$\begin{array}{lll}7.2 & \text { References } & 205\end{array}$ 


\section{LIST OF FI GURES}

Figure 1-1: The crystal structure of calcite. Blue, red, and white spheres represent calcium ions, oxygen atoms, and carbon atoms, respectively. The crystallographic axes are indicated on the left. The original image was created by NIMSoffice at en.wikipedia.

Figure 1-2: SEM images of a NZ sea urchin spine. Septa, bridges, and trabeculae are indicated.

Figure 2-1: Scan of SDS-PAGE gels (12\%) of SMP (10 $\mu \mathrm{g}$ each) stained with Coomassie Blue (lane 1) and silver stain (lane 2: Morrissey method; and lane 3: Gotliv method). The molecular weights $(\mathrm{kDa})$ as determined relative to standard proteins are indicated (black star).

Figure 2-2: Scan of SDS-PAGE gel (12\%) stained with periodic acid-Schiff base. The positive response returned from fetuin is indicated in lane $1(10 \mu \mathrm{g})$ and lane $2(20 \mu \mathrm{g})$. Approximate MWs are indicated on the left.

Figure 2-3: Scan of an Alcian blue stained ( $\mathrm{pH}$ 1) SDS-PAGE gel (10-20\%) showing the selectivity of Alcian blue. Odd and even numbered lanes $10 \mu \mathrm{g}$ and $20 \mu \mathrm{g}$, respectively. Casein (lanes 1 and 2: phosphorylated and calcium-binding), the soluble matrix extracted from the calcitic prisms of Pinna nobilis (lanes 3 and 4: sulfated), and fetuin (lanes 5 and 6: glycosylated). The Pinna nobilis sample was kindly provided by Frédérick Marin. The molecular weights $(\mathrm{kDa})$ as determined relative to standard proteins are indicated on the left.

Figure 2-4: Scan of a Stains-All stained SDS-PAGE gel (10-20\%) of showing that the calcium-binding soluble matrix extracted from the calcitic prisms of Pinna nobilis stains blue under the staining protocol used. The Pinna nobilis sample was kindly provided by Frédérick Marin. The molecular weights $(\mathrm{kDa})$ as determined relative to standard proteins are indicated on the left (black star).

Figure 2-5: SEM images showing the morphology of crystals produced using the standard crystal growth conditions ( $10 \mathrm{mM} \mathrm{CaCl}{ }_{2}$ and $5 \mu \mathrm{g} / \mathrm{mL}$ organic additive). Organic additives used, from left to right: SMP, N-glycans, and O-glycans. The other crystallisation variables included: 48 hours, $15^{\circ} \mathrm{C}$, and $0.1 \mathrm{~g}$ ammonium carbonate.

Figure 2-6: SEM images showing the different growth observed at $25^{\circ} \mathrm{C}$ (row A) and $15^{\circ} \mathrm{C}$ (row B). The other crystallisation variables included: 48 hours, $10 \mathrm{mM} \mathrm{CaCl}_{2}$, and $0.1 \mathrm{~g}$ ammonium carbonate.

Figure 2-7: SEM images showing the number of crystals grown after 48,72 , and 96 hours (from left to right). The other crystallisation variables included: $15^{\circ} \mathrm{C}, 100 \mathrm{mM} \mathrm{CaCl}$, and $0.4 \mathrm{~g}$ ammonium carbonate.

Figure 2-8: SEM images showing the number of crystals grown in the presence of 7.5, 100, and $500 \mathrm{mM} \mathrm{CaCl}$. The other crystallisation variables included: $15^{\circ} \mathrm{C}, 48$ hours, and $0.4 \mathrm{~g}$ ammonium carbonate.

Figure 2-9: SEM images showing the different growth observed upon varying ammonium carbonate concentration. Rows $\mathrm{A}$ to $\mathrm{C}: 0.04,0.07$, and $0.10 \mathrm{~g}$ ammonium carbonate, 
respectively. The other crystallisation variables included: $15^{\circ} \mathrm{C}, 500 \mathrm{mM} \mathrm{CaCl}$, and 48 hours.

Figure 2-10: SEM images showing the different growth observed upon varying SMP concentration from 5,30 , and $60 \mu \mathrm{g} / \mathrm{mL}$ (left to right). The other crystallisation variables included: $15^{\circ} \mathrm{C}, 500 \mathrm{mM} \mathrm{CaCl}_{2}, 48$ hours, and $0.1 \mathrm{~g}$ ammonium carbonate.

Figure 2-11: SEM images showing the morphology of calcium carbonate crystals grown in the presence of PNGase F contaminants. The additive included: excess glycerol (left: 10 $\mu \mathrm{L} / \mathrm{mL}$ ) and excess PNGase $\mathrm{F}$ (right: 10 units $/ \mathrm{mL}$ ). The conditions used to grow the crystals were: $15^{\circ} \mathrm{C}, 500 \mathrm{mM} \mathrm{CaCl}_{2}$, 48 hours, and $0.1 \mathrm{~g}$ ammonium carbonate.

Figure 2-12: Scan of a silver stained SDS-PAGE gel (12\%) of $5 \mu \mathrm{g}$ fetuin (lane 1) and $5 \mu \mathrm{g}$ TFMS treated (deglycosylated) fetuin (lane 2). Molecular weight standards with masses $(\mathrm{kDa})$ indicated on the left (black star).

Figure 4-1: A280 standard curve generated for the quantification of SMP protein concentration in MQ. SMP protein concentration was determined by AAA. The standardisation was completed in duplicate (orange and blue dots). The line of best-fit is depicted (red line).

Figure 4-2: Standard curve generated against D-mannose (blue dots) using the phenolsulfuric acid assay. The line of best-fit is depicted (red line). Alanine was also tested to demonstrate that there was no cross-reactivity (orange dots).

Figure 4-3: Determination of the hexose content of SMP using the phenol-sulfuric acid assay. A range of SMP concentrations were used (orange dots) and a line of best-fit generated (red line).

Figure 4-4: Standardisation chart generated for the ferric-orcinol assay. $N$ acetylneuraminic acid (NANA) was used as the standard. The standardisation was completed in duplicate (orange and blue dots) and a line of best-fit (red) generated. 99

Figure 4-5: Standardisation chart generated using the malachite green assay against a series of $\mathrm{KH}_{2} \mathrm{PO}_{4}$ solutions. The line of best-fit is depicted (red line).

Figure 4-6: An overlay trace monitoring for sugar (blue) and protein (green). Elution times and intensities were determined by measuring refractive index and A280, respectively. 1 , 2 , and 3 mark the protein trace features. The negative values $(X)$ represent the elution front. These data were kindly collected by Dr lan Simms at Industrial Research Ltd.

109

Figure 4-7: Scans of silver stained SDS-PAGE gels of SMP. Lane 1: 12\% gel. Lane 2: 4-20\% gradient gel. Relative molecular weights as determined by electrophoresis of standards are indicated (black star).

Figure 4-8: Scans of Alcian blue stained SDS-PAGE gels (12\%) of SMP. Gels A (pH 3) and B $(\mathrm{pH} 1): 10 \mu \mathrm{g}$. Gels $\mathrm{C}(\mathrm{pH} 3)$ and $\mathrm{D}(\mathrm{pH} 1): 40 \mu \mathrm{g}$. Approximate MWs are indicated on the left.

Figure 4-9: Scan of a periodic acid-Schiff base stained SDS-PAGE gel of SMP (12\%). Material which did not enter into the gel is marked by the orange arrow. Approximate MWs are indicated. 
Figure 4-10: Scan of a Stains-All stained SDS-PAGE gel (10-20\%) of SMP (lane 1). Relative molecular weights as determined by electrophoresis of standards are indicated (black star).

Figure 4-11: Scans of 2D SDS-PAGE gels of SMP. The gels were stained with silver stain (A), Alcian blue at $\mathrm{pH} 1$ (B), and Stains-All (C). The first dimension was a non-equilibrium gradient gel using Immobiline with a $\mathrm{pH}$ range of 3 to 10 . The second dimension was a SDS-PAGE gel (12\%). Molecular weights $(\mathrm{kDa})$ were determined relative to $\mathrm{MW}$ standards as indicated on the Alcian blue stained gel (B). The direction of the applied electric field is represented by the charge symbols above the gels. The features marked with arrows are discussed in the text.

Figure 4-12: SEM images depicting the morphology of crystals grown in the presence of SMP.

Figure 5-1: SEM images showing the morphology of $\mathrm{CaCO}_{3}$ crystals grown in the presence of fractionated SMP. Additives are as follows: SMP<10kDa (row A), SMP10-30kDa (row B), and SMP $>30 \mathrm{kDa}$ (row C).

Figure 5-2: Scan of a silver stained SDS-PAGE gel (12\%) of SMP (lane 1), SMP<30kDa (lane 2 ), and SMP $>30 \mathrm{kDa}$ (lane 3). Relative molecular weights as determined by electrophoresis of standards are indicated (black star).

Figure 5-3: Scans of Alcian blue pH 1 (lanes 1 to 3) and Stains-All (lanes 4 to 6) stained 10$20 \%$ gradient SDS-PAGE gels of: SMP10-30kDa (lanes 1 and 4), SMP>30kDa (lanes 2 and 5), and SMP $<10 \mathrm{kDa}$ (lanes 3 and 6), respectively. Relative molecular weights as determined by electrophoresis of standards are indicated (black star).

Figure 5-4: Overlay trace of SMP (black line) and a series of Pullulan standards monitored using refractive index following elution through a size-exclusion HPLC column. Assignment of peaks from left to right: $100 \mathrm{kDa}$ (blue), $48 \mathrm{kDa}$ (light blue), $24 \mathrm{kDa}$ (green), $12 \mathrm{kDa}$ (pink), and $6 \mathrm{kDa}$ (blue). All of these were detected using refractive index. Bovine serum albumin $(67 \mathrm{kDa}$, red trace) was detected measuring A280. These data were kindly collected by Dr lan Simms at Industrial Research Ltd.

Figure 6-1: Scans of silver stained SDS-PAGE gels (12\%) of SMP (lanes 1 and 3), SMPDeN-g (lane 2), and SMPDeGly (lane 4). Relative molecular weights as determined by electrophoresis of standards are indicated (black star).

156

Figure 6-2: Scans of Alcian blue (pH 1) stained SDS-PAGE gels (10-20\%) of SMP (lane 1), SMPDeN-g (lane 2), and SMPDeGly (lane 3). Relative molecular weights as determined by electrophoresis of standards are indicated (black star).

Figure 6-3: Scans of Stains-All stained SDS-PAGE gels (10-20\%) of SMP (lane 1), SMPDeN-g (lane 2), and SMPDeGly (lane 3). Relative molecular weights as determined by electrophoresis of standards are indicated (black star).

Figure 6-4: Structures of the neutral N-glycans of SMP. Squares represent HexNAcs, black squares GlcNAc, circles hexoses, gray circles mannose, gray triangles fucose, diamonds $\mathrm{N}$-glycolylneuraminic, and gray diamond $\mathrm{N}$-acetylneuraminic acid. Results were collected as part of the GlycoTRIC programme, Dell Laboratory, Imperial College of London. 
Figure 6-5: Structures of the neutral O-glycans of SMP. Squares represent HexNAcs, circles hexoses, triangles fucose, and diamonds $\mathrm{N}$-glycolylneuraminic acid (a sialic acid). Results were collected as part of the GlycoTRIC programme, Dell Laboratory, Imperial College of London.

Figure 6-6: SEM images showing the morphology of $\mathrm{CaCO}_{3}$ crystals grown in the presence of SMPDeN-g (row A), N-glycans (row B), O-glycans (row C), and SMPDeGly (rows D and E).

Figure 6-7: Scans of the Alcian blue (pH 1) stained SDS-PAGE gels (10-20\%) of SMP (lane 1), SMPDeSia (lane 2), and SMPDeSO3, 5, 7, and 9hr (lanes 3 to 6, respectively). Relative molecular weights as determined by electrophoresis of standards are indicated (black star).

Figure 6-8: Scans of silver stain SDS-PAGE gels (12\%) of SMP (lanes 1 and 3), SMPDeSia (lane 2), SMPDeSO7hr (lane 4), and SMPDeSO9hr (lane 5). Relative molecular weights as determined by electrophoresis of standards are indicated (black star).

Figure 6-9: Scans of Stains-All stained SDS-PAGE gels (10-20\%) of SMP (lane 1) and SMPDeSia (lane 2), and SMPDeSO3, 5, 7, and 9hr (lanes 3 to 6, respectively). Relative molecular weights as determined by electrophoresis of standards are indicated (black star).

Figure 6-10 SEM images showing morphology of $\mathrm{CaCO}_{3}$ crystals grown in the presence of SMPDeSO3, 5, 7, and 9hr (rows A to D, respectively).

Figure 6-11: SEM images demonstrating morphology of $\mathrm{CaCO}_{3}$ crystals grown in the presence of SMPDeSia.

Figure 6-12: Scans of SDS-PAGE gels (10-20\%) of SMPDePO and SMPDePTM. Lanes 1 and 2: silver stained SMP and SMPDePO, respectively. Lanes 3 and 4: Alcian blue $(\mathrm{pH} 1)$ stained SMP and SMPDePO, respectively. Lanes 5 and 6: Stains-All stained SMP and SMPDePO, respectively. Lane 7: Stains-All stained SMPDePTM. Relative molecular weights as determined by electrophoresis of standards are indicated (black star) with MWs indicated on the left.

Figure 6-13: SEM images showing the morphology of $\mathrm{CaCO}_{3}$ crystals grown in the presence of SMPDePO (row A) and SMPDePTM (row C). The morphology of crystals grown in the presence of SMP is included for comparison (rows B and D).

Figure 6-14: SEM images of calcium carbonate crystals grown in the presence of the soluble OM extracted from the nacreous layer of Haliotis iris. These images were kindly provided by Catherine Davis.

Figure 6-15: Scanned images of silver stained 2D SDS-PAGE gels of SMP (gel A), SMPDeSO (gel B), SMPDePO (gel C), and SMPDeGly (gel D). The first dimension was a non-equilibrium gradient gel using Immobiline with a $\mathrm{pH}$ range of 3 to 10 . The second dimension was a SDS-PAGE gel (12\%). Molecular weights ( $\mathrm{kDa}$ ) were determined relative to MW standards as indicated on gel D. The direction of the applied electric field is represented by the charge symbols above gel $\mathrm{D}$. The boxed features are discussed in the text. 


\section{LIST OF TABLES}

Table 2-1: Outline of the general differences between the two classes of glycans, that is, $\mathrm{N}$ - and O-linked glycans. Man is mannose, Gal is galactose, GlcNAc is $\mathrm{N}$-acetylglucosamine, and GalNAc is $N$-acetylgalactosamine.

Table 4-1: Tabulation of the amino acid analysis results for SMP. Shown are the means \pm the standard deviation of 4 experiments. Asx and Glx represent; aspartic acid and asparagine, and glutamic acid and glutamine, respectively. The tests for tryptophan or any unusual amino acids were not completed. These data were collected by the Australian Proteome Analysis Facility.

Table 4-2: The monosaccharide content of SMP. GIcNAc and GalNAc (HexNAcs) are $N$ acetyl glucosamine and $\mathrm{N}$-acetyl galactosamine, respectively. The hexoses, HexNAcs, and uronic acids were determined following TFA, $\mathrm{HCl}$, and $\mathrm{MeOH}-\mathrm{HCl}$ digestion, respectively. Shown are the means \pm the standard deviation of 4 experiments testing for each of the hexoses and HexNAcs, and 2 experiments testing for uronic acids. Column 2 depicts the mass of sugar relative to the mass of protein within SMP. Column 3 takes into account the results of this chapter and depicts the wt\% of each sugar relative to the mass of SMP, including the mass of all the PTMs quantified (protein, phosphate, and sugars (including sialic acid)).

106

Table 4-3: The number of crystals grown (nucleation density) per $\mathrm{mm}^{2}$ in the presence of SMP and with no organic additive (blank). Shown are the means \pm the standard deviation (8 experiments blank, 7 experiments SMP).

Table 4-4: A summary of the quantitative data collected throughout the chapter. Shown are the means \pm the standard deviation of at least 4 experiments. In column 2 the masses provided are relative to $100 \mu \mathrm{g}$ protein, and in column 3 the various chemical moieties have been converted to a wt\% of the complete ensemble.

Table 5-1: The number of crystals grown per $\mathrm{mm}^{2}$ in the presence of the various fractionated additives. SMP and blank results are included for comparison. Shown are the means \pm the standard deviation of 4 experiments for the fractionated samples.

Table 5-2: The distribution of protein across the 3 fractioned samples SMP $<10 k D a$, SMP10$30 \mathrm{kDa}$, and $\mathrm{SMP}>30 \mathrm{kDa}$. as determined by $\mathrm{A} 280$ measurements. Shown are the means \pm the standard deviation of 4 experiments.

Table 5-3: Amino acid analysis of each of the fractionated samples. The fractionated samples include SMP $<10 \mathrm{kDa}$, SMP10-30kDa, and SMP $>30 \mathrm{kDa}$. Shown are the means \pm the standard deviation of 2 experiments. Asx and Glx represent aspartic acid and asparagine, and glutamic acid and glutamine, respectively. Cysteine, tryptophan, and the unusual amino acids were not tested for. These data were collected by the Australian Proteome Analysis Facility (APAF).

Table 5-4: Tabulation of the monosaccharide analyses completed on each of the fractionated samples. The fractionated samples include SMP $<10 \mathrm{kDa}$, SMP10-30kDa, and $\mathrm{SMP}>30 \mathrm{kDa}$. Hexoses and HexNAcs were determined following TFA and $\mathrm{HCl}$ digestion, respectively. Shown are the means \pm the standard deviation of 4 experiments. The top section represents the mass of sugar in $100 \mu \mathrm{g}$ protein of the fractionated sample. The 
middle section depicts the data scaled to reflect its contribution to the ensemble as determined by $\mathrm{A} 280$ (p. 47).

Table 5-5: Results for the malachite green assay of the SMP fractionated samples. Shown are the means \pm the standard deviation of 4 experiments. In column 2 the results represent the mass of phosphate within $100 \mu \mathrm{g}$ protein of that fraction. Column 3 shows the results scaled according to how much each fraction contributes to the SMP ensemble as determined by A280 measurements (p. 47).

Table 6-1: The results obtained following AAA of SMPDeGly and SMP (included for comparison). The tests for cysteine, tryptophan, or any unusual amino acids, were not completed. Shown are the means \pm the standard deviation of 2 experiments. Asx and Glx represent; Asp and Asn, and Glu and Gln, respectively. These data were collected by the Australian Proteome Analysis Facility.

150

Table 6-2: Monosaccharide analyses of the SMP N- and O-glycones. Shown are the means \pm the standard deviation of 4 experiments. In column 2 the results depict the mass of each sugar relative to $100 \mu \mathrm{g}$ protein SMP. In column 4 the mass of each sugar has been compared to the mass of that monosaccharide present in the total ensemble (p. 47). The hexoses and HexNAcs were determined from TFA and $\mathrm{HCl}$ digestion, respectively. 151

Table 6-3: Tabulation of the results obtained following monosaccharide analysis of SMPDeGly. Shown are the means \pm the standard deviation of 4 experiments. The hexoses and $\mathrm{HexNAcs}$ were determined from an $\mathrm{HCl}$ digestion only.

Table 6-4: The phosphate content of SMPDeN-g and SMPDeGly as determined using the malachite green assay. Shown are the means \pm the standard deviation of 4 experiments. SMP is included for comparison.

Table 6-5: The number of crystals grown in the presence of the various glycan derivatives. Shown are the means \pm the standard deviation of 4 experiments for the glycan derivative samples. SMP and blank results are included for comparison.

165

Table 6-6: The AAA results obtained for SMPDeSO9hr. SMP is included as a comparison. Shown are the means \pm the standard deviation of 2 experiments. Asx and Glx represent aspartic acid and asparagine, and glutamic acid and glutamine, respectively. Cysteine, tryptophan, and the unusual amino acids were not tested for. These data were collected by the Australian Proteome Analysis Facility (APAF).

Table 6-7: The monosaccharide distribution of SMPDeSia. Shown are the means \pm the standard deviation of 4 experiments. The hexoses and HexNAcs were quantified following TFA hydrolysis. The sialic acid content was determined using the ferric-orcinol assay. In column 2 are the masses for each monosaccharide relative to protein mass. In column 3 the mass in column 2 is compared to the mass of each monosaccharide as determined for native SMP (p. 47).

Table 6-8: The averaged MSA results from the series of desulfated samples. Shown are the means \pm the standard deviation of 4 experiments. The hexoses and HexNAcs were quantified following TFA hydrolysis. The sialic acid content was determined using the ferric-orcinol assay. In column 2 are the masses for each monosaccharide relative to 
protein mass. In column 3 the mass in column 2 is compared to the mass of each monosaccharide as determined for native SMP (p. 47).

Table 6-9: Phosphate content of the various glycan neutralised samples, as determined using the malachite green assay. Shown are the means \pm the standard deviation of 4 experiments. SMP is included for comparison.

Table 6-10: The nucleation density (crystals $/ \mathrm{mm}^{2}$ ) of the various SMP glycan neutralised samples. Shown are the means \pm the standard deviation of 4 experiments for the glycan neutralised samples. The blank and SMP sample results are included for comparison. 179

Table 6-11: The phosphate content of SMPDePO (SMPDePO>3kDa) and SMPDePTM as determined using the malachite green assay. Shown are the means \pm the standard deviation of 4 experiments. SMP, SMPDePO $<3 \mathrm{kDa}$, and $\mathrm{SMP}<3 \mathrm{kDa}$ are included for comparison.

Table 6-12: The nucleation density (crystals $/ \mathrm{mm}^{2}$ ) of the dephosphorylated samples SMPDePO and SMPDePTM. Shown are the means \pm the standard deviation of 4 experiments for the dephosphorylated samples. SMP and blank results are included for comparison. 


\section{CHAPTER 1 : I NTRODUCTI ON}

The focus of this investigation was on the post-translational modification (PTM) of the water soluble acidic organic matrix (SMP) occluded in the spines of the New Zealand sea urchin Evechinus chloroticus. The spines themselves are constructed from calcium carbonate and are an example of a biomineral. The PTMs were characterised in terms of both their chemical structures and their ability to exert influence over crystal growth in vitro. In this chapter we provide a background to previous research which put the results of this thesis in context.

\subsection{Calci um Carbonate}

The six most common polymorphs of calcium carbonate include: calcite, aragonite, vaterite, calcium carbonate monohydrate, calcium carbonate hexahydrate, and amorphous calcium carbonate. ${ }^{[1]}$ While having a different spatial arrangement of atoms, both vaterite and calcite have a face-centred rhombohedral unit cell, which is in contrast to the more densely packed orthorhombic cell of aragonite. Under ambient conditions and high purity, calcite is the thermodynamically preferred polymorph. ${ }^{[2-4]}$ The crystal structure of calcite is depicted in Figure 1-1 below.

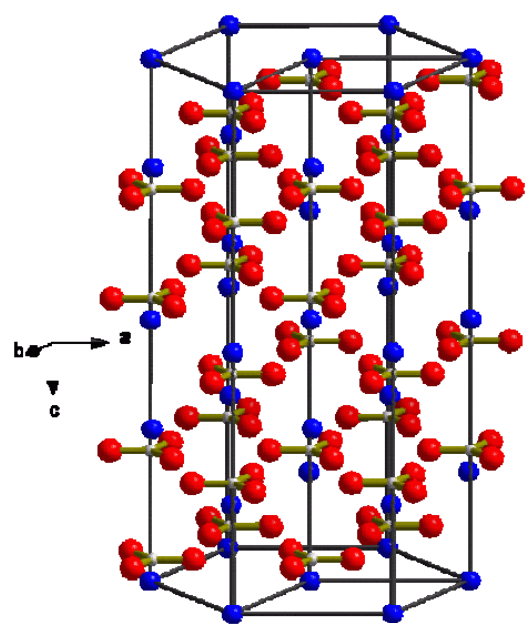

Figure 1-1: The crystal structure of calcite. Blue, red, and white spheres represent calcium ions, oxygen atoms, and carbon atoms, respectively. The crystallographic axes are indicated on the left. The original image was created by NIMSoffice at en.wikipedia. 
The acute rhombohedron of the calcite unit cell contains two $\mathrm{CaCO}_{3}$ units. The c-axis of the cell is orientated perpendicular to the planes of $\mathrm{Ca}^{2+}$ and $\mathrm{CO}_{3}{ }^{2-}$ ions. The crystallographic features of calcite are, however, normally reported in relation to the hexagonal unit cell as it is more convenient for visualisation. This unit cell incorporates $\operatorname{six} \mathrm{CaCO}_{3}$ units and has the same height as the long diagonal of the rhombohedral cell. Layers of $\mathrm{Ca}^{2+}$ and $\mathrm{CO}_{3}{ }^{2-}$ alternate with a rotation of $60^{\circ}$ between adjacent $\mathrm{CO}_{3}{ }^{2-}$ layers. There are 12 layers to the hexagonal cell with each $\mathrm{Ca}^{2+}$ atom adapting an octahedral arrangement to neighbouring $\mathrm{CO}_{3}{ }^{2-}$ molecules. ${ }^{[5]}$

Equation 1-1 gives the chemical equations ( $a$ and $b$ ) which account for the formation of calcium carbonate from the starting materials carbon dioxide and water. $^{[6]}$

$$
\begin{aligned}
& \mathrm{CO}_{2}+\mathrm{H}_{2} \mathrm{O} \rightleftarrows \mathrm{HCO}_{3}{ }^{-}+\mathrm{H}^{+} \\
& \mathrm{Ca}^{2+}+\mathrm{HCO}_{3}{ }^{-} \rightleftarrows \mathrm{CaCO}_{3}+\mathrm{H}^{+}
\end{aligned}
$$

Equation 1-1: The chemical equations demonstrating the equilibria which lead to calcium carbonate precipitation. $^{[6]}$

\subsection{BIOMI NERALI SATION}

Biomineralisation is defined as the process by which soft organic organisms form rigid inorganic functional crystals. ${ }^{[1]}$ With the advancement of relevant analytical methods in the 1930s access to these highly detailed structures became possible. These methods included X-ray diffraction and higher-resolution optical microscopes, which provided improved access to their construction. The study of biomineralisation is interdisciplinary with investigators originating from fields such as palaeontology, oceanography, microbiology, biochemistry, dentistry and materials science. ${ }^{[7]}$

Biomineralisation is ubiquitous throughout nature and incorporates the use of over 60 different biogenic minerals. ${ }^{[5]}$ These range from the relatively simple $\mathrm{CaCO}_{3}$, the focus in this investigation, through to relatively complex 
$\mathrm{Ca}_{18} \mathrm{H}_{2}(\mathrm{Mg}, \mathrm{Fe})^{2+}{ }_{2}\left(\mathrm{PO}_{4}\right)_{14}$ and $\mathrm{CaC}_{2} \mathrm{O}_{4} \cdot(2+\mathrm{X}) \mathrm{H}_{2} \mathrm{O}(\mathrm{X}<0.5)$. Of all the biogenic mineral types, approximately $50 \%$ contain calcium. ${ }^{[5,7]}$

In the natural environment organisms tailor the mineral phase so that the final material demonstrates targeted properties. For example, nacre, the protective aragonitic bricks of molluscan shell, is three thousand times more resistant to fracture than non-biological aragonite. ${ }^{[8]}$ The level of control required to produce a material with specific properties targeted at a particular function is well beyond what we are currently able to achieve in the laboratory. ${ }^{[9]}$ This is in part because nature has developed mechanisms to overcome fundamental constraints such as kinetics and thermodynamics and grow inorganic structures that are energetically unfavoured. For example, some sea urchin biominerals are constructed of magnesian calcite, ${ }^{[2,10]}$ which should convert to the thermodynamically preferred aragonite ${ }^{[1,11]}$ at the levels of $\mathrm{Mg}^{2+}$ incorporated (3.0 to $43.5 \mathrm{~mol} \% \mathrm{Mg}^{2+}$ ). This demonstrates that nature has developed methods of mineral manipulation which would be useful to understand. An important feature of biomineral construction is that they are fabricated at ambient temperature which could have economic and environmental benefits. ${ }^{[12]}$ We want to therefore study how nature manipulates crystal growth and apply these in a different context such as the laboratory. ${ }^{[1,7,13]}$ Calcium carbonate provides a good test case. Extension of the techniques beyond calcium carbonate is likely to lead to novel materials with optimised properties. ${ }^{[5]}$

\subsection{Biomi neral CONSTRUCtion}

The process of biomineralisation is extremely complicated. In order to simplify and generalise this process, Lowenstam, Weiner, ${ }^{[7]}$ and Mann ${ }^{[1]}$ proposed a universal scheme fro biomineralisation that involves four fundamental parameters: space delineation, establishment of a saturated solution, onset of nucleation, and modulation until cessation (Scheme 1-1). Space delineation (A) involves the isolation of an area where the mineralisation takes place. This is usually constructed from a semi-permeable lipid membrane, polymerised proteins, or polysaccharides. This delineated space may act as a mould for the final 
morphology of the biominerals. Subsequently, there is the establishment of a supersaturated solution (B), which is thermodynamically controlled with kinetic influences. Kinetics becomes the constraining influence at the onset of nucleation (C), which can either occur in solution or on the surface of the membrane; in this case the membrane may act as a template. Crystal type and orientation can be set at this stage. Finally, controlled modulation of the mineralisation process until cessation (D) involves spatially controlled ion concentration within the delineated space. There are many layers of complexity that overlay this general biomineralisation scheme. ${ }^{[1,5,7]}$ Shell biomineralisation is under biological control and is an organic matrix (OM) meditated process. ${ }^{[14-16]}$ The organic matrix controls each of these four stages (A-D) from confining a space, forming an OM framework, controlling ion input, constructing a nucleation site, controlling orientation and nucleation, and terminating crystal growth. ${ }^{[9]}$

A

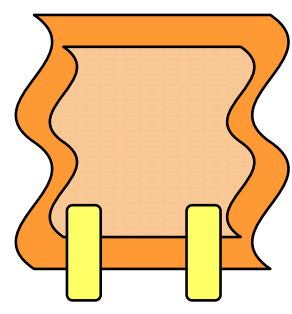

D - Ion channel
B

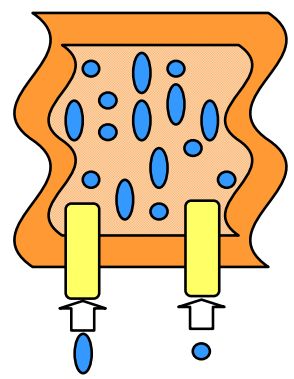

0o - Crystal constituent ions
C

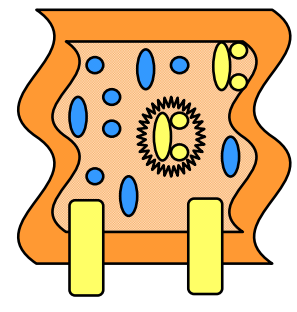

Oo - Membrane initiated

- Macromolecule assisted nucleation

Scheme 1-1: Pictorial representation of a generalised biomineral scheme. ${ }^{[7]} \mathrm{A}$, space delineation; $\mathrm{B}$, establishment of a saturated solution; C, onset of nucleation; and D, controlled modulation of the mineralisation process until cessation.

The outcome of this controlled mineralisation process is materials which are hierarchically constructed. That is, materials which have distinct textures over multiple length scales organised from nanometre to macroscopic scales. ${ }^{[3,13]}$ This type of construction requires controlled manipulation of crystal shape, orientation, 
and connectivity, leading to materials with enhanced functional properties. ${ }^{[13]}$ For example, calcite crystallised in the laboratory is typically rhombohedral and fractures easily. ${ }^{[17]}$ This is in stark contrast to the hard fenestrated stereom of protective sea urchin spines, ${ }^{[5]}$ which fracture conchoidally, being smooth and slightly concave, unlike pure calcite. ${ }^{[4]}$ Attempts to mimic biological constructions are very limited with many publications only showing slight deviations from the stepped calcite cylindrical growth. ${ }^{[13,18-21]}$ Analogous to the mineral phase, the organic matrix displays short- and long-range order, that is, it is hierarchically complex. The levels of construction include chemical composition, macromolecular construction, and 3-dimensional assembly.

\subsubsection{The Organic Matrix}

The organic matrix is intimately associated with the mineralisation process. ${ }^{[22]}$ It is comprised of a very complex mixture of chemical moieties which are highly varied both between species but also within a single biomineral. ${ }^{[15,16,23]}$ The chemical species which have been shown to be involved include: proteins, ${ }^{[24]}$ glycoproteins, ${ }^{[13,16,17,24,25]}$ proteoglycans, ${ }^{[24]}$ mucins, ${ }^{[26]}$ sugar polymers, ${ }^{[23,24]}$ and lipids. ${ }^{[14,27]}$ The roles mediated by these species include: crystal nucleation ${ }^{[17,22,28 \text {, }}$ ${ }^{29]}$ and growth, ${ }^{[24,29]}$ polymorph selection, ${ }^{[22,30,31]}$ morphological control, ${ }^{[15,17,22,32]}$ crystal inhibition, ${ }^{[28,29]}$ and fracture resistance properties. ${ }^{[17]}$

To explain the organic matrix construction, a two-component model based on empirical evidence has been proposed. ${ }^{[1]}$ This model includes two classes of species: framework insoluble hydrophobic macromolecules and acidic soluble macromolecules. The framework macromolecules are responsible for structural and biomechanical features whereas the acidic macromolecules are involved in processes such as crystal nucleation, mineral growth, ion transport, and general cellular processing. In this work we focused on the acidic glycoproteins, which have been shown to be essential in the formation of sea urchin larval spicules. ${ }^{[33]}$

Recent evidence, however, challenges the distinction between the two components. For example, Marin et al. ${ }^{[23]}$ showed that caspartin, a protein with 
both hydrophobic and hydrophilic components, was localised in both the intra (soluble) and intercrystalline (insoluble) domains. In addition to demonstrating the inadequacy of the two-component model, this observation demonstrates the critical relevance of microenvironment on activity, with the putative function of caspartin switching from nucleating (intracrystalline) to inhibiting (intercrystalline) depending on its local surroundings.

If we are going to successfully harness the methods used by nature in crystal manipulation we need to understand the interactions that are occurring at a molecular level, that is, we need to probe the structure-function relationship of the macromolecules. ${ }^{[17,23,34]}$ One of the reasons why deciphering the structurefunction relationship of the individual macromolecules is so difficult is that purification and characterisation of the native extracted species is extremely challenging. ${ }^{[9]}$ This is because these macromolecules are often glycosylated, ${ }^{[34]}$ charged, ${ }^{[7]}$ and tend to aggregate; ${ }^{[34]}$ all of these processes contribute to smearing on fractionation media and SDS-PAGE as opposed to migrating as discrete bands. ${ }^{[35]}$ For this reason cloning-based techniques have become prevalent. ${ }^{[27,34]} \mathrm{A}$ limitation of this approach is that the influential, often present, post-translational modifications are omitted. ${ }^{[36]}$ Indeed it has been experimentally demonstrated that the cloned and native species can be functionally disparate. ${ }^{[26]}$ Proteomic methods have also been productive in characterising the ensemble of proteins within a biomineral. The limitation of this type of analysis is that functional assessments are not completed. As a consequence the functional biochemical understanding of the structure-function relationship of the post-translational modifications remains very poor. In this work we have attempted to determine the structure and function of the post-translational modifications associated with the soluble acidic OM occluded in the spines of Evechinus chloroticus.

\subsubsection{Composition: I ndividual Chemi Cal Moieties}

One of the fundamental challenges for understanding biomineralisation is a thorough understanding of the roles mediated by the various macromolecules. ${ }^{[27]}$ However, as discussed, isolation and testing of individual macromolecules from 
biomineral sources is extremely difficult. Therefore the approach adopted in this thesis was to analyse the ensemble according to chemical functionalities with particular attention on the post-translational modifications, including glycosylation, sulfation, and phosphorylation.

\subsection{ACIDIC AMINO ACIDS}

A component of the $\mathrm{OM}$ which has received much attention is the acidic proteins which display a large number of aspartic and/or glutamic acid residues. ${ }^{[15]}$ In a wide variety of molluscan calcitic tissues, aspartic acid usually comprises more than 50 mol\% of the soluble organic matrix. ${ }^{[37]}$ The Asprich protein family which is occluded in the calcitic prisms of Atrina rigida is $\sim 75$ mol\% aspartic and glutamic acid. $^{[38,39]}$ The functions associated with these acidic proteins and domains ${ }^{[23]}$ include: templation and orientation of calcium carbonate and control of polymorphism. ${ }^{[15]}$

Berman et al. ${ }^{[0]}$ demonstrated that not all biomineral associated macromolecules are rich in acidic amino acids. From the amino acid analysis (AAA) of the organic matrix extracted from calcitic tissues of the sea urchin Paracentrotus lividus they showed that the extracted macromolecules only contained small amounts of aspartic and glutamic acid. Marie et al. ${ }^{[14]}$ contributed to this in their investigation on the water soluble OM extracted from the aragonitic layer of Unio pictorum. In this work they showed that the acidity was instead encoded via the sulfated glycan framework.

Previous investigations on the matrix have focused on the protein, with few investigations addressing the other occluded macromolecules. This is surprising given that it is a common feature of biomineral systems to have a wide variety of

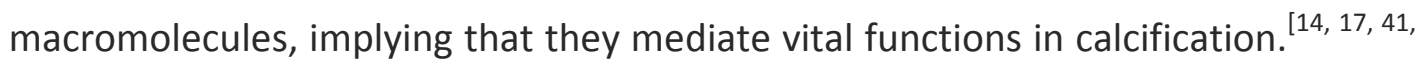
${ }^{42]}$ However, their action and structure remain poorly understood. ${ }^{[14]}$ 


\subsection{GLYCOSYLATION AND SULFATION}

Generally, glycans exhibit two modes of attachment to the protein scaffold in a glycoprotein. They are either attached to the protein through an asparagine amino acid (N-glycan), serine, or a threonine amino acid (O-glycan). The mode of attachment is reflected throughout the glycan structure and function. N-glycans have a common core structure (Man $\alpha 1,3($ Man $\alpha 1,6)$ Man $\beta 1,4 G I c N A c \beta 1,4 G I c N A c-N-$ Asn) and a consensus peptide triplet, Asn-Xaa-Ser/Thr; where Xaa is not proline. ${ }^{[43}$ 44]

Sulfated glycoproteins were first shown to be present within the mineralised tissues of the Roman snail Helix pomatia. ${ }^{[45,46]}$ While the full complement of roles fulfilled still remains vague, ${ }^{[14,27]}$ the importance of sulfated glycoproteins has been demonstrated. Currently the roles fulfilled include; inducing nucleation via an ionotropic effect, ${ }^{[15,47-49]}$ mineral surface recognition, ${ }^{[17,50]}$ calcium-binding, ${ }^{[14]}$ and isoelectric point $(\mathrm{pl})$ rendering. ${ }^{[14]}$ These researchers suggested that there are sulfated glycan structures similar to mucins and carrageenans; ${ }^{[26]}$ carrageenans being sulfated galactose homopolymers. Functions exerted by these glycan structures include: ion and water entrapment and viscosity modification. These species could therefore be active in the crystallisation process through modification of the local crystallisation environment. In order to more completely list the roles fulfilled by protein glycosylation, in the biomineralisation context, determination of the glycan primary structures is essential. ${ }^{[14]}$

Proteoglycans and mucins are examples of macromolecules which are heavily glycosylated. There are many similarities between these two types of macromolecules. For example, the ratio of sugar to protein is high ( $\sim 50 \mathrm{wt} \%$ ) and the glycan chains are often sulfated. ${ }^{[51]}$ Proteoglycans are proteins modified with a specific class of sugar called glycosaminoglycans (GAGs). These glycan chains often contain uronic acid, however, there are exceptions, such as keratan sulfate. Mucins and keratan sulfate are similar in that they both often contain galactoseGlcNAc dimer repeats throughout the backbone of the glycan. ${ }^{[12,51]}$ 
Mucin macromolecules can be very large with monomeric mucins displaying MW in the vicinity of 1 to $4 \mathrm{MDa} .{ }^{[52,53]}$ Mucins also tend to form oligomeric structures mediated through $\mathrm{N}$-terminal cysteine bridges ${ }^{[54]}$ with the overall $\mathrm{MW}$ of the oligomer being up to $40 \mathrm{MDa}{ }^{[51-53]}$. However, not all mucins form oligomeric structures. ${ }^{[51]}$ In this report by Marin et al., the first demonstration of mucin-like macromolecules in a molluscan mineralised tissue, the $\mathrm{MW}$ of so-called Mucoperlin was determined to be $\sim 70 \mathrm{kDa}$. The diagnosis of mucin-like structure was based on the protein sequence as opposed to glycosylation.

These heavily glycosylated macromolecules, proteoglycans and mucins have been shown to perform functions which may be relevant in the biomineralisation context. For example, they have the ability to form a selective barrier which can influence the diffusion of protons and bicarbonate, both of which are active species in the formation of calcium carbonate (p. 2). ${ }^{[12,51]}$

Sulfated glycans have been purported to be involved in nucleation events. ${ }^{[47]}$ The suggested mechanism involves the sulfates indirectly, as their role is to attract ions in the vicinity of a nucleating site. ${ }^{[48,49]}$ This model, referred to as an ionotropic effect, involves the electrostatic accumulation of ions in a localised area by low affinity-high capacity species, such as sulfate. ${ }^{[1,5,36]}$ These low affinity-high capacity species are able to bring about the supersaturation (high capacity) required for nucleation without binding to the ions of interest irreversibly (low affinity). This type of calcium-binding is in contrast to the high affinity-low capacity calcium-binding associated with proteins that, for example, calmodulin and Troponin C which exhibit an EF hands. These EF hands involve two protein helices and a calcium-binding loop. ${ }^{[55]}$

An example of a sulfated glycan which induces nucleation via an ionotropic effect is over-sulfated keratan sulfate, identified in the avian egg calcite shell occluded as a sugar chain attached to the proteoglycan mammallian. ${ }^{[56]}$ The function of the mammallian in the avian system was shown to be nucleation of calcite, and this process was dependent on the sulfation. Indeed, it has been shown that egg shell 
mineralisation starts with the formation of calcite crystals on the mammillae which contain mammallian. ${ }^{[56]}$

The first sequence of a protein-bound oligosaccharide covalently $\mathrm{N}$-linked to a dermatopontin, extracted from within a biomineral, was determined in 2003. ${ }^{[57]}$ This structure was relatively simple, containing only the five monosaccharides of the ubiquitous $\mathrm{N}$-glycan core. The only modification distinct from the core structure involved $\mathrm{O}$-methylation of the terminal mannose residues. The structure of a Nacrein $\mathrm{N}$-linked glycan was also recently published. ${ }^{[58]}$ This structure was slightly more complex, including three additional HexNAcs, a sialic acid, and a sulfate. In this report the authors speculated that these $\mathrm{N}$-glycan associated acidic features may be responsible for the calcium-binding ability of Nacrein as opposed to aspartic acid. The ability of the isolated $\mathrm{N}$-glycans or O-glycoproteins to affect crystal growth in vitro was not tested in either of these cases.

\subsection{PHOSPHOPROTEINS}

Phosphoproteins are a subsection of acidic proteins and have been shown to be integral components of calcium phosphate based biominerals, such as human bone and teeth. These macromolecules have domains which are rich in aspartic and glutamic acid, and serine. The serine residue provides a hydroxyl group which is available for covalent modification with phosphate, augmenting the overall negative charge. The precise role of these types of proteins is not yet known; however, they strongly interact with calcium ions. ${ }^{[1]}$ Phosphoproteins have also been found in calcium carbonate-based mineralised tissues, for example, in the shell matrix of the oyster Crassostrea nippona ${ }^{[22]}$ and numerous other molluscs. ${ }^{[59]}$ Borbas et al. ${ }^{[59]}$ examined a range of phosphoproteins extracted from eight superfamilies including both aragonitic and calcitic microstructures. In this work Borbas used colorimetric assays to quantify the amount of phosphate associated with the organic matrix, and attempted to determine its functional role by completing crystallisation assays monitoring the rate of crystal growth before and after dephosphorylation. The results of this analysis showed that both the calcitic and aragonitic tissues generally contained small amounts of phosphate ( 1 wt\%); 
however, the calcitic foliated microstructures averaged a phosphate content of 14 $\pm 1 \mathrm{wt} \%$. They also showed that the extracted phosphoproteins inhibited crystal growth in vitro and this was dependent on the extent of phosphorylation. A 50 wt\% decrease in phosphate had no effect on the rate of crystal growth, whereas an 85 wt\% dephosphorylation showed a dramatic increase in the rate of crystal growth.

\subsubsection{MACROMOLECULAR StRUCTURE: Meccano}

The interaction at the organic-inorganic interface occurs at the molecular level and is mediated through the chemical functionality. The morphological activity exerted by a macromolecule may not be confined to either the protein or the glycans. For example, analyses have shown an abundance of acidic moieties on both the protein and sugar chains in the form of aspartic and glutamic acid, and sialic acid, respectively. ${ }^{[1,60]}$ The carboxyl group has indeed been shown to have an affinity for $\mathrm{Ca}^{2+}$ ions in other situations and this would provide a simple explanation for the mode of interaction. ${ }^{[61,62]}$ Sulfate groups have been shown to be present within the $\mathrm{OM}$ and it is believed that the carboxyl and sulfate groups may bind cooperatively for enhanced affinity. ${ }^{[63]}$ The complexity of the organic-inorganic interaction is more complicated than these chemical functionalities. Experiments using acidic additives have not produced crystals with such developed structure as that obtained when using the sea urchin spine macromolecules. ${ }^{[13]}$ Recent studies have redirected the focus to the macromolecular components; that is the protein and sugar, with attempts to quantify the extent which each of these participates in, and directs calcium carbonate growth. ${ }^{[13,64,65]}$

Biomineral-associated macromolecules are often multifunctional and composed of independent co-operating functional modules. The functional motifs are thought to be compiled like building blocks, or Meccano, ${ }^{[27]}$ to produce proteins with a diverse set of functions from a limited set of building blocks. The resulting mosaic proteins have tailor-made functionality. ${ }^{[36]}$ This hypothesis is supported by the observation that biomineral-associated proteins share short sequence homologies, but homology of the full length protein is low. This Meccano analogy also extends 
to include the piecing together of different chemical functionalities, such as carbohydrate and protein. This hypothesis of macromolecular construction allows for the observation that peptide and carbohydrate building blocks are conserved across the different mineralised tissues within an organism, as well as across different organisms. ${ }^{[23]}$

Nacrein demonstrates how various functional modules can be spliced together for a particular function. The peptide structure of Nacrein incorporates a calciumbinding domain straddled by two catalytic carbonic anhydrase-like subdomains which catalyse the production of bicarbonate, a calcium carbonate precursor (Equation 1-1). ${ }^{[27,66]}$ In this model the calcium would be fixed in the vicinity of the bicarbonate production sites, which presumably lead to controlled mineralisation.

Addadi et al. ${ }^{[49]}$ demonstrated how the peptide and anionic carbohydrate structures can co-operate to bring about controlled nucleation when pieced together. The amino acid carboxylate groups can only weakly bind calcium. However, due to their ordered secondary structure they have calcium carbonate facial selectivity encoded. ${ }^{[67-69]}$ In contrast, the sulfated glycans are relatively disordered and with the sulfation modification attract calcium. This unordered polyanion induces an ionotropic effect, generating the necessary supersaturation calcium ions ${ }^{[48]}$ for nucleation in the vicinity of the organised acidic peptide template.

\subsubsection{3D AsSEMBLI ES: MACROMOLECULAR ARCHITECTURES}

The OM operates as an integrated system. ${ }^{[36]}$ The functional capability of the macromolecules is not only controlled by their structure. The surrounding microenvironment, including the neighbouring macromolecules, modulates their activity and performance. ${ }^{[34]}$

The organic matrix framework in mollusc shells demonstrates 3D assembly. ${ }^{[7]}$ There are three general chemical structures which are used to fine-tune the crystallisation microenvironment, which function as a unit to control mineral growth. These include chitin, silk-like proteins, and the water soluble OM. In the 
calcitic prisms of Atrina rigida $^{[39]}$ there are intracrystalline chitin filaments which are purported to provide structural integrity, ${ }^{[39]}$ as easy fracture along the (104) planes $^{[32]}$ is not observed. In the context of the aragonitic layer of the molluscan shell the function of the chitin is different, as the structural requirements of the mineral are different. Aragonite does not exhibit cleavage planes and therefore does not require the same reinforcement. In the aragonitic nacreous layer of the molluscan shell the chitin is inter-lamellar, external to the mineral. In this location the role of the chitin is to constrict crystal growth and therefore control the overall morphology of the crystal. In both of these polymorphic contexts the chitin is modified through the addition of functional macromolecules, including acid-rich proteins and sulfated sugars. The functions performed by the macromolecules in this context include: initiating nucleation, directing crystal orientation, polymorph selection, amorphous calcium carbonate (ACC) stabilisation, and influencing morphology. ${ }^{[32,39]}$ The role of the silk-like proteins also depends on the polymorphic context. In the context of the calcitic prismatic layer they form the intercrystalline layer and therefore act as a mould by constricting growth. In the aragonitic nacreous layer they form a hydrated gel-like state which fills the chitin compartments prior to aragonite formation, ${ }^{[70,71]}$ inhibiting spurious nucleation. ${ }^{[39]}$ The function of these three chemical structures is not limited to those described. For example, it has been shown that the chitin is highly ordered in relation to the mineral phase, indicating that crystal orientation is directly influenced by the chitin substructure. ${ }^{[72]}$

Crenshaw and Ristedt, ${ }^{[73]}$ and subsequently Nudelman et al. ${ }^{[15]}$ demonstrated assembled $\mathrm{OM}$ stratification within the interlamellar matrices beneath the aragonitic tablets of Nautilus pompilius. In these reports chemical imprints were considered to explain the observed controlled nucleation, emanating from the centre of these nacreous tablets. Using histological methods they showed that there are spots rich in carboxylates at the centre of the tablets. Surrounding this chemical functionality is a ring of sulfated material which presumably functions to attract the calcium ions in the vicinity of the central carboxylated spot. The 
carboxylate-rich spot and sulfate-rich surrounding ring are presumed to be protein and sugar based, respectively. Whether these two chemical groups were covalently bound was not determined. These chemical functionalities are held in place by a chitin framework, which also serves as a mould for the final crystal morphology. These investigations demonstrate that the $\mathrm{OM}$ is highly ordered and therefore only in its organised state do the individual components realise their intended function.

\subsection{SEA URChI N}

Adult echinoderms possess calcareous endoskeletal elements such as tests, plates, spines, pedicellarie, and teeth. ${ }^{[4]}$ The morphogenic development leading to spicule formation involves five stages: micromere formation, primary mesenchyme cell formation, syncytium formation, skeleton deposition, and skeleton remodelling and elaboration. ${ }^{[4]}$ The spicule is formed in a membrane bound extracellular compartment. ${ }^{[33]}$ Formation of the adult tissue occurs during the planktonic phase and is complex. In this work we focus on the adult spines which are covered by a thin epidermis. ${ }^{[4]}$

\subsubsection{The Spine Mineral}

Figure 1-2 shows images of various structural features of a sea urchin spine. These include; septa, bridges, and trabeculae. ${ }^{[16]}$ The labyrinth or fenestrate which is created is known as the stereom space. Spines demonstrate conchoidal fracture properties, a characteristic of an amorphous or glassy material, even though they are made of calcite. ${ }^{[1,7]}$ The spines are particularly strong, with equivalent strength-to-weight ratios as molluscan shells but with increased stiffness. ${ }^{[74]}$ The adult endoskeleton is comprised of magnesian calcite, usually about $5 \mathrm{wt} \% \mathrm{MgCO}_{3}$, and occluded matrix glycoproteins. ${ }^{[4,75]}$ They are therefore a nanocomposite, with $\sim 0.1 \mathrm{wt} \%$ of their mass being organic material. It is believed that it is the occluded OM which reinforces the mineral against fracture. ${ }^{[5]}$ 


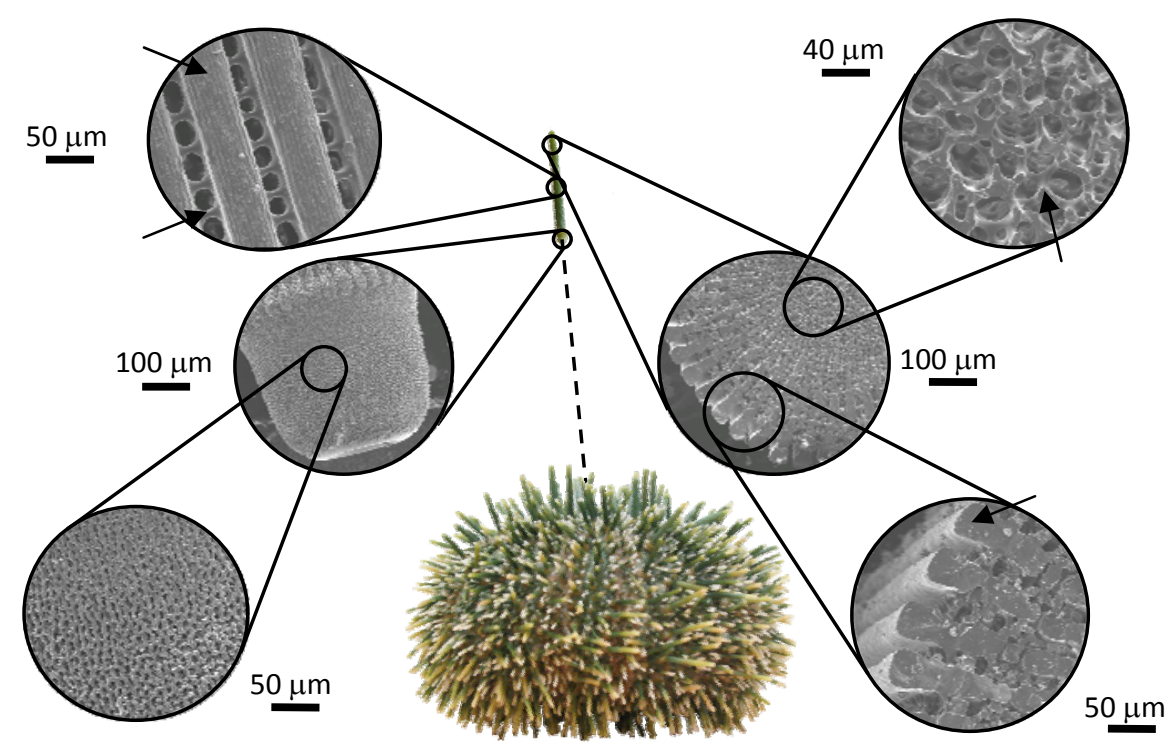

Figure 1-2: SEM images of a NZ sea urchin spine. Septa, bridges, and trabeculae are indicated.

Sea urchin biominerals appear as a single crystal to X-ray diffraction, ${ }^{[76]}$ and under polarised light, ${ }^{[4]}$ with the c-axis of the calcite spines being parallel to the length of the spine for all sea urchin species. ${ }^{[4]}$ While these composites appear as a single crystal they are actually comprised of an array of crystallographically orientated nanocrystals fused by mineral bridges. ${ }^{[77]}$ The size of the nanocrystals was demonstrated to be within $10-80 \mathrm{~nm} .{ }^{[77]}$ This type of construction is similar to the non-classical kinetically-controlled modular nanoblock-building mechanism of mesocrystals, in contrast to the classical thermodynamically-controlled construction involving the stepwise addition of atoms, ions, or molecules to the crystal. ${ }^{[78]}$ These two mechanisms of crystal formation can be distinguished based on the nature of the nucleation event. Under a thermodynamic regime a single nucleation event occurs, while nanoparticle mediated crystallisation is associated with multiple nucleation events with controlled orientation. ${ }^{[7,9,77,79,80]}$ An advantage of the non-classical crystallisation regime is that the nanoparticles can be synthesised elsewhere and subsequently transported to the site of mineralisation. ${ }^{[9]}$ In addition, the mesocrystal-based model allows for the incorporation of organic matter, as is observed, into the crystal lattice surrounding the nanocrystals. ${ }^{[78]}$ This many-nucleators model was supported by Marin and 
associates $^{[23]}$ who observed punctuated spots of the protein ${ }^{[23]}$ throughout the shell of Pinna nobilis that may be acting as intracrystalline nanocrystal nucleators.

\subsubsection{AMORPHOUS CALCI UM CARbonate}

A mineral is considered to be amorphous if it lacks long-range order. ${ }^{[36]}$ The role of amorphous calcium carbonate (ACC) in the biomineralisation process has received much attention. ${ }^{[1,61,64,81-84]}$ Transient conversion from ACC as a mineral precursor to calcite was first observed in the larvae of a sea urchin. ${ }^{[5]}$ It was shown using X-ray absorption and IR spectroscopy that the initially deposited larval spicule is more than half amorphous calcium carbonate. This subsequently converts to calcite. ${ }^{[79]}$ It was also noted that the rate at which this conversion occurs is much slower in the larvae, in comparison to that observed in vitro. ${ }^{[5]}$ This stabilisation of the metastable ACC could potentially be an important parameter in the overall morphological control exerted by the sea urchin. Since ACC is thermodynamically unstable it is believed that the matrix proteins are integral to this stabilisation. ${ }^{[4,5 \text {, }}$ 37, 85-87]

Meldrum and Cölfen ${ }^{[9]}$ have offered an explanation as to the implications of the precursor ACC phase. As a spicule grows a precipitating front is not observed, indicating that crystallisation occurs via a solid-state transformation process involving the fusion of ACC nanoparticles which align, order, and coalesce to form a single crystal. This method of crystal development falls under the mesocrystal paradigm and appears to also apply in the context of an adult sea urchin spine, as regeneration following spine fracture demonstrates calcification via an ACC precursor phase. ${ }^{[88]}$

\subsubsection{Sea UrChi n Organic Matri X}

As a sea urchin grows, its skeletal development is biologically controlled. Various groups have shown that a significant contributor to this process is an ensemble of soluble organic macromolecules, primarily glycoproteins, ${ }^{[75]}$ which are embedded within the skeleton. ${ }^{[5,13,16,17,25]}$ In the following section we outline what has been previously established on the structural and functional aspects of the occluded OM 
within the spines of various sea urchin classes including the New Zealand sea urchin Evechinus chloroticus. Results obtained from analyses of both juvenile and adult sea urchin have been included. We believe that the distinction between the two stages of development are not relevant in the context of the current work based on the work of Killian et al. ${ }^{[89]}$ In this report they demonstrated that there was significant Western blot cross-reactivity between the embryonic anti-total spicule matrix antiserum and the adult spine matrix indicating that the occluded OMs are relatively similar.

\section{Strongylocentrotus purpuratus}

Mann et al. ${ }^{[90]}$ analysed the proteomes of the adult spines and test of Strongylocentrotus purpuratus using MS techniques. In this investigation they listed 110 proteins that were present within these mineralised tissues. Approximately 40 of these were present in both tissues and a total of 60 to 70 were identified as being located in the spines. This result is consistent with, but slightly higher than, that enumerated by Killian et al. ${ }^{[89]}$ who observed, using 2D electrophoretic techniques, approximately 50 proteins within the embryonic spicules of the same species. The identified proteins can be grouped into protein families. These include: spicule matrix (SM) proteins, C-type lectin-like (CLECT) proteins, carbonic anhydrase species, collagens, MSP130 and related proteins, various metalloproteases, cyclophilins, and calcium-binding phosphoproteins. ${ }^{[90,91]}$

Of these proteins the SM proteins are the most abundant within the mineralised tissues. These can be divided into two groups: the SM50 and SM30 subfamilies. ${ }^{[90]}$ The SM50 subfamily includes; PM27, SM29, SM32, SM37, and SM50. ${ }^{[91]}$ As this collection of proteins present basic pl values they are probably not included within the OM analysed in this study (SMP) as we selectively isolated the acidic glycoproteins (p. 74). The SM30 subfamily includes SM30A-F and is probably included in SMP, as these species are slightly acidic with a theoretical pl of 5.94 based on the peptide sequence. SM30 has been shown to be glycosylated ${ }^{[92]}$ and common across sea urchin species, having been shown to also be present within 
the spicules of sea urchins Lytechinus pictus and Lytechinus variegatus. ${ }^{[93]}$ We would therefore expect this family of proteins to be the most abundant species in our extract. There is some controversy over the relative abundances of the different SM30 isoforms within the spines, presumably because the proportions change depending on the developmental stage of the organism. ${ }^{[89,90]}$ The function of SM30, which is synthesised by the primary mesenchyme cells and then transferred to the growing spicule, is unknown. ${ }^{[93]}$

The MW of SM30 excreted proteins is predicted to be $30.6 \mathrm{kDa}$ from the deduced amino acid sequence. However, from Western blots using SM30 antisera it was shown that the SM30 has a mass of approximately $46 \mathrm{kDa}$. To test whether this additional mass was the result of glycosyl modification, Killian et al. ${ }^{[25,93]}$ conducted two deglycosylation experiments. From these results they showed that there was $3 \mathrm{kDa}$ of $\mathrm{N}$-glycosylation and no O-glycosylation. This mass discrepancy of approximately $13 \mathrm{kDa}$ between the observed and accounted for $\mathrm{MW}$ is still unexplained. They then went on to analyse SM30 extracted from adult spines and showed that while they were approximately $3 \mathrm{kDa}$ heavier ( 46 and $49 \mathrm{kDa}$ ) than SMP30 extracted from embryonic spicules ( 43 and $46 \mathrm{kDa}$ ), the cause of this mass increase was not the result of $\mathrm{N}$-glycosylation, as the deglycosylated adult SM30 also showed a MW decrease of $3 \mathrm{kDa}$ following removal of the $\mathrm{N}$-glycans.

The MSP130 species are primary mesenchyme cell specific $\mathrm{N}$-glycosylated species which have been shown to mediate calcium carbonate deposition. The N-glycans, which have been shown to be anionic, include sulfate and sialic acid, ${ }^{[94,95]}$ are essential to spiculogenesis as inhibiting the attachment of the N-glycans to the protein using tunacimycin stopped skeletal formation. ${ }^{[95]}$ The deposition of calcium has been attributed to the ability to sequester calcium ions via the acidic carbohydrate moieties. $^{[95,96]}$

It has been shown that these MSP130 carbohydrate structures are displayed by other macromolecules, including SM30. This was demonstrated by their crossreactivity with the monoclonal antibody mAB1223, which selects for the MSP130 
calcium-binding carbohydrate. This mAB1223 epitope was shown to be essential in spiculogenesis as in vitro blocking with the antibody blocked calcium carbonate deposition. ${ }^{[95]}$ Using Western blot analyses it was shown that the binding of the antibody was diminished but still apparent following removal of the $\mathrm{N}$-glycans, indicating that other chemical components of the glycoprotein are involved in the antibody recognition. ${ }^{[93]}$

Within the spicules is a fibrous, presumably organic, meshwork. ${ }^{[4]}$ This network presents concentric rings perpendicular to the length of the spine which are potentially linked via struts between laminae. ${ }^{[97]}$ Seto et al. ${ }^{[75]}$ expanded on this work in an attempt to localise the SM30 and SM50 proteins spatially within the spines. Following partial dissolution of the mineral exposing the meshwork they treated it with antibodies raised against the SM proteins. As they observed no clear ordering of these species they hypothesised that the multiprotein assemblage is woven throughout the organic fabric to form orientated microcrystalline domains.

\section{Paracentrotus lividus}

The investigation completed in this thesis builds on the work of Albeck et al. ${ }^{[17,98]}$ In this report they extracted the OM from the spines of Paracentrotus lividus and tested its ability to affect crystal growth in vitro. Subsequently, they selectively digested the $\mathrm{OM}$ and tested the activity of the digestion components on crystal growth. The digests they prepared included the N-glycans, the O-glycosylated proteins, and the fully deglycosylated protein. From the crystal growth experiments they showed that the complete ensemble produced crystals with faces that were almost parallel to the c-axis and not the typical (104) faces of rhombohedral calcite. Following $\mathrm{C}_{18}$ chromatography they were able to delineate the mixture slightly and show that the macromolecules which interacted with planes parallel to the c-axis were glycosylated while macromolecules that interacted with planes perpendicular were not. This facial selectivity was shown to be dependent on the glycans as their removal, through treatment with HF, 
changed the selectivity of the glycoproteins from faces parallel to faces perpendicular to the c-axis. Consistent with this assignment the isolated $\mathrm{N}$-glycans influenced crystal growth in the direction of the c-axis, that is, similar to the glycoproteins. This result, that the $\mathrm{N}$-glycans are implicated in the mineralisation process, is consistent with other studies. ${ }^{[16,17,25]}$

Albeck et al. ${ }^{[17,98]}$ used PNGase $\mathrm{F}$ to selectively release the $\mathrm{N}$-glycans from the protein component. However, the sea urchin glycoproteins did not yield significant quantities of $\mathrm{N}$-glycans. This resistance to the enzyme was suggested to be due to steric hindrance as chemical hydrolysis of the O-glycans also demonstrated poor efficiency. Neither the quantity of N-glycans collected nor the conditions used to release the 0 -glycans were reported. Proton NMR showed that $\sim 40 \mathrm{wt} \%$ of the ensemble is comprised of carbohydrate, and infrared spectroscopy indicated that the occluded glycans are sulfated.

Ameye et al. ${ }^{[16]}$ attempted structural elucidation of the glycan component using lectins, proteins that selectively bind carbohydrates based on structural features. From this investigation they identified several important features: both $\mathrm{N}$ - and O-glycans; abundant 1,4-GlcNAc repeats; abundant Galß1-4(3)GIcNAc repeats (lactosamine units, LacNAcs), Galß1-3GalNAc repeats, and terminal L-fucose and sialic acids. The presence of the sialic acid moiety was considered to be important as it has been demonstrated that this structure can interact with calcium ions. ${ }^{[62]}$

Using gold-labelled lectins and field-emission scanning electron microscopy, Ameye et al. ${ }^{[16]}$ went on to show that there is organised distribution of the glycoproteins within the spines based on the glycan framework. Macromolecules displaying the O-glycan Galß1-3GalNAc dimer are located on the outer surface of the bridges, whereas in the septa, sialic acid dominated. They also noted that the putative ACC inner core of the trabeculae is more prevalently loaded with $\mathrm{N}$-glycan containing proteins displaying GIcNAc repeats with no sialic acid. From these results it was speculated that $\mathrm{N}$-glycosylated proteins stabilise ACC whereas 
O-glycan dominated proteins influence morphology as they are found in skeletal regions where calcite growth was inhibited.

Berman et al. ${ }^{[40]}$ demonstrated that the use of the OM extracted from the tests of Paracentrotus lividus as an additive influences the mechanical properties of synthetic calcite crystals. This property was not observed for crystals grown in the presence of molluscan OM (Mytilus californianus). The explanation offered was that the macromolecules preferentially adsorbed to (110) faces and therefore interfered with the low energy (104) cleavage planes.

\section{Evechinus chloroticus}

MacKenzie et al. ${ }^{[13]}$ conducted an investigation on an equivalent acidic glycoprotein ensemble as that analysed in this thesis, namely, SMP. In this report they determined the sugar content of SMP, using the phenol-sulfuric acid assay to be $\sim 20$ protein $w t \%$. As this assay only quantifies the hexose sugars it is likely to be an underestimate. Following PNGase F treatment approximately half of this sugar was removed indicating a $1: 1 \mathrm{~N}$ - to O-glycan ratio. Neither the protein nor the glycans were characterised any further.

The morphological activity of the SMP ensemble, the N-glycans, and SMP with the $\mathrm{N}$-glycans removed (SMPDeN-g) were tested by MacKenzie et al. ${ }^{[13]}$ in vitro. The results showed that crystal growth was completely inhibited by SMPDeN-g at concentrations greater than $30 \mu \mathrm{g} / \mathrm{mL}$. At lower concentrations of SMPDeN-g the crystals appeared to have no discernable order or structure above multinucleation. In contrast to this, crystallisation in the presence of the isolated N-glycans produced crystals displaying 3-fold symmetry reminiscent of rhombohedral (104) faces but superimposed with crystal towers as the surface topography. As this morphological activity mirrored that of the native ensemble they therefore concluded that the morphological activity is held in the N-glycan framework. In contrast, SMPDeN-g held very little influence. ${ }^{[13]}$ This was surprising given that the SMPDeN-g fraction contained over 90 ensemble wt\% of the OM. For this reason it 
was mentioned that the composition and structure of the $\mathrm{N}$-glycans was worthy of further investigation.

\section{Sphaerechinus granularis}

Karamanos et al. ${ }^{[60,99]}$ have published two reports on the glycan structures of glycoproteins extracted from within the shell of Sphaerechinus granularis. This work represents the most comprehensive analysis of glycans occluded in sea urchin mineral tissue. Three macromolecules were isolated: a dermatan sulfate proteoglycan and two sialoproteins (SPI and SPII). The proteoglycan was determined to have a MW of $16.5 \mathrm{kDa}$ and the glycan chains involved uronic acids as well as over-sulfated galactosamine ( $>1$ sulfate per residue) in the dimer repeats. The SP proteins are much larger, with an average MW of $625 \mathrm{kDa}$, and include both $\mathrm{N}$ - and O-glycans. They observed that the O-glycans include polysialic acid chains in the terminal position. In the second report they suggested that the sialic acid residues could be involved in binding calcium and therefore implicated in the biomineralisation process.

\section{Lytechinus variegatus}

Swift et al. ${ }^{[100]}$ demonstrated the first example of phosphoproteins within the mineralised tests of the sea urchin Lytechinus variegates. In this report they showed that the phosphate content of the soluble OM was $3.9 \mathrm{wt} \%$. It was stated by Swift et al. that the functional role of this phosphate, however, remains unknown.

\subsection{ChAPTER OUTLINE}

In this thesis we have investigated the structure and function of the PTMs of the acidic water soluble macromolecules occluded in the spines of the sea urchin Evechinus chloroticus. The post-translational modifications assessed in this thesis include: $\mathrm{N}$ - and O-glycosylation, sulfation, and phosphorylation. 
Chapter 2 and chapter 3 outline the experimental framework and the protocols used to access the structure and function of the PTMs. Following this, the results and discussion chapters follow: analysis of the complete SMP ensemble (chapter 4), fractionation of the ensemble based on MW (chapter 5), and selective removal of specific PTMs (chapter 6). In chapter 7 we summarise the outcomes of this research and identify future directions to be pursued. 


\subsection{References}

[1] S. Mann, Biomineralization: Principles and Concepts in Bioinorganic Materials Chemistry, Oxford University Press, Oxford, 2001.

[2] F. Lippmann, Minerals, Rocks, and Inorganic Materials: Monograph Series of Theoretical and Experimental Studies, Vol. 6: Sedimentary Carbonate Minerals, 1973.

[3] G. Fu, S. Valiyaveettil, B. Wopenka, D. E. Morse, Biomacromolecules 2005, 6, 1289.

[4] C. E. Killian, F. H. Wilt, Chemical Reviews 2008, 108, 4463.

[5] F. C. Meldrum, International Materials Reviews 2003, 48, 187.

[6] M. Cusack, A. Freer, Chemical Reviews 2008, 108, 4433.

[7] S. Weiner, H. A. Lowenstam, On Biomineralization, Oxford University Press, New York, Oxford, 1989.

[8] J. D. Currey, Proceedings of the Royal Society of London Series B-Biological Sciences 1977, 196, 443.

[9] F. C. Meldrum, H. Col`^Ifen, Chemical Reviews 2008, 108, 4332.

[10] J. H. Schroeder, E. J. Dwomik, J. J. Papike, Geology Society of America Bulletin 1969, $80,1613$.

[11] A. Lerman, Geochim. Cosmochim. Acta 1965, 29, 977.

[12] J. L. Arias, M. S. Fernandez, Chemical Reviews 2008, 108, 4475.

[13] C. R. MacKenzie, S. M. Wilbanks, K. M. McGrath, Journal of Materials Chemistry 2004, 14, 1238.

[14] B. Marie, G. Luquet, J. P. P. De Barros, N. Guichard, S. Morel, G. Alcaraz, L. Bollache, F. Marin, Febs Journal 2007, 274, 2933.

[15] F. Nudelman, B. A. Gotliv, L. Addadi, S. Weiner, J Struct Biol 2006, 153, 176.

[16] L. Ameye, G. De Becker, C. Killian, F. Wilt, R. Kemps, S. Kuypers, P. Dubois, Journal of Structural Biology 2001, 134, 56.

[17] S. Albeck, S. Weiner, L. Addadi, Chemistry--A European Journal 1996, 2, 278.

[18] C. T. Kresge, M. E. Leonowicz, W. J. Roth, J. C. Vartuli, J. S. Beck, Nature (London, United Kingdom) 1992, 359, 710.

[19] K. M. McGrath, D. M. Dabbs, N. Yao, I. A. Aksay, S. M. Gruner, Science (Washington, D. C.) $1997,277,552$.

[20] A. Bigi, E. Boanini, D. Walsh, S. Mann, Angewandte Chemie, International Edition 2002, 41, 2163. 
[21] R. J. Park, F. C. Meldrum, Advanced Materials (Weinheim, Germany) 2002, 14, 1167.

[22] T. Samata, D. Ikeda, A. Kajikawa, H. Sato, C. Nogawa, D. Yamada, R. Yamazaki, T. Akiyama, Febs Journal 2008, 275, 2977.

[23] F. Marin, B. Pokroy, G. Luquet, P. Layrolle, K. De Groot, Biomaterials 2007, 28, 2368.

[24] K. Simkiss, K. M. Wilbur, Biomineralization. Cell Biology and Mineral Deposition, Academic Press, San Diego, CA, 1989.

[25] C. Killian, F. Wilt, Journal of Biological Chemistry 1996, 271, 9150.

[26] F. Marin, P. Corstjens, B. de Gaulejac, E. de Vrind-De Jong, P. Westbroek, J Biol Chem 2000, 275, 20667.

[27] B. Marie, G. Luquet, L. Bedouet, C. Milet, N. Guichard, D. Medakovic, F. Marin, Chembiochem 2008, 9, 2515.

[28] S. Weiner, L. Hood, Science 1975, 190, 987.

[29] R. A. Metzler, I. W. Kim, K. Delak, J. S. Evans, D. Zhou, E. Beniash, F. Wilt, M. Abrecht, J. W. Chiou, J. H. Guo, S. N. Coppersmith, P. U. P. A. Gilbert, Langmuir 2008, 24, 2680.

[30] A. M. Belcher, X. H. Wu, R. J. Christensen, P. K. Hansma, G. D. Stucky, D. E. Morse, Nature (London) 1996, 381, 56.

[31] G. Falini, S. Albeck, S. Weiner, L. Addadi, Science 1996, $271,67$.

[32] S. Weiner, L. Addadi, Journal of Materials Chemistry 1997, 7, 689.

[33] F. H. Wilt, Journal of Structural Biology 1999, 126, 216.

[34] B.-A. Gotliv, L. Addadi, S. Weiner, Chembiochem : a European journal of chemical biology 2003, 4, 522.

[35] S. Weiner, W. Traub, Febs Letters 1980, 111, 311.

[36] F. Marin, G. Luquet, B. Marie, D. Medakovic, Current Topics in Developmental Biology, Vol 80 2008, 80, 209.

[37] S. Albeck, J. Aizenberg, L. Addadi, S. Weiner, Journal of the American Chemical Society 1993, 115, 11691.

[38] B. A. Gotliv, N. Kessler, J. L. Sumerel, D. E. Morse, N. Tuross, L. Addadi, S. Weiner, Chembiochem 2005, 6, 304.

[39] F. Nudelman, H. H. Chen, H. A. Goldberg, S. Weiner, L. Addadi, Faraday Discuss 2007, $136,9$.

[40] A. Berman, L. Addadi, S. Weiner, Nature 1988, 331, 546.

[41] Y. Dauphin, F. Marin, Experientia 1995, 51, 278.

[42] J. C. Marxen, M. Hammer, T. Gehrke, W. Becker, Biological Bulletin 1998, 194, 231. 
[43] A. Varki, R. Cummings, J. Esko, H. Freeze, G. Hart, J. Marth, Editors, Essentials of Glycobiology, Cold Spring Harbor Laboratory Press, 1999.

[44] J. Montreuil, Adv. Carb. Chem. Biochem. 1980, 37, 157.

[45] A. AbolinÅi-Krogis, Acta Zoologica 1958, 39, 19.

[46] J. L. Arias, A. Neira-Carrillo, J. I. Arias, C. Escobar, M. Bodero, M. David, M. S. Fernandez, Journal of Materials Chemistry 2004, 14, 2154.

[47] K. Wada, Initiation of mineralization in bivalve molluscs. In: The Mechanisms of Biomineralization in Animals and Plants, Tokai University Press, Tokyo, 1980.

[48] E. M. Greenfield, D. C. Wilson, M. A. Crenshaw, American Zoologist 1984, $24,925$.

[49] L. Addadi, J. Moradian, E. Shay, N. G. Maroudas, S. Weiner, Proc Natl Acad Sci U S A 1987, 84, 2732.

[50] J. M. Didymus, P. Oliver, S. Mann, A. L. DeVries, P. V. Hauschka, P. Westbroek, Journal of the Chemical Society, Faraday Transactions 1993, 89, 2891.

[51] G. J. Strous, J. Dekker, Crit Rev Biochem Mol Biol 1992, $27,57$.

[52] J. K. Sheehan, D. J. Thornton, M. Somerville, I. Carlstedt, Am Rev Respir Dis 1991, 144, S4.

[53] D. J. Thornton, I. Carlstedt, M. Howard, P. L. Devine, M. R. Price, J. K. Sheehan, Biochem J 1996, 316 ( Pt 3), 967.

[54] B. J. Van Klinken, A. W. Einerhand, H. A. Buller, J. Dekker, Anal Biochem 1998, 265, 103.

[55] R. H. Kretsinger, Annual Review of Biochemistry 1976, 45, 239.

[56] M. Soledad Fernandez, A. Moya, L. Lopez, J. L. Arias, Matrix Biology 2001, 19, 793.

[57] J. C. Marxen, M. Nimtz, W. Becker, K. Mann, Biochimica Et Biophysica Acta-Proteins and Proteomics 2003, 1650, 92.

[58] D. Takakura, M. Norizuki, F. Ishikawa, T. Samata, Marine Biotechnology 2008, 10, 290.

[59] A. P. W. Jill E. Borbas, C. Steven Sikes,, Journal of Experimental Zoology 1991, $258,1$.

[60] N. K. Karamanos, A. Manouras, S. Anagnostides, E. Makatsori, T. Tsegenidis, C. A. Antonopoulos, Biochimie 1996, 78, 171.

[61] S. Weiner, Journal of Experimental Zoology 1985, 234, 7.

[62] L. W. Jaques, E. B. Brown, J. M. Barrett, W. S. Brey, W. J. Weltner, J. Biol. Chem. 1977, $252,4533$.

[63] L. Adaddi, S. Weiner, Angew. Chem. Int. Ed. Engl. 1992, 31, 153.

[64] S. Weiner, L. Addadi, Trends in Biochemical Sciences 1991, 16, 252. 
[65] L. Yang, X. Zhang, Z. Liao, Y. Guo, Z. Hu, Y. Cao, Journal of Inorganic Biochemistry 2003, $97,377$.

[66] H. Miyamoto, T. Miyashita, M. Okushima, S. Nakano, T. Morita, A. Matsushiro, Proceedings of the National Academy of Sciences of the United States of America 1996, 93, 9657.

[67] L. Addadi, S. Weiner, Nature 2001, 411, 753.

[68] L. Addadi, S. Weiner, M. Geva, Z Kardiol 2001, 90 Suppl 3, 92.

[69] J. Aizenberg, A. J. Black, G. M. Whitesides, Nature 1999, 398, 495.

[70] Y. Levi-Kalisman, G. Falini, L. Addadi, S. Weiner, Journal of Structural Biology 2001, $135,8$.

[71] L. Addadi, D. Joester, F. Nudelman, S. Weiner, Chemistry 2006, 12, 980.

[72] S. Weiner, Y. Talmon, W. Traub, International Journal of Biological Macromolecules $1983,5,325$.

[73] M. A. Crenshaw, H. Ristedt, The histochemical localization of reactive groups in septal nacre from Nautilus pompilius. In: The Mechanisms of Mineralization in the Invertebrates and Plants., University of South Carolina Press, Colombia, 1976.

[74] R. B. Emlet, Biological Bulletin 1982, 163, 264.

[75] J. Seto, Y. Zhang, P. Hamilton, F. Wilt, Journal of Structural Biology 2004, 148, 123.

[76] D. F. Blake, D. R. Peacor, Scan Electron Microsc 1981, 321.

[77] A. K. Y. Oaki, T. Miura, H. Imai,, Advanced Functional Materials 2006, 16, 1633.

[78] M. A. Helmut Cölfen, Angewandte Chemie International Edition 2005, 44, 5576.

[79] E. Beniash, J. Aizenberg, L. Addadi, S. Weiner, Proceedings of the Royal Society of London, Series B: Biological Sciences 1997, 264, 461.

[80] L. Adaddi, S. Weiner, R. Z. Wang, Philosophical Transactions of the Royal Society of London B 1997, 352, 469.

[81] S. Weiner, L. Addadi, H. D. Wagner, Materials Science \& Engineering, C: Biomimetic and Supramolecular Systems 2000, C11, 1.

[82] L. Addadi, S. Raz, S. Weiner, Advanced Materials (Weinheim, Germany) 2003, 15, 959.

[83] S. Mann, D. D. Archibald, J. M. Didymus, T. Douglas, B. R. Heywood, F. C. Meldrum, N. J. Reeves, Science (Washington, DC, United States) 1993, 261, 1286.

[84] S. Weiner, W. Traub, Philosophical Transactions of the Royal Society of London, Series B: Biological Sciences 1984, 304, 425.

[85] S. Raz, S. Weiner, L. Addadi, Advanced Materials (Weinheim, Germany) 2000, 12, 38. 
[86] F. C. Meldrum, S. T. Hyde, Journal of Crystal Growth 2001, 231, 544.

[87] G. Falini, S. Fermani, M. Gazzano, A. Ripamonti, Journal of Materials Chemistry 1998, 8, 1061.

[88] Y. Politi, T. Arad, E. Klein, S. Weiner, L. Addadi, Science 2004, 306, 1161.

[89] C. E. Killian, F. H. Wilt, J. Biol. Chem. 1996, 271, 9150.

[90] K. Mann, A. J. Poustka, M. Mann, Proteome Science 2008, 6.

[91] B. T. Livingston, C. E. Killian, F. Wilt, A. Cameron, M. J. Landrum, O. Ermolaeva, V. Sapojnikov, D. R. Maglott, A. M. Buchanan, C. A. Ettensohn, Developmental Biology 2006, 300, 335.

[92] Fred H. Wilt, Christopher E. Killian, Brian T. Livingston, Differentiation 2003, 71, 237.

[93] Martin F. Brown, Jacqueline S. Partin, Christopher E. Killian, William J. Lennarz, Development Growth \& Differentiation 1995, 37, 69.

[94] B. Kabakoff, S.-P. L. Hwang, W. J. Lennarz, Developmental Biology 1992, 150, 294.

[95] M. C. Farachcarson, D. D. Carson, J. L. Collier, W. J. Lennarz, H. R. Park, G. C. Wright, Journal of Cell Biology 1989, 109, 1289.

[96] J. Anstrom, J. Chin, D. Leaf, A. Parks, R. Raff, Development 1987, 101, 255.

[97] L. Ameye, R. Hermann, C. Killian, F. Wilt, P. Dubois, J. Histochem. Cell Biol. 1999, 110, 1189.

[98] S. Albeck, L. Addadi, S. Weiner, Connective Tissue Research 1996, 35, 365.

[99] A. Manouras, N. K. Karamanos, T. Tsegenidis, C. A. Antonopoulos, Comparative Biochemistry and Physiology, Part B: Biochemistry \& Molecular Biology 1991, 99B, 119.

[100] Debbie M. Swift, C. Steven Sikes, A. P. Wheeler, Journal of Experimental Zoology 1986, $240,65$. 


\section{CHAPTER 2 : EXPERI MENTAL FRAMEWORK}

In this chapter we outline the experimental framework used to address the PhD topic: analysis of the roles administered, in vitro, by the various post-translational modifications present in SMP. The methodology adopted is similar to the work of Albeck et al. ${ }^{[1,2]}$ and more recently the investigations completed by Marin and associates. ${ }^{[3-5]}$ These investigations involved characterisation of the occluded OM using a variety of analytical procedures followed by selective removal of the identified chemical modifications and assessing the function of the isolated digest products. This body of work followed the same approach. It deviates from the earlier work in that a different organism was analysed, a more comprehensive structural investigation of the glycans was completed, and a wider range of digestion products were tested.

All of the methods used in this investigation are in vitro. This ex vivo approach was appropriate for the current study as we were interested in advancing the understanding of crystal growth manipulation in the laboratory. The protocols referred to in this chapter are explicitly detailed in chapter 3. Blank samples are also included in this chapter, where appropriate, to validate the results present in the results and discussion chapters 4, 5, and 6 .

All experiments were completed at least in duplicate on at least two different samples. Uncertainties were determined as standard deviations using Microsoft Office Excel. Where analytical results are summed, the uncertainties were calculated as the square root of the sum of the squares.

\subsection{SOLATI ON OF SMP}

\subsubsection{Preparation Of SPI nes}

The echinoderm shell is an extracellular endoskeleton covered by an epidermis. ${ }^{[6]}$ To remove this layer the porous spines were washed extensively in base. This is an 
established method ${ }^{[7]}$ to remove the all organic material which is not embedded within the spines; the material we were interested in investigating.

\subsubsection{SpIne DeCALCI fication}

The release of the OM needs to be very gentle as the decalcification process can alter the structural and functional properties of the OM. ${ }^{[8]}$ This is because there may be chemical functionalities which are susceptible to acid hydrolysis once liberated into the bulk solution.

There have been three generic methods employed in the decalcification of mineralised tissues to release the occluded OM. These include the use of chelating agents, acid, and ion exchange resins. The use of chelating agents, such as EDTA, has become less popular as the chelating agent itself is difficult to remove and can interfere with subsequent analysis. ${ }^{[9,10]}$ We adopted the use of acid to dissolve the mineral as opposed to ion exchange, which typically takes 2-5 days for $2 \mathrm{~g}$ of mineralised tissue. ${ }^{[2]}$ This process was considered to be too slow as sea urchin spines only contain a relatively low proportion of OM (0.1 wt\%). ${ }^{[96[11]}$ Through the dropwise addition of $1 \mathrm{M} \mathrm{HCl}$ the $\mathrm{pH}$ of the decalcification solution did not drop below 5.5 , which was considered to be sufficiently mild to preserve the integrity of the $\mathrm{OM}^{[2]}$

\subsubsection{ULTRAFI LTRATI ON}

Ultrafiltration involves the superposition of solution desalting and concentration. This process is achieved by passing a solution across a membrane of a given molecular weight cut-off (MWCO) at sufficient pressure that species below the MWCO, including salt and water, pass through the filter and into a waste container. Reconstitution of the concentrated analyte solution with $\mathrm{MQ}$ and repetition of the ultrafiltration process further removes the contaminating salt.

\subsubsection{Protei N I SOLATION}

The anionic proteins were extracted from the crude macromolecular mixture with the use of an anion exchange column. Following preparation with salt the anion 
exchange column presents positively charged quaternary amine groups. Through an ionic interaction negatively charged analytes selectively bind to the stationary phase while neutral and positively charged species elute as waste. The analyte can subsequently be released from the stationary phase and collected by passing a high concentration salt solution through the column which exchanges with the analyte on the amine sites. This preferential exchange is favourable as the salt, typically $\mathrm{NaCl}$, has a greater charge density.

\subsection{StRuctural Methods}

The structural methods used throughout this thesis are outlined in this section. In order to increase our understanding of the roles mediated by the post-translational modifications within SMP we needed to increase our understanding of the structural elements present throughout the ensemble. As SMP has never been characterised in terms of the PTMs we needed to employ a variety of analytical techniques to survey the OM (chapter 4). In chapter 5 we fractionated the SMP ensemble into three fractions based on MW: $<10,10-30$, and $>30 \mathrm{kDa}$. We then repeated the analytical procedures on each of the three fractions to determine the PTM distribution within the ensemble. Based on the chemical functionalities detected in chapter 4 we developed a strategy to selectively remove each of the PTM types (chapter 6) in an attempt to better understand their role in affecting crystallisation in vitro. The structural methods were used to monitor the selectivity of the various chemical digestions.

\subsubsection{SPECTROSCOPIC ASSAYS}

\subsubsection{Protein Quantitation}

The Bradford reagent is a common and convenient laboratory reagent for detecting protein. Its mode of interaction is through the basic and aromatic amino acid residues. ${ }^{[12]}$ Following the formation of a complex between the analyte and the dye the protein concentration can be determined by measuring the absorption at $595 \mathrm{~nm}$. However, we observed that there was no chromophore produced following addition of the Bradford reagent to a solution of SMP. We rationalised 
this as being due to the low amount of the relevant amino acids (p. 101). The low representation of the basic amino acids is consistent with our SMP isolation procedure which involved removing all species which have neutral and basic pl values. For this reason the Bradford reagent was not used in this work.

\subsection{BICINCHONINIC ACID ASSAY}

The bicinchoninic acid assay is the most amenable colorimetric method to determine protein concentration for the SMP system. The colour development involves an interaction between $\mathrm{Cu}^{+}$and bicinchoninic acid. ${ }^{[13]}$ Cysteine, tryptophan, tyrosine, and peptide bonds can all reduce $\mathrm{Cu}^{2+}$ to $\mathrm{Cu}^{+}$and this reaction is the basis for concentration determination. ${ }^{[14]}$ As a result the absorption at $562 \mathrm{~nm}$ reflects the abundance of protein. Studies have shown that the extent of colour formation is not a linear combination of the interacting groups. ${ }^{[14]}$ Therefore a standard curve must be generated for the specific analyte, in this case SMP, relative to the protein as quantified by AAA. The bicinchoninic acid assay was only used to a limited extent as the colour development process is time-consuming (30 $\mathrm{min}$ ) and the volume of sample required for detection is relatively high $(20 \mu \mathrm{L})$.

\subsection{ABSORPTION AT $280 \mathrm{NM}$}

Aromatic amino acids, such as tyrosine and tryptophan, absorb radiation at $280 \mathrm{~nm}$ (A280). ${ }^{[12]}$ It was determined that SMP absorbed sufficient radiation at this wavelength so as to make this technique of protein quantitation viable. A280 was used as the standard method to assess SMP solution concentration throughout this work. While there are other biological macromolecules which absorb radiation at $280 \mathrm{~nm}$, such as nucleic acids, presence of such contaminants was not tested for by alternative methods.

The volume of solution required to determine SMP concentration, using a NanoDrop spectrometer, was only $2 \mu \mathrm{L}$. Close monitoring of the SMP concentration was essential as a small change in concentration $( \pm 20 \mu \mathrm{g} / \mathrm{mL})$ could dramatically influence the results observed. 


\subsubsection{OTher Detection}

There is a variety of sugar specific assays for detecting or quantifying monosaccharides on native glycoproteins. The residues which these assays test for include; neutral (phenol-sulfuric acid), hexosamines (benzothiazolone), uronic acids (methahydroxybiphenyl), and sialic acid (ferric-orcinol). ${ }^{[15]}$ Results obtained using the phenol-sulfuric acid and ferric-orcinol assays are presented in this thesis.

\subsection{PHENOL-SULFURIC ACID ASSAY}

The phenol-sulfuric acid assay reveals hexoses including glucose, galactose, and mannose. ${ }^{[15]}$ This assay was used qualitatively as a simple method to test for the presence of sugar. It was not used as a quantitative method due to the lack of reproducibility observed between duplicate analyses. This problem of result irregularity may have been due to paper contamination. The standard curve generated of absorption ( $485 \mathrm{~nm}$ ) versus concentration of mannose is presented in chapter 4 (р. 97).

\subsection{FERRIC-ORCINOL ASSAY}

The ferric-orcinol assay tests for both sialic acids: $\mathrm{N}$-acetylneuraminic acid (NANA) and N-glycolylneuraminic acid (NGNA). An advantage of this assay is that it will return a positive result irrespective of whether the sialic acid is bound or liberated as the monosaccharide. ${ }^{[15]}$ The ferric-orcinol assay was used to quantify the amount of sialic acid in SMP. This was because the monosaccharide analysis, which was used to characterise the abundance of all other sugars, degrades sialic acid as it is particularly labile. ${ }^{[15]}$ The ferric-orcinol assay was used following the selective removal of sulfate and sialic acid to test the selectivity and efficacy, respectively. The standard curve generated of absorption at $570 \mathrm{~nm}$ versus concentration of NANA is presented in chapter 4 (p. 99).

\subsection{MaLACHITE Green Assay}

The malachite green assay was used to quantify the mass of phosphate within the SMP ensemble (chapter 4), fractionated SMP (chapter 5) and SMP digestion products (chapter 6). As the assay only detects inorganic phosphate, or liberated 
organic phosphate; a pre-treatment of the analyte with base was required. The quantity of phosphate in each of the analysed samples was determined relative to the standard curve generated from a series of $\mathrm{K}_{3} \mathrm{PO}_{4}$ solutions of known concentration (chapter 4, p. 100).

\subsubsection{MONOMER ANALYSES}

The methods developed to quantify amino acids and sugar monomers within biological species are generically similar. Initially the polymer species is digested using acid. The liberated constituent monomer units are then chemically derivatised to render them amenable to the analytical technique and to facilitate structural identification. Identification and quantification of the derivatised monomers is achieved based on their elution times relative to a series of standards. The specific details as they relate to the protein and glycan contingents are discussed below.

\subsubsection{AMI NO ACID ANALYSIS}

All amino acid analysis (AAA) data presented in this thesis were collected by the Australian Proteome Analysis Facility (APAF) and was therefore facilitated using infrastructure provided by the Australian Government through the National Collaborative Research Infrastructure Strategy (NCRIS). Amino Acid Analysis was used to determine the amino acid composition of SMP, its fractionated products (chapter 5), and various digestion products (chapter 6). In chapter 5 we were interested in whether there were any amino acid trends between the fractions, and in chapter 6 whether the protein contingent had been inadvertently digested following acid digestion.

Aspartic acid and glutamic acid have been shown to be extremely important in biomineralisation. ${ }^{[16,17]}$ Unfortunately, these two amino acids are presented as mixtures in AAA as Asx (aspartic acid and asparagine) and Glx (glutamic acid and glutamine), respectively. This is because asparagine and glutamine are converted to aspartic and glutamic acid respectively in the acid hydrolysis of the peptide 
backbone. Methods to deconvolute the relative contribution of these four amino acids, such as BTI-derivatisation prior to hydrolysis, were not completed.

\subsubsection{MONOSACCHARI De ANALYSIS}

A monosaccharide analysis (MSA) quantifies the constituent monosaccharides that comprise the glycone: it is the sugar analogue of an amino acid analysis. MSA was used extensively in this work. There are a few methods used for the quantification of monosaccharides. These include GC-MS, HPLC-MS, ${ }^{[18]}$ and HPAEC. In this thesis GC-MS was used. In chapters 4 and 5 it was used to map the monosaccharide profiles of SMP and its fractionated constituents, respectively. In chapter 6 it was used to monitor the selectivity of the various digestions, for example, following the release of sialic acid (SMPDeSia) and sulfate removal (SMPDeSO). Similar to the $A A A$, the results represent the monosaccharide composition across a mixture a glycoproteins.

There are two widely used methods for the release and derivatisation of monosaccharides: acid hydrolysis and alditol acetate derivatisation; and methanolysis and trimethylsilyl (TMS) derivatisation. Using either of these methods, substitutents such as sulfate and phosphate are removed. ${ }^{[15]}$ Methanolysis has the advantage over acid hydrolysis in that all sugar types can be released in one step. However, the subsequent work-up is more laborious as the auxiliaries, such as $\mathrm{N}$-acetyl groups, are lost and therefore need to be replaced. ${ }^{[15]}$ An advantage of the acid hydrolysis/alditol acetate method is that the MS spectrum is simplified as the stereochemistry at the anomeric carbon (formerly involved in the glycosidic bond) is lost in the liberation of the monomers. Following hydrolysis of the sugar chain there can be two diastereoisomers for each sugar variety depending on whether the sugar was formally involved in either an $\alpha$ or $\beta$ glycosidic linkage. This results in a lower overall signal response and increases spectral complexity. To remove this stereocentre it is common to reduce the liberated monosaccharides using sodium borodeuteride $\left(\mathrm{NaBD}_{4}\right)$, which provides the linear alditol. Acetylation of the hydroxyl groups using acetic anhydride increases signal intensity for gas chromatography-mass spectrometry (GC-MS) 
analysis by increasing sample volatility and inducing more consistency in sample fragmentation. ${ }^{[15,18,19]}$

As many sugars are related as diastereoisomers at positions other than the anomeric carbon: for example glucose, galactose, and mannose; no assignment can be made from their MS fragmentation patterns. The MS is used primarily to detect the time at which a fraction elutes off the separating column as sugar cannot be detected by the more simple methods, such as A280. The MS fingerprint can be used, however, to distinguish between varieties of sugars; such as hexoses, $\mathrm{N}$-acetylhexosamines, (HexNAcs) and pentoses. The mass of pure glycoprotein required to obtain a monosaccharide composition is between $1 \mu \mathrm{g}$ and $10 \mu \mathrm{g} .{ }^{[15,19]}$

Sialic acids, hexoses, HexNAcs, and uronic acids all hydrolyse at different rates depending on the sugar residues involved, the nature of the glycosidic bond, and the auxiliary groups attached to the residue. In addition, they also vary in susceptibility to destruction once released into the acidic solution. ${ }^{[15]}$ Therefore, the experimental conditions used to liberate the targeted monosaccharides, such as acid strength and temperature, must be optimised so as to minimise monomer destruction leading to erroneous data. ${ }^{[15]}$

Both methods of sugar quantification, acid hydrolysis/alditol acetate and methanolysis/TMS derivatisation were used in this thesis. Acid hydrolysis/alditol acetate derivatisation was used to determine the quantity of the hexoses and HexNAcs while methanolysis/TMS derivatisation was used to determine the quantity of uronic acids. Hydrochloric acid digestion followed by alditol acetate derivatisation can be used to liberate and detect uronic acids; however, the uronic acids can be resistant under these conditions to hydrolysis, for example in glycosaminoglycan (GAG) chains. GAG chains are sugar polymers bound to the class of macromolecules known as proteoglycans which have been shown to be important in various biomineral extracts, for example, egg shell. ${ }^{[20]}$ Therefore, it was important to test for the presence of uronic acid as an indicator of 
proteoglycan presence within SMP. The optimum method to test for uronic acids involves methanolysis followed by trimethylsilyl (TMS) derivatisation. ${ }^{[15]}$

Following the acid hydrolysis/alditol acetate derivatisation methodology we used two types of acid. It was shown by Takemoto et al. ${ }^{[21]}$ that the optimum acid reagents for quantification of hexoses and HexNAcs are trifluoroacetic acid (TFA) and $\mathrm{HCl}$, respectively. This is because TFA is sufficiently strong to successfully liberate neutral sugars, ${ }^{[22]}$ but not strong enough to liberate HexNAcs. Hydrochloric acid, in contrast, releases amino sugars but decomposes liberated neutral sugars. ${ }^{[21]}$

\subsection{StANDARDISATION OF THE SPECTRA}

Typically the quantification of each monosaccharide is achieved by comparing the area of the signal associated with an analyte to the area of a known mass of internal standard, typically myo-inositol. With the incentive to quantify the monosaccharides as accurately as possible we incorporated a correction factor which was based on the relative susceptibilities of the various monosaccharides.

To determine the relative susceptibilities of the various monosaccharides the following procedure was completed in duplicate. Standard samples, containing $5 \mu \mathrm{g}$ of each common monosaccharide (fucose, rhamnose, xylose, mannose, galactose, glucose, $\mathrm{N}$-acetylglucosamine (GlcNAc), and $\mathrm{N}$-acetylgalactosamine (GalNAc)), were worked up in parallel to SMP. That is, they were digested in acid, one set in TFA and one set in $\mathrm{HCl}$, derivatised and analysed as per the acid hydrolysis/alditol acetate work-up. Implicit within the area of each monosaccharide signal was the susceptibility of the monomer to acid destruction, and its relative response to the GC-MS. The area of each standard signal was normalised to the area of the internal standard.

In order to determine the mass of each monosaccharide in an analyte the following scaling was applied. The area for each monosaccharide signal in the analyte spectrum was divided by the area of the internal standard. This normalised area was then divided by the normalised area for that sugar in the standard 
spectrum, and multiplied by $5 \mu \mathrm{g}$, the mass represented in the standard spectrum. This value, in $\mu \mathrm{g}$, represents the mass of monosaccharide in the analyte sample.

Glucose was observed in all samples analysed by MSA. We believe that this monosaccharide was introduced as contamination. The first indication of contamination was that the mass of glucose did not vary whether analysing the complete ensemble, fractionated SMP, or a digestion sample. Supporting this contamination hypothesis we observe glucose in the deglycosylated sample SMPDeGly (p.154). As the HexNAcs are the most acid resistant sugars it is unbelievable that glucose, if it is of SMP origin, would still be present. In addition, the amount of glucose in SMPDeGly was the same as in the native ensemble; $1.5 \pm$ 0.5 and $2.0 \pm 0.4$ protein $w t \%$, respectively which implies that no glucose was liberated in the acid digestion. Additional confirmation of the glucose contamination was that it was present in a blank run at 0.7 protein wt\%. As such the MSA data are tabulated with the omission of glucose. We believe that the source of this glucose contamination was paper fragments in the laboratory.

\subsubsection{SDS-PAGE}

SDS-PAGE was used in a variety of ways throughout this thesis. In particular it was used for MW profiling, to monitor reaction success, and to reveal the heterogeneity of SMP and its derivatives. There were three gel pore size variations including $12 \%, 4-20 \%$, and $10-20 \%$, where the percentage represents the total acrylamide-bisacrylamide monomer concentration.

Determination of MW using SDS-PAGE is achieved by exposing an analyte to an electric field which causes migration towards an electrode of opposite charge proportional to the extent of charge. Charge is imposed on an analyte by enveloping it in anionic SDS. The velocity of migration which leads to the separation of species based on size is proportional to the electric field strength, the net charge on the protein, and the frictional coefficient. Factors which can lead to anomalous MW results include species which have PTMs and implicit charge. 
There is a wide variety of SDS-PAGE stains which can be used to reveal structural and functional features of a biological extract. The stains used in this thesis included (detect): Coomassie blue (protein), silver stain (protein), periodic-Schiff base (sugar), Alcian blue at pH 1 (carboxylate) and pH 3 (carboxylate and sulfate), and Stains-All (anionic and calcium-binding functionality). These stains have been used in other biomineral investigations. ${ }^{[4]}$ Each of these stains is discussed in more detail as follows.

\subsubsection{COOMASSIE BLUE}

Coomassie blue is the most common SDS-PAGE stain used in the biological sciences. ${ }^{[12]}$ Its mode of attachment to an analyte is similar to that of the Bradford reagent: through the side arms of basic amino acids. ${ }^{[23]}$ As these residues are poorly represented in SMP (p. 102) it only stains faintly (Figure 2-1, lane 1). Therefore, like other biomineral systems, ${ }^{[8,24]}$ Coomassie blue could not be used for the analysis of SMP.

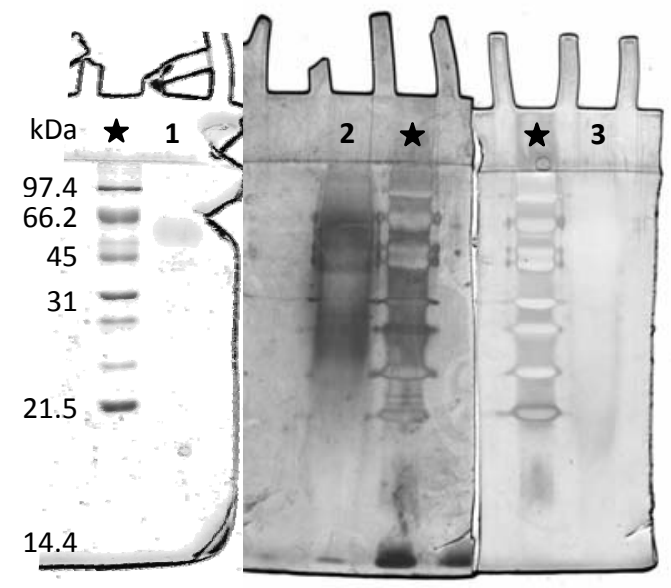

Figure 2-1: Scan of SDS-PAGE gels (12\%) of SMP (10 $\mu \mathrm{g}$ each) stained with Coomassie Blue (lane 1) and silver stain (lane 2: Morrissey method; and lane 3: Gotliv method). The molecular weights (kDa) as determined relative to standard proteins are indicated (black star).

\subsubsection{Si LVER Stai N}

Silver stain is a typical stain for protein. The selectivity of the stain is not well understood with the intensity of a band not necessarily proportional to quantity. The silver stain was only of limited utility in this work. This was because, in 
contrast to Alcian blue and Stains-All, it only stains proteins within SMP which have MWs greater than approximately $22 \mathrm{kDa}$.

Two silver stain protocols were tested; the methods of Morrissey, ${ }^{[8,25]}$ and Gotliv et al. ${ }^{[8]}$ (Figure 2-1, lanes 2 and 3, respectively). The method published by Gotliv et al. is tailored to highly acidic biomineral extracts. They noticed that by intensifying the fixation process the number of proteins visualised on a silver stain gel was dramatically increased. It was postulated that the reason for this increase in the number of bands observed was because the fixing procedure stopped the highly acidic proteins popping out of the gel. In the context of the SMP system, however, it appears that the Morrissey staining procedure produced better protein rendering (Figure 2-1, lane 2).

\subsubsection{Peri Odic ACId-SChi fF Base Stal N}

Periodic acid-Schiff base stain is used to visualise glycosylation. This stain reveals carbohydrates which have vicinal diols available for oxidation, including sialic acid. ${ }^{[26]}$ While the periodic acid-Schiff base stain is not very sensitive was used to profile the SMP ensemble (chapter 4, p. 114).

The formation of the red-purple complex is as follows. Initially the sugar hydroxyl groups are oxidised to their aldehyde version by reaction with periodic acid. This oxidised species is reacted with the complex which is formed by the reaction between pararosaniline and three sulfur dioxide molecules. The sulfur dioxide is formed in situ by the addition of sodium metabisulfite. The coloured chromophore results from an addition type reaction between the oxidised sugars and the complex with a sulfurous acid by-product. The ratio of the aldehyde to complex appears to be 3:1.(Sigma-Aldrich, product information, S5133)

Fetuin, a glycoprotein, was run as a positive control to test that the staining conditions used would indeed reveal glycosylation. As can be seen in Figure 2-2 (lanes 1 and 2) fetuin returned a positive result. 


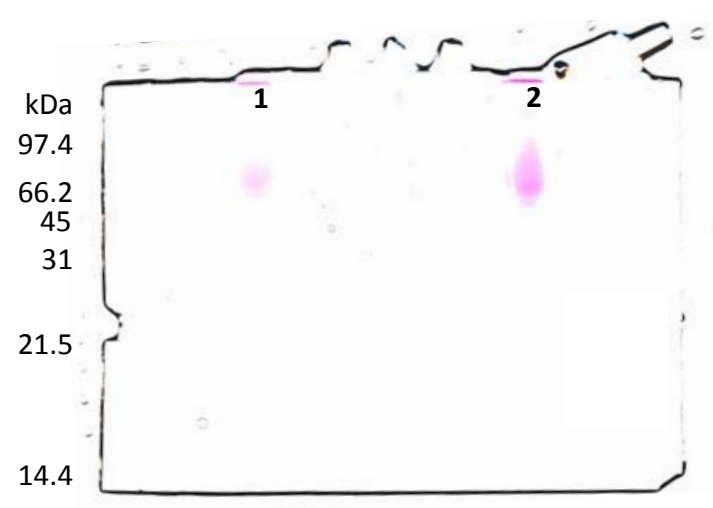

Figure 2-2: Scan of SDS-PAGE gel (12\%) stained with periodic acid-Schiff base. The positive response returned from fetuin is indicated in lane $1(10 \mu \mathrm{g})$ and lane $2(20 \mu \mathrm{g})$. Approximate MWs are indicated on the left.

\subsubsection{Alcian Blue Stal n}

It has been shown in the literature that structural information can be obtained using the Alcian blue stain. ${ }^{[27]}$ Alcian blue is a cationic heterocyclic dye which binds to species exhibiting negative charge. The groups exhibiting negative charge on the analyte can be manipulated depending on the $\mathrm{pH}$ of the Alcian blue stain solution. At $\mathrm{pH} 3$ the Alcian blue stain reveals both sulfates and carboxylates. At pH 1the stain selectively binds sulfates. ${ }^{[28]}$ The $\mathrm{pH}$ of the dye is tailored to $\mathrm{pH} 3$ using acetic acid, or to $\mathrm{pH} 1$ using $\mathrm{HCl}$. In addition to mapping the sulfate profile of SMP the Alcian blue stain was used in chapter 6 (p. 175) to monitor the efficacy of SMP desulfation (SMPDeSO).

In order to test the selectivity of the Alcian blue dye at $\mathrm{pH} 1$ to reveal sulfates a range of controls were analysed. These included: casein (phosphorylated and calcium-binding), fetuin (glycosylated), and the soluble matrix extracted from the calcitic prisms of Pinna nobilis (sulfated). As we can see Figure 2-3 (lanes 3 and 4) the sulfated standard was the only protein to stain. This result indicates that the Alcian blue stain at $\mathrm{pH} 1$ is selective for sulfation. 


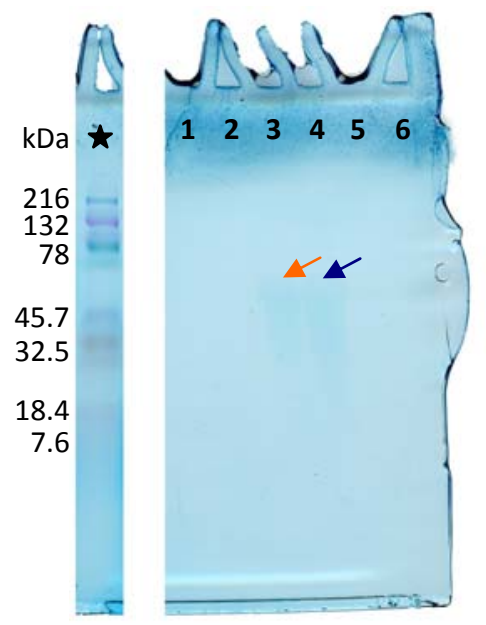

Figure 2-3: Scan of an Alcian blue stained ( $\mathrm{pH} 1)$ SDS-PAGE gel (10-20\%) showing the selectivity of Alcian blue. Odd and even numbered lanes $10 \mu \mathrm{g}$ and $20 \mu \mathrm{g}$, respectively. Casein (lanes 1 and 2: phosphorylated and calcium-binding), the soluble matrix extracted from the calcitic prisms of Pinna nobilis (lanes 3 and 4: sulfated), and fetuin (lanes 5 and 6: glycosylated). The Pinna nobilis sample was kindly provided by Frédérick Marin. The molecular weights ( $\mathrm{kDa}$ ) as determined relative to standard proteins are indicated on the left.

\subsubsection{Stal ns-All Stal N}

It has been shown in the literature that the ability to bind calcium can be determined using the metachromatic cationic carbocyanine dye Stains-All (1-ethyl-2-[3-(1-ethylnaphtho[1,2-d]thiazolin-2-ylidene)-2-methylpropenyl] naphtho $[1,2-d]$ thiazolium bromide). ${ }^{[29]}$ The versatility of this stain has been demonstrated as glycoproteins, proteins, and carbohydrates which bind calcium all returned an absorption maximum at $615 \mathrm{~nm}^{[3,4,29]}$ Stains-All has been used by other biomineral researchers to test for calcium-binding function. ${ }^{[4,30]}$ In this work we were interested in determining the structural features which contribute to the ability to bind calcium. This stain was therefore used extensively in chapter 6 following selective structural modifications.

Typical proteins stain red or pink with Stains-All. ${ }^{[29,31-34]}$ For this reason proteins that bind calcium may appear purple, instead of blue, due to there being absorption maxima other than that at $615 \mathrm{~nm}$. Stains-All will stain sialic acid-rich and heavily phosphated proteins blue ${ }^{[31-34]}$ so the observation of blue-staining 
does not confirm the ability to bind calcium. However, the protocol used in this work was optimised to reveal calcium-binding proteins blue. ${ }^{[29]}$

The blue colour arises from the complex formed through the interaction between the dye and the anionic sites on the protein. ${ }^{[31-34]}$ It has been reported that the extent of colour development is relative to the number of calcium-binding sites, ${ }^{[29]}$ and the calcium-binding strength. ${ }^{[31-34]}$ However, it is not related to the type of calcium-binding as demonstrated by Troponin $C^{[35]}$ and calsequestrin ${ }^{[29]}$ which employ different methods to bind calcium. It is important to note that preparation for electrophoresis denatures the analyte ${ }^{[12,29]}$ which can remove their ability to bind calcium. ${ }^{[5]}$ Therefore, it does not follow that a lack of blue colour development indicates the inability to bind calcium.

The observation of calcium-chelating functionality does not imply the ability to affect the morphology of calcium carbonate grown in vitro as stated by Fu et al. ${ }^{[30]}$ who grew perfect rhombohedra in the presence of calmodulin and S100. The corollary of this is that the interactions at the protein-crystal interface involve precise sites of interaction. ${ }^{[30]}$

The soluble matrix extracted from the calcitic prisms of Pinna nobilis which has been shown in the literature ${ }^{[5]}$ to bind calcium, was run as a positive control: a calcium-binding standard. As can be seen in Figure 2-4 this analyte returned a blue colour under the staining conditions used in this thesis.

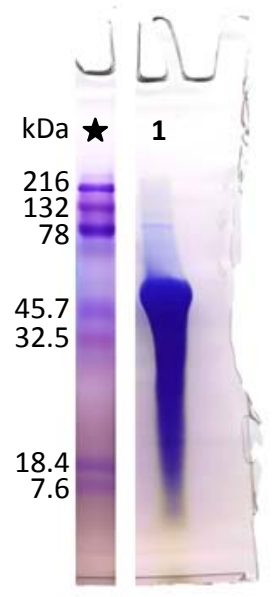

Figure 2-4: Scan of a Stains-All stained SDS-PAGE gel (10$20 \%)$ of showing that the calcium-binding soluble matrix extracted from the calcitic prisms of Pinna nobilis stains blue under the staining protocol used. The Pinna nobilis sample was kindly provided by Frédérick Marin. The molecular weights $(\mathrm{kDa})$ as determined relative to standard proteins are indicated on the left (black star). 


\subsubsection{2D SDS-PAGE}

Two-dimensional gel electrophoresis has been used to reveal structural and functional features of other biomineral extracts. For example, it was used to map the OM within the mineralised tissues of juvenile sea urchin Strongylocentrotus purpuratus. ${ }^{[36]}$ The additional dimension over one-dimensional SDS-PAGE involves isoelectric focussing where proteins are separated on the basis of pl (isoelectric point, the $\mathrm{pH}$ at which the protein exhibits neutrality). Marie et al. ${ }^{[3,4]}$ exploited this technique to good affect. In these reports they demonstrated that removal of PTM had a dramatic effect on the pl value of the modified macromolecules.

2D SDS-PAGE was used in two ways in this thesis. Initially to map the native ensemble using silver stain, Alcian blue pH 1, and Stains-All (chapter 4, p. 118). It was also used to analyse SMP following the selective removal of phosphates (SMPDePO), sulfates (SMPDeSO), and glycans (SMPDeGly) (chapter 6, p. 190).

\subsubsection{HPLC}

There is a variety of different media that can be used in HPLC. These come under the generic headings (and separate on the basis of); gel filtration (size), ion exchange (charge), and normal and reverse phases (polarity). HPLC can be used as a method to fractionate a mixture and/or to determine the MW of an analyte relative to standards. Size exclusion HPLC was used in this project to demonstrate: that the protein and glycan functionalities are covalently linked (p. 109); and the extent of error when determining the MW of an analyte which includes more than one chemical functionality (p. 143).

The procedure of MW profiling using the size-exclusion HPLC column involves running a series of standards of known MW as well as the analyte. The MW of the analyte is determined relative to the elution time of the standards. However, in order to get an accurate result the physical characteristics of the standards and the analyte need to be matched as the physical characteristics of the analyte affect the interaction with the stationary phase and therefore the elution time. These 
physical features of the analyte and standards include factors such as: shape, charge, chemical structure, and aggregation.

\subsubsection{Glycan Structure Determi nation}

There is a variety of analytical procedures that need to be completed in order to determine the complete structure of a glycan or glycone (the complete set of glycan structures within an analyte). There are three generic techniques which, when the information is combined, can lead to complete characterisation of the glycone. These techniques are: monosaccharide analysis, linkage analysis, and glycan profiling. These techniques provide information on the absolute abundance of the monomer units, how the monomer units are bound together, and the glycan sequence. The monosaccharide analysis was discussed earlier in the chapter (p. 37). The linkage analysis and glycan profile are discussed herein. These techniques are related experimentally as both methods require initial release of the intact glycan followed by chemical derivatisation.

\subsubsection{Chemical Preparation}

To isolate the liberated intact glycans the analyte macromolecule is subjected to the following sequence of treatment: protein denaturation including reduction of the disulfide bridges and derivatisation of the liberated thiols to inhibit bridge reformation, digestion of the peptide backbone with trypsin to yield more susceptible glycopeptides, selective release of the N-glycans with PNGase $\mathrm{F}$, and finally isolation of the O-glycans using reductive elimination. The methods adopted in this project to affect this procedure are similar to those used by Jang-Lee et al. ${ }^{[37]}$

As with the MSA, the sensitivity of the linkage analysis and glycan profiling techniques is enhanced if derivatisation of the sample is completed prior to MS analysis. For both analyses the isolated glycans are permethylated, that is, the available hydroxyl groups converted to methyl ether functionality. Additional derivatisation steps are required for the linkage analysis. These are analogous to 
the MSA: acid digestion to release the monosaccharides, reduction to form their alditols, and finally acetylation of the hydroxyl groups.

\subsubsection{MASS SPECTROMETRY}

MS was the method used for all sugar analyses completed in this project. This included: MSA, linkage analysis, and the glycan profiles. Mass spectrometers ionise and fragment species and accelerate the ions through a vacuum using an electric field. Particles of different mass/charge ratios $(\mathrm{m} / \mathrm{z})$ are then separated by either deflecting them in a magnetic field or by measuring their time-of-flight (Tof) to a detector. ${ }^{[19]}$ Generation of analyte fragments follow specific pathways based on the ionisation method. For structural determination of glycans electrospray ionisation (ESI) and matrix-assisted laser desorption ionisation (MALDI) are used. These ionisation methods were developed in the $1990 \mathrm{~s}$ and are more sensitive ${ }^{[18,}$ ${ }^{19,38]}$ than their predecessors, such as fast atom bombardment (FAB). ESI is often used in-line with LC (HPLC) or GC. Hence it can be used for monosaccharide composition and linkage analyses which require fractionation of the sample for analyte identification. GC-MS detection limits are in the vicinity of $500 \mathrm{pmol}(100 \mathrm{ng}) .^{[19]}$ In a MALDI experiment the analyte of interest is co-crystallised in a suitable matrix of small organic molecules on a smooth metal surface. The crystal is then obliterated using a high intensity laser which ionises and throws the analyte into a vacuum. The ionised analyte is then attracted to a charged area and detected using a Tof analyser. ${ }^{[39]}$ This type of analyser allows for a larger mass range ( $\mathrm{m} / \mathrm{z}$ 1000-7000 (permethylated $\mathrm{N}$-glycans) and $\mathrm{m} / \mathrm{z}$ 500-4000 (permethylated O-glycans)). Only a few femtomoles of sample are required for detection. $^{[18]}$

$\mathrm{MS}^{\mathrm{x}}$ is ay very powerful technique for the assignment of MALDI generated MS signals. Ions which led to the signals on the initial spectrum can be further fragmented if an ion trap is incorporated into the MS system hardware. Fragmentation of glycans are dominated by two types of cleavages; glycosidic, and cross-ring. Glycosidic cleavage provides information on the carbohydrate sequence and branching. ${ }^{[38]}$ From the carbohydrate sequence and branching the glycan 
profile can be constructed. While derivatisation is not required, permethylated and peracetylated samples cleave in a very predictable manner, in contrast to native samples. Hence, the fragmentation patterns of oligosaccharides can be mapped. ${ }^{[15]}$

\subsubsection{LINKAGE ANALYSIS}

A linkage analysis determines how the monosaccharides are put together. The various methods used to determine this information include; Smith degradation, acetolysis, exoglycosidase digestion, and methylation analysis. The most commonly used method is the methylation analysis which involves the formation of partially methylated alditol acetates (PMAAs).

The linkage information is determined as follows. All hydroxyl groups that are not involved in bonding to adjacent sugars are methylated. The glycosidic bonds are then broken with new hydroxyl groups marking the positions that were previously involved in a linkage. These hydroxyl groups are then converted to acetates using the MSA alditol acetate protocol. Explicitly, acetate functionality marks positions on the monomer units which were involved in glycosidic linkages. Fractionation, identification, and quantitation are then achieved using GC-MS. Typical columns used include: DB-1, DB-5 SPB-1, SPB-5, or SPB-35 bonded phase fused silica capillary column. ${ }^{[15]}$

As with a monosaccharide composition, assignment of signals is based on the relative elution time and diagnostic MS fragmentation signals. ${ }^{[15]}$ Standards are generated by intentionally undermethylating a series of monosaccharides species that were shown to be present in the MSA. For each monosaccharide there is considerable variety of linkage possibilities, for example 1,$2 ; 1,3$; and $2,3,5$. This structural variety can complicate signal assignment and reduce signal intensity. Web-based databases are available to aid assignment of retention peaks.

Linkage analysis was of limited utility in this $\mathrm{PhD}$. At the time that we completed the linkage analysis we did not know that the glycone was charged so the method used to complete the permethylation was the $\mathrm{NaOH}$ method, a method developed for neutral glycans. Following the permethylation reaction the excess $\mathrm{NaOH}$ is 
removed by washing with $M Q$. Glycans which are charged are discarded in the $M Q$ waste. As a consequence the majority of the glycone, the charged contingent, was lost during this permethylation work-up. An alternative method to permethylate the liberated glycans would have been used had we known that the majority of glycone was charged. These methods include: using Hakomori permethylation or by removing the charged auxiliaries using methanolysis prior to $\mathrm{NaOH}$ permethylation. Neither of these was completed due to time constraints.

\subsubsection{GLycan Profiling}

The structure of a glycan cannot be deduced by indirect methods, which is in contrast to the determination of a protein sequence. With the use of DNA sequencing it is possible to deduce the complete sequence of a protein from the DNA nucleotides, without working on the protein itself. From the derived amino acid sequence many of the protein's properties can be predicted, including its ER-translocation signals, transmembrane domains, and even assertions as to the three-dimensional shape of the protein can be made. These predictions are limited, however, as they do not include the PTMs. These post-translational modifications can only be deduced from purified protein samples. ${ }^{[15]}$

Currently the best method to determine the sequence or arrangement of the monosaccharides in a glycone involves a glycan profile analysis, acquired using MALDI TOF/TOF. This method does not provide linkage information; the anomericity, that is, whether the glycosidic bond is $\alpha$ or $\beta$; or the relative abundance of each glycan.

Preparation of samples for glycan profiling involves permethylation. As with the linkage analysis, the method used in this thesis to complete this derivatisation was developed for neutral glycans. Glycans which are charged, with sulfate for example, are disposed in the aqueous phase of the permethylation work-up. The glycan profiles presented in this document are therefore limited to the neutral glycans. Similar to the linkage analysis we could not repeat the glycan profile using protocols developed for charged species due to time constraints. 


\subsection{FUNCTI ONAL METHODS}

Two functional methods were used in this work: the in vitro crystallisation assay and the Stains-All SDS-PAGE stain. Using the crystallisation assay we tested the effect of an analyte on the number and morphology of crystals grown. The StainsAll stain was used to test whether the analyte had the ability to bind calcium. There are other functional analyses that would complement these techniques, such as the calcium carbonate precipitation assay ${ }^{[40]}$ and the carbonic anhydrase assay. ${ }^{[41]}$ These analyses were not completed however due to limited resources.

In the crystal growth experiments we were not attempting to replicate the sponge-like internal structure of a sea urchin spine. To achieve this, a shape-defining template would be required to control the gross morphology. ${ }^{[42]}$

\subsubsection{Crystalli sati ON Assay}

Crystallisation of calcium carbonate on an amorphous glass substrate in the presence of additives, SMP or its digests, was used to assess the link between biomolecular structure and function. By function we mean the ability of the macromolecules to affect the number and habit of calcium carbonate crystals grown in vitro.

Scanning electron microscopy (SEM) was used to view the crystals grown. SEM is an appropriate technique to use given the average size of a crystal is approximately $10-120 \mu \mathrm{m}$. In addition, SEM is well suited to providing depth of field information which was required for visualising the topographical features of the crystals.

The in vitro crystallisation assay is limited in two significant ways. As this method is abiotic the relevance of the results to the in vivo model is uncertain. For example, it has been shown that molecules on a fixed substrate which nucleate and effect morphology inhibit crystal growth when liberated in solution. ${ }^{[40]}$ However, given the complexity of in vivo models, use of this in vitro crystallisation assay provides a means to build towards understanding the realistic greater mélange of 
macromolecules. ${ }^{[43]}$ Another limitation of this assay is that we were investigating an ensemble using a bulk technique. We were therefore unable to probe functionality at the individual macromolecular level. Given these caveats, in vitro systems of analysis provide the much needed information on the roles of proteins within mineralising systems. From this level of understanding more complex models can be developed towards a greater appreciation of the in vivo systems. ${ }^{[43]}$

There is a variety of published methods available to grow calcium carbonate crystals from aqueous solutions in the laboratory. These include the vapour diffusion, Kitano, and the calcium hydroxide methods. The vapour diffusion method is the most common method used to test the in vitro functionality of biomineral extracts ${ }^{[2,10,30,44-47]}$ and was the method adopted in this thesis. It is the most amenable method as the crystallisation kinetics, the range of calcium ion concentration, the number of crystals precipitated, and the time before crystals begin to crash out are all able to be tailored in the small volumes of solution often used. $^{[48]}$

To effect crystallisation a calcium chloride solution is infused, through slow diffusion, with carbonate ions which leads to calcium carbonate formation. ${ }^{[4]}$ The rate of crystal growth is controlled by the rate of sublimation of ammonium carbonate. ${ }^{[49]}$ The OM additive is added to the calcium solution with its activity represented by the number and shape of the precipitated crystals. The crystallisation experiment variables include: temperature; growth duration; ammonium carbonate, calcium ion, and organic additive concentrations.

In this thesis the crystallisation conditions were modified towards two outcomes. As sea urchin spines are made of calcite we adapted the crystallisation conditions to nucleate this polymorph. Secondly, we wanted the conditions to realise the most profound effect of the organic additive. The motivation for this was two-fold: the organic material was limited in supply, and we wanted slight changes in the organic additive to manifest as substantial changes in crystallisation activity. 
Historically $10 \mathrm{mM}$ calcium is used in the crystallisation experiments. The rationale being that this is the concentration of calcium in sea water, ${ }^{[50]}$ and sea water is the primary source of calcium to the organism. However, this concentration is irrelevant for two reasons. Firstly, it has been shown that mineral growth occurs via ACC. ${ }^{[42]}$ Secondly, the soluble macromolecules which promote nucleation create a supersaturation of calcium ions in the vicinity of an organic template, ${ }^{[48]}$ generating a local concentration of calcium greater than $10 \mathrm{mM}$. For these two reasons we do not believe that crystallisation experiments should be restricted to a $10 \mathrm{mM}$ calcium ion concentration.

A limitation of the standard crystallisation conditions was first demonstrated by MacKenzie et al. ${ }^{[46]}$ In their study on the acidic OM extracted from the spines of Evechinus chloroticus they showed that hierarchical crystal growth was only observed when the calcium concentration was high (500 mM).

To demonstrate the analytical limits of using $10 \mathrm{mM}$ calcium we have presented three SEM images in Figure 2-5. These images display the morphology of crystals grown in $10 \mathrm{mM}$ calcium solutions in the presence of SMP, isolated $\mathrm{N}$-glycans, and O-glycans from left to right, respectively. From this comparison it could be concluded that the organic additives affect morphology in a similar fashion, at least for crystals grown in the presence of the isolated glycans. This conclusion is in stark contrast to the results obtained when the calcium ion concentration is $500 \mathrm{mM}$ (p. 168).
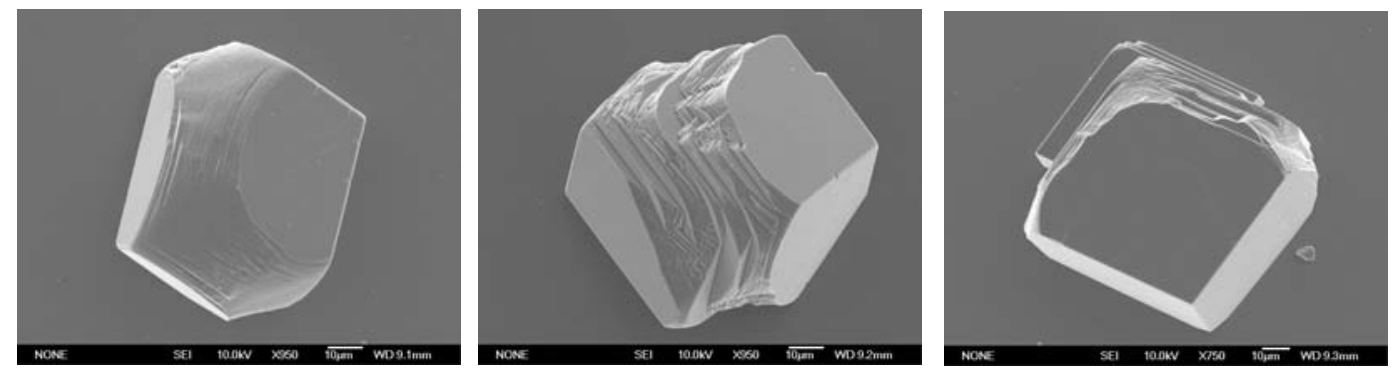

Figure 2-5: SEM images showing the morphology of crystals produced using the standard crystal growth conditions ( $10 \mathrm{mM} \mathrm{CaCl}_{2}$ and $5 \mu \mathrm{g} / \mathrm{mL}$ organic additive). Organic additives used, from left to right: SMP, N-glycans, and O-glycans. The other crystallisation variables included: 48 hours, $15^{\circ} \mathrm{C}$, and $0.1 \mathrm{~g}$ ammonium carbonate. 


\subsubsection{Opti MI SATI ON OF the CRystal Growth Conditions}

Determining the optimum conditions; such as ion concentration, temperature, and pressure, under which to grow the calcium carbonate crystals is vital if useful data is to be collected. This is because they all have influence over crystal formation including, the number of crystals, the overall morphology, and which polymorph is deposited. ${ }^{[42]}$ Depicted below are a series of experiments which illustrate the methodology employed to determine the optimum crystal growth conditions for the SMP extract.

Sea urchin spines are made of calcite. We therefore targeted blank crystallisation conditions which selectively produced calcite crystals. The two temperatures tested were 15 and $25^{\circ} \mathrm{C}$. SEM images depicting crystals grown at these two temperatures are presented in Figure 2-6. From this experiment we demonstrated that both calcite and vaterite are formed at $25^{\circ} \mathrm{C}$ (row A) while at $15^{\circ} \mathrm{C}$ (row B) calcite is formed exclusively. The crystallisation conditions throughout this work were therefore conducted at $15^{\circ} \mathrm{C}$.
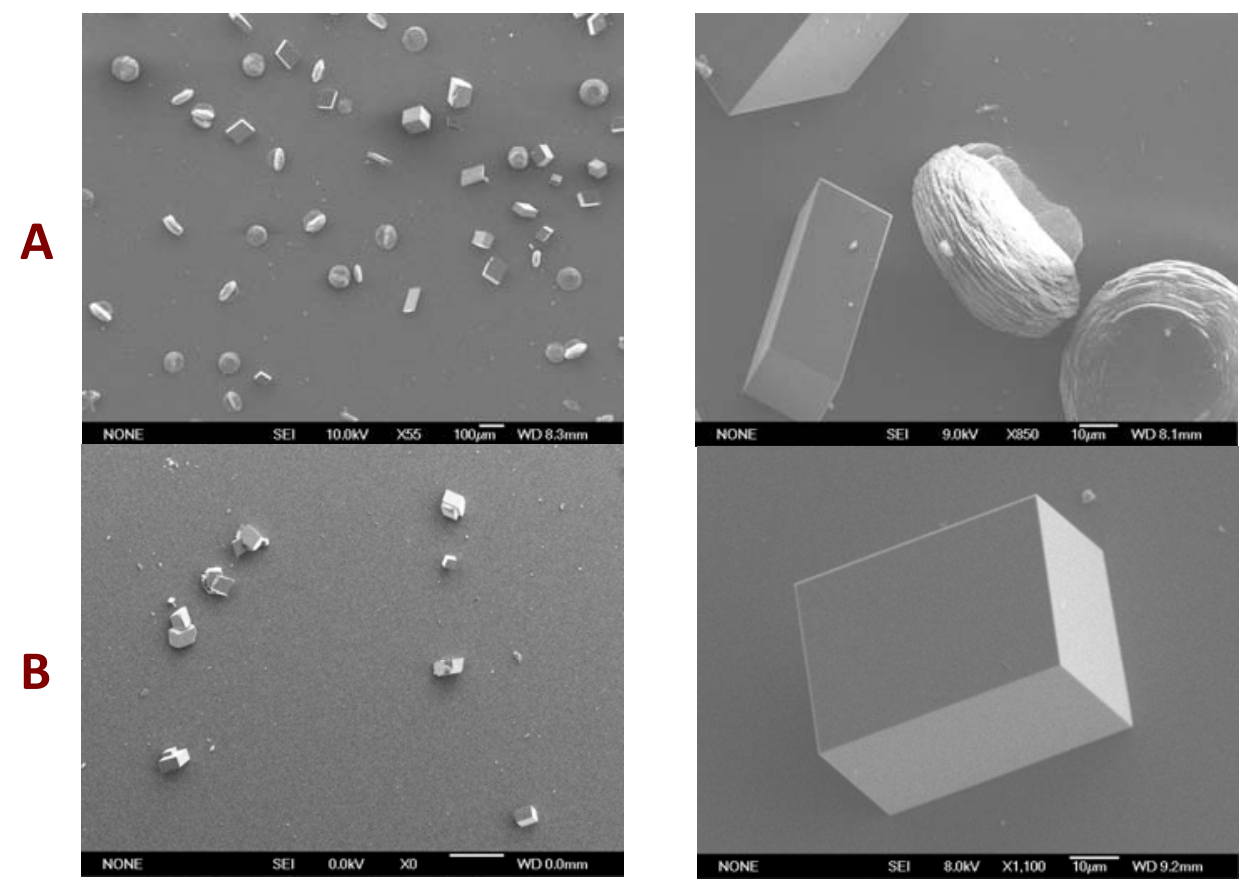

Figure 2-6: SEM images showing the different growth observed at $25^{\circ} \mathrm{C}$ (row A) and $15^{\circ} \mathrm{C}$ (row B). The other crystallisation variables included: 48 hours, $10 \mathrm{mM} \mathrm{CaCl}$, and $0.1 \mathrm{~g}$ ammonium carbonate. 
Another variable that was manipulated was the length of time to grow the crystals. In Figure 2-7 are example SEM images depicting the number of crystals grown after 48, 72, and 96 hours. From these results we decided to grow crystals for 48 hours as there is no apparent change in the number or size of crystals grown throughout this time range.
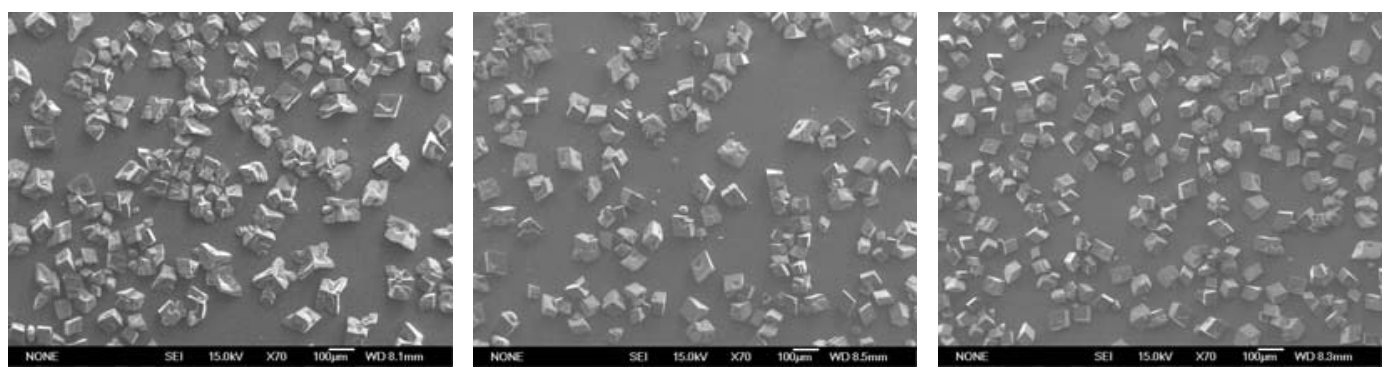

Figure 2-7: SEM images showing the number of crystals grown after 48, 72, and 96 hours (from left to right). The other crystallisation variables included: $15^{\circ} \mathrm{C}, 100 \mathrm{mM} \mathrm{CaCl}$, and $0.4 \mathrm{~g}$ ammonium carbonate.

A series of experiments were completed varying the concentration of calcium chloride; the source of calcium. Representative SEM images from these experiments are depicted in Figure 2-8. From analysis of the crystals grown we have demonstrated that the number of crystals nucleated and calcium concentration are positively correlated.
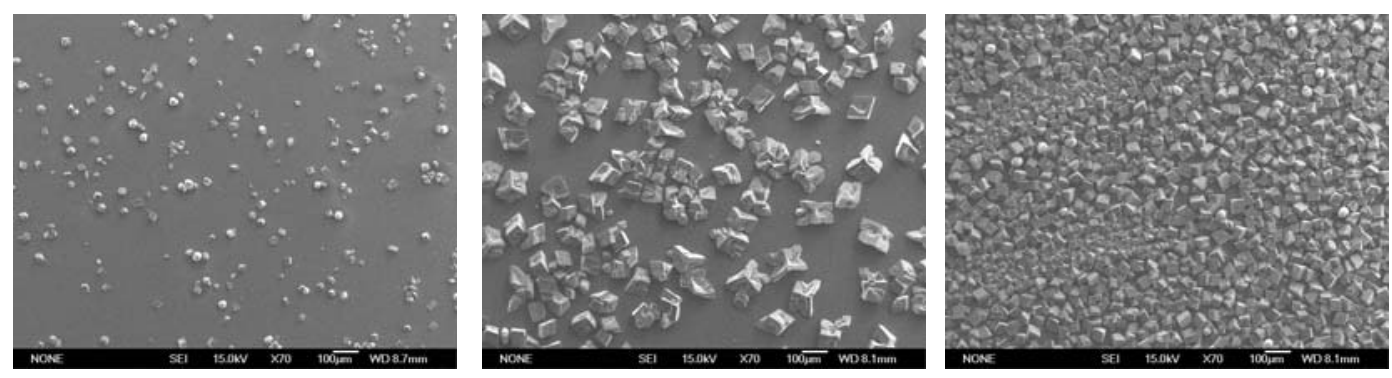

Figure 2-8: SEM images showing the number of crystals grown in the presence of 7.5, 100, and 500 $\mathrm{mM} \mathrm{CaCl}$. The other crystallisation variables included: $15^{\circ} \mathrm{C}, 48$ hours, and $0.4 \mathrm{~g}$ ammonium carbonate.

In Figure 2-9 is a series of SEM images which demonstrate the effect of varying the ammonium carbonate mass. In these experiments there was SMP added so that we could monitor the effect of ammonium carbonate on modified crystal 
morphology as well as the number of crystals nucleated. From a comparison of the number of crystals nucleated (left column) we can conclude that as the ammonium carbonate mass increases so does the crystal density. From a comparison of the morphological features we also observe that the surface towers become broader as the ammonium carbonate mass increases.
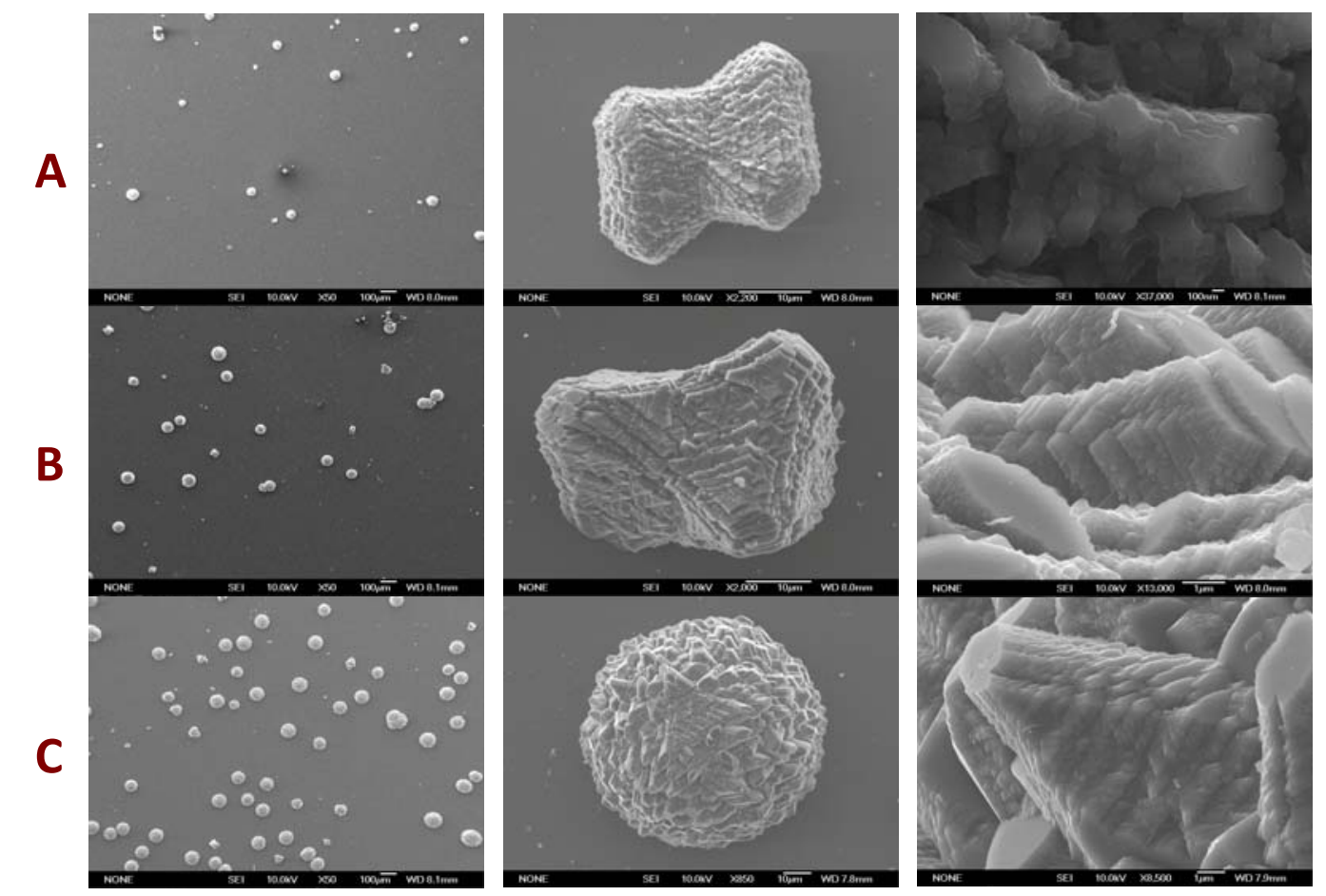

Figure 2-9: SEM images showing the different growth observed upon varying ammonium carbonate concentration. Rows A to C: $0.04,0.07$, and $0.10 \mathrm{~g}$ ammonium carbonate, respectively. The other crystallisation variables included: $15^{\circ} \mathrm{C}, 500 \mathrm{mM} \mathrm{CaCl}_{2}$, and 48 hours.

We also completed a series of experiments to assess the effect of the SMP matrix at various concentrations. SEM images depicting the morphology of the crystals grown in the presence of 5, 30, and $60 \mu \mathrm{g}$ protein/mL are depicted in Figure 2-10. From these experiments we have demonstrated that the morphological influence of SMP becomes more profound as the concentration of SMP increases. That is, the crystal's surface features become more intricate from left to right (Figure 2-10). 

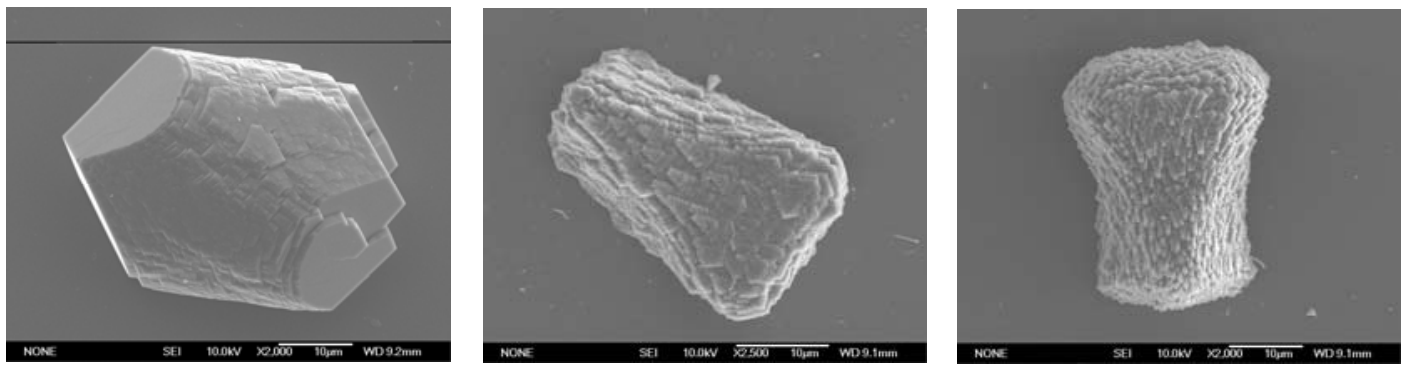

Figure 2-10: SEM images showing the different growth observed upon varying SMP concentration from 5,30 , and $60 \mu \mathrm{g} / \mathrm{mL}$ (left to right). The other crystallisation variables included: $15^{\circ} \mathrm{C}, 500 \mathrm{mM}$ $\mathrm{CaCl}_{2}, 48$ hours, and $0.1 \mathrm{~g}$ ammonium carbonate.

By completing this series of experiments we determined the optimum conditions to monitor the effect of SMP and its derivatives on crystal growth. These are: $500 \mathrm{mM}$ calcium chloride, $30 \mu \mathrm{g}$ protein $/ \mathrm{mL}$ organic additive, $15^{\circ} \mathrm{C}, 48$ hours, and $0.1 \mathrm{~g}$ ammonium carbonate. These conditions were used for all crystallisation results presented in this thesis. A SMP concentration of 30 protein $\mu \mathrm{g} / \mathrm{mL}$ was selected as the affect on crystal morphology was sufficiently profound to observe an affect yet low enough so as to conserve the limited amount of SMP available.

\subsection{SMP ENSEMBLE MANI PULATI ON}

In order to increase our understanding of the roles mediated by the post-translational modifications within SMP we needed to manipulate the ensemble and analyse the activity of the resultant fractions. The manipulations completed are outlined below.

\subsubsection{SMP FRACTIONATION (ChAPTER 5)}

Due to the wide chemical polydispersity (included as post-translational modification) and an abundance of charge, fractionation of a biomineral extract usually fails to reveal discrete macromolecules. This technical obstacle remained insurmounted for two decades. Biomineral extracts stick and smear to the fractionation media. ${ }^{[8]}$ As a result the first full-length sequence of a biomineral occluded protein was only obtained in 1996. ${ }^{[51]}$ And as of the year 2008 there are still only four that have been determined by direct protein sequencing out of the 43 fully characterised biomineral protein backbones. ${ }^{[52]}$ SMP consists of a tightly 
diverse system of charged biomolecules which also stick and smear to fractionation media as demonstrated from SDS-PAGE analysis (p. 115). Hence the only attempt made in this work to fractionate the ensemble was crude, that is, into subfamilies of macromolecules based on MW. Specifically, fractions including species of $<10,10-30$, and $>30 \mathrm{kDa}$. The choice of $30 \mathrm{kDa}$ as a molecular weight cut-off (MWCO) was based on experimental evidence suggesting that there was a structure-function division near this MW. This structural difference was especially obvious in the Stains-All stained gel of the native extract (p. 115). Using analytical procedures on these MW fractions we mapped the PTM distribution throughout the ensemble and compared these to the functional analyses of calcium-binding and influence on crystal growth in vitro.

We decided to use spin-filters to affect these group isolations. The decision to use spin-filters was primarily based on the minimal cross-sectional area of the stationary phase. This was of critical importance as we had observed for other fractionation methods, such as porous graphitised carbon mini-columns, there was extensive sample loss through irreversible binding to the fractionation media. Using these spin-filters the extent of contact between the analyte and the stationary phase was considered to be minimal. This technique was practically feasible due to the high solubility of SMP. This physical property is required as the analyte must stay in solution in the retentate solution which is reduced to $\sim 75 \mu \mathrm{L}$. The reproducibility, reliability, and efficacy of these separations were monitored using A280 (absorption at $280 \mathrm{~nm}$ ) and SDS-PAGE.

The defined MWCO associated with the spin-filters can be misleading. The MWCO is used to define the pore size relative to an ideal protein. These ideal proteins are relatively neutral, are not post-translationally modified, and do not tend to aggregate. As biomineral extracts often include these non-ideal features ${ }^{[5,53,54]}$ the relevance of the MWCO of the spin-filters to SMP is questionable. 


\subsubsection{SPECIFIC DI gesti ON OF SMP (ChAPTER 6)}

To better understand the roles mediated by the PTMs of SMP the ensemble was pruned based on the various chemical modifications determined to be present in chapter 4. We incorporated both enzymatic and chemical based methods to selectively remove these modifications in an attempt to recognise their role in binding calcium and influencing crystallisation in vitro. Most of the methods used are adaptations of protocols used in glycobiology to determine glycan structure. When deciding which methods were amenable to our investigation it was imperative that we could isolate usable quantities of the digestion products (> $\sim 100 \mu \mathrm{g}$ ) for use as an additive in the calcium carbonate crystallisation assay. This is obviously not the motivation in structural glycobiology.

Fundamental to the exploitation of these glycobiological methods is an understanding of glycan structures. Glycans exhibit two modes of attachment to the protein scaffold in a glycoprotein. They are attached to the protein either through an asparagine amino acid ( $\mathrm{N}$-glycan), or a serine or threonine amino acid (O-glycan). The mode of attachment is reflected in the glycan structure, and therefore function. The methods employed to release the glycans is dependent on the nature of this attachment. Intact $\mathrm{N}$-glycans are typically removed prior to the O-glycans with the use of endoglycosidases. Subsequently, the O-glycans are released using base hydrolysis. Hence, resolution of the two sugar classes is not an issue. ${ }^{[18,39,55,56]}$ The general distinguishing parameters between these two classes of glycan are summarised in Table $2-1 .{ }^{[18,55]}$ 


\begin{tabular}{|c|c|c|}
\hline Class & N-linked & O-linked \\
\hline $\begin{array}{l}\text { Attachment } \\
\text { to protein }\end{array}$ & $\begin{array}{c}\text { - } \mathrm{NH}_{2} \text { sidechain of asparagine } \\
\text { (Asn) residues }\end{array}$ & $\begin{array}{l}\text {-OH sidechain of either a } \\
\text { serine or a threonine }\end{array}$ \\
\hline Sugar core & $\begin{array}{c}\text { Man } \alpha 1,3(\text { Man } \alpha 1,6) M a n \beta 1,4 \\
\text { GIcNAc } \beta 1,4 \text { GIcNAc-N-Asn }\end{array}$ & $\begin{array}{l}\text { Serine/Threonine-O-GalNAc } \\
\text { or Serine/Threonine } \\
\text {-O-Gal( } \beta 1-3 G a l) N A c \alpha 1-3\end{array}$ \\
\hline $\begin{array}{c}\text { Mode of } \\
\text { Attachment }\end{array}$ & Added to the protein en bloc & $\begin{array}{l}\text { Glycosyltranferases add one } \\
\text { monosaccharide at a time }\end{array}$ \\
\hline Type & $\begin{array}{l}\text { i) Only mannose residues } \\
\text { (high-mannose), } \\
\text { ii) No mannose residues } \\
\text { beyond core (complex), } \\
\text { iii) One mannose only arm } \\
\text { and one arm no mannose } \\
\text { (hybrid) }\end{array}$ & \\
\hline
\end{tabular}

Table 2-1: Outline of the general differences between the two classes of glycans, that is, $\mathrm{N}$ - and Olinked glycans. Man is mannose, Gal is galactose, GlcNAc is $N$-acetylglucosamine, and GalNAc is $N$ acetylgalactosamine.

\subsubsection{GLYCOSYLATION}

\subsection{N-GLYCANS AND SMPDEN-G}

PNGase $F$ (peptide- $\mathrm{N}^{4}$-(acetyl- $\beta$-glucosaminyl)-asparagine amidase) is widely used in glycobiology. ${ }^{[15]}$ This is because of its conveniently broad specificity to cleave Nglycans. ${ }^{[57,58]}$ It does not, however, release N-glycans which exhibit $\alpha(1-3)$ linked fucose to the $\mathrm{N}$-glycan core. As it is an endoglycosidase it cleaves at the proteinglycan bond ${ }^{[59]}$ releasing the complete $\mathrm{N}$-glycan which is ideal for structural analyses. Its mode of $\mathrm{N}$-glycan recognition also involves amino acid components ${ }^{[15,}$ ${ }^{60]}$ so there must be peptide associated with the N-glycan for PNGase F to function. In a typical glycobiological analytical procedure $\mathrm{N}$-glycans are selectively released prior to O-glycans because of the convenient utility of PNGase F. By using PNGase $\mathrm{F}$ we isolated two significant products: $\mathrm{N}$-glycans and SMP with the $\mathrm{N}$ glycans removed (SMPDeN-g). This was appealing as there has been much interest in the roles fulfilled by the $\mathrm{N}$-glycans in biomineralisation. ${ }^{[46,61]}$

To increase the efficiency of PNGase F the glycoprotein analyte is usually pre-digested with a protease, such as trypsin, to increase steric access to the $\mathrm{N}$-glycan site of attachment. Detergent is also included to unfold the protein and further increase glycan accessibility. However, both of these preparatory steps 
were undesirable as we were interested in testing the function of an intact, free from contaminants, SMPDeN-g. We were able to monitor the efficacy of the Nglycan liberation using MSA as all N-glycans have a minimum of three mannose units in the common pentasaccharide core.

Typical methods for isolation of the $\mathrm{N}$-glycans involves fractionation of the PNGase F digest over a G50 Sephadex or a $C_{18}$ Sep-Pak. Both of these methods were not ideal for our investigation. Firstly, as the only modification to the ensemble was removal of the $\mathrm{N}$-glycans, the likelihood of irreversible binding to the fractionation media was high, especially for the $\mathrm{C}_{18}$ Sep-Pak. An additional complication with the $\mathrm{G} 50$ column was that the analyte would be spread over a number of fractions, that is, a large volume of eluant. As we were dealing with relatively small masses of material, for example $100 \mu \mathrm{g}$ of $\mathrm{N}$-glycan, detection across a number of fractions using the phenol-sulfuric acid assay would not work. We therefore decided that the ideal method of $\mathrm{N}$-glycan isolation was to spin the digestion mixture across a $10 \mathrm{kDa}$ filter. This method proved to be reliable and reproducible with no material lost as determined using A280 and MSA.

PNGase F was purchased as a glycerol suspension. As the reaction products were separated using a $10 \mathrm{kDa}$ spin-filter, the $\mathrm{N}$-glycan fraction contained glycerol, and the SMPDeN-g fraction contained PNGase F. We therefore tested the effect that both glycerol and PNGase $F$ have on crystal formation. From this analysis we observed that the effect of these additives on the number and shape of crystals grown was minor. From the SEM images presented in Figure 2-11 we can see that excess glycerol (left: $10 \mu \mathrm{L} / \mathrm{mL}$ ) has no effect on crystal morphology. However, excess PNGase F (right: 10 units $/ \mathrm{mL}$ ) does cause crystal elongation. This result demonstrates that PNGase F may contribute to the morphological activity observed for the SMPDeN-g sample. We believe, however, that the relative contribution of the PNGase $F$ to the morphological activity would be near negligible when using SMPDeN-g as an additive. This is because the amount of PNGase F included is approximately 20 times lower (0.5 units $/ \mathrm{mL}$ ) than the test experiment presented in Figure 2-11. 

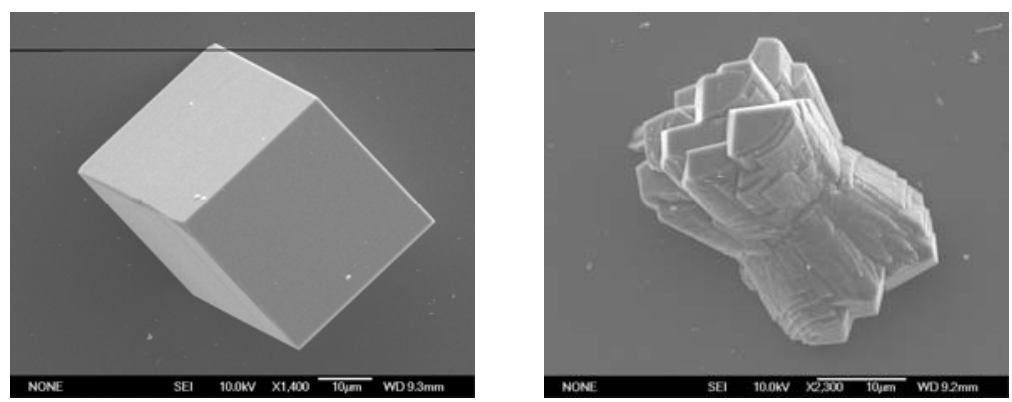

Figure 2-11: SEM images showing the morphology of calcium carbonate crystals grown in the presence of PNGase F contaminants. The additive included: excess glycerol (left: $10 \mu \mathrm{L} / \mathrm{mL}$ ) and excess PNGase F (right: 10 units $/ \mathrm{mL}$ ). The conditions used to grow the crystals were: $15^{\circ} \mathrm{C}, 500 \mathrm{mM}$ $\mathrm{CaCl}_{2}, 48$ hours, and $0.1 \mathrm{~g}$ ammonium carbonate.

A PNGase F deglycosylation blank was prepared by incubating SMP in the absence of PNGase F, in parallel to the PNGase F digested sample. This blank sample was then fractionated in a similar manner to the PNGase F sample, across a $10 \mathrm{kDa}$ spin-filter. The greater than $10 \mathrm{kDa}$ fraction was electrophoresed on SDS-PAGE and produced a migration profile which was identical to SMP. Using the blank fractions in calcium carbonate crystallisation experiments returned results which were no different to SMP. This result therefore demonstrates that any change in activity following treatment of SMP with PNGase $\mathrm{F}$ is due to N-glycosylation.

Borohydride reduction of $\mathrm{O}$-glycopeptides is the standard technique for the isolation of the O-glycone. Under the alkali conditions used (p. 76) the intact Oglycans are liberated. ${ }^{[15]} \mathrm{A}$ high concentration of borohydride is incorporated to inhibit reductive degradation of the glycans once liberated into the basic solution. The reason that chemical methods are used is because there is no O-glycan equivalent of PNGase F. The one endoglycosidase available that selects for O-glycans, O-glycanase (endo- $\alpha-N$-acetyl-D-galactosaminidase), specifically cleaves unsubstituted $\beta$-Gal(1-3) $\alpha$-GalNAc-O-serine/threonine (Core 1). ${ }^{[15]}$ However, as Oglycans display a variety of core structures it is unlikely that the complete O-glycone gets released using this enzyme.

The efficacy of the O-glycan liberation and isolation were monitored using A280, MSA, and MALDI TOF/TOF. These methods revealed that: there was no protein in 
the O-glycan sample, the complete O-glycone had been isolated, and the only structures present in the sample were O-glycans, respectively.

\subsection{SUGAR AND SULFATE REMOVED (SMPDEGLY)}

Selective removal of the glycans while leaving the protein intact provides a means to test the function of these chemical architectures. To achieve this isolation of the intact protein in one step chemical methods are required, ${ }^{[62]}$ as they are able to liberate both classes of glycan regardless of linkage or composition. All glycosidic bonds are cleaved leaving one GlcNAc attached to the asparagine amino acid. ${ }^{[62]}$ The two most common procedures use either trifluoromethane sulfonic acid (TFMS) or hydrogen fluoride (HF). We did not use the method which involves the use of HF due to its high level of toxicity. ${ }^{[63,64]}$ TFMS has been used previously to unravel structure-function relationships in other biomineral systems. ${ }^{[65,66]}$

TFMS (trifluoromethane sulfonic acid) has been used extensively to deglycosylate glycoproteins. ${ }^{[67]}$ The sources of the glycoproteins range from bacteria and yeast through to mammals. For example; parasites, ${ }^{[68]}$ insects, ${ }^{[69]}$ and mice. ${ }^{[70]}$ It has also been used successfully in a variety of biomineral investigations. ${ }^{[3-5]}$ This method has been shown to be successful for all types of sugars including N-glycans, ${ }^{[67,70]}$ O-glycans, ${ }^{[67,71]}$ and GAGs. ${ }^{[72,73]}$ Because of the breadth of applicability this method is amenable to glycoproteins of unknown structure, ${ }^{[62]}$ and for ensembles of glycoproteins which display a variety of glycan types, as is the case for SMP.

TFMS is ideal to hydrolyse glycans as it is sufficiently mild to prevent scission of the peptide bonds ${ }^{[62]}$ under anhydrous conditions leaving the protein intact. In the presence of a scavenger the reaction proceeds by solvolytic cleavage of the glycosidic bonds. ${ }^{[62]}$ The scavenger species, an electrophile sink, inhibits reactions between the deglycosylation agent TFMS and susceptible amino acids such as; serine, threonine, aspartate, cysteine, methionine, and the aromatic amino acids, which could lead to protein degradation. ${ }^{[63,74]}$

The TFMS procedure has shown to selectively remove sugar. That is, other PTMs such as sulfates ${ }^{[75,76]}$ and phosphates ${ }^{[77]}$ attached directly to the protein backbone 
are not removed by TFMS. This selectivity for glycan structures was useful as it allowed us to determine whether the sulfates and phosphates were bound to the protein or glycan frameworks.

The typical method employed to assess the efficacy of a TFMS deglycosylation is to demonstrate a reasonable mass reduction on SDS-PAGE for a characterised protein standard. As a positive control we deglycosylated fetuin in parallel to SMP. Fetuin is 22.5 wt\% carbohydrate. ${ }^{[78]}$ With a MW of approximately $70 \mathrm{kDa}$ we should therefore observe a decrease in mass of $\sim 13 \mathrm{kDa}$ to $57 \mathrm{kDa}$. This calculation is consistent with what we observed for fetuin and deglycosylated fetuin (Figure 2-12, lanes 1 and 2, respectively). The deglycosylation reaction also leads to a sharpening of the band which is consistent with successful deglycosylation. In this work we used additional methods to validate the selectivity of the deglycosylation. These included MSA of deglycosylated SMP (SMPDeGly) to assess the extent of deglycosylation (p. 154), and AAA (p. 150) to test whether the deglycosylation reaction had resulted in unwanted proteolysis.

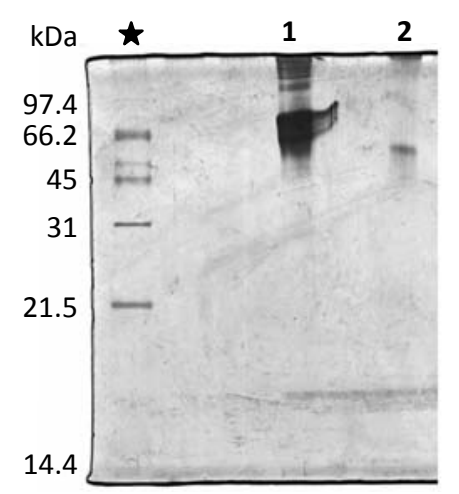

Figure 2-12: Scan of a silver stained SDS-PAGE gel (12\%) of $5 \mu \mathrm{g}$ fetuin (lane 1) and $5 \mu \mathrm{g}$ TFMS treated (deglycosylated) fetuin (lane 2). Molecular weight standards with masses (kDa) indicated on the left (black star).

A few methods were used to isolate the reaction product SMPDeGly. These included fractionating over a G25 Sephadex column, dialysis, and across a $3 \mathrm{kDa}$ spin-filter. From these analyses we determined that the Sephadex column, eluting with $M Q$, was the most reliable. The problem with separation across a spin-filter is that the method involves an increase in the concentration of the retained analyte 
as the water passes through the filter. We observed that the solubility of deglycosylated SMP was drastically reduced in comparison to SMP, resulting in precipitation of SMPDeGly and therefore sample loss on the spin-filter membrane.

\subsubsection{ACIDIC GLYCOSYLATI ON}

\subsection{SiaLIC ACID REMOVEd (SMPDESIA)}

Karamanos et al. ${ }^{[79,80]}$ completed glycan structure analysis on two glycoproteins extracted from the tests of Sphaerechinus granularis. In this report they showed that there was a significant representation of sialic acid. With its carboxylic acid moiety it is believed that this chemical structure may be involved in biomineralisation. ${ }^{[79-81]}$ We were therefore motivated to test the function of the sialic acid incorporated in the SMP glycone.

Sialic acid monosaccharides can be selectively liberated from glycan chains with the use of acetic acid. ${ }^{[15]}$ This acid treatment is a glycobiological method to release sialic acids for quantification purposes. From this digestion there are two significant products: sialic acid monomers and SMP with the sialic acids removed (SMPDeSia). To assess the efficacy of the sialic acid release we completed a MSA to test whether other sugar monomers had been inadvertently removed, and a ferricorcinol assay to test whether the sialic acid functionality had been successfully removed. To isolate SMPDeSia we fractionated the crude acid hydrolysis mixture over a 3 kDa spin-filter.

\subsection{SULFATE REMOVED (SMPDESO)}

Sulfates have been reported to be implicated in biomineralisation. ${ }^{[3,9,49,82-85]}$ We therefore wanted to test the function of SMP with sulfate removed (SMPDeSO). Desulfation of glycans is a common method employed in glycobiology to determine sulfate distribution. ${ }^{[15]}$ As sulfate esters are unstable in acidic conditions $^{[15]}$ the method involves mild methanolysis. Using a desulfation protocol developed by Taguchi et al. ${ }^{[86]}$ we prepared a series of samples, from partial through to complete desulfation. The efficacy of this digestion was monitored 
using MSA to show that the glycans were still intact, and $\mathrm{pH} 1$ Alcian blue stained SDS-PAGE to demonstrate sulfate removal.

\subsubsection{Phosphate Removed (SMPDePO and SMPDePTM)}

Phosphate has been shown to be present in various biomineral systems and is reported to participate in the biomineralisation process. ${ }^{[24,87]}$ Phosphatases can be extremely useful as they have wide susceptibilities including the ability to liberate phosphate bound to protein and sugar. ${ }^{[15]}$ As the product of the dephosphorylation reaction is phosphate ${ }^{[88]}$ it can subsequently be removed over a 3 kDa spin-filter.

Treatment of SMP with a phosphatase followed by purification did not remove all of the phosphate from the ensemble. This was not due to the process used as the dephosphorylation of casein was shown to go to completion when worked up in parallel. Analysis of SMPDeGly showed that the phosphate was protein bound ( $p$. 155). We therefore treated SMPDeGly with phosphatase. Using the malachite green assay we demonstrated that the dephosphorylation reaction in the absence of glycosylation goes to completion (p. 182). We have therefore developed protocols to successfully remove all of the post-translational modifications (SMPDePTM) from the SMP ensemble.

The phosphatase used in these experiments has a MW of $56 \mathrm{kDa}$. It is therefore present in dephosphorylated SMP (SMPDePO). It was therefore necessary to test the activity of phosphatase to affect crystal growth. From this experiment we observed that the phosphatase does not affect either the number of crystals grown or their morphology. 


\subsection{References}

[1] S. Albeck, L. Addadi, S. Weiner, Connective Tissue Research 1996, 35, 365.

[2] S. Albeck, S. Weiner, L. Addadi, Chemistry--A European Journal 1996, 2, 278.

[3] B. Marie, G. Luquet, L. Bedouet, C. Milet, N. Guichard, D. Medakovic, F. Marin, Chembiochem 2008, 9, 2515.

[4] B. Marie, G. Luquet, J. P. P. De Barros, N. Guichard, S. Morel, G. Alcaraz, L. Bollache, F. Marin, Febs Journal 2007, 274, 2933.

[5] F. Marin, R. Amons, N. Guichard, M. Stigter, A. Hecker, G. Luquet, P. Layrolle, G. Alcaraz, C. Riondet, P. Westbroek, J Biol Chem 2005, 280, 33895.

[6] Barry M. Heatfield, Dorothy F. Travis, Journal of Morphology 1975, 145, 13.

[7] K. Mann, A. J. Poustka, M. Mann, Proteome Science 2008, 6.

[8] B.-A. Gotliv, L. Addadi, S. Weiner, Chembiochem : a European journal of chemical biology 2003, 4, 522.

[9] F. Nudelman, B. A. Gotliv, L. Addadi, S. Weiner, J Struct Biol 2006, 153, 176.

[10] S. Albeck, J. Aizenberg, L. Addadi, S. Weiner, Journal of the American Chemical Society 1993, 115, 11691.

[11] L. Ameye, R. Hermann, C. Killian, F. Wilt, P. Dubois, J. Histochem. Cell Biol. 1999, 110, 1189.

[12] I. M. Rosenberg, Second edition ed., Birkhauser Boston, Boston, MA, 2006.

[13] P. K. Smith, R. I. Krohn, G. T. Hermanson, A. K. Mallia, F. H. Gartner, M. D. Provenzano, E. K. Fujimoto, N. M. Goeke, B. J. Olson, D. C. Klenk, Analytical Biochemistry 1985, 150, 76.

[14] K. J. Wiechelman, R. D. Braun, J. D. Fitzpatrick, Analytical Biochemistry 1988, 175, 231.

[15] M. Fukuda, ed; A. Kobata, ed, Glycobiology : a practical approach, Oxford University Press, Oxford, 1993.

[16] S. Weiner, Calcified Tissue International 1979, 29, 163.

[17] S. Weiner, J Struct Biol 2008, 163, 229.

[18] A. Varki, R. Cummings, J. Esko, H. Freeze, G. Hart, J. Marth, Editors, Essentials of Glycobiology, Cold Spring Harbor Laboratory Press, 1999. 
[19] P. J. Baugh, Gas Chromatography A Practical Approach, Oxford University Press, Oxford, 1994.

[20] J. L. Arias, M. S. Fernandez, Chemical Reviews 2008, 108, 4475.

[21] H. Takemoto, S. Hase, T. Ikenaka, Analytical Biochemistry 1985, 145, 245.

[22] Y. Arakawa, T. Imanari, Z. Tamura, Chemical \& Pharmaceutical Bulletin 1976, 24, 2032.

[23] P. G. Righetti, F. Chillemi, Journal of Chromatography 1978, 157, 243.

[24] T. Samata, D. Ikeda, A. Kajikawa, H. Sato, C. Nogawa, D. Yamada, R. Yamazaki, T. Akiyama, Febs Journal 2008, 275, 2977.

[25] J. H. Morrissey, Anal Biochem 1981, 117, 307.

[26] R. M. Zacharius, T. E. Zell, J. H. Morrison, J. J. Woodlock, Anal Biochem 1969, 30, 148.

[27] R. S. Wall, T. J. Gyi, Anal Biochem 1988, 175, 298.

[28] R. Lev, S. S. Spicer, Journal of Histochemistry \& Cytochemistry 1964, 12, 309.

[29] K. P. Campbell, D. H. Maclennan, A. O. Jorgensen, Journal of Biological Chemistry 1983, 258, 1267.

[30] G. Fu, S. Valiyaveettil, B. Wopenka, D. E. Morse, Biomacromolecules 2005, 6, 1289.

[31] L. E. King, M. Morrison, Analytical Biochemistry 1976, 71, 223.

[32] A. E. Dahlberg, C. W. Dingman, A. C. Peacock, Journal of Molecular Biology 1969, 41, 139.

[33] M. R. Green, J. V. Pastewka, Journal of Histochemistry \& Cytochemistry 1974, 22, 774.

[34] M. R. Green, J. V. Pastewka, A. C. Peacock, Analytical Biochemistry 1973, 56, 43.

[35] R. H. Kretsinger, C. D. Barry, Biochim Biophys Acta 1975, 405, 40.

[36] C. E. Killian, F. H. Wilt, J. Biol. Chem. 1996, 271, 9150.

[37] J. JangLee, S. J. North, M. SuttonSmith, D. Goldberg, M. Panico, H. Morris, S. Haslam, A. Dell, F. Minoru, in Methods in Enzymology, Vol. Volume 415, Academic Press, 2006, pp. 59.

[38] D. J. Harvey, PROTEOMICS 2005, 5, 1774.

[39] M. van Holde, Biochemistry, 2nd ed., The Benjamin/Cummings Publishing Company, Inc., 1995.

[40] A. P. Wheeler, J. W. George, C. A. Evans, Science 1981, 212, 1397. 
[41] T. H. Maren, Physiol. Rev. 1967, 47, 595.

[42] F. C. Meldrum, H. Col`Ifen, Chemical Reviews 2008, 108, 4332.

[43] R. A. Metzler, I. W. Kim, K. Delak, J. S. Evans, D. Zhou, E. Beniash, F. Wilt, M. Abrecht, J. W. Chiou, J. H. Guo, S. N. Coppersmith, P. U. P. A. Gilbert, Langmuir 2008, 24, 2680.

[44] L. Addadi, S. Weiner, Proc Natl Acad Sci U S A 1985, 82, 4110.

[45] G. Falini, S. Fermani, M. Gazzano, A. Ripamonti, Journal of Materials Chemistry 1998, 8, 1061.

[46] C. R. MacKenzie, S. M. Wilbanks, K. M. McGrath, Journal of Materials Chemistry 2004, 14, 1238.

[47] L. Treccani, K. Mann, F. Heinemann, M. Fritz, Biophys J 2006, 91, 2601.

[48] F. C. Meldrum, International Materials Reviews 2003, 48, 187.

[49] L. Addadi, J. Moradian, E. Shay, N. G. Maroudas, S. Weiner, Proc Natl Acad Sci U S A 1987, 84, 2732.

[50] E. Nakano, T. Iwamatsu, K. Okazaki, Biological Bulletin 1963, 125, 125.

[51] H. Miyamoto, T. Miyashita, M. Okushima, S. Nakano, T. Morita, A. Matsushiro, Proceedings of the National Academy of Sciences of the United States of America 1996, 93, 9657.

[52] F. Marin, G. Luquet, B. Marie, D. Medakovic, Current Topics in Developmental Biology, Vol 80 2008, 80, 209.

[53] B. A. Gotliv, N. Kessler, J. L. Sumerel, D. E. Morse, N. Tuross, L. Addadi, S. Weiner, Chembiochem 2005, 6, 304.

[54] J. L. Arias, A. Neira-Carrillo, J. I. Arias, C. Escobar, M. Bodero, M. David, M. S. Fernandez, Journal of Materials Chemistry 2004, 14, 2154.

[55] J. Montreuil, Adv. Carb. Chem. Biochem. 1980, 37, 157.

[56] T. Millar, Biochemistry Explained, Gordon and Breach Publishing Group, Amsterdam, 2000.

[57] A. L. Tarentino, T. H. Plummer, Jr., Methods Enzymol 1994, 230, 44.

[58] A. L. Tarentino, C. M. Gomez, T. H. Plummer, Jr., Biochemistry 1985, 24, 4665.

[59] F. Maley, R. B. Trimble, A. L. Tarentino, T. H. Plummer, Analytical Biochemistry 1989, 180, 195.

[60] A. L. Tarentino, T. H. Plummer, Jr., Glycobiology 1994, 4, 771. 
[61] J. C. Marxen, M. Nimtz, W. Becker, K. Mann, Biochimica Et Biophysica ActaProteins and Proteomics 2003, 1650, 92.

[62] A. S. B. Edge, Biochem. J. 2003, 376, 339.

[63] M. Lebl, J. Pires, P. Poncar, V. Pokorny, Journal of Combinatorial Chemistry 1999, 1,474 .

[64] B. Torok, I. Bucsi, G. K. S. Prakash, G. A. Olah, Chemical Communications 2002, 2882.

[65] N. Itano, K. Oguri, H. Nakanishi, M. Okayama, Journal of Biochemistry 1993, 114, 862.

[66] J. X. Gu, T. Matsuda, R. Nakamura, H. Ishiguro, I. Ohkubo, M. Sasaki, N. Takahashi, Journal of Biochemistry 1989, 106, 66.

[67] A. S. B. Edge, C. R. Faltynek, L. Hof, L. E. Reichert, P. Weber, Analytical Biochemistry 1981, 118, 131.

[68] C. Dissous, J. M. Grzych, A. Capron, Nature 1986, 323, 443.

[69] M. Okano, K. Nishizaki, A. R. Satoskar, T. Yoshino, Y. Masuda, D. A. Harn, Allergy 1999, 54, 811.

[70] D. R. Karp, K. L. Parker, D. C. Shreffler, C. Slaughter, J. D. Capra, Proceedings of the National Academy of Sciences of the United States of America-Biological Sciences 1982, 79, 6347.

[71] V. L. Herzberg, F. Grigorescu, A. S. B. Edge, R. G. Spiro, C. R. Kahn, Biochemical and Biophysical Research Communications 1985, 129, 789.

[72] A. S. B. Edge, R. G. Spiro, Journal of Biological Chemistry 1987, 262, 6893.

[73] C. J. Jost, J. L. Funderburgh, M. Mann, J. R. Hassell, G. W. Conrad, Journal of Biological Chemistry 1991, 266, 13336.

[74] P. E. Thompson, H. H. Keah, P. T. Gomme, P. G. Stanton, M. T. W. Hearn, International Journal of Peptide and Protein Research 1995, 46, 174.

[75] H. Y. Yun, H. T. Keutmann, B. A. Eipper, Journal of Biological Chemistry 1994, 269, 10946.

[76] R. Kohli, N. Chadha, K. Muralidhar, Febs Letters 1988, 242, 139.

[77] E. Horvath, A. M. Edwards, J. C. Bell, P. E. Braun, Journal of Neuroscience Research 1989, 24, 398.

[78] R. G. Spiro, V. D. Bhoyroo, J. Biol. Chem. 1974, 249, 5704.

[79] N. K. Karamanos, A. Manouras, S. Anagnostides, E. Makatsori, T. Tsegenidis, C. A. Antonopoulos, Biochimie 1996, 78, 171. 
[80] A. Manouras, N. K. Karamanos, T. Tsegenidis, C. A. Antonopoulos, Comparative Biochemistry and Physiology, Part B: Biochemistry \& Molecular Biology 1991, 99B, 119.

[81] L. Adaddi, S. Weiner, Angew. Chem. Int. Ed. Engl. 1992, 31, 153.

[82] S. Weiner, Calcif Tissue Int 1979, 29, 163.

[83] E. M. Greenfield, D. C. Wilson, M. A. Crenshaw, American Zoologist 1984, 24, 925.

[84] M. A. Crenshaw, H. Ristedt, The histochemical localization of reactive groups in septal nacre from Nautilus pompilius. In: The Mechanisms of Mineralization in the Invertebrates and Plants., University of South Carolina Press, Colombia, 1976.

[85] K. Wada, Initiation of mineralization in bivalve molluscs. In: The Mechanisms of Biomineralization in Animals and Plants, Tokai University Press, Tokyo, 1980.

[86] T. Taguchi, M. Iwasaki, Y. Muto, K. Kitajima, S. Inoue, K. H. Khoo, H. R. Morris, A. Dell, Y. Inoue, European Journal of Biochemistry 1996, 238, 357.

[87] A. P. W. Jill E. Borbas, C. Steven Sikes,, Journal of Experimental Zoology 1991, 258, 1.

[88] J. E. Coleman, Annual Review of Biophysics and Biomolecular Structure 1992, 21, 441. 


\section{CHAPTER 3 : EXPERI MENTAL PROTOCOLS}

In this chapter we outline the relevant protocols that were used throughout this $\mathrm{PhD}$ thesis. Where percentages are reported which do not add up to $100 \%$, the remaining percentage was made up with water. Tris refers to tris(hydroxymethyl)aminomethane. Where the source of a chemical is not provided it was purchased from Sigma-Aldrich Chemical Co.

\subsection{SOLATI ON OF SMP}

There are many methods used to extract and collect the macromolecules occluded within sea urchin hard parts. ${ }^{[1-7]}$ SMP was extracted using an adaptation of the method briefly outlined by MacKenzie et al. ${ }^{[1]}$ The complete extraction protocol is outlined below.

Spines were obtained from Ngai Tahu seafoods (Otago, New Zealand), a subsidiary of Ngai Tahu Holdings Group. The shucked shells were left for 48 hours so that the organic matter which holds the spine to the shell would rot. The spines could then be easily brushed from the shells. The spines were then washed extensively with tap water to remove organic debris.

\subsubsection{Preparation OF SPI nes}

$150 \mathrm{~g}$ of spines were divided evenly between $8 \times 250 \mathrm{~mL}$ (12.5 g each) and $2 \times 500$ $\mathrm{mL}$ (25 g each) Schott bottles. The bottles were then half-filled with $2.5 \%$ sodium hypochlorite (Andrew, 15\% Sodium Hypo) and shaken vigorously for 1 hour. The hypochlorite was then poured off and fresh $2.5 \%(\mathrm{v} / \mathrm{v})$ hypochlorite was added. The spines were then shaken overnight. The following morning the spines were washed and shaken throughout the day with approximately 13 changes of distilled water. This was followed by 2 final shaking washes using $M Q$. The spines were then left to dry for a couple of days on filter paper (Whatman). 


\subsubsection{SPI Ne DeCALCI FI CATION}

$50 \mathrm{~g}$ of spines were crushed to form a slurry using a planetary ball-mill (Retsch). This slurry was made up to $600 \mathrm{~mL}$ with $\mathrm{MQ}$ in a $2 \mathrm{~L}$ plastic beaker. $3 \mathrm{~mL}$ of phenylmethanesulfonyl fluoride (PMSF) stock (0.52 g in $60 \mathrm{~mL}$ isopropanol) were added. The solution was stirred overnight using an overhead stirrer (IKA). Meanwhile, $800 \mathrm{~mL} 1 \mathrm{M} \mathrm{HCl}$ were added dropwise at $1 \mathrm{~mL} / \mathrm{min}$ using a Marlow peristaltic pump. The $\mathrm{pH}$ of the stirred solution was carefully monitored to ensure the $\mathrm{pH}$ never dropped below 5.5. The following morning an additional $3 \mathrm{~mL}$ of PMSF stock were added. The stirring was stopped and the solution was left to settle for 10 minutes. To remove any residual undissolved matter the $1.4 \mathrm{~L}$ solution was filtered through a $0.22 \mu \mathrm{m}$ PVDF membrane (Millipore).

\subsubsection{ULTRAFI LTRATI ON}

The solution was then desalted and reduced using the process of ultrafiltration (10000 MWCO, regenerated cellulose, Vivaflow 200, Sartorius-Stedim Biotech). Once the solution had been reduced to approximately $50 \mathrm{~mL}$ it was reconstituted to $2 \mathrm{~L}$ with $\mathrm{MQ}$. This process of reduction and reconstitution was repeated twice more, however, the reconstituted solution was changed to a $2 \mathrm{~L}$ salt solution (5 $\mathrm{mM} \mathrm{NaCl}$ (Pure Science Ltd), $10 \mathrm{mM}$ Tris (Pure Science Ltd). The final solution volume was approximately $50 \mathrm{~mL}$.

\subsubsection{PROTEI N I SOLATI ON}

SMP was then purified over a $5 \mathrm{~mL}$ HiTrap Q FF anionic exchange column (GE Healthcare). The protein adhered to the column was washed of contaminants with a degassed low salt solution ( $5 \mathrm{mM} \mathrm{NaCl}$, Pure Science Ltd), $10 \mathrm{mM}$ Tris (Pure Science Ltd). The purified protein was eluted from the column using degassed high salt solution (2 M NaCl, Pure Science Ltd), $10 \mathrm{mM}$ Tris (Pure Science Ltd) collecting $1 \mathrm{~mL}$ fractions. Location of the protein was achieved measuring A280 (NanoDrop, NanoDrop Technologies Inc, ND-1000). Fractions which contained protein were pooled and extensively dialysed (8-10 kDa MWCO, ZelluTrans, Carl Roth GmbH) 
against $M Q$ to remove the salt. The purified protein was quantified by either A280 measurement or weighing, and stored as the lyophilisate.

\subsection{FRACTIONATION OF THE SMP ENSEMBLE}

The protocol used to fractionate the SMP ensemble was similar to that outlined in the product brochure (Amicon Ultra-4, Millipore).

The filter membrane, either 10 or $30 \mathrm{kDa}$, was washed of preservative with a preliminary centrifuge with $M Q$ in the cartridge. SMP was solubilised in $M Q$ and applied to the filter system. The filter was centrifuged until the retentate volume was less than $100 \mu \mathrm{L}$. The volume of the retentate was reconstituted to $4 \mathrm{~mL}$ with $M Q$. This centrifugation-reconstitution procedure was repeated eight times. The final retentate was removed and stored as the lyophilisates.

\subsection{SPECI FIC DI GESTI ON OF SMP}

\subsubsection{N-GLYCANS AND SMPDEN-G}

The $\mathrm{N}$-glycans were removed using peptide- $\mathrm{N}^{4}$-(acetyl- $\beta$-glucosaminyl) asparagine amidase (PNGase F, Roche). SMPDeN-g was the useful by-product of this reaction. The experimental protocol used was a modification to that developed by Jang-Lee et al. ${ }^{[8]}$

$1 \mathrm{mg}$ of SMP was dissolved in $300 \mu \mathrm{L}$ of $50 \mathrm{mM}$ ammonium bicarbonate (pH 8.4, adjusted with ammonia). To this 5 units of PNGase F were added. The solution was incubated at $37^{\circ} \mathrm{C}$ overnight. The following morning an additional 5 units of PNGase F were added and the sample was incubated for a further 8 hours.

Isolation of the two products was achieved using a $10 \mathrm{kDa}$ MWCO spin-filter (Amicon Ultra-4, Millipore). The eluant and retentate containing the N-glycans and SMPDeN-g, respectively, were then lyophilised. The efficacy of the digestion and isolation were assessed using A280, MSA and SDS-PAGE. 


\subsubsection{O-GLYCANS}

The O-glycans were isolated using reductive elimination. Borohydride reduction is the common method employed to release the O-glycone following liberation and isolation of the N-glycans by PNGase F. The method adopted was similar to that used by Piller and Piller. ${ }^{[9]}$

$400 \mu \mathrm{L}$ of $1 \mathrm{M} \mathrm{NaBH}_{4}$ and $0.1 \mathrm{M} \mathrm{NaOH}$ were added to $1 \mathrm{mg}$ glycoprotein analyte. This solution was incubated at $45^{\circ} \mathrm{C}$ for 24 hours. The reaction was terminated through the dropwise addition of acetic acid until the fizzing stopped. A desalting column was prepared to remove the sodium ions. The desalting column was constructed using a Pasteur pipette filled with Dowex beads. The desalting column was equilibrated with $15 \mathrm{~mL}$ of $5 \%(\mathrm{v} / \mathrm{v})$ acetic acid. The sample was loaded onto the beads. The column was eluted twice with $5 \%(\mathrm{v} / \mathrm{v})$ acetic acid ( $5 \mathrm{~mL}$ each). The two fractions were dried separately on a Speed-Vac and lyophilised. Subsequently, the contaminating borates were removed to yield the glycans by co-evaporation with $4 \times 0.5 \mathrm{~mL} 10 \%(\mathrm{v} / \mathrm{v})$ methanolic acetic acid under a stream of nitrogen. The efficacy of the preparation was monitored using MSA.

\subsubsection{Sugar AND Sulfate Removed (SMPDeGly)}

The glycans and their associated functional groups were removed using the Sigma GlycoProfile IV, Chemical Deglycosylation Kit (PP0510) similar to the supplied protocol in conjunction with the method described by Edge et al. ${ }^{[10]}$

All reagents were stored in a refrigerator $\left(2-8^{\circ} \mathrm{C}\right) .1 \mathrm{mg}$ of SMP was lyophilised in a Reactivial and purged in argon. $64 \mu \mathrm{L}$ of anisole were added to a vial containing $1 \mathrm{~g}$ of trifluoromethane sulfonic acid (TFMS). $200 \mu \mathrm{L}$ of this mixture were added to the SMP vial. The glycoprotein was dissolved but not shaken. The reaction mixture was left for 3 hours in the refrigerator.

To stop the reaction the sample was put in a $\mathrm{NaCl}$ ice bath. $4 \mu \mathrm{L}$ of bromophenol blue solution $0.2 \%$ were added to the sample to monitor the neutralising of the acidic solution (from red initially to bluish purple on neutralisation). $60 \%$ pyridine 
(cooled in a freezer) was added dropwise. After the addition of approximately 150 $\mu \mathrm{L}$ of $60 \%$ pyridine a fine precipitate forms. This was redissolved with the addition of $40 \mu \mathrm{L}$ of $\mathrm{MQ}$. Approximately a further $100 \mu \mathrm{L}$ of $60 \%$ pyridine were added. The crude digest was lyophilised.

The reaction products were separated over a $30 \mathrm{~cm}$ G25 Sephadex (GE Healthcare) column equilibrated in $\mathrm{MQ}$, collecting $1 \mathrm{~mL}$ fractions. The contents of the fractions were identified using colorimetric assays (phenol-sulfuric acid (hexoses) and Bicinchoninic acid Assay (protein)). Fractions containing protein were pooled and lyophilised. The efficacy of the digestion was monitored using MSA (p. 154) and SDS-PAGE (p. 156).

\subsubsection{Si ali A ACI d Removed (SMPDeSia)}

The method employed was similar to that explained by Manzi and Varki. ${ }^{[9]}$ SMP was dissolved in $0.75 \mathrm{~mL}$ of $2 \mathrm{M}$ acetic acid at $1 \mathrm{mg} / \mathrm{mL}$. The solution was held at $80^{\circ} \mathrm{C}$ for 3 hours. To remove the liberated sialic acid residues the crude solution was passed over a 3 kDa spin-filter (Amicon Ultra-4, Millipore). The retentate (SMPDeSia) was dried under vacuum and stored as a lyophilisate. Confirmation of the sialic acid removal was achieved using the ferric-orcinol assay (p. 172) on SMPDeSia.

\subsubsection{Sulfate Removed (SMPDeSO)}

The method employed to remove the sulfates was similar to that used by Tagushi et al. ${ }^{[11]} 0.5 \mathrm{mg}$ SMP were dissolved in $0.5 \mathrm{~mL}$ of $0.5 \mathrm{M}$ methanolic $\mathrm{HCl}$ (Supelco). The protein/acid solution was incubated at $20^{\circ} \mathrm{C}$ for $3,5,7$, or 9 hours. The resulting digest was fractionated across a $3 \mathrm{kDa}$ spin-filter and retentate lyophilised. Alcian blue staining $(\mathrm{pH} 1)$ was used on the SDS-PAGE gels of the desulfated products. The extent of $\mathrm{pH} 1$ Alcian blue staining in gel electrophoresis (p. 175) demonstrated the degree of desulfation was dependent on the incubation time. 


\subsubsection{Phosphate Removed (SMPDePO and SMPDePTM)}

The phosphates were removed using rAPid Alkaline Phosphatase (Roche). The protocol used was as provided with the product. In brief, 10 units of phosphatase was added to a $175 \mu \mathrm{L}$ buffered solution including $350 \mu \mathrm{g}$ SMP (SMPDePO) or SMPDeGly (SMPDePTM). The supplied $10 \times(0.5 \mathrm{M}$ Tris $\mathrm{pH} 8.5)$ buffer solution was not used as it included $1 \mathrm{mM}$ ethylene diamine tetraacetic acid (EDTA). We therefore prepared an EDTA-free equivalent. The digestion mixture was incubated overnight at $37^{\circ} \mathrm{C}$. The liberated phosphates were removed using a $3 \mathrm{kDa}$ spinfilter. The phosphate content of both the eluant and retentate was monitored using the malachite green assay to assess the efficacy of the dephosphorylation reaction.

\subsection{Structural Protocols}

\subsubsection{ABSORPTI ON AT 280 NM}

Samples were made up to concentrations generally between 0.5 and $2.0 \mathrm{mg} / \mathrm{mL}$ in $\mathrm{MQ}$ and their absorption at $280 \mathrm{~nm}$ measured using a NanoDrop (NanoDrop Technologies Inc, ND-1000).

\subsubsection{COLORI METRIC ASSAYS}

\subsubsection{BICINCHONI NIC ACID ASSAY}

The method used was based on that provided with the bicinchoninic acid (BCA) Assay Protein Assay Kit from Pierce Biotech. The method was adapted for use in a 96-well microtitre plate (Greiner Bio-One).

$180 \mu \mathrm{L}$ of $\mathrm{BCA}$ reagent (made up of $50: 1$ reagent $A$ : reagent $B$ as provided with the Kit) were added to $20 \mu \mathrm{L}$ of analyte. The solution was heated to $37^{\circ} \mathrm{C}$ for $30 \mathrm{~min}$. Following this the absorption at $562 \mathrm{~nm}$ was measured.

\subsubsection{Phenol-Sulfuric ACid Assay}

The method used in this investigation was an adaptation of that previously published by Dubois et al. ${ }^{[12]}$ 
In a 96-well microtitre plate (Greiner Bio-One) $40 \mu \mathrm{L}$ of sample were mixed with $40 \mu \mathrm{L}$ of 5 wt\% phenol (Sigma-Aldrich) solution. This $80 \mu \mathrm{L}$ solution was then rapidly mixed with $200 \mu \mathrm{L}$ of concentrated $\mathrm{H}_{2} \mathrm{SO}_{4}$. The standard curve generated is presented in chapter 4 (p. 97).

\subsubsection{Malachite Green Assay}

For a more complete survey of the functional groups present in SMP, the ensemble was tested for the presence of phosphates. However, the malachite green assay only gives a positive result to phosphate if it is free in solution, not in a bound organic state. For this reason the malachite green assay procedure requires an initial base digestion if the phosphate is bound to an organic polymer such as protein or sugar. The following procedure was an adaptation of Hess et al. ${ }^{[13]}$ and a protocol sheet which accompanies a phosphate detection kit produced by R\&Dsystems.

$50 \mu \mathrm{L}$ of sample were mixed with $25 \mu \mathrm{L}$ of $4 \mathrm{M} \mathrm{NaOH}$. This was then heated at $100^{\circ} \mathrm{C}$ for 30 minutes. On cooling, the solution was neutralised with the addition of $4 \mathrm{M} \mathrm{HCl}$ and centrifuged. $20 \mu \mathrm{L}$ of Reagent $\mathrm{A}(17 \mathrm{~g} / \mathrm{L}$ ammonium molybdate in $3 \mathrm{M}$ $\mathrm{H}_{2} \mathrm{SO}_{4}$ ) were added and the sample was left at room temperature for $10 \mathrm{~min}$. Following this $20 \mu \mathrm{L}$ of Reagent $B(70 \mathrm{mg} / \mathrm{L}$ malachite green oxalate salt (Sigma-Aldrich, in MQ) were added and the sample was left for a further 20 minutes. The absorbance at $620 \mathrm{~nm}$ was recorded on the NanoDrop. The quantity of phosphate was determined relative to a standard curve generated using solutions of $\mathrm{KH}_{2} \mathrm{PO}_{4}$ of known concentration (p. 100).

\subsubsection{FERRIC-ORCINOL ASSAY}

The ferric-orcinol assay tests for both free and bound sialic acid. The chromophore formed is organic soluble and absorbs at $570 \mathrm{~nm} .{ }^{[9]}$ The procedure followed was similar to that published previously. ${ }^{[14]}$

$\mathrm{FeCl}_{3}$ reagent (1 wt\%) was made by dissolving $0.005 \mathrm{~g} \mathrm{FeCl}_{3}$ in $0.5 \mathrm{~mL}$ of $\mathrm{MQ}$. Orcinol reagent (Bial reagent) was made by dissolving $0.05 \mathrm{~g}$ of orcinol in $24.2 \mathrm{~g}$ 
(20.35 mL) of cooled concentrated $\mathrm{HCl}$. To this was added $0.5 \mathrm{~mL}$ of $\mathrm{FeCl}_{3}$ reagent and $4.15 \mathrm{~mL}$ of $\mathrm{MQ}$.

The assay involved heating $50 \mu \mathrm{L}$ of Bial reagent and $50 \mu \mathrm{L}$ of sample for $15 \mathrm{~min}$ at $100^{\circ} \mathrm{C}$. To this was added $250 \mu \mathrm{L}$ of 3-methyl-1-butnanol (amyl alcohol) and vortexed. This was cooled in ice for $5 \mathrm{~min}$ and centrifuged at $1000 \mathrm{~g}$ for $3 \mathrm{~min}$. $200 \mu \mathrm{L}$ of the upper organic phase were removed and the absorbance at $570 \mathrm{~nm}$ measured. The standard curve generated is presented in chapter 4 (p. 99).

\subsubsection{GeL ELECTROPHORESI S (SDS-PAGE)}

The electrophoresis system used in this investigation followed the method developed by Laemmli. ${ }^{[15]}$ The acrylamide cross-linking exploited to separate the ensemble mixtures included both linear ( $12 \%$ acrylamide) and gradient (4-20\% and 10-20\% acrylamide, Bio-Rad) gels.

SDS-PAGE was completed using the Mini-PROTEAN Tetra Electrophoresis System (Bio-Rad). Minigels were handcast using modules of either 0.75 or $1.0 \mathrm{~mm}$ thickness with either 15 or 10 wells, respectively. The protocol for the gels was similar to that of Bollag et al. ${ }^{[16]}$. The two (stacking and resolving) $4 \times$ buffers were made up from $3.03 \mathrm{~g}$ of Tris (Pure Science Ltd), $1 \mathrm{~mL}$ of 20 wt\% SDS (Sigma-Aldrich), $\mathrm{HCl}$ to $\mathrm{pH}$ 6.8, made up to $50 \mathrm{~mL}$ with $\mathrm{MQ}$; and $9.09 \mathrm{~g}$ of Tris (Pure Science Ltd), $1 \mathrm{~mL}$ of 20 wt\% SDS (Sigma-Aldrich), $\mathrm{HCl}$ to $\mathrm{pH} 8.8$, made up to $50 \mathrm{~mL}$ with $\mathrm{MQ}$; respectively. These $4 \mathrm{x}$ buffers were used as reagents in gels. An example of the gel recipe for $4 \times 1.0 \mathrm{~mm} \mathrm{12 \%} \mathrm{gels} \mathrm{is} \mathrm{(stacking} \mathrm{gel)} 5.84 \mathrm{~mL}$ of $\mathrm{MQ}, 2.5 \mathrm{~mL} 4 \mathrm{x}$ stacking buffer, $150 \mu \mathrm{L}$ of ammonium persulfate (Sigma-Aldrich) $(0.1 \mathrm{~g} / \mathrm{mL}), 1.66$ $\mathrm{mL}$ of $30 \%$ Acrylamide/Bis solution 37.5:1 (Bio-Rad), $16 \mu \mathrm{L}$ of TEMED $\left(N, N, N^{\prime}, N^{\prime}\right.$-Tetramethylethylenediamine) (Sigma); (resolving gel) $7.0 \mathrm{~mL}$ of $\mathrm{MQ}, 5$ $\mathrm{mL}$ of $4 \mathrm{x}$ resolving buffer, $240 \mu \mathrm{L}$ of ammonium persulfate $(0.1 \mathrm{~g} / \mathrm{mL}), 8.0 \mathrm{~mL}$ of 30\% Acrylamide/Bis solution 37.5:1 (Bio-Rad), $20 \mu \mathrm{L}$ of TEMED (Sigma). To ensure a level top on the resolving gel a 0.1 wt\% solution of SDS (Sigma-Aldrich) was sprayed across the top of the resolving gel solution before it set. 
Gels were electrophoresed in a Mini-PROTEAN Tetra cell using a glycine buffer. The 10 x running buffer, $\mathrm{pH} \sim 8.9$, was made up of: $1.0 \mathrm{M}$ (144 g) glycine (Sigma-Aldrich), $0.125 \mathrm{M}$ Tris (30 g), $0.5 \mathrm{wt} \%$ (10 g) SDS, made up to $2 \mathrm{~L}$ with distilled water.

All samples were quantified, aliquoted, freeze-dried, and reconstituted to $10 \mu \mathrm{L}$ in $\mathrm{MQ}$ prior to electrophoresis. The sample was boiled for 10 minutes to unravel protein secondary structure which can interfere with analyte mobility. The $10 \mu \mathrm{L}$ sample was then mixed well with $2 \mu \mathrm{L}$ of $5 \times$ sample buffer $(60 \mathrm{mM}$ Tris, $\mathrm{HCl}$ to $\mathrm{pH}$ 6.8, 25\% (v/v) glycerol, 2 wt\% SDS, 0.1 wt\% bromophenol blue (Sigma-Aldrich)). $\beta$-mercaptoethanol (Sigma-Aldrich) was added to the $5 \times$ sample buffer (to $1 \%$ $(v / v))$ prior to mixing with the sample to aid the unfolding of the protein through the reduction of the potential disulfide bridges. Prior to application of the sample to the gel wells $5 \times$ sample buffer was lightly pipetted across the top of the gel to facilitate well visualisation.

Gels were run at $100 \mathrm{mV}$ until the samples compressed at the resolving gel front, at which time the power was increased to $200 \mathrm{mV}$. Power was supplied by a Labnet PowerStation 300.

\subsubsection{Gel Electrophoresis Stai nS}

\subsection{SILVER STAIN}

Two silver stain protocols were tested. ${ }^{[17,18]}$ It was determined that the method published by Morrissey et al. ${ }^{[17]}$ produced better results for the SMP system. The method was modified slightly as outlined below.

All solutions were $50 \mathrm{~mL}$ except where indicated. An equivalent of $5 \mu \mathrm{g}$ of SMP and a $0.138 \mu \mathrm{L}$ equivalent of marker (Bio-Rad) were sufficient for observation by silver stain. Following electrophoresis the gel was fixed in three stages. These were: 50\% (v/v) MeOH 10\% (v/v) acetic acid (30 minutes); 5\% (v/v) MeOH, 7\% (v/v) acetic acid (30 minutes); and finally $25 \mathrm{~mL}$ of $5 \%(\mathrm{v} / \mathrm{v})$ glutaraldehyde (30 minutes) (Sigma-Aldrich). The solution was then washed extensively with three changes of 
distilled water over 2 hours. The gel was then rocked for 30 minutes in $5 \mu \mathrm{g} / \mathrm{mL}$ DTT (dithiothreitol, Sigma-Aldrich). Without rinsing the gel was then impregnated with $\mathrm{AgNO}_{3}$ (Sigma-Aldrich). The gel was quickly rinsed with distilled water before addition of the developing solution (3 wt\% of $\mathrm{Na}_{2} \mathrm{CO}_{3}$ (Scientific Supplies Ltd) and $25 \mu \mathrm{L}$ of $18 \%(\mathrm{v} / \mathrm{v})$ formaldehyde (Sigma-Aldrich)). The reaction was left to proceed until the desired level of band development had occurred at which time the stopping solution was added directly. The stopping solution contained $1.10 \mathrm{~g}$ citric acid (Sigma-Aldrich) (2.5 mL). After 10 minutes the gel was washed with distilled water and rocked for a further 30 minutes before scanning and analysis.

\subsection{AlCian BLUe Stain}

The method used was an adaptation of that published by Wall et al. ${ }^{[19]}$ All solutions were $50 \mathrm{~mL}$ except where indicated.

$20 \mu \mathrm{g}$ of SMP were optimal for observation by Alcian blue. Following electrophoresis the gel was fixed in a $50 \%(\mathrm{v} / \mathrm{v}) \mathrm{MeOH}, 7 \%(\mathrm{v} / \mathrm{v})$ acetic acid solution for 1 hour. The gel was then rinsed in distilled water and rocked in distilled water for 1 hour. These fixing and washing steps were repeated. The distilled water was poured off and the gels were rocked in Alcian blue stain solution overnight. The Alcian blue stain solution was made up of $0.2 \mathrm{wt} \%$ Alcian Blue 8GX (Fluka), $0.05 \mathrm{M} \mathrm{MgCl}_{2}$ (BDH Laboratory Supplies), with the $\mathrm{pH}$ adjusted using either acetic acid or $\mathrm{HCl}$ to $\mathrm{pH} 3$ or $\mathrm{pH} 1$, respectively. If the background was coloured this could be removed using a $3 \%(\mathrm{v} / \mathrm{v})$ acetic acid $0.05 \mathrm{M} \mathrm{MgCl}_{2}$ destain.

\subsection{StAlnS-All StAin}

The method used was an adaptation of that published by King and Morrison. ${ }^{[20]}$ All solutions were $50 \mathrm{~mL}$ except where indicated.

$20 \mu \mathrm{g}$ of SMP were optimal for observation by Stains-All. Following electrophoresis the gel was fixed in $25 \%$ isopropanol overnight. The following day the gel was washed several more times in fixative of the same composition. The composition of the Stains-All dye solution is: $0.0025 \mathrm{wt} \%$ Stains-All (Fluka), 25\% (v/v) 
isopropanol, 7.5\% (v/v) formamide (Sigma), $30 \mathrm{mM}$ Tris with the $\mathrm{pH}$ adjusted to 8.8 with $\mathrm{HCl}$. The gel was rocked in the stain in the dark for 48 hours. To reduce the background the gel was exposed to light.

\subsection{PERI ODIC ACID-SCHIFF BASE StAIN}

The method used to stain the SDS-PAGE was an adaptation of that published by Zacharius et al. ${ }^{[21]}$ All solutions were $50 \mathrm{~mL}$ except where indicated.

In a typical preparation $20 \mu \mathrm{g}$ of SMP were sufficient to observe pink staining. Following electrophoresis the gel was fixed with $40 \%(\mathrm{v} / \mathrm{v}) \mathrm{MeOH}, 7 \%(\mathrm{v} / \mathrm{v})$ acetic acid. This was done four times for 30 minutes each. This same fixative was then used again and the gel was rocked overnight. The following morning the same fixative was used a further two times for 30 minutes each. The initial step in the staining procedure involved $1 \%(\mathrm{v} / \mathrm{v})$ periodic acid and $3 \%(\mathrm{v} / \mathrm{v})$ acetic acid for 1 hour. The gel was then washed ten times in distilled water, 10 minutes each time. Schiff's reagent (Sigma-Aldrich) was then rocked with the gel for 1 hour in the dark. For destaining and/or storage the gel was soaked in 0.58 wt\% sodium metabisulfite and $3 \%(\mathrm{v} / \mathrm{v})$ acetic acid.

\subsubsection{2D GEL ELECTROPHORESIS}

The 2D gel electrophoresis presented in this thesis was supervised by $\operatorname{Dr}$ Alan Carne from the Biochemistry Department (University of Otago). Briefly, the method used was as follows.

Seven centimetre pH 3 to 10 IPG dry-strip Immobiline IEF strips (GE Healthcare) were rehydrated in $130 \mu \mathrm{L}$ rehydration buffer which included the solubilised analyte. The rehydration buffer used was: $25 \mu \mathrm{L}$ IPG buffer concentrate $(\mathrm{pH} 3$ to 10), $7 \mathrm{M}$ urea (Invitrogen), $2 \mathrm{M}$ thiourea (BDH), 2 wt\% CHAPS (Roche), $50 \mathrm{mM}$ DTT (Pierce), $4 \mathrm{mM}$ Tris carboxyethyl phosphine (TCEP) (Pierce), 2-5 mM Tributyl phosphine (TBP). The rehydrated strips were subjected to $\sim 30,000 \mathrm{~V} / \mathrm{hr}$, over 8 to $9 \mathrm{hr}$ in ceramic manifold (GE HealthCare) using an IPGphor instrument. Following isoelectric focusing the strip was incorporated into a $1 \mathrm{~mm}$ thick $12 \%$ acrylamide 
SDS-PAGE mini-gel. As MS was not going to be used to determine mass information MW markers (Novex sharp pre-stained protein standards, Invitrogen) were co-migrated.

A variety of stains were used to visualise the results of the two-dimensional separation. The staining procedures used were the same as those used for the one dimensional gels.

\subsubsection{HPLC}

These experiments were run by $\mathrm{Dr}$ lan Simms from the Complex Carbohydrate Team at Industrial Research Ltd. The protocol that he used was similar to that described elsewhere, ${ }^{[22]}$ and briefly outlined below.

The SEC-MALLS system consisted of a Waters 2690 Alliance separations module, a Waters 450 variable wavelength detector set at $280 \mathrm{~nm}$, and a Waters 2410 refractive index monitor. Samples were filtered $(0.45 \mathrm{~mm})$ before injection and eluted with $0.1 \mathrm{~mol} / \mathrm{L}$ LiNO3 containing $0.02 \mathrm{wt} \% \mathrm{NaN} 3(0.7 \mathrm{ml} / \mathrm{min})$ from two columns (TSK-Gel G5000PWXL and G4000PWXL, 300 x 7.8 mm, Tosoh Corp., Tokyo, Japan) connected in series.

\subsubsection{MONOMER ANALYSES}

\subsubsection{AMI NO ACI D ANALYSIS}

AAA was performed by The Australian Proteome Analysis Facility (APAF) and therefore facilitated using infrastructure provided by the Australian Government through the National Collaborative Research Infrastructure Strategy (NCRIS). The method used was high sensitivity amino acid analysis of purified protein using gas phase hydrolysis (AAA-100). Samples underwent $24 \mathrm{hr}$ gas phase hydrolysis in $6 \mathrm{M}$ $\mathrm{HCl}$ at $110^{\circ} \mathrm{C}$. Amino acids were analysed using the Waters AccQTag Ultra chemistry. The quantity of the individual amino acids was deduced relative to the internal standard AABA ( $\alpha$-aminobutyric acid). Samples were analysed in duplicate. 


\subsubsection{MONOSACCHARI DE ANALYSIS}

\subsection{ACID DI GESTION WITH Alditol ACETATE DeRIVATISATION}

Two digestion protocols were used with the discriminating feature being the type of acid used. The concentrations of acid and incubation times used were adaptations of that previously published. ${ }^{[23-25]}$ The method used to analyse and quantify the monosaccharides was similar to that published elsewhere. ${ }^{\left[{ }^{9]}\right.}$

To isolate the glycan monomers $40 \mu \mathrm{g}$ of SMP were dissolved in $0.30 \mathrm{~mL}$ of $2 \mathrm{M}$ TFA or $4 \mathrm{M} \mathrm{HCl}$. The solution was heated to $100^{\circ} \mathrm{C}$ for 4 hours or 6 hours, respectively. The crude product was dried under vacuum. $5 \mu \mathrm{g}$ of the internal standard myo-inositol was added.

The liberated monomers were converted to their alditol acetate analogues as follows. To reduce and deuterate the released monomers the lyophilisate was dissolved in $250 \mu \mathrm{L}$ of $1 \mathrm{M} \mathrm{NH}_{4} \mathrm{OH}, 15 \mathrm{mg} / \mathrm{mL} \mathrm{NaBD4}$ (Sigma). This solution was mixed gently and left for 1 hour at room temperature. $500 \mu \mathrm{L}$ of acetone were then added and the solution was then reduced to dryness under a stream of air. To acetylate the sugar hydroxyl groups the dried product was suspended in: acetic acid $(40 \mu \mathrm{L})$, ethyl acetate $(200 \mu \mathrm{L})$, acetic anhydride $(600 \mu \mathrm{L})$ and perchloric acid $(23 \mu \mathrm{L})$. This solution was left at room temperature for 15 minutes. To stop the reaction $2 \mathrm{~mL}$ of distilled water were added with $40 \mu \mathrm{L}$ of 1-methylimidazole to decompose the excess acetic anhydride. $1 \mathrm{~mL}$ of dichloromethane was added, the solution vortexed, and centrifuged briefly. The upper aqueous layer was discarded. This vortexing, centrifugation, and upper layer removal was repeated three more times using; distilled water, $0.5 \mathrm{M} \mathrm{Na}_{2} \mathrm{CO}_{3}$, and distilled water, respectively. The dichloromethane was removed under a stream of air. To ensure the complete removal of water $500 \mu \mathrm{L}$ of acetonitrile were added to the sample and removed under a stream of air. The dried sample was dissolved in $75 \mu \mathrm{L}$ of acetone and transferred to a GC-MS sample vial for analysis. Monomer identity and quantity were determined relative to myo-inositiol. 
The alditol acetates were detected and quantified using GC-MS (Agilent 6890N MS equipped with a HP5MS capillary column ( $25 \mathrm{~m} \times 0.25 \mathrm{~mm}$ i.d.)). The GC oven was programmed to follow $70^{\circ} \mathrm{C}$ (held for $1 \mathrm{~min}$ ), and then ramped to $140^{\circ} \mathrm{C}$ at a rate of $25^{\circ} \mathrm{C} / \mathrm{min}$, and then to $230^{\circ} \mathrm{C}$ at a rate of $3^{\circ} \mathrm{C} / \mathrm{min}$ with analysis by $\mathrm{MS}$ using an Agilent 5973. Signal assignment was made relative to peak retention times and by comparison of electron impact spectra with standard spectra.

\subsection{METHANOLYSIS WITH TRI METHYLSILANE (TMS) DERIVATISATION}

Detection for the presence of uronic acids was achieved following previously published protocols. ${ }^{[26]}$ The method involves hydrolysis using $\mathrm{MeOH}-\mathrm{HCl}$ followed by TMS derivatisation.

In brief, $\sim 50 \mu \mathrm{g}$ of analyte was dissolved in $200 \mu \mathrm{L}$ of $3 \mathrm{M}$ methanolic $\mathrm{HCl} .50 \mu \mathrm{L}$ of methyl acetate were added. The samples were vortexed and heated at $85^{\circ} \mathrm{C}$ for $24 \mathrm{hr} .25 \mu \mathrm{L}$ of tert-butyl alcohol were added, the sample vortexed, and reduced to dryness under nitrogen. Re- $N$-acetylation was completed with the addition of $250 \mu \mathrm{L}$ of methanol, $25 \mu \mathrm{L}$ of pyridine, and $25 \mu \mathrm{L}$ of acetic anhydride. This solution was incubated at room temperature for $15 \mathrm{~min}$. The solution was reduced to dryness under argon. This lyophilisate was now ready for TMS derivatisation. To the dry analyte $100 \mu \mathrm{L}$ of Tri-Sil ([dimethyl-(trimethylsilylamino)silyl]methane) was added and incubated at $70^{\circ} \mathrm{C}$ for $10 \mathrm{~min}$. Just prior to analysis on the GC-MS the sample solution was dried under nitrogen and resuspended in $500 \mu \mathrm{L}$ of $n$-hexane.

\subsubsection{Glycan Profi Li ng}

The method used to isolate the glycans was the same as that developed in the Dell Glycobiology Laboratory at Imperial College London. ${ }^{[8]}$ The sample preparation sequence follows: isolation of the target species, cleavage and blocking of the disulfide bridges to unfold the protein, digestion with trypsin to yield more susceptible glycopeptides, selective release of the N-glycans with PNGase F, and finally isolation of the O-glycans using reductive elimination. The isolated glycans that were used in subsequent structural studies were permethylated to increase the sensitivity of the sample to MS. ${ }^{[27-29]}$ 


\subsubsection{Cleavage ANd Blocking OF Disulfide BRI DgeS}

In a typical procedure $1 \mathrm{mg}$ SMP was dissolved in $0.5 \mathrm{~mL}$ of $0.6 \mathrm{M}$ Tris (Sigma), $\mathrm{pH}$ adjusted to 8.5 with acetic acid, with $2 \mathrm{mg} / \mathrm{mL}$ of dithiothreitol to reduce the potential disulfide bridges. This solution was incubated at $37^{\circ} \mathrm{C}$ for $1 \mathrm{hr}$. The liberated thiol groups were carboxymethylated in the dark at room temperature for 90 minutes using $6 \mathrm{mg}$ of iodoacetic acid $(0.5 \mathrm{~mL}$ of Tris, $\mathrm{pH} 8.5)$ to inhibit the reformation of the bridge. The resultant solution was purified of contaminants using snakeskin dialysis tubing (7 kDa MWCO) (Pierce Biotech) across a $50 \mathrm{mM}$ Ambic buffer, $\mathrm{pH}$ adjusted to 8.5 with acetic acid. The sample was then lyophilised.

\subsubsection{Cleavage Into GLyCopeptides}

To digest the derivatised protein into glycopeptides the sample was subjected to trypsin cleavage. A solution of $1 \mathrm{mg} / \mathrm{mL}$ trypsin (Sigma) was made up in $50 \mathrm{mM}$ $\mathrm{NH}_{4} \mathrm{HCO}_{3}, \mathrm{pH}$ adjusted to 8.4 with ammonia solution. $300 \mu \mathrm{L}$ of the trypsin solution were added to the derivatised SMP lyophilisate. This protease solution was left to incubate for 5 hours before the addition of 3 drops of acetic acid to terminate the reaction. The sample was then lyophilised in preparation for the propan-1-ol $C_{18}$ Sep-Pak purification system.

$20 \%$ and $40 \%(\mathrm{v} / \mathrm{v})$ propan-1-ol solutions were prepared using $5 \%(\mathrm{v} / \mathrm{v})$ acetic acid to dilute. A Sep-Pak Plus $\mathrm{C}_{18}$ cartridge (Waters) was conditioned with methanol (5 $\mathrm{mL}), 5 \%(\mathrm{v} / \mathrm{v})$ acetic acid $(5 \mathrm{~mL})$, propan-1-ol $(5 \mathrm{~mL}), 5 \%(\mathrm{v} / \mathrm{v})$ acetic acid $(3 \times 5 \mathrm{~mL})$. The crude SMP trypsin digest was resuspended in $200 \mu \mathrm{L}$ of $5 \%(\mathrm{v} / \mathrm{v})$ acetic acid and loaded onto the column. The crude mixture contents were isolated stepwise with $5 \%(\mathrm{v} / \mathrm{v})$ acetic acid $(20 \mathrm{~mL}), 20 \%(\mathrm{v} / \mathrm{v})$ propan-1-ol solution $(4 \mathrm{~mL}), 40 \%(\mathrm{v} / \mathrm{v})$ propan-1-ol solution (4 mL), and $100 \%$ propan-1-ol $(4 \mathrm{~mL})$. The propan-1-ol containing solutions were collected and dried under vacuum. The 20 and $40 \%(\mathrm{v} / \mathrm{v})$ propan-1-ol samples contained the glycopeptides. 


\subsubsection{ReLEASE OF GLYCANS FROM GLYCOPEPTIDES}

\subsection{N-GLYCANS}

The two fractions containing glycopeptides were dissolved in $150 \mu \mathrm{L}$ of $50 \mathrm{mM}$ ammonium bicarbonate buffer, $\mathrm{pH} 8.4$, ammonia adjusted, and combined. 5 units of peptide- $\mathrm{N}^{4}$-(acetyl- $\beta$-glucosaminyl) asparagine amidase (PNGase $\mathrm{F}$, Roche) were added and the sample was incubated overnight at $37^{\circ} \mathrm{C}$. The following morning an additional 5 units of PNGase F were added. The sample was lyophilised 8 hours later. The liberated $\mathrm{N}$-glycans were isolated from the contaminating O-glycopeptides and proteinaceous materials using the propanol-1-ol Sep-Pak purification system as previously described. A deviation from this method: the first fraction (5\% ( $\mathrm{v} / \mathrm{v})$ acetic acid, $\mathrm{N}$-glycan containing) was only $5 \mathrm{~mL}$ as opposed to $20 \mathrm{~mL}$. The O-glycopeptides were in the $20 \%(\mathrm{v} / \mathrm{v})$ propan-1-ol fraction. Both fractions were dried.

\subsection{O-GLYCANS}

Isolation of the O-glycans was completed as outlined earlier in this chapter (p. 76). The modification to the protocol for the release of the O-glycans was as follows.

$400 \mu \mathrm{L}$ of $1 \mathrm{M} \mathrm{KBH}_{4}, 0.1 \mathrm{M} \mathrm{KOH}$ were added to the dried $20 \%$ (v/v) propan-1-ol fraction. This solution was incubated at $45^{\circ} \mathrm{C}$ for 24 hours.

\subsubsection{NAOH Permethylation}

Both of the glycan samples were permethylated for subsequent structural analysis on a MALDI TOF/TOF mass spectrometer (Applied Biosystems, Analyzer 4800). The $\mathrm{NaOH}$ permethylation was as follows.

Five pellets of $\mathrm{NaOH}$ were crushed in a dry mortar and pestle. $2.5 \mathrm{~mL}$ of dry DMSO were added and a slurry was formed. 0.5 to $1 \mathrm{~mL}$ of the slurry were added to the dry glycan sample. To this, 0.2-0.5 mL iodomethane (Alfa Aesar) were added. The sample was then shaken on a vortex for 10 minutes. Approximately $1 \mathrm{~mL}$ of $\mathrm{MQ}$ was added dropwise to quench the reaction. 1-2 mL of chloroform were added and the sample was made up to $5 \mathrm{~mL}$ with $\mathrm{MQ}$. The solution was vortexed thoroughly 
and centrifuged briefly. The upper aqueous layer was discarded. The chloroform layer was washed several times more with $\mathrm{MQ}$. The chloroform was removed under a stream of nitrogen.

To obtain pure permethylated glycans the sample was purified over Sep-Pak Plus $\mathrm{C}_{18}$ cartridge (Waters) using the acetonitrile system. The Sep-Pak was conditioned with methanol $(5 \mathrm{~mL}), \mathrm{MQ}(5 \mathrm{~mL})$, acetonitrile $(5 \mathrm{~mL})$, and $\mathrm{MQ}(3 \times 5 \mathrm{~mL})$. The sample was dissolved in $200 \mu \mathrm{L}$ of $50 \%(\mathrm{v} / \mathrm{v})$ methanol and loaded onto the column. The column was eluted stepwise with, $\mathrm{MQ}(5 \mathrm{~mL}), 15 \%$ acetonitrile $(3 \mathrm{~mL})$, $35 \%(\mathrm{v} / \mathrm{v})$ acetonitrile $(3 \mathrm{~mL}), 50 \%$ acetonitrile $(3 \mathrm{~mL}), 75 \%(\mathrm{v} / \mathrm{v})$ acetonitrile $(3 \mathrm{~mL})$. The liberated $\mathrm{N}$ - and O-glycans eluted in the 35 and $50 \%(\mathrm{v} / \mathrm{v})$ fractions, respectively. These samples were reduced under vacuum to dryness.

\subsubsection{MALDI TOF/ TOF}

MALDI sample preparation of derivatised glycans was as follows. The matrix solution (10 mg/mL 2,5-dihydroxybenzoic acid (DHB) (Fluka) in 80\% (v/v) methanol) was vortexed until all the DHB had dissolved. The permethylated glycans were then dissolved in $5-10 \mu \mathrm{L}$ of methanol. $1 \mu \mathrm{L}$ aliquots of the matrix and the glycans were mixed, and spotted onto a clean stainless steel target and left to dry. The MS was operated in reflector mode to get better resolution with $4000-$ 6000 shots.

MALDI MS was performed in positive reflectron mode using a Perspective Biosystems Voyager-DE STR MALDI workstation equipped with delayed extraction technology. Data acquisition was performed using Voyager 5 Instrument Control Software, and data processing by Data Explorer MS processing software.

\subsubsection{Glycosyl LI NKAge ANALYSIS}

The liberated intact glycans obtained for glycan profiling were treated in a manner similar to the monosaccharide analysis. That is, the intact glycans were hydrolysed with TFA or $\mathrm{HCl}$, reduced and acetylated prior to analysis by GC-MS as described previously (p. 85). Interpretation of the spectra was made based on signal relative 
retention times and by comparison of electron impact spectra with standard spectra generated at Industrial Research Ltd (IRL).

\subsection{Functi onal Protocols}

\subsubsection{Crystallisati ON}

\subsubsection{Crystal Growth}

The procedure adopted was based on literature preparations. ${ }^{[1,30-32]}$ Adaptations were as stated below. All additive concentrations stated are relative to protein as measured by A280. Typically, the SEM images presented throughout the thesis were grown in the presence of $30 \mu \mathrm{g} / \mathrm{mL}$ organic matrix.

Crystals were grown in 24-well culture plates (Greiner Bio-One) on $10 \mathrm{~mm}$ microscope cover slips which were added to each well. The calcium concentration was either 10 or $500 \mathrm{mM}$ and the total volume of the crystallisation solution was $500 \mu \mathrm{L}$. The concentration of organic matrix was generally $30 \mu \mathrm{g} / \mathrm{mL}$. The plate was wrapped in tinfoil and each of the wells was pierced with a $0.9 \mathrm{~mm}$ needle to allow for the infusion of the carbonate vapour into the crystal growth solution. $0.1 \mathrm{~g}$ ammonium carbonate (Sigma-Aldrich) was dissolved in $20 \mathrm{~mL} \mathrm{MQ}$ in a $50 \mathrm{~mL}$ Schott beaker. The 24-well plate and the beaker were placed in a $1.5 \mathrm{~L}$ sealable plastic container. The container was lined with Parafilm to minimise the loss of ammonium carbonate vapour. Crystals were grown at $15^{\circ} \mathrm{C}$ for 48 hours in an incubator.

The glass slides were removed from the well plate and washed with $\mathrm{MQ}$ for $10 \mathrm{~s}$ twice. Residual calcium chloride solution on the slide was removed under a stream of air. The slide was washed and air-dried three times before being left to dry overnight. Crystallisation experiments were completed at least in duplicate.

\subsubsection{SCANNING ELECTRON MICROSCOPY}

The calcium carbonate crystals grown on the amorphous glass slides were harvested for determination of crystal morphologies and nucleation densities using scanning electron microscopy (SEM). The dry slides were mounted on $10 \mathrm{x}$ 
$12.5 \mathrm{~mm}$ JEOL SEM Stubs with carbon tape. To minimise charging in the SEM, slides were sputter coated with 4 layers of carbon ( $16 \mathrm{~nm})$ using a JEOL JEC-560 Auto Carbon Coater. A JEOL JSM-6500F Field Emission Scanning Electron Microscope was used in SEI mode and a working distance of $10 \mathrm{~mm}$ to view the crystals. An accelerating voltage of $10.00 \mathrm{kV}$ and a probe current of $10 \mu \mathrm{A}$ were determined as the optimum conditions to minimise charging.

The software used to enumerate the crystal density was a demo version of GSA Image Analyzer 3.4.3. 


\subsection{References}

[1] C. R. MacKenzie, S. M. Wilbanks, K. M. McGrath, Journal of Materials Chemistry 2004, 14, 1238.

[2] L. Ameye, G. De Becker, C. Killian, F. Wilt, R. Kemps, S. Kuypers, P. Dubois, Journal of Structural Biology 2001, 134, 56.

[3] S. Weiner, L. Addadi, Trends in Biochemical Sciences 1991, 16, 252.

[4] N. K. Karamanos, A. Manouras, S. Anagnostides, E. Makatsori, T. Tsegenidis, C. A. Antonopoulos, Biochimie 1996, 78, 171.

[5] S. Albeck, L. Addadi, S. Weiner, Connective Tissue Research 1996, 35, 365.

[6] F. H. Wilt, Developmental Biology (San Diego, CA, United States) 2005, 280, 15.

[7] J. Aizenberg, S. Albeck, S. Weiner, L. Addadi, Journal of Crystal Growth 1994, 142, 156.

[8] J. JangLee, S. J. North, M. SuttonSmith, D. Goldberg, M. Panico, H. Morris, S. Haslam, A. Dell, F. Minoru, in Methods in Enzymology, Vol. Volume 415, Academic Press, 2006, pp. 59.

[9] M. Fukuda, ed;, A. Kobata, ed, Glycobiology : a practical approach, Oxford University Press, Oxford, 1993.

[10] A. S. B. Edge, C. R. Faltynek, L. Hof, L. E. Reichert, P. Weber, Analytical Biochemistry 1981, 118, 131.

[11] T. Taguchi, M. Iwasaki, Y. Muto, K. Kitajima, S. Inoue, K. H. Khoo, H. R. Morris, A. Dell, Y. Inoue, European Journal of Biochemistry 1996, 238, 357.

[12] M. Dubois, K. A. Gilles, J. K. Hamilton, P. A. Rebers, F. Smith, Analytical Chemistry 1956, 28, 350.

[13] H. H. Hess, J. E. Derr, Analytical Biochemistry 1975, 63, 607.

[14] R. Schauer, G. Victor, in Methods in Enzymology, Vol. Volume 50, Academic Press, 1978, pp. 64.

[15] U. K. Laemmli, Nature 1970, 227, 680.

[16] D. M. Bollag, M. D. Rozycki, S. J. Edelstein, Protein Methods, Wiley-Liss, New York, 1996. 
[17] J. H. Morrissey, Anal Biochem 1981, 117, 307.

[18] B.-A. Gotliv, L. Addadi, S. Weiner, Chembiochem : a European journal of chemical biology 2003, 4, 522.

[19] R. S. Wall, T. J. Gyi, Anal Biochem 1988, 175, 298.

[20] L. E. King, M. Morrison, Analytical Biochemistry 1976, 71, 223.

[21] R. M. Zacharius, T. E. Zell, J. H. Morrison, J. J. Woodlock, Anal Biochem 1969, 30, 148.

[22] I. M. Sims, R. H. Furneaux, Carbohydrate Polymers 2003, 52, 423.

[23] H. Takemoto, S. Hase, T. Ikenaka, Analytical Biochemistry 1985, 145, 245.

[24] Y. Arakawa, T. Imanari, Z. Tamura, Chemical \& Pharmaceutical Bulletin 1976, 24, 2032.

[25] C. J. Biermann, Analysis of Carbohydrates by GLC and MS, 1988 ed., CRC Press, 1988.

[26] W. S. York, A. G. Darvill, M. Mcneil, T. T. Stevenson, P. Albersheim, Methods in Enzymology 1986, 118, 3.

[27] M. Fukuda, B. Bothner, P. Ramsamooj, A. Dell, P. R. Tiller, A. Varki, J. C. Klock, Journal of Biological Chemistry 1985, 260, 2957.

[28] M. Fukuda, A. Dell, M. Fukuda, J. Biol. Chem. 1984, 259, 4782.

[29] A. Dell, R. S. Tipson, H. Derek, in Advances in Carbohydrate Chemistry and Biochemistry, Vol. Volume 45, Academic Press, 1987, pp. 19.

[30] L. Addadi, S. Weiner, Proc Natl Acad Sci U S A 1985, 82, 4110.

[31] S. Albeck, J. Aizenberg, L. Addadi, S. Weiner, Journal of the American Chemical Society 1993, 115, 11691.

[32] G. Falini, S. Fermani, M. Gazzano, A. Ripamonti, Journal of Materials Chemistry 1998, 8, 1061 


\section{CHAPTER 4 : RESULTS AND DI SCUSSI ON NATI VE ENSEMBLE}

The key to understanding mineralisation is a detailed knowledge of the matrix structure. ${ }^{[1]}$ In order to elucidate the roles mediated by the various chemical moieties within the SMP extract we first needed to determine the molecular composition. In this chapter we lay this foundation by characterising the structural components of the SMP organic matrix. To achieve this we completed a variety of colorimetric and monomer analyses. From these results we generated strategies to deconvolute the complexity of the SMP system, including: fractionation (chapter 5) and selective digestion (chapter 6), in an attempt to understand the structurefunction relationships.

Based on previous analyses ${ }^{[2,3]}$ spine matrix extracts include: spicule matrix (SM) proteins, carbonic anhydrases, collagens, MSP130 and related proteins, various metalloproteases, calcium-binding phosphoproteins, and others. Of these we expect the SMP ensemble to be enriched in SM30 and MSP130 as they have been shown to be acidic and abundant within the spines of Strongylocentrotus purpuratus. $^{[3]}$

The structural analysis completed in this work on the post-translational modification of the occluded $\mathrm{OM}$ is the most comprehensive to date for any sea urchin mineral. An overview of these results is presented in the chapter summary (p. 122).

\subsection{SPECTROSCOPIC MetHOdS}

\subsubsection{ABSORPTI ON AT $280 \mathrm{NM}$}

In this work A280 was the predominant method used to monitor the protein concentration of SMP solutions. To increase the accuracy of the A280 measurement a standard curve was generated which included calibration relative to the mass of protein as determined using AAA (p. 102). We then made up 
solutions of known concentration and measured the A280 values. The standard curve generated for concentration SMP versus A280 is given in Figure 4-1.

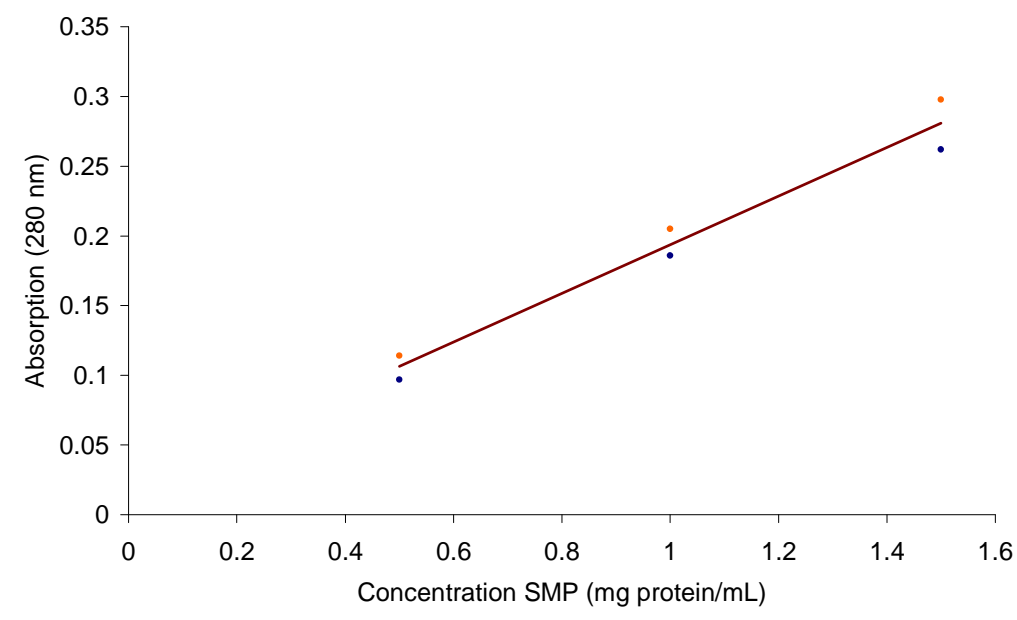

Figure 4-1: A280 standard curve generated for the quantification of SMP protein concentration in MQ. SMP protein concentration was determined by AAA. The standardisation was completed in duplicate (orange and blue dots). The line of best-fit is depicted (red line).

From the plot shown in Figure 4-1 we were able to determine the relationship, and associated uncertainty, between SMP concentration and absorption at $280 \mathrm{~nm}$. This relationship is:

$$
(\mathrm{A} 280-0.019) / 0.174=[\mathrm{SMP}](\mathrm{mg} \text { protein } / \mathrm{mL})
$$

\subsubsection{Phenol-Sulfuri C ACI d Assay}

The phenol-sulfuric acid assay can be used to quantify the hexose content within a sample. The common hexoses include: mannose, galactose, fucose, and glucose. A standardisation curve was generated using a series of D-mannose solutions of various concentrations and measuring the absorption at $485 \mathrm{~nm}$ (A485) (Figure 4-2, blue dots). To test the specificity of the assay for hexose we tested the response of the assay to alanine (Figure 4-2, orange dots). 


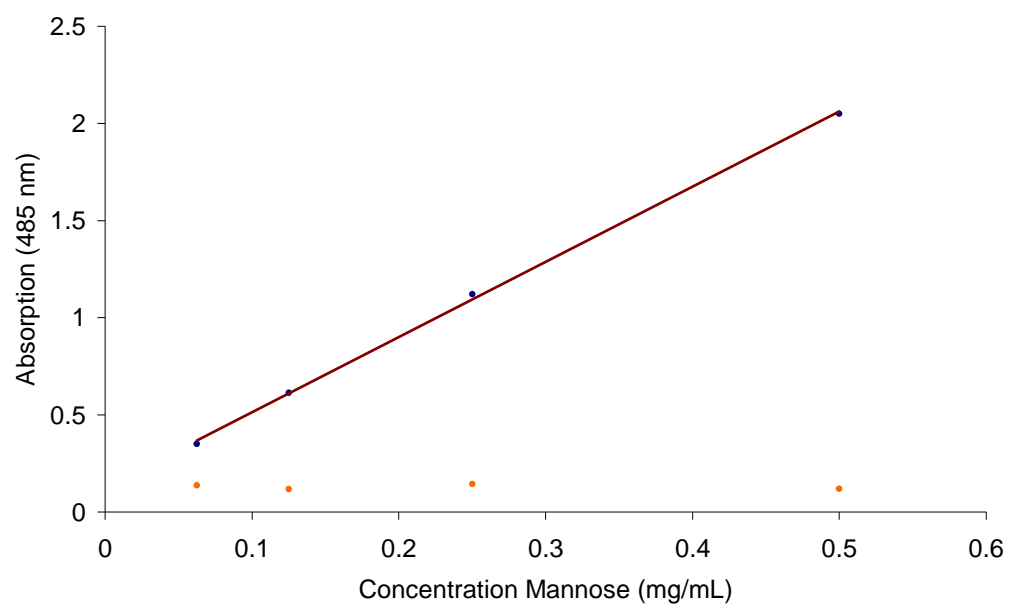

Figure 4-2: Standard curve generated against D-mannose (blue dots) using the phenol-sulfuric acid assay. The line of best-fit is depicted (red line). Alanine was also tested to demonstrate that there was no cross-reactivity (orange dots).

The resulting standard equation is:

$$
(\mathrm{A} 485-0.126) / 3.872=[\text { Hexose }](\mathrm{mg} / \mathrm{mL})
$$

So that the concentration of SMP could be monitored using this assay we generated a line of best-fit over a range of SMP concentrations (Figure 4-3). This had the additional benefit of reducing the uncertainty associated with using the phenol-sulfuric acid assay to determine the hexose content of SMP. From the standardisation curve we determined the following relationship between the concentration of SMP (mg protein/mL) and absorption at $485 \mathrm{~nm}$ (A485) using the phenol-sulfuric assay:

$$
(\mathrm{A} 485-0.06) / 0.91=[\mathrm{SMP}](\mathrm{mg} \text { protein } / \mathrm{mL})
$$




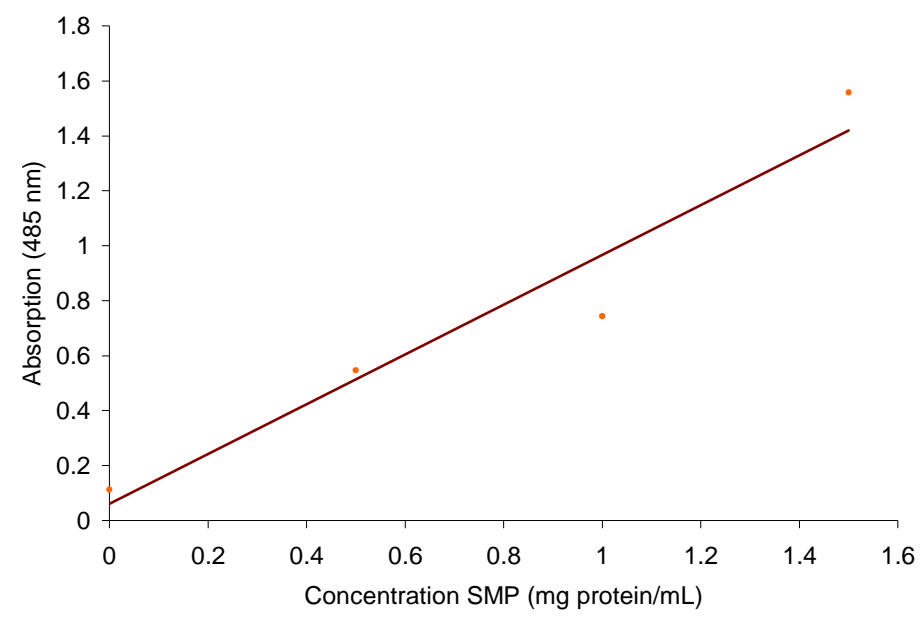

Figure 4-3: Determination of the hexose content of SMP using the phenol-sulfuric acid assay. A range of SMP concentrations were used (orange dots) and a line of best-fit generated (red line).

Using this result in conjunction with the hexose standard curve (Figure 4-2) we determined the hexose content of SMP to be 22 protein $w t \%$. This result is consistent with the analysis completed by MacKenzie et al. ${ }^{[4]}$ who determined the hexose content of their SMP extract to be $15-22$ protein wt\% using similar quantification methods. Both of these values are, however, less than observed using the more accurate monosaccharide analysis (MSA, p. 105) which showed that the hexose content is $32.3 \pm 7.1$ protein wt $\%$.

\subsubsection{Ferric-OrCinol Assay}

Sialic acid has been shown to be present within the spines of Paracentrotus lividus. ${ }^{[5]}$ The ferric-orcinol assay was used to quantify the sialic acid content of SMP. It has been postulated that sialic acid is an important component of the organic matrix in biominerals. ${ }^{[6,7]}$ It is thought to exert influence on the mineralisation process through its interaction with calcium ions via the carboxylate functionality. ${ }^{[8]} \mathrm{N}$-acetylneuraminic acid (NANA) was used as a ferric-orcinol standard as recommended. ${ }^{[9]}$ The standard curve generated is depicted in Figure 4-4. 


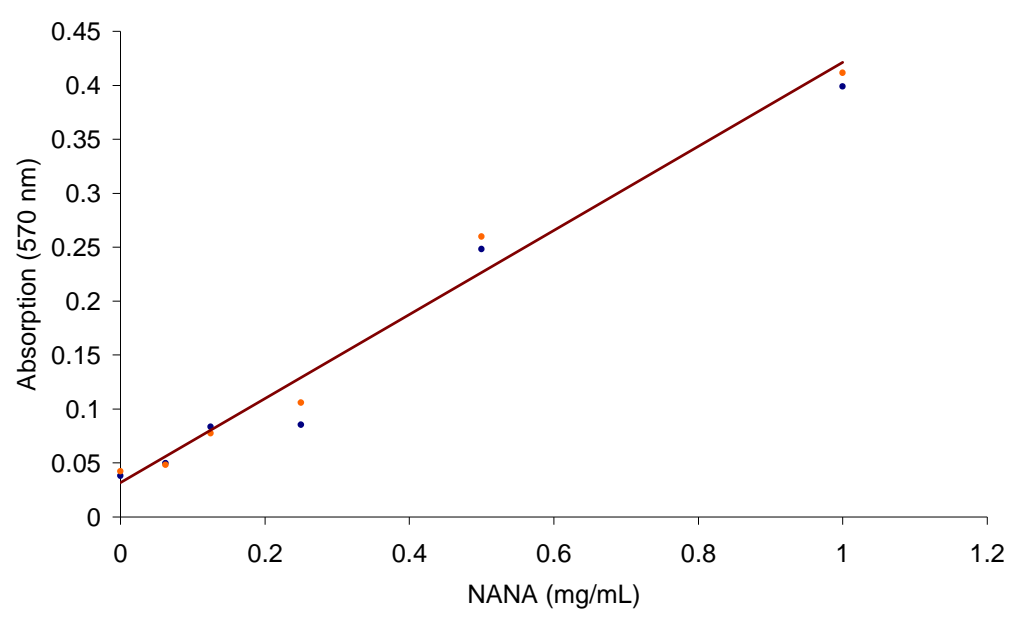

Figure 4-4: Standardisation chart generated for the ferric-orcinol assay. $\mathrm{N}$-acetylneuraminic acid (NANA) was used as the standard. The standardisation was completed in duplicate (orange and blue dots) and a line of best-fit (red) generated.

From the data presented in Figure 4-4 we generated a line of best-fit (red line) and were therefore able to determine the relationship between absorption at $570 \mathrm{~nm}$ (A570) and the concentration of NANA ( $\mathrm{mg} / \mathrm{mL})$, as follows:

$$
(A 570-0.032) / 0.390=[N A N A](\mathrm{mg} / \mathrm{mL})
$$

Absorption of $0.099 \pm 0.03$ at $570 \mathrm{~nm}$ for a $1 \mathrm{mg}$ protein/mL SMP solution corresponds to $0.17 \pm 0.05 \mathrm{mg} / \mathrm{mL}$ NANA equivalents. That is, the SMP ensemble is $17 \pm 5$ protein wt\% sialic acid. This is the first example of sialic acid quantification within the spines of any sea urchin species. This level of sialic acid content is higher than the 10 protein wt\% determined by Karamanos et al. ${ }^{[6]}$ for the glycoproteins SPI and SPII extracted from the tests of Sphaerechinus granularis. These carbohydrate structures were determined to have a terminal polymer of sialic acid attached to a core structure of sulfated hexose and HexNAc.

Due to the high abundance of sialic acid and its ability to interact with calcium ions we were interested in testing its role in crystal modification in vitro. We therefore grew calcium carbonate crystals in the presence of SMP which had been treated to selectively remove the sialic acid (SMPDeSia). The results of this analysis are presented in chapter 6 (p. 181). 


\subsubsection{Malachite Green Assay}

The malachite green assay tests for inorganic phosphate. Phosphate has been shown to be present in the $\mathrm{OM}$ in many mineralised tissues, ${ }^{[10]}$ including the soluble OM extracted from the tooth of the sea urchin Lytechinus variegatus. ${ }^{[11]}$ In this investigation Veis et al. showed that the phosphate was bound to the protein, as opposed to the sugar, via serine residues. Livingston et al. ${ }^{[2]}$ speculated that there are phosphated macromolecules within the spines of sea urchin. This assertion was based on sequence homology with calcium-binding phosphoproteins found in bone.

The malachite green analysis depicted here represents the first analysis of the phosphate content of any OM extracted from within the spines of any sea urchin species. In order to determine the phosphate content of SMP we generated a standardisation curve (Figure 4-5) using $\mathrm{KH}_{2} \mathrm{PO}_{4}$ as a standard. The relationship between phosphate concentration $(\mathrm{mg} / \mathrm{mL}$ ) and absorption at $620 \mathrm{~nm}(A 620)$ was determined to be:

$$
(\mathrm{A} 620-0.016) / 2.566=\left[\mathrm{PO}_{4}{ }^{3-}\right](\mathrm{mg} / \mathrm{mL})
$$

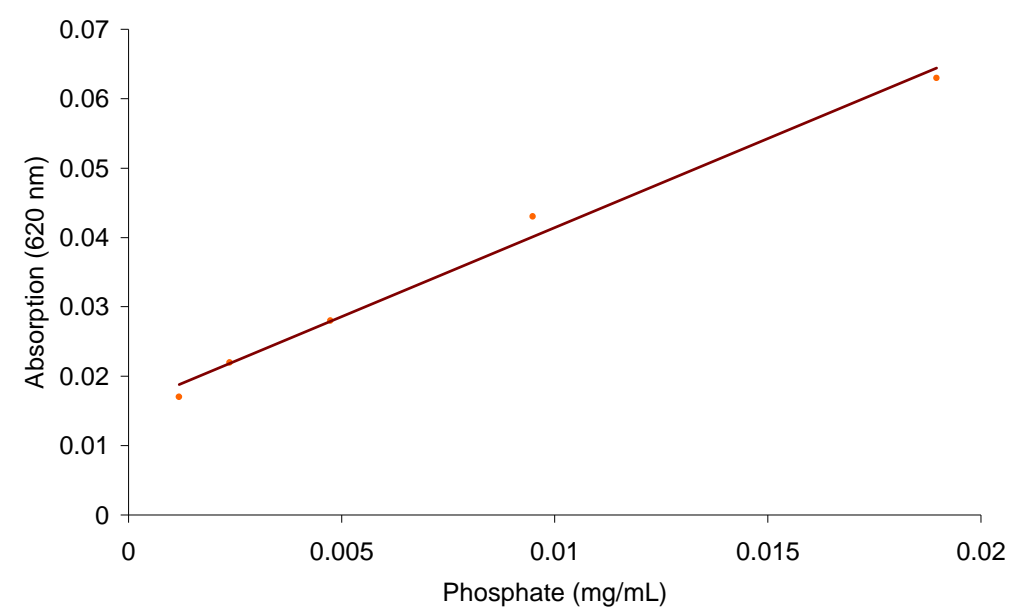

Figure 4-5: Standardisation chart generated using the malachite green assay against a series of $\mathrm{KH}_{2} \mathrm{PO}_{4}$ solutions. The line of best-fit is depicted (red line).

Casein, a phosphoprotein, was worked up in parallel with SMP to verify the results from this assay. The phosphate content of casein, using the standard curve in 
Figure $4-5$, was determined to be $3.14 \pm 0.68$ protein wt\%. As this result is within uncertainty of the phosphate content as provided by the casein supplier (Sigma, 2.9 protein wt\%) the malachite green line of best-fit was considered to be reliable.

With an A620 value of 0.0776 for a 1.0 protein $\mathrm{mg} / \mathrm{mL} \mathrm{SMP} \mathrm{solution} \mathrm{the} \mathrm{phosphate}$ content of SMP was determined to be $2.40 \pm 0.61$ protein wt\%. This proportion of phosphate is similar to that of ensembles extracted from other calcitic tissues at $\sim 0.85$ wt ${ }^{[10]}$ when taking into account the complete mass of SMP, that is, including the glycans and other PTMs (1.08 \pm 0.43 ensemble wt\%, Table 4-4, p. 123). This value is, however, lower than the 3.9 wt\% observed by Swift et al. ${ }^{[12]}$ for the $\mathrm{OM}$ extracted from the tests of Lytechinus variegates. No phosphate was detected on the sialoproteins, SPI and SPII, isolated from the shell of Sphaerechinus granularis. ${ }^{[6]}$

Phosphate has been shown to exert considerable influence on the rate of crystal growth in vitro. ${ }^{[10,13]}$ To test the functional role of the phosphate in SMP we used a phosphatase to selectively remove this PTM and used the dephosphorylation products SMPDePO and SMPDePTM as additives in the crystallisation assay (p. 186).

\subsection{AMI NO ACI D ANALYSIS}

AAA is a quantitative technique used to determine the monomer units that comprise the peptide backbone of a proteinaceous material. The results presented here are the first AAA for any OM occluded in the mineralised tissues of Evechinus chloroticus. In addition, as the SMP extraction procedure involved isolation across an anionic exchange column these results demonstrate the first AAA of the acidic macromolecule contingent for any sea urchin mineralised tissue.

In the data presented in Table 4-1 there are four entries which collectively account for $59 \pm 3.1 \mathrm{~mol} \%$ of the protein. These amino acids are glycine (22.9 $\pm 1.5 \mathrm{~mol} \%)$, Asx (14.1 $\pm 0.4 \mathrm{~mol} \%)$, Alanine (12.1 $\pm 0.9 \mathrm{~mol} \%)$, and Glx (9.9 $\pm 0.3 \mathrm{~mol} \%)$; where Asx and Glx represent aspartic acid and asparagine, and glutamic acid and 
glutamine, respectively. These amino acids cannot be distinguished using AAA technology as outlined previously (p. 36). This property of a few amino acids dominating the amino acid composition is characteristic of biomineral associated macromolecules. $^{[14,15]}$

\begin{tabular}{|l|c|c|}
\hline \multicolumn{1}{|c|}{ Amino Acid } & $\begin{array}{c}\mu \mathrm{g} / 100 \mu \mathrm{g} \\
\text { protein SMP }\end{array}$ & $\mathrm{mol} \%$ \\
\hline Asx & $16.2 \pm 1.1$ & $14.1 \pm 0.4$ \\
\hline Serine & $6.0 \pm 0.4$ & $6.6 \pm 0.5$ \\
\hline Glx & $12.5 \pm 1.1$ & $9.9 \pm 0.3$ \\
\hline Glycine & $14.9 \pm 1.4$ & $22.9 \pm 1.5$ \\
\hline Histidine & $1.1 \pm 0.1$ & $0.8 \pm 0.1$ \\
\hline Arginine & $4.5 \pm 0.2$ & $3.0 \pm 0.7$ \\
\hline Threonine & $5.3 \pm 0.5$ & $5.1 \pm 0.8$ \\
\hline Alanine & $9.3 \pm 0.6$ & $12.1 \pm 0.9$ \\
\hline Proline & $7.3 \pm 0.8$ & $7.3 \pm 0.7$ \\
\hline Tyrosine & $2.5 \pm 0.5$ & $1.6 \pm 0.1$ \\
\hline Valine & $3.1 \pm 0.3$ & $3.1 \pm 0.5$ \\
\hline Methionine & $2.4 \pm 0.6$ & $1.9 \pm 0.5$ \\
\hline Lysine & $0.7 \pm 0.1$ & $0.6 \pm 0.2$ \\
\hline Isoleucine & $2.9 \pm 0.3$ & $2.5 \pm 0.2$ \\
\hline Leucine & $3.0 \pm 0.4$ & $2.6 \pm 0.3$ \\
\hline Phenylalanine & $7.2 \pm 1.2$ & $5.1 \pm 0.6$ \\
\hline Cysteine & $1.0 \pm 0.0$ & $0.9 \pm 0.0$ \\
\hline \multicolumn{1}{|c|}{ Total } & $100.0 \pm 2.9$ & $100.0 \pm 2.5$ \\
\hline
\end{tabular}

Table 4-1: Tabulation of the amino acid analysis results for SMP. Shown are the means \pm the standard deviation of 4 experiments. Asx and Glx represent; aspartic acid and asparagine, and glutamic acid and glutamine, respectively. The tests for tryptophan or any unusual amino acids were not completed. These data were collected by the Australian Proteome Analysis Facility.

Albeck et al. ${ }^{[16,17]}$ completed an AAA on the water soluble OM within the spines of Paracentrotus lividus. Their results are within $2.8 \mathrm{~mol} \%$ for all amino acids, except glycine and proline, in comparison to the amino acid mol\% of Evechinus chloroticus. This similarity in the AAA indicates that the structures of the occluded macromolecules may be conserved across these two species. It is surprising that the Asx and Glx values were both within 1.6 mol\% given that the SMP extract includes only the acidic glycoproteins. This result is significant as it indicates that the acidity of the spine $\mathrm{OM}$ is not encoded via the protein backbone. This observation was explored further using 2D SDS-PAGE electrophoresis (p. 118). In comparison to Paracentrotus lividus, the SMP extract was significantly lower in 
proline $(-5.7 \mathrm{~mol} \%)$. This result was to be expected. The most abundant species within the spines of Strongylocentrotus purpuratus are the proline-rich SM proteins. As the majority of these SM proteins were removed in the preparation of SMP, by fractionation across an anionic exchange column, the observation of a lower contribution of proline to the AAA was to be expected. SM30 is the only SM protein which is not basic.

From the results presented in Table 4-1 we can see that the amounts of the non-polar amino acids glycine (22.9 $\pm 1.5 \mathrm{~mol} \%)$ and alanine $(12.1 \pm 0.9 \mathrm{~mol} \%)$ are particularly high. This result cannot be rationalised from an enrichment of SM30 or MSP130 alone. SM30 is relatively low in glycine $(8.6 \mathrm{~mol} \%)$ and higher in alanine (10.0 mol\%), whereas MSP130 is rich in glycine (18.3 mol\%) but low in alanine (7.2 mol\%). The enrichment in glycine and alanine observed may indicate the first observation of silk-like protein domains within the sea urchin extract. In the absence of sequence information this speculation cannot be verified. These silklike proteins have been shown to be present in molluscan shell structures such as the mineralised tissues of Pinctada fucata. ${ }^{[18]}$ The contribution of these silk-like species in crystal nucleation was demonstrated by Falini et al. ${ }^{[19]}$ who showed that aragonite could be selectively precipitated in the presence of biomineral extracted macromolecules if chitin/silk-like composite templates were used. It has been suggested that the silk-like proteins may contribute to controlled nucleation by inhibiting spurious crystal nucleation. ${ }^{[20]}$ Other functions associated with macromolecules which have silk-like domains include the ability to influence ion diffusion. ${ }^{[19]}$

For controlled calcium carbonate growth the active macromolecules contain chemical functionality which enables them to manipulate the calcium and carbonate components. The chemical functionality to achieve this includes carboxylates and hydrogen-bonding species, respectively. The relevant structures in terms of the hydrogen-bonding include: serine, tyrosine, threonine, asparagine, glutamine, lysine, arginine, and extended or random coil secondary structure. ${ }^{[21]}$ Of these SMP is most abundant in serine $(6.6 \pm 0.5 \mathrm{~mol} \%)$ and threonine $(5.1 \pm 0.8$ 
mol\%). The presence of both proline and glycine has been shown to decrease tertiary folding leading to random coil and extended conformations. ${ }^{[22]}$ As both of these amino acids are abundant within the SMP ensemble $(7.3 \pm 0.7$ and $22.9 \pm 1.5$ mol\%, respectively) this extended conformation may be the dominant mechanism in carbonate recognition. This analysis demonstrates that there are a variety of species within the protein backbone which could be involved in calcium carbonate crystal modification.

Berman et al. ${ }^{[23]}$ collected the partial AAA of the OM extracted from the tests of the sea urchin species Paracentrotus lividus. The results of this analysis showed that the OM composition comprised (mol\%): glycine (24), Asx (16), Glx (13), alanine (10), and serine (8) for the most abundant amino acids. These figures do not deviate by more than a few percent in comparison to the values obtained for the SMP OM. This observation is consistent with the results of Mann et al. ${ }^{[3]}$ who showed that the tests and spines contain a significant number of macromolecules which are present in both tissues.

In the investigation by Berman et al. ${ }^{[23]}$ they compared the amino acid analyses of both sea urchin and molluscan based organic matrices. From this comparison they showed that the sea urchin proteinaceous material is less acidic. This result appears consistent with the acidic amino acid content of SMP which is relatively low (Asx $+\mathrm{Glx}<24.0 \pm 0.5 \mathrm{~mol} \%)$ in comparison to the acidic proteins of molluscan calcitic tissues which can be greater than $50 \mathrm{~mol} \%{ }^{[24]}$ The overall acidity of a macromolecule is not, however, controlled exclusively by the protein framework, as demonstrated by Marie et al. ${ }^{[25]}$ From their analysis of the water soluble OM extracted from the aragonitic layer of Unio pictorum they demonstrated that the $\mathrm{pl}$ values of two of the three most abundant calcium-binding glycoproteins, P95 and P50, were heavily influenced by PTM. They supported this observation with AAA which showed that the protein backbone was relatively neutral with an acidic amino acid content $(A s x+G l x=22.1$ mol\%) similar to SMP. 
From this analysis we have shown that the spines of Evechinus chloroticus are 0.03 wt\% protein. This figure was calculated by comparison of the mass of protein extracted, as determined from the AAA, relative to the initial mass of spines dissolved to liberate the OM. This result is similar to that for the protein occluded in the adult spines of Strongylocentrotus purpuratus at $0.02 \mathrm{wt} \%$ protein. ${ }^{[26]}$

\subsection{MONOSACCHARI DE ANALYSIS}

Using a monosaccharide analysis the abundance of each sugar residue within a sample can be determined. Similar to the AAA, as we were analysing an ensemble of glycoproteins, the result represents the monosaccharides as distributed throughout the organic matrix as opposed to associated with a single glycoprotein. This analysis represents the first example of a MSA of an ensemble of proteins occluded within any mineral of any sea urchin species.

To increase the accuracy of the results, data from three different acid digestions were combined to generate a complete MSA of SMP. These acid digestions included: TFA, $\mathrm{HCl}$, and $\mathrm{MeOH}-\mathrm{HCl}$ hydrolysis to quantify hexoses (fucose, mannose, and galactose), HexNAcs (GIcNAc and GalNAc), and uronic acids (GIcA and IdoA), respectively. The collated results are presented in Table 4-2. The reason that three different hydrolysis conditions were used is because the strength of the glycosidic linkages vary depending on the monosaccharides involved. ${ }^{[27]}$ Glucose has been omitted from Table 4-2 because, even though it was detected (2.03 \pm 0.37 protein wt\%), we believe that it was present due to paper contamination. This was demonstrated by the presence of glucose in the MSA of the deglycosylated SMP (SMPDeGly, p. 154) and is discussed in more detail therein. 


\begin{tabular}{|l|c|c|c|}
\hline \multicolumn{1}{|c|}{ Sugar } & $\begin{array}{c}\mu \mathrm{g} / 100 \mu \mathrm{g} \\
\text { protein SMP }\end{array}$ & $\begin{array}{c}\mu \mathrm{g} / 100 \mu \mathrm{g} \mathrm{SMP} \\
\text { ensemble }\end{array}$ & mol\% \\
\hline Fucose & $11.5 \pm 2.9$ & $5.2 \pm 2.1$ & $14.4 \pm 3.6$ \\
\hline Mannose & $2.3 \pm 0.9$ & $1.0 \pm 0.6$ & $2.6 \pm 1.0$ \\
\hline Galactose & $18.5 \pm 3.3$ & $8.3 \pm 2.7$ & $21.1 \pm 3.8$ \\
\hline GlcNAc & $44.7 \pm 9.5$ & $20.1 \pm 7.3$ & $41.5 \pm 8.8$ \\
\hline GalNAc & $26.5 \pm 2.1$ & $11.9 \pm 2.7$ & $20.3 \pm 8.1$ \\
\hline Uronic acid & $0.0 \pm 0.0$ & $0.0 \pm 0.0$ & $0.0 \pm 0.0$ \\
\hline Total & $103.5 \pm 10.7$ & $46.6 \pm 8.5$ & $100.0 \pm 13.1$ \\
\hline
\end{tabular}

Table 4-2: The monosaccharide content of SMP. GlcNAc and GalNAc (HexNAcs) are $N$-acetyl glucosamine and $\mathrm{N}$-acetyl galactosamine, respectively. The hexoses, HexNAcs, and uronic acids were determined following TFA, $\mathrm{HCl}$, and $\mathrm{MeOH}-\mathrm{HCl}$ digestion, respectively. Shown are the means \pm the standard deviation of 4 experiments testing for each of the hexoses and HexNAcs, and 2 experiments testing for uronic acids. Column 2 depicts the mass of sugar relative to the mass of protein within SMP. Column 3 takes into account the results of this chapter and depicts the wt\% of each sugar relative to the mass of SMP, including the mass of all the PTMs quantified (protein, phosphate, and sugars (including sialic acid)).

From this analysis we have shown that for every $100 \mu \mathrm{g}$ of protein (Table 4-2, column 2$)$ there is an equivalent mass $(103.5 \pm 10.7 \mu \mathrm{g})$ of sugar. That is, SMP is one to one protein to sugar by mass. This ratio is indicative of macromolecules such as proteoglycans and mucins which demonstrate functional capacity within the glycan architecture. The function of the SMP glycans is tested in chapter 6 by the selective removal of the N- and O-glycans (SMPDeN-g and SMPDeGly, p. 149).

The relative abundance of sugar and protein for the SMP ensemble is within uncertainty of that determined by Albeck et al. ${ }^{[17]}$ who analysed the complete ensemble within the spines of Paracentrotus lividus. Using NMR they showed that the number of sugar residues/100 amino acids was $38 \pm 14$ as compared to $56.1 \pm$ 7.3 for Evechinus chloroticus as determined using MS. Mackenzie et al. ${ }^{[4]}$ used the phenol-sulfuric acid assay to estimate the sugar content of SMP. Using this technique they reported a sugar to protein proportion of 15-22 protein wt\%. The discrepancy between our results and theirs can be rationalised as the phenolsulfuric acid assay is limited to hexose detection. From the MSA analysis presented in Table 4-2 the hexose content of SMP is $32.3 \pm 4.5$ protein wt\%, which is within uncertainty of their results. 
The diversity of the monosaccharides within the SMP glycone is very limited with $82.9 \pm 10.3$ mol\% accounted for by only three sugars (GIcNAc, GalNAc, and galactose). This trend reflects the AAA of SMP (p. 102) which showed that the protein portion was dominated by a limited variety of amino acids. Due to the limited diversity of the SMP MSA structural inferences can be made. For example, the low proportion of mannose $(2.3 \pm 0.9$ protein $w t \%)$ demonstrates that the number of $\mathrm{N}$-glycan chains must be relatively low as the core of every $\mathrm{N}$-glycan consists of at least three mannose residues. ${ }^{[5]}$ From this observation we predict that O-glycosylation accounts for a significant proportion of the SMP glycone.

There are no uronic acids within the SMP glycone. The absence of these sugar monomers means that if there are proteoglycans in SMP then the only common glycosaminoglycan chain attached can be keratan sulfate. This GAG chain is constructed from Gal-GlcNAc dimer repeats. As both of these monomers are abundant within the SMP ensemble ( $44.7 \pm 9.5$ and $18.5 \pm 3.3$ protein wt\%) this is a feasible glycan structure. Keratan sulfate was shown to be vital in the nucleation of calcite in the avian egg shell occluded as the proteoglycan mammallian. ${ }^{[28]}$ This nucleating function was dependent on its sulfation.

Mucin glycosylation also involves sulfated Gal-GlcNAc dimer repeats and therefore may present within the SMP glycone. This type of glycosylation has the ability to perform a variety of relevant functions including regulating $\mathrm{HCO}_{3}{ }^{-}$levels. Overall the MSA profile for SMP is suggestive of mucin-like glycosylation: an abundance of GlcNAc, GalNAc, and galactose; accompanied by small amounts of mannose, fucose and sialic acid. ${ }^{[29,30]}$ Based on the studies by Karamanos et al. ${ }^{[6]}$ which showed that there are sialoproteins within the mineralised tissues of the sea urchin Sphaerechinus granularis we would expect sialic acid enrichment, as was observed (17 \pm 5 protein wt $\%$, p. 98$)$.

An alternative sequencing of the GIcNAc and galactose monosaccharides involves homopolymeric structures. Chitin is a GlcNAc-based polymer and has been shown to be active in biomineralisation. ${ }^{[20]}$ Chitin and chitosan have been shown in other 
contexts to neutralise acidic solutions and to bind metals ${ }^{[31]}$ which would be functionally relevant. Galactans have the ability to affect solution viscosity ${ }^{[32]}$ and therefore affect crystal growth.

The results and structural interpretations made are consistent with the analysis completed by Ameye et al. $^{[5]}$ on the OM extracted from the spines of Paracentrotus lividus. In the investigation they attempted structural elucidation of the glycan component using lectins. From this analysis they showed that there are: both N- and O-glycans; abundant 1,4-GIcNAc repeats; abundant Galß1-4(3)GIcNAc repeats, Galß1-3GalNAc repeats, terminal fucose and sialic acids. 1,4-GIcNAc repeats and Galß1-4(3)GIcNAc repeats are consistent with chitin-like and keratan sulfate/mucin-like structures, respectively.

From a comparison of the mass of sugar extracted relative to the initial mass of inorganic we determined that carbohydrate structures comprise $0.03 \mathrm{wt} \%$ of these sea urchin spines. Combining this result with the weight percent of occluded protein at $0.03 \mathrm{wt} \%$ (p. 101) we can conclude that the spines of Evechinus chloroticus are overall 0.06 wt\% acidic OM to inorganic material. This result is consistent with the results of Ameye et al. ${ }^{[33]}$ who reported a $0.1 \mathrm{wt} \%$ organic to inorganic for the spines of Paracentrotus lividus. The difference between our OM extraction techniques may explain the discrepancy between these two values; we removed all species from the OM which have basic pl values.

In both the molluscan and sea urchin biomineral systems there is both proteinaceous and sugar material. In the molluscan system these chemical architectures exist both as separate entities, chitin and protein, and covalently linked as glycoproteins. ${ }^{[20]}$ We therefore needed to ascertain whether the protein and sugar components identified in the AAA (p. 102) and MSA (p. 106) exist within the spines as separate or covalently connected architectures. We therefore passed SMP over a size-exclusion HPLC column monitoring the eluant for both the protein (A280) and sugar (refractive index). The elution profiles generated from this analysis are presented in Figure 4-6. 
As glycans are chiral they interact with plane polarised light and can therefore their elution off a column can be monitored. ${ }^{[9]}$ The elution profiles of both the protein using A280 (green trace), and the sugar (blue trace) are overlaid in Figure 4-6. As the two traces demonstrate co-elution there is the possibility that the two chemical types are covalently linked, that is, the SMP ensemble is comprised of glycoproteins and proteins. The A280 profile demonstrates three distinct peaks (1, 2 , and 3). The first eluting, smallest species in the ensemble, are predominantly proteins (peak 1). The second peak (peak 2) appears to represent the most abundant species and is comprised of heavily glycosylated proteins. The final peak (peak 3) appears to represent a mixture of macromolecules including both proteins and glycoproteins.

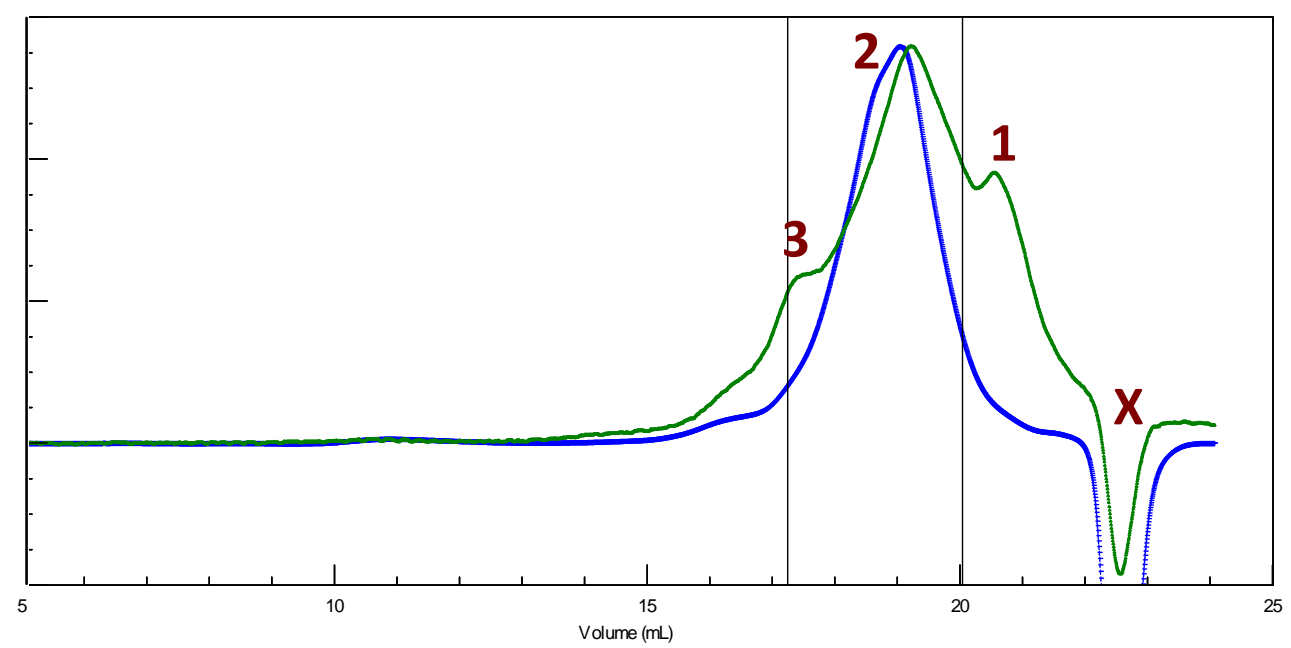

Figure 4-6: An overlay trace monitoring for sugar (blue) and protein (green). Elution times and intensities were determined by measuring refractive index and A280, respectively. 1, 2, and 3 mark the protein trace features. The negative values $(X)$ represent the elution front. These data were kindly collected by Dr lan Simms at Industrial Research Ltd.

From the MSA (Table 4-2) we ascertained that SMP is approximately half sugar by mass. Due to the low abundance of mannose (Table 4-2) these results suggest that there is a significant abundance of O-glycosylation within the SMP ensemble. This assertion is supported by the prevalence of serine and threonine in the AAA (Table 4-1). Protein O-glycosylation has never been demonstrated before in the context 
of sea urchin spines. The assignment is explored and discussed in more detail in chapter 6 (p. 149).

From our analysis we have shown that a significant proportion of the SMP ensemble is carbohydrate and that the protein portion is relatively neutral. The same characteristics were observed by Albeck et al. ${ }^{[17]}$ who analysed the OM within the spines of Paracentrotus lividus. This OM construction is in contrast to the scarce glycosylation/acidic protein OM documented in some molluscan tissues. For example, Albeck et al. ${ }^{[17]}$ found that the OM extracted from Atrina rigida had only $1 \pm 1$ sugar residues/100 amino acids and a 74.7 mol\% Asx + Glx content. Similarly, Marin et al. ${ }^{[34]}$ found, using HPAEC, that the soluble OM extracted from the mussel Pinna nobilis is $0.75-0.87 \mathrm{wt} \%$ neutral and amino sugars and 68.49 mol\% Asx + Glx. However, this construction of the OM involving minimal glycosylation and acidic protein is not conserved throughout bivalvia as demonstrated by Marie et al. ${ }^{[25]}$ From their analysis of the OM extracted from the aragonitic layer of Unio pictorum they showed that it is extensively glycosylated ( $\sim 0$ ensemble $w t \%)$ and the protein relatively neutral ( $\sim 17 \mathrm{~mol} \% \mathrm{Asx}+\mathrm{Glx})$.

\subsection{SDS-PAGE}

SDS-PAGE was used to visualise the molecular weight (MW) profile of SMP. To increase our understanding of the molecular features within the ensemble we incorporated a variety of SDS-PAGE stains in our analysis. From this type of investigation we were able to associate chemical moieties, such as sulfates and carboxylates, to species of various MWs. The stains used included (and revealed): silver stain (protein), Alcian blue at $\mathrm{pH} 1$ (sulfates) and $\mathrm{pH} 3$ (sulfates and carboxylates), and periodic acid-Schiff stain (glycosylation). Using the Stains-All dye we were also able to screen for calcium-binding activity. Of these, only the silver stain has been used previously to characterise an OM ensemble extracted from a sea urchin mineralised tissue. 2D SDS-PAGE gels were also completed, using the various stains, so that we could map the relationship between $\mathrm{MW}$ and pl. This type of analysis has never been completed for organic material extracted from the 
mineralised tissues of Evechinus chloroticus, or for any sea urchin using the Alcian blue and Stains-All stains.

\subsubsection{Silver Stain}

In Figure 4-7 are scans of silver stained gels obtained following electrophoresis of SMP. The result displayed in lane 1 is equivalent to the result of MacKenzie et al. ${ }^{[4]}$ who also analysed SMP using this stain. Features in common include a broad heavily stained band centred at approximately $50 \mathrm{kDa}$ and $\mathrm{MW}$ smearing down to approximately $20 \mathrm{kDa}$.
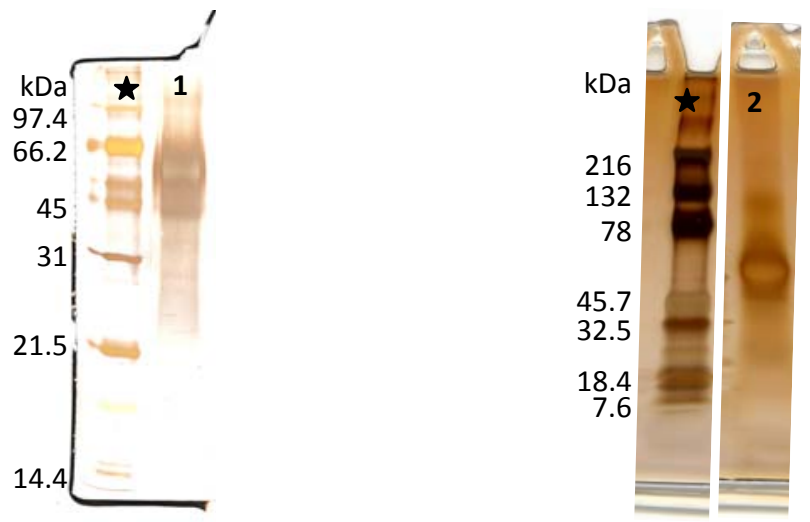

Figure 4-7: Scans of silver stained SDS-PAGE gels of SMP. Lane 1: 12\% gel. Lane 2: 4-20\% gradient gel. Relative molecular weights as determined by electrophoresis of standards are indicated (black star).

Based on previous characterisation ${ }^{[3,35,36]}$ of the OM occluded in the spines of other sea urchin species we expect SMP to include SM30 and MSP130. Wilt et al. ${ }^{[37]}$ observed a broad band of similar MW range for the OM extracted from the adult spines of Strongylocentrotus purpuratus. They then completed a Western blot analysis of this same extract, developed using anti-SM30 antiserum. This revealed that SM30 migrated at 46 and $49 \mathrm{kDa}$. As the material within SMP which stains most profoundly is between the MW range of 35 to $70 \mathrm{kDa}$ we expect that the various isoforms of SM30 if present within Evechinus chloroticus would be within this feature.

A 4-20\% gradient gel was used to visualise a wider MW range, including heavier MW species. From this analysis (lane 2) we observe that there is a wide range of 
MWs represented within the SMP ensemble as demonstrated by the smearing from 20 to $120 \mathrm{kDa}$. Smearing over wide $\mathrm{MW}$ ranges is common on electrophoresis of biomineral extracts. ${ }^{[37-40]}$ There is a band that migrates at $\sim 120 \mathrm{kDa}$. We suspect that this band may include the MSP130 isoforms.

\subsubsection{Alcian Blue Stai n}

Both carboxylate and sulfate functionalities have been shown to be involved in biomineral formation. ${ }^{[1,41-43]}$ The Alcian blue stain can be tailored, by varying the $\mathrm{pH}$ of the staining solution, to reveal both of these chemical functionalities. At $\mathrm{pH}$ 3 the Alcian blue solution binds to both functionalities whereas at $\mathrm{pH} 1$ only the sulfates are revealed. In Figure 4-8 are the results obtained following electrophoresis of SMP on 12\% SDS-PAGE gels. The results for two loading capacities are depicted; $10 \mu \mathrm{g}$ ( $\mathrm{A}$ and B) and $40 \mu \mathrm{g}$ SMP (C and D) as different structural information is apparent at each loading. These results represent the first example of SDS-PAGE mapping of the sulfates and carboxylates for any OM extracted from any sea urchin mineral.

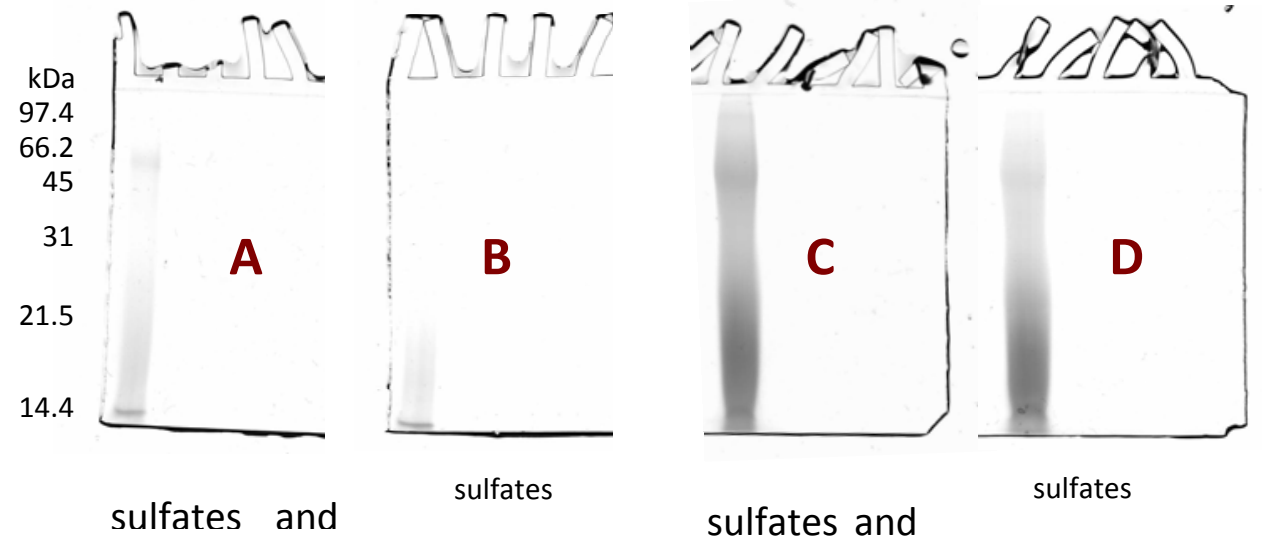

Figure 4-8: Scans of Alcian blue stained SDS-PAGE gels (12\%) of SMP. Gels A (pH 3) and B (pH 1): $10 \mu \mathrm{g}$. Gels $\mathrm{C}(\mathrm{pH} 3)$ and $\mathrm{D}(\mathrm{pH} 1): 40 \mu \mathrm{g}$. Approximate MWs are indicated on the left.

The Alcian blue stained gel (D) reveals that there is sulfated material across the MW range of the gel, from 14 to over $100 \mathrm{kDa}$ with no discrete bands observable. This is in contrast to the silver stained gel of SMP (Figure 4-7) which did not show any material below $\sim 20 \mathrm{kDa}$ and the most prominent feature was centred at 
$\sim 50 \mathrm{kDa}$. We also observe that the most heavily stained region is below $30 \mathrm{kDa}$, centred at approximately $16 \mathrm{kDa}$. Sulfates can be incorporated into an $\mathrm{OM}$ either via protein or glycan frameworks. To test the location of the sulfate within SMP we completed analysis of SMP following the removal of the glycans (SMPDeGly). The results of this analysis are presented in chapter 6 (p. 158). From the MSA (p. 106) we showed that there is the potential for keratan sulfate, mucin-like, and carrageenan (sulfated galactans) structures within the SMP glycone. The observation of sulfates within SMP supports the presence of these structures.

In Figure 4-8 we observe more intense staining at $\mathrm{pH} 3$ (gel A) in comparison to $\mathrm{pH}$ 1 (gel B) across the MW profile of SMP. And in gel C we observe an increase in staining at molecular weights greater than $97 \mathrm{kDa}$ in comparison to gel $\mathrm{D}$. Together these results indicate that there are carboxylate structural features throughout the MW range of SMP.

\subsubsection{Peri OdI C ACI D-SChI FF StAi N}

The periodic acid-Schiff stain turns magenta in the presence of species which display vicinal diols such as sugars. This stain is not very sensitive ${ }^{[44]}$ and is most amenable to glycoproteins which bare a significant amount of sialic acid. ${ }^{[45]}$ In contrast, the staining intensity is diminished if the sugar hydroxyl groups are modified as the oxidation process which leads to colour development does not proceed. These modifications include sulfation and acetylation, both of which we have observed in abundance in SMP (p. 112 and p. 106, respectively). In Figure 4-9 is the first example of electrophoresis of a sea urchin mineral-based extract visualised using the periodic acid-Schiff base stain. 


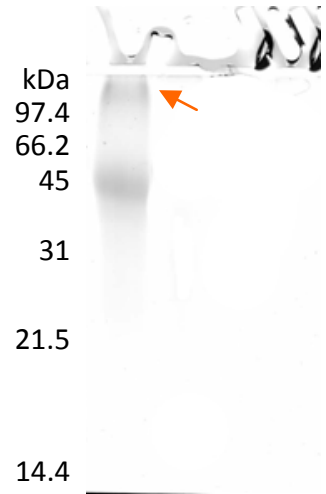

Figure 4-9: Scan of a periodic acid-Schiff base stained SDS-PAGE gel of SMP (12\%). Material which did not enter into the gel is marked by the orange arrow. Approximate MWs are indicated.

Under the periodic acid-Schiff base stain of SMP only the heavier MW species (greater than $30 \mathrm{kDa}$ ) are observed, including species that barely migrate (Figure $4-9$, orange arrow). This result suggests that the species above and below $30 \mathrm{kDa}$ are structurally distinct. That is, there are chemical moieties within the macromolecules which are distinctive. Given the large abundance of sugar in the ensemble (120.5 \pm 23.6 protein wt\%) it is surprising that there is no staining observed below $30 \mathrm{kDa}$. However, as there is an abundance of sulfate associated with these lower MW species (Figure 4-8, gel D) this may be inhibiting formation of the coloured complex.

SMP is rich in sialic acid (17 \pm 5 protein wt\%). Given the propensity for the periodic acid-Schiff base stain to reveal sialic acid it appears that the sialic acid is more prolific amongst the heavier MW species. Karamanos et al. ${ }^{[6]}$ demonstrated that there are sialoproteins within the tests of Sphaerechinus granularis. As these proteins had MWs of approximately $625 \mathrm{kDa}$ the material that barely migrates into the gel (Figure 4-9, orange arrow) may reflect these species.

\subsubsection{Stal ns-All Stal N}

Stains-All reveals different structural features as different colours, for example, lipids appear yellow-orange while proteins appear red. ${ }^{[46]}$ This stain is distinct from the others used in this work as it can also reveal functional information, that is, the ability to bind calcium appears blue. ${ }^{[47]}$ This is especially relevant in the context of calcium carbonate-based mineralisation. In Figure 4-10 is the result obtained using 
this stain following electrophoresis of SMP. This is the first time that this metachromatic dye has been used to analyse any OM extracted from any sea urchin biomineral.

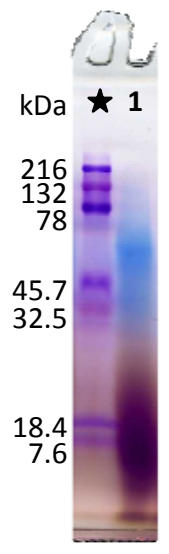

Figure 4-10: Scan of a Stains-All stained SDS-PAGE gel (10-20\%) of SMP (lane 1). Relative molecular weights as determined by electrophoresis of standards are indicated (black star).

A continuous smear from approximately $180 \mathrm{kDa}$ to below $7.6 \mathrm{kDa}$ was observed for SMP on a 10-20\% SDS-PAGE gel (Figure 4-10). It has been recognised in the literature ${ }^{[38,48]}$ that extracted organic matrices can be better visualised using the Alcian blue and Stains-All stains as opposed to silver stain. This trend holds for SMP as no species below $20 \mathrm{kDa}$ stained using the silver stain.

Both the Alcian blue (p. 112) and Stains-All profiles of SMP are broad and non-discrete. This smearing is a common trait of biomineral extracts examined using SDS-PAGE. For example, this was observed for the OMs extracted from the pen shell Pinna Nobilis ${ }^{[34]}$ and the freshwater snail Biomphalaria glabrata. ${ }^{[49]}$ Factors which cumulatively contribute to diffuse SDS-PAGE migration include macromolecular acidity, PTM, and self-assembly; all of which may apply in the case of SMP. PTM can contribute as it creates structural microheterogeneity and therefore a tight spread of MWs. Biomineral extracts have a propensity to aggregate $^{[38]}$ and the SDS detergent only inhibits this to a limited extent. ${ }^{[39]}$

There are two distinct colour developments observed for SMP: a blue region $(>30 \mathrm{kDa})$ and a red region $(<30 \mathrm{kDa})$. This change in colour demonstrates a distinct change in the structure, and therefore potentially functions, between these two groups of macromolecules. This result, that the macromolecules which migrate at 
MWs above and below $30 \mathrm{kDa}$ being structurally distinct, is consistent with the SDS-PAGE result following periodic acid-Schiff base stain (p. 114). To investigate whether these trends across the SDS-PAGE data correlate with changes in functional capacity we fractionated SMP across a $30 \mathrm{kDa}$ filter and analysed both the greater than 30 and less than $30 \mathrm{kDa}$ fractions. The results from this analysis are presented and discussed in chapter 5.

As this SDS-PAGE experiment is one-dimensional we cannot preclude that there are other colours contributing to, or obscured by, the overall colour observed. Through the selective removal of various PTMs followed by SDS-PAGE analysis we were able to complete a thorough investigation into the structural features contributing to the Stains-All colour profile of SMP. This investigation is presented throughout chapter 6 .

A blue colour development in the presence of Stains-All indicates: sialic acid, phosphate, and/or calcium-binding functionality. ${ }^{[47]}$ Using the ferric-orcinol and malachite green assays we have shown that there are sialic acids and phosphates so these groups may be contributing to the blue colour observed for SMP. From the Alcian blue staining at $\mathrm{pH} 1$ following electrophoresis of SMP we identified that sulfate is present throughout the ensemble (p. 112). This chemical feature has been associated with calcium-binding in the context of biomineralisation. ${ }^{[6,13,15,43 \text {, }}$ ${ }^{50]}$ In the MSA of SMP (p. 106) we observed that a significant proportion of SMP is comprised of $\mathrm{N}$-acetylated sugars. As these sugars have the ability to bind cations $^{[31]}$ they may also be involved in binding calcium. This has, however, never been shown previously in the context of biomineralisation.

The blue colour developed, located between 30 and $180 \mathrm{kDa}$, is most pronounced between 43 to $70 \mathrm{kDa}$; the region believed to contain the SM30 isoforms. SM30 is an acidic glycoprotein which has been shown to display an asparagine-linked anionic carbohydrate which is purported to be involved in the deposition of calcium in a growing spicule. This same carbohydrate structure, which is conserved and presented on MSP130, has been shown to be able to bind calcium. ${ }^{[1]}$ This 
glycan structure may therefore contribute to the blue colour observed in this greater than $30 \mathrm{kDa}$ region.

We did not expect there to be material within the SMP ensemble with a MW lower than $10 \mathrm{kDa}$ because the SMP isolation procedure involved filtration across a $10 \mathrm{kDa}$ membrane (p. 74). We were therefore surprised to observe material which migrates in the SDS-PAGE to MWs below 7.3 kDa. Explanations to account for this discrepancy are discussed in detail in chapter 5 (p. 139).

\subsubsection{D SDS-PAGE}

2D SDS-PAGE is a useful tool for visualising the impact of PTM on the pl of biomineral extracts. ${ }^{[25,44]}$ Given that macromolecular charge is an important variable in biomineralisation ${ }^{[15]}$ it was important to complete 2D electrophoresis for SMP. In this investigation the first dimension separated on the basis of isoelectric point and the second dimension, similar to standard electrophoresis, separated on the basis of size. As we observed from the one-dimensional SDSPAGE analyses different components of the ensemble are revealed using different stains. For this reason we used the three most informative stains to visualise SMP on 2D SDS-PAGE, including; silver stain, Alcian blue, and Stains-All. These results (Figure 4-11) demonstrate the first example of 2D SDS-PAGE analysis under these three stains for any OM from any sea urchin-related biomineral tissue. 


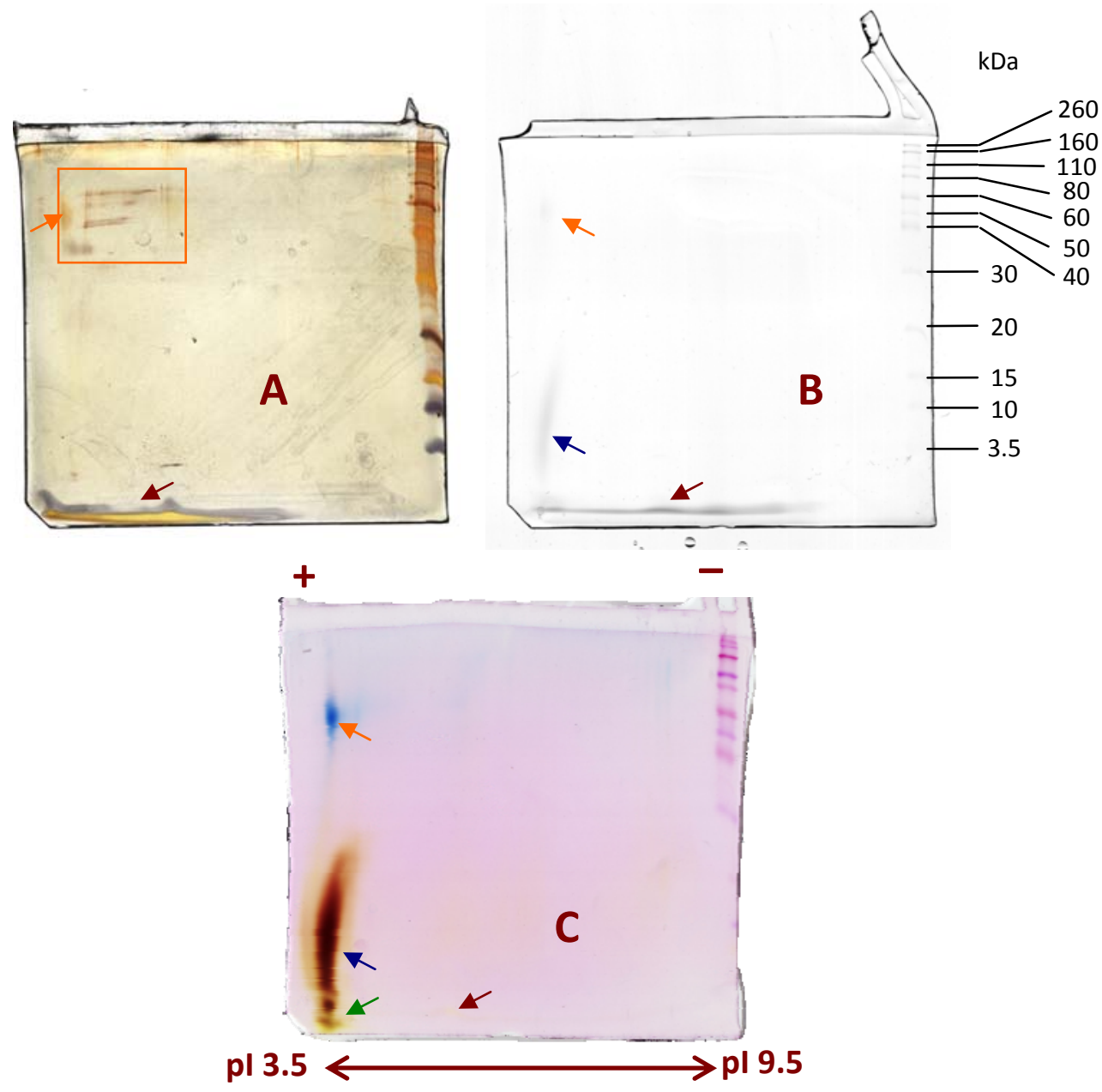

Figure 4-11: Scans of 2D SDS-PAGE gels of SMP. The gels were stained with silver stain (A), Alcian blue at $\mathrm{pH} 1$ (B), and Stains-All (C). The first dimension was a non-equilibrium gradient gel using Immobiline with a pH range of 3 to 10 . The second dimension was a SDS-PAGE gel (12\%). Molecular weights $(\mathrm{kDa})$ were determined relative to MW standards as indicated on the Alcian blue stained gel (B). The direction of the applied electric field is represented by the charge symbols above the gels. The features marked with arrows are discussed in the text.

The three gels depicted in Figure 4-11 show that there are no basic species within the ensemble, that is, with a pl greater than 7. This is consistent with our SMP extraction protocol (p. 74) which involves an anionic exchange column. We can therefore conclude that, of the spicule matrix (SM) proteins, which are the most abundant species in the spines of Strongylocentrotus purpuratus, ${ }^{[3]}$ we do not have; PM27, SM29, SM32, SM37, and SM50, within our SMP extract as these species have basic $\mathrm{pl}$ values. ${ }^{[35]}$ Within the SM group of proteins the remaining species are the SM30 and SMC-lectin subfamilies. 
The silver stained gel $(A)$ only displays a few features. This is consistent with the limited staining observed in the silver stained 1D gel of SMP (p. 111). The spots marked by the orange square represent the features in the 1D gel that smear from 40 to $70 \mathrm{kDa}$. Given this MW range and the relative acidity ( $\mathrm{pl} \sim 3.5$ to 6 ) we believe that the SM30 isoforms are represented within this square. The SM30 isoforms have MWs from 43 to $49 \mathrm{kDa}$ and a pl of 4.0. The feature marked with the orange arrows on all of the gels is a sulfated (gel B), calcium-binding (gel C) group of proteins (gel A) with a pl of approximately 4.0 and $\mathrm{MW}$ around $50 \mathrm{kDa}$. All of these characteristics match the profile of SM30. ${ }^{[37,52]}$ We did not, however, confirm the presence of SM30. This could have either been achieved through MS analysis following excision and treatment of the likely spots, or through a Western blot analysis using an antibody raised against SM30.

Killian et al. $^{[37]}$ completed a comprehensive 2D SDS-PAGE experiment using glycoproteins extracted from the spicule of the juvenile sea urchin Strongylocentrotus purpuratus which had been radio-labelled with ${ }^{35} \mathrm{~S}$-methionine to aid spot visualisation. The features indicated by the orange and blue arrows (gels $A, B$ and C) are in close agreement with their results. A difference between their results and those presented here is that there appears to be only a limited range of pl values (less horizontal smearing) represented within SMP. The blue arrows (gel B and C) mark a feature which appears to indicate a wide variety of species all of similar pl values but of variable MW. We believe that this result reflects a compression of species at the low pl range limit of the isoelectric focusing strip used in our experiment. That is, the pl values of these macromolecules are at most 3.5.

There is significant staining at very low MW, less than $3.5 \mathrm{kDa}$ (red arrows gels $\mathrm{A}, \mathrm{B}$ and $\mathrm{C}$ ). This feature spans a wide range of $\mathrm{pl}$ values (from $\sim 3.5-8 \mathrm{pH}$ ). We did not attempt to use additional experimental methods to characterise this material. This feature stained very faintly yellow in gel $\mathrm{C}$ with the most pronounced colouration indicated by the green arrow. Yellow staining using Stains-All is indicative of lipid material. ${ }^{[46]}$ This type of material could have been introduced from cellular 
remnants or extracellular matrix material that persisted through the spine bleaching procedure. This was not expected as the stereom space is open and should be accessible to the cleaning solution. ${ }^{[3]}$

\subsection{Crystallisation}

To test whether SMP is involved in the biomineralisation process we grew calcium carbonate crystals from a solution which included SMP as an additive. The effect of the SMP ensemble was determined by comparison of the crystals grown in the presence of the $\mathrm{OM}$ and a blank experiment; crystal growth with no organic additive. The variables monitored included the nucleation density and crystal morphology. In Table 4-3 are the nucleation densities of these two crystallisation experiments. As there is a greater number of crystals grown in the experiment which includes SMP we can conclude that there are species with the SMP ensemble which promote nucleation. Numerous macromolecules have been shown in the literature to be involved in the deposition of calcite in vivo. For example, MSP130 ${ }^{[51]}$ in the context of sea urchin spicules and mammallian ${ }^{[28]}$ in the context of avian egg shell. This increase in the number of crystals grown in the presence of SMP may indicate that there are macromolecules within SMP which perform a similar function in vivo.

\begin{tabular}{|l|c|}
\hline Sample & $\begin{array}{c}\text { Nucleation density } \\
\text { (crystals/mm2) }\end{array}$ \\
\hline Blank & $14 \pm 7$ \\
\hline SMP & $87 \pm 41$ \\
\hline
\end{tabular}

Table 4-3: The number of crystals grown (nucleation density) per $\mathrm{mm}^{2}$ in the presence of SMP and with no organic additive (blank). Shown are the means \pm the standard deviation (8 experiments blank, 7 experiments SMP).

In Figure 4-12 are SEM images which demonstrate the range of morphological activities exerted by SMP on calcite growth. The influence of an additive is dependent on the experimental conditions used to induce crystal formation, as outlined in chapter 2 (p. 54). Even within a fixed set of growth conditions, such as $500 \mathrm{mM} \mathrm{CaCl}_{2}$ and $0.10 \mathrm{~g}$ ammonium carbonate, there is variability in the shapes of crystals grown. As such, there is no one discrete characteristic morphological 
effect. We have therefore included a variety of images in Figure 4-12 so as to better represent the broad morphological activity of SMP.
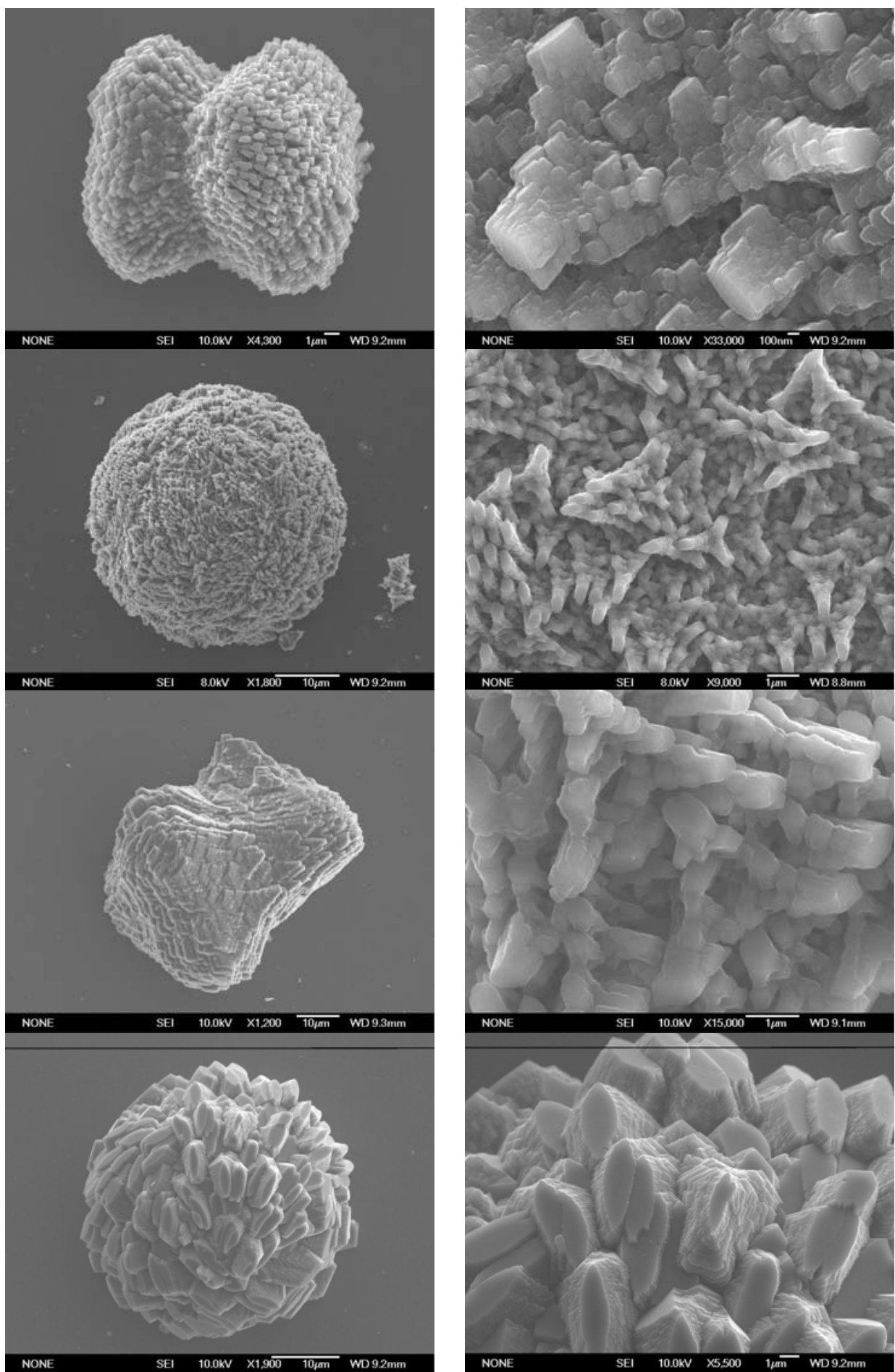

Figure 4-12: SEM images depicting the morphology of crystals grown in the presence of SMP. 
From analysis of the SEM images presented in Figure 4-12 in comparison to the blank experiment which produces rhombohedral structures we can see that SMP has a dramatic influence on crystal morphology. The morphology of the crystals grown in the presence of the native SMP extract are similar to those grown by MacKenzie et al. ${ }^{[4]}$ who also analysed SMP using this experimental set-up. In both cases crystals demonstrating three-fold symmetry corresponding to the (104) faces superimposed on crystal towers were grown.

To better understand the chemical structures which lead to these nucleating and morphological activities we manipulated the ensemble in two ways. In chapters 5 we present the results and discussion following the fractionation of the macromolecular mixture. To better understand the roles of the PTMs we selectively removed the PTMs; including phosphorylation, sulfation, and glycosylation, and grew crystals in the presence of these digested versions of SMP. These results are presented in chapter 6 .

\subsection{Chapter 4: Nati ve Ensemble Summary}

A summary of the quantitative data presented throughout this chapter is collected in Table 4-4. From this compilation we were able to determine the relative contribution of the PTMs and the protein (column 2) and therefore the overall wt\% for each chemical group (column 3). These results do not include the input from sulfate modification. This PTM was shown to be present throughout the ensemble (p. 112) but was not quantified. By combining the results from the MSA and the ferric-orcinol assay we have shown that there is $120.5 \pm 23.6 \mu \mathrm{g}$ of sugar for every $100 \mu \mathrm{g}$ protein representing $54.0 \pm 5.3 \mathrm{wt} \%$ of the SMP ensemble. Using HPLC we demonstrated that the glycan is covalently linked to the protein and therefore the SMP ensemble is comprised of glycoproteins and proteins. 


\begin{tabular}{|l|c|c|}
\hline \multicolumn{1}{|c|}{ Chemical } & $\begin{array}{c}\text { Mass } / 100 \mu \mathrm{g} \mathrm{SMP} \\
\text { protein }\end{array}$ & wt\% of SMP \\
\hline Protein & $100 \pm 2.9$ & $44.9 \pm 1.3$ \\
\hline Hexoses and HexNAcs & $103.5 \pm 10.7$ & $46.4 \pm 4.8$ \\
\hline Sialic acid & $17 \pm 5$ & $7.6 \pm 2.2$ \\
\hline Phosphate & $2.40 \pm 0.61$ & $1.08 \pm 0.27$ \\
\hline Total & $222.9 \pm 15.5$ & $100 \pm 5.4$ \\
\hline
\end{tabular}

Table 4-4: A summary of the quantitative data collected throughout the chapter. Shown are the means \pm the standard deviation of at least 4 experiments. In column 2 the masses provided are relative to $100 \mu \mathrm{g}$ protein, and in column 3 the various chemical moieties have been converted to a wt\% of the complete ensemble.

Based on the monomer analyses of the protein (AAA) and the glycans (MSA) we were able to outline some of the potential structural features within SMP. For example, in the AAA (p. 102) we observed significant amounts of glycine and alanine. This could represent silk-like domains within the SMP ensemble. From the relative abundance of the monosaccharides which comprise the SMP glycone ( $p$. 106) we demonstrated that there may be HexNAc oligomers, mucin-like, carrageenan, and/or keratan sulfate oligomers within the spines of Evechinus chloroticus.

In addition to the quantitative data we collected qualitative data. Using SDS-PAGE we characterised the distribution of functional groups by MW. From these analyses it was shown that there is; carboxylate and sulfate functionality throughout the MW range of the ensemble. Using the periodic acid-Schiff base stain it appears that the sialic acid residues are associated with species which have MWs greater than $30 \mathrm{kDa}$.

Using 2D SDS-PAGE we have demonstrated that the $\mathrm{pl}$ values of all species included in SMP is approximately 4.0 or lower. From a comparison of the 2D SDSPAGE gels (p. 118) with the literature ${ }^{[37]}$ we appear to have isolated members of the SM30 glycoprotein family.

Using SMP as an additive in the in vitro crystallisation assay demonstrated that both the number of crystals nucleated and their morphology were affected. This 
result demonstrates that there are species with the OM which interfere with the in vitro precipitation of calcite.

The SDS-PAGE data consistently indicated that there are structurally distinct areas within the SMP ensemble. For example the higher MW species (>30 kDa) stained well with silver and periodic acid-Schiff base, and appear blue with Stains-All. In contrast, the low MW species $(<30 \mathrm{kDa})$ stain well with Alcian blue at $\mathrm{pH} 1$ and red under Stains-All. Based on these observations we attempted to fractionate SMP across a series of spin-filters, as presented in the following chapter. 


\subsection{References}

[1] F. Nudelman, B. A. Gotliv, L. Addadi, S. Weiner, J Struct Biol 2006, 153, 176.

[2] B. T. Livingston, C. E. Killian, F. Wilt, A. Cameron, M. J. Landrum, O. Ermolaeva, V. Sapojnikov, D. R. Maglott, A. M. Buchanan, C. A. Ettensohn, Developmental Biology 2006, $300,335$.

[3] K. Mann, A. J. Poustka, M. Mann, Proteome Science 2008, 6.

[4] C. R. MacKenzie, S. M. Wilbanks, K. M. McGrath, Journal of Materials Chemistry 2004, 14, 1238.

[5] L. Ameye, G. De Becker, C. Killian, F. Wilt, R. Kemps, S. Kuypers, P. Dubois, Journal of Structural Biology 2001, 134, 56.

[6] N. K. Karamanos, A. Manouras, S. Anagnostides, E. Makatsori, T. Tsegenidis, C. A. Antonopoulos, Biochimie 1996, 78, 171.

[7] A. Manouras, N. K. Karamanos, T. Tsegenidis, C. A. Antonopoulos, Comparative Biochemistry and Physiology, Part B: Biochemistry \& Molecular Biology 1991, 99B, 119.

[8] L. Adaddi, S. Weiner, Angew. Chem. Int. Ed. Engl. 1992, 31, 153.

[9] M. Fukuda, ed;, A. Kobata, ed, Glycobiology : a practical approach, Oxford University Press, Oxford, 1993.

[10] A. P. W. Jill E. Borbas, C. Steven Sikes,, Journal of Experimental Zoology 1991, 258, 1.

[11] Deborah J. Veis, Todd M. Albinger, John Clohisy, Mohammed Rahima, Boris Sabsay, Arthur Veis, Journal of Experimental Zoology 1986, 240, 35.

[12] Debbie M. Swift, C. Steven Sikes, A. P. Wheeler, Journal of Experimental Zoology 1986, 240, 65 .

[13] T. Samata, D. Ikeda, A. Kajikawa, H. Sato, C. Nogawa, D. Yamada, R. Yamazaki, T. Akiyama, Febs Journal 2008, 275, 2977.

[14] S. Weiner, H. A. Lowenstam, On Biomineralization, Oxford University Press, New York, Oxford, 1989.

[15] F. Marin, G. Luquet, B. Marie, D. Medakovic, Current Topics in Developmental Biology, Vol $802008,80,209$.

[16] S. Albeck, L. Addadi, S. Weiner, Connective Tissue Research 1996, 35, 365.

[17] S. Albeck, S. Weiner, L. Addadi, Chemistry--A European Journal 1996, 2, 278.

[18] S. Sudo, T. Fujikawa, T. Nagakura, T. Ohkubo, K. Sakaguchi, M. Tanaka, K. Nakashima, T. Takahashi, Nature 1997, 387, 563.

[19] G. Falini, S. Albeck, S. Weiner, L. Addadi, Science 1996, 271, 67. 
[20] F. Nudelman, H. H. Chen, H. A. Goldberg, S. Weiner, L. Addadi, Faraday Discuss 2007, 136, 9.

[21] Martina Michenfelder, Germaine Fu, Camille Lawrence, James C. Weaver, Brandon A. Wustman, Laura Taranto, John Spencer Evans, Daniel E. Morse, Biopolymers 2003, 70, 522.

[22] Brandon A. Wustman, Rudolpho Santos, Bo Zhang, John Spencer Evans, Biopolymers 2002, 65, 362.

[23] A. Berman, L. Addadi, S. Weiner, Nature 1988, 331, 546.

[24] S. Albeck, J. Aizenberg, L. Addadi, S. Weiner, Journal of the American Chemical Society 1993, 115, 11691.

[25] B. Marie, G. Luquet, J. P. P. De Barros, N. Guichard, S. Morel, G. Alcaraz, L. Bollache, F. Marin, Febs Journal 2007, 274, 2933.

[26] S. Mann, Biomineralization: Principles and Concepts in Bioinorganic Materials Chemistry, Oxford University Press, Oxford, 2001.

[27] H. Takemoto, S. Hase, T. Ikenaka, Analytical Biochemistry 1985, 145, 245.

[28] M. Soledad Fernandez, A. Moya, L. Lopez, J. L. Arias, Matrix Biology 2001, 19, 793.

[29] J. F. Forstner, G. G. Forstner, Physiology of the Gastrointestinal Tract, 3rd ed., Raven, New York, 1994.

[30] G. J. Strous, J. Dekker, Crit Rev Biochem Mol Biol 1992, 27, 57.

[31] M. A. Robinson-Lora, R. A. Brennan, Bioresource Technology 2009, 100, 5063.

[32] V. L. Campo, D. F. Kawano, D. B. d. Silva Jr, I. Carvalho, Carbohydrate Polymers 2009, 77, 167.

[33] L. Ameye, R. Hermann, C. Killian, F. Wilt, P. Dubois, J. Histochem. Cell Biol. 1999, 110, 1189.

[34] F. Marin, R. Amons, N. Guichard, M. Stigter, A. Hecker, G. Luquet, P. Layrolle, G. Alcaraz, C. Riondet, P. Westbroek, J Biol Chem 2005, 280, 33895.

[35] Fred H. Wilt, Christopher E. Killian, Brian T. Livingston, Differentiation 2003, 71, 237.

[36] J. Anstrom, J. Chin, D. Leaf, A. Parks, R. Raff, Development 1987, 101, 255.

[37] C. E. Killian, F. H. Wilt, J. Biol. Chem. 1996, 271, 9150.

[38] B.-A. Gotliv, L. Addadi, S. Weiner, Chembiochem : a European journal of chemical biology 2003, 4, 522.

[39] J. C. Marxen, W. Becker, Comparative Biochemistry and Physiology Part B: Biochemistry and Molecular Biology 1997, 118, 23.

[40] G. Fu, S. Valiyaveettil, B. Wopenka, D. E. Morse, Biomacromolecules 2005, 6, 1289.

[41] F. Marin, B. Pokroy, G. Luquet, P. Layrolle, K. De Groot, Biomaterials 2007, 28, 2368. 
[42] J. L. Arias, A. Neira-Carrillo, J. I. Arias, C. Escobar, M. Bodero, M. David, M. S. Fernandez, Journal of Materials Chemistry 2004, 14, 2154.

[43] J. L. Arias, M. S. Fernandez, Chemical Reviews 2008, 108, 4475.

[44] I. M. Rosenberg, Second edition ed., Birkhauser Boston, Boston, MA, 2006.

[45] J. A. Kiernan, Histological and histochemical methods : theory and practice, Pergamon Press, Oxford ; New York, 1990.

[46] L. E. King, M. Morrison, Analytical Biochemistry 1976, 71, 223.

[47] K. P. Campbell, D. H. Maclennan, A. O. Jorgensen, Journal of Biological Chemistry 1983, $258,1267$.

[48] Y. Dauphin, J. P. Cuif, Electrophoresis 1997, 18, 1180.

[49] J. C. Marxen, W. Becker, Comp Biochem Physiol B Biochem Mol Biol 2000, 127, 235.

[50] L. W. Jaques, E. B. Brown, J. M. Barrett, W. S. Brey, W. J. Weltner, J. Biol. Chem. 1977, 252, 4533.

[51] M. C. Farachcarson, D. D. Carson, J. L. Collier, W. J. Lennarz, H. R. Park, G. C. Wright, Journal of Cell Biology 1989, 109, 1289.

[52] Martin F. Brown, Jacqueline S. Partin, Christopher E. Killian, William J. Lennarz, Development Growth \& Differentiation 1995, 37, 69. 


\section{CHAPTER 5 : RESULTS AND DISCUSSI ON FRACTIONATED SMP}

As demonstrated in chapter 4 numerous chemical functionalities and susceptibilities exist within the SMP ensemble. Disentanglement of the chemical mélange followed by analysis in vitro provides the necessary information to understand the more complex full complement. ${ }^{[1]}$ In this chapter we delineate the ensemble by fractionating the OM into smaller units based on MW. We did not attempt to isolate individual proteins for functional analysis as there were no apparent discrete bands which would make this approach feasible. As recognised by Marin et al. ${ }^{[2]}$ the technical obstacle of isolating individual proteins 'pestered for more than two decades the life of researchers involved in biomineralisation'.

From the SDS-PAGE analysis of SMP we observed that there were chemically distinct species above and below $30 \mathrm{kDa}$. To assess the significance of this observation we fractionated SMP across a $30 \mathrm{kDa}$ filter and tested the greater than $30 \mathrm{kDa}$ fraction (SMP>30kDa) using the in vitro crystallisation assay. The less than $30 \mathrm{kDa}$ sample was fractionated across a $10 \mathrm{kDa}$ spin-filter to prepare the other two samples analysed in this chapter: SMP<10kDa and SMP10-30kDa. Using the various quantitative analyses of $A A A, M S A$, and malachite green assay we mapped the structural features within each of the fractions and related these to their ability to affect crystal growth. This work represents the first time that an OM extracted from within a sea urchin mineral has been partitioned based on MW and the resulting fractions analysed in terms of their function.

\subsection{Crystallisation}

As we saw in chapter 4, SMP has a pronounced effect on crystallisation in vitro; both in terms of the morphology and nucleation density. To assess whether these traits are emergent properties of the full complement, or if they are controlled by subsections of the OM we tested the functionality of the fractionated species as additives in crystallisation experiments. 
The densities of crystals grown in the presence of the various fractionated samples are presented in Table 5-1. From this experiment we have demonstrated that there are species which have the ability to promote nucleation in the SMP>30kDa sample. The density of crystals grown in the presence of this additive (113 \pm 27 crystals $/ \mathrm{mm}^{2}$ ) is within uncertainty of the number of crystals grown in the presence of SMP $\left(87 \pm 41\right.$ crystals $\left./ \mathrm{mm}^{2}\right)$. This result demonstrates that only, at most, a limited number of species are required to bring about the nucleating activity of SMP. That is, the crystallisation variable of nucleation is not an emergent property of many macromolecules in concert. This assertion is supported by the observation that the other two fractions, SMP $<10 k D a$ and SMP10-30kDa, both have nucleation densities (16 \pm 2 and $14 \pm 2$ crystals $/ \mathrm{mm}^{2}$, respectively) which are within uncertainty of the blank sample (14 \pm 7 crystals $/ \mathrm{mm}^{2}$ ).

\begin{tabular}{|l|c|}
\hline \multicolumn{1}{|c|}{ Sample } & $\begin{array}{c}\text { Nucleation density } \\
\text { (crystals/mm2) }\end{array}$ \\
\hline Blank & $14 \pm 7$ \\
\hline SMP & $87 \pm 41$ \\
\hline SMP $<10 k D a$ & $16 \pm 2$ \\
\hline SMP10-30kDa & $14 \pm 2$ \\
\hline SMP $>30 k D a$ & $113 \pm 27$ \\
\hline
\end{tabular}

Table 5-1: The number of crystals grown per $\mathrm{mm}^{2}$ in the presence of the various fractionated additives. SMP and blank results are included for comparison. Shown are the means \pm the standard deviation of 4 experiments for the fractionated samples.

In Figure 5-1 are SEM images of the crystals grown in the presence of SMP $<10 k D a$ (row A), SMP10-30kDa, (row B), and SMP>30kDa (row C). We have therefore shown that the $<10$ and $>30 \mathrm{kDa}$ samples are relatively morphologically benign as the crystal shapes are reminiscent of a blank experiment, that is, rhombohedral structures with truncated edges. In contrast, using the SMP10-30kDa sample as an additive produced crystals which were indistinguishable from those grown in the presence of the complete SMP ensemble (p. 121). From these results we have demonstrated that the macromolecules in the SMP<10kDa and SMP $>30 k D a$ samples are superfluous for the in vitro morphological activity to be realised. 


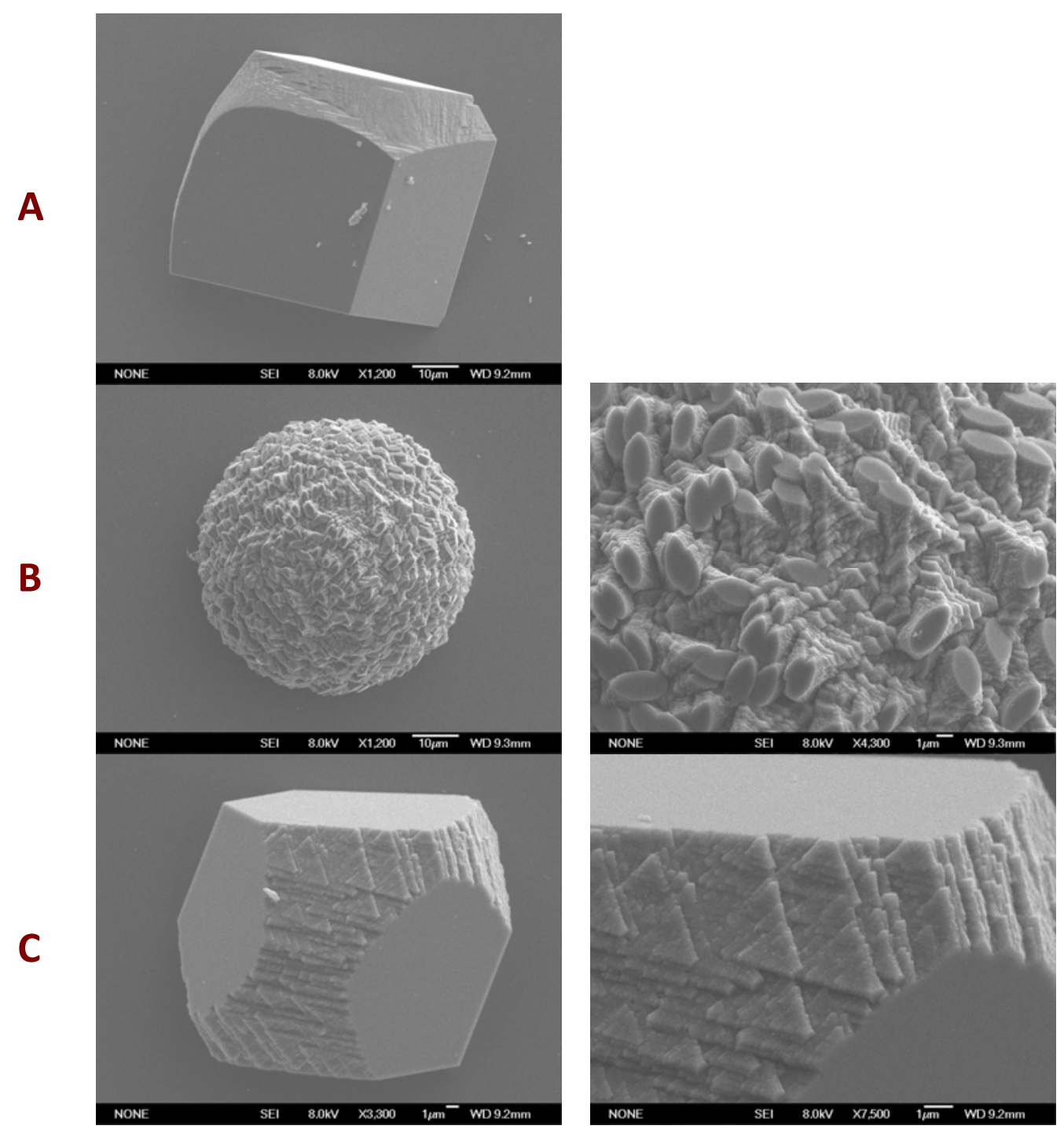

Figure 5-1: SEM images showing the morphology of $\mathrm{CaCO}_{3}$ crystals grown in the presence of fractionated SMP. Additives are as follows: SMP<10kDa (row A), SMP10-30kDa (row B), and SMP>30kDa (row C).

We have shown that the crystallisation activities of morphological control and nucleating are independently controlled within the limits of this experimental system, and are contained within the SMP10-30kDa and SMP>30kDa fractions, respectively. As these fractionated samples still contain an ensemble of proteins, while reduced in number, we have not determined whether these experimental observables are controlled by a single protein, a range of proteins with common chemical features, or an emergent property of a group of different species. As each of these scenarios have been proffered in the context of biomineralisation ${ }^{[3,4]}$ 
they all remain a possibility in the context of this system. We have also demonstrated that the material in the SMP $<10 \mathrm{kDa}$ sample is redundant in this context as it did not affect either the number of crystals grown or their morphology.

Using the SMP $>30 \mathrm{kDa}$ sample as an additive resulted in a significant increase in the number of crystals grown. If we assume that the nucleating species are occluded within the growing crystal, the data indicates that there are many nucleators within the SMP ensemble. This result supports recent investigations ${ }^{[5,6]}$ which have shown that the sea urchin spine, while appearing as a single crystal to X-ray, is a mesocrystal made up of many aligned nanobricks. This kinetically-controlled crystallisation regime relies on many punctuated nucleators that initiate calcium carbonate growth, controlled crystal orientation, and growth until they coalescence. While we have demonstrated that there are species which nucleate within our ensemble, the ability to control crystal orientation is beyond the experimental parameters of the in vitro crystallisation assay.

Given the MW of SM30 and MSP130 they are presumably within the SMP>30kDa fraction and are therefore candidates for the nucleating function observed. With this, we have also identified that their function, at least in vitro, is limited to nucleation. It is important to reiterate that the behaviour of a species in a fixed environment in vivo can be drastically distinct from its activity when isolated in vitro. ${ }^{[7,8]}$ This phenomenon has been demonstrated in other investigations. ${ }^{[9,10]}$

Seto et al. ${ }^{[11]}$ analysed the fixed distribution of the SM30 epitope throughout the embedded fibril meshwork within a sea urchin spicule. In this investigation they removed the mineral phase with EDTA and then treated the remaining organic framework with labelled anti-SM30 antibodies. The results showed a punctuated distribution of the SM30 epitope-containing species throughout the spicule. This result would match the conclusion that macromolecules displaying this epitope are involved in initiating mineral growth, if the mesocrystal scenario applies. 
The assignment of the nucleating capability to SM30 and MSP130 would appear to correlate to the in vivo system. However, determining whether these macromolecules are responsible for this in vitro nucleating function is beyond the scope of this work. The approach adopted here was to identify the chemical moieties which participate. It has been shown that the mAb1223 epitope, which is presented by both of these macromolecules, is involved in spicule deposition in vivo. $^{[12,13]}$ The ability to perform this function is dependent on the calcium-binding sialic acid-containing N-glycans. Determining whether these chemical functionalities are involved in the nucleating capability of SMP is explored in chapter 6 (p. 179).

From this functional analysis we identified that nucleation and morphological activity are independently controlled within this in vitro system. To better understand the chemical construction which brings about these functions we completed a compositional analysis of the fractions as follows.

\subsection{COMPOSI TI ONAL ANALYSIS OF SMP FrACTIONS}

\subsubsection{ABSORPTI ON AT $280 \mathrm{NM}$}

Measuring the absorption at $280 \mathrm{~nm}$ is a convenient method to estimate the quantity of protein in a sample. Using the standard equation presented in chapter 4 (p. 96) which related the absorption of a SMP solution at $280 \mathrm{~nm}$ to the concentration we estimated the relative abundance of protein in each of the fractionated samples. The results of this analysis are presented in Table 5-2.

\begin{tabular}{|c|c|}
\hline \multicolumn{1}{|c|}{ Sample } & Proportion (A280) \\
\hline SMP $<10 k D a$ & $0.265 \pm 0.032$ \\
\hline SMP10-30kDa & $0.303 \pm 0.036$ \\
\hline SMP $>30 k D a$ & $0.432 \pm 0.015$ \\
\hline Total & $1.00 \pm 0.05$ \\
\hline
\end{tabular}

Table 5-2: The distribution of protein across the 3 fractioned samples SMP<10kDa, SMP10-30kDa, and SMP $>30 \mathrm{kDa}$. as determined by A280 measurements. Shown are the means \pm the standard deviation of 4 experiments. 
In Table 5-2 we can see a significant proportion of the SMP ensemble has a MW less than $10 \mathrm{kDa}(0.265 \pm 0.032)$. This observation was surprising as all material with a MW below $10 \mathrm{kDa}$ should have been removed from the SMP ensemble ( $p$. 74). One explanation for the persistence of material with MWs below $10 \mathrm{kDa}$ through the SMP isolation procedure involves calcium-mediated macromolecular assembly. Farach-Carsen et al. ${ }^{[12]}$ demonstrated that MSP130 glycopeptides eluted significantly later on a size exclusion column if calcium was included in the eluant. They therefore concluded that the presence of calcium ions leads to selfassembled structures. As the extraction of SMP involves dissolution of calcium carbonate there is a high concentration of calcium ions in the isolation procedure.

We are not sure of the identity or source of these $<10 \mathrm{kDa}$ species. For example, they could either be proteinaceous and/or lipid based. They may be present within the sea urchin spine as is, or they may be a by-product of the OM isolation. Research to answer these questions was not completed. This was in part because the results of the crystallisation assay (Table 5-1, Figure 5-1) showed that the species below $10 \mathrm{kDa}$ are not active in our in vitro crystallisation assay.

\subsubsection{AMI No ACID ANALYSIS}

APAF completed an AAA on the various fractionated SMP samples (Table 4-1). The amino acids which support the PTMs researched in this PhD work include: asparagine (N-glycans), serine (O-glycans and phosphate), threonine (O-glycans), and tyrosine (sulfate). As all of these amino acids are present within each of the SMP fractionated samples, all samples have the potential to be post-translationally modified in a variety of ways. 


\begin{tabular}{|l|c|c|c|}
\hline \multirow{2}{*}{ Amino Acid } & SMP $<10 \mathrm{kDa}$ & SMP10-30kDa & SMP>30kDa \\
\cline { 2 - 4 } Asx & $10.8 \pm 0.2$ & $15.4 \pm 0.9$ & $11.1 \pm 0.0$ \\
\hline Serine & $6.8 \pm 0.1$ & $5.6 \pm 0.2$ & $6.0 \pm 0.0$ \\
\hline Glx & $8.0 \pm 0.1$ & $8.6 \pm 0.8$ & $10.9 \pm 0.0$ \\
\hline Glycine & $26.7 \pm 0.1$ & $28.4 \pm 2.2$ & $14.2 \pm 0.1$ \\
\hline Histidine & $0.9 \pm 0.0$ & $0.2 \pm 0.0$ & $1.7 \pm 0.0$ \\
\hline Arginine & $1.7 \pm 0.1$ & $0.8 \pm 0.0$ & $3.0 \pm 0.0$ \\
\hline Threonine & $5.3 \pm 0.0$ & $4.0 \pm 0.1$ & $8.2 \pm 0.0$ \\
\hline Alanine & $10.9 \pm 0.1$ & $15.0 \pm 0.8$ & $8.9 \pm 0.0$ \\
\hline Proline & $7.6 \pm 0.0$ & $5.8 \pm 0.4$ & $11.8 \pm 0.1$ \\
\hline Tyrosine & $2.3 \pm 0.0$ & $1.7 \pm 0.1$ & $3.0 \pm 0.0$ \\
\hline Valine & $3.3 \pm 0.0$ & $2.1 \pm 0.1$ & $5.3 \pm 0.0$ \\
\hline Methionine & $4.2 \pm 0.1$ & $3.7 \pm 1.2$ & $1.4 \pm 0.0$ \\
\hline Lysine & $0.6 \pm 0.0$ & $0.3 \pm 0.0$ & $1.4 \pm 0.0$ \\
\hline Isoleucine & $2.3 \pm 0.0$ & $1.9 \pm 0.0$ & $3.2 \pm 0.0$ \\
\hline Leucine & $3.1 \pm 0.0$ & $1.6 \pm 0.1$ & $5.8 \pm 0.0$ \\
\hline Phenylalanine & $5.6 \pm 0.2$ & $5.0 \pm 0.6$ & $4.2 \pm 0.0$ \\
\hline \multicolumn{1}{|c|}{ Total } & $100.0 \pm 0.3$ & $100.0 \pm 3.0$ & $100.0 \pm 0.1$ \\
\hline
\end{tabular}

Table 5-3: Amino acid analysis of each of the fractionated samples. The fractionated samples include SMP $<10 \mathrm{kDa}$, SMP10-30kDa, and SMP>30kDa. Shown are the means \pm the standard deviation of 2 experiments. Asx and Glx represent aspartic acid and asparagine, and glutamic acid and glutamine, respectively. Cysteine, tryptophan, and the unusual amino acids were not tested for. These data were collected by the Australian Proteome Analysis Facility (APAF).

In chapter 4 we observed high levels of both glycine and alanine in the AAA of SMP (p. 102) which indicates that there may be silk-like domains within SMP. From the AAA results of the various fractions it appears that, if this protein domain is present within the SMP ensemble, it may be within the morphologically-active SMP10-30kDa fraction. In this sample the percentage of glycine and alanine are $28.4 \pm 2.2$ and $15.0 \pm 0.8$ mol\%, respectively. Consistent with this assignment there are significantly lower levels of both of these amino acids in the SMP>30kDa sample at $14.2 \pm 0.1$ and $8.9 \pm 0.0$ mol\% for glycine and alanine, respectively. The decrease in the amount of these amino acids in the heaviest MW fraction may reflect the predominance of SM30 and MSP130 in SMP>30kDa which are relatively low in both of these amino acids compared to SMP.

Michenfelder et al. ${ }^{[14]}$ reported that for protein-mediated macromolecular recognition of calcium and carbonate the relevant amino acids are: aspartic acid, glutamic acid, serine, tyrosine, threonine, asparagine, glutamine, lysine, arginine, 
glycine and proline. It is interesting to note that the SMP>30kDa fraction is relatively diminished in the calcium-binding amino acid Asx while being enriched in the carbonate-binding amino acids tyrosine, threonine, arginine, proline, and lysine. This result could imply that the calcium-binding is mediated through the post-translational modifications.

\subsubsection{MONOSACCHARI DE ANALYSIS}

In chapter 4 (p. 106) we determined that the glycans constitute $54 \pm 18.7$ wt\% of SMP. To gain a better understanding of the distribution of this sugar, the potential structures, and therefore the structure-function relationships we completed a monosaccharide analysis (MSA) on the fractionated samples. The results of this analysis are presented in Table 5-4. Use of the ferric-orcinol assay to determine the sialic acid content for the various fractions was not completed due to time constraints.

\begin{tabular}{|l|c|c|c|}
\hline \multicolumn{1}{|c|}{ Sample } & SMP $<10 \mathrm{kDa}$ & \multicolumn{1}{c|}{ SMP10-30kDa } & SMP $>30 \mathrm{kDa}$ \\
\hline Fucose & $5.26 \pm 1.28$ & $16.98 \pm 4.14$ & $7.60 \pm 1.85$ \\
\hline Mannose & $1.05 \pm 0.25$ & $2.70 \pm 0.64$ & $1.71 \pm 0.40$ \\
\hline Galactose & $8.75 \pm 3.34$ & $32.16 \pm 12.25$ & $6.80 \pm 2.59$ \\
\hline GlcNAc & $5.54 \pm 0.09$ & $77.63 \pm 16.85$ & $45.40 \pm 0.77$ \\
\hline GalNAc & $4.27 \pm 1.11$ & $34.18 \pm 9.14$ & $22.58 \pm 5.85$ \\
\hline \multicolumn{1}{|c|}{ Total } & $24.88 \pm 3.60$ & $163.65 \pm 23.13$ & $84.08 \pm 6.72$ \\
\hline & \multicolumn{2}{|c|}{$\mu \mathrm{g}$ sugar $/ 100 \mu \mathrm{g}$ protein $(\mathrm{SMP}$ ensemble) } \\
\hline Fucose & $1.39 \pm 0.34$ & $5.14 \pm 1.25$ & $3.28 \pm 0.80$ \\
\hline Mannose & $0.28 \pm 0.07$ & $0.82 \pm 0.19$ & $0.74 \pm 0.17$ \\
\hline Galactose & $2.32 \pm 0.88$ & $9.74 \pm 3.71$ & $2.94 \pm 1.12$ \\
\hline GlcNAc & $1.47 \pm 0.02$ & $23.52 \pm 5.10$ & $19.61 \pm 0.33$ \\
\hline GalNAc & $1.13 \pm 0.29$ & $10.36 \pm 2.77$ & $9.75 \pm 2.53$ \\
\hline Total & $6.59 \pm 0.99$ & $49.59 \pm 7.00$ & $36.32 \pm 2.90$ \\
\hline & & \multicolumn{3}{c|}{ mol\% $\%$} \\
\hline Fucose & $24.49 \pm 5.96$ & $12.32 \pm 3.00$ & $10.11 \pm 2.46$ \\
\hline Mannose & $4.47 \pm 1.05$ & $1.96 \pm 0.46$ & $2.07 \pm 0.49$ \\
\hline Galactose & $37.15 \pm 14.15$ & $23.34 \pm 8.89$ & $8.24 \pm 3.14$ \\
\hline GlcNAc & $19.14 \pm 2.24$ & $41.82 \pm 4.89$ & $52.70 \pm 6.16$ \\
\hline GalNAc & $14.76 \pm 1.86$ & $20.56 \pm 2.59$ & $26.87 \pm 3.39$ \\
\hline Total & $100.00 \pm 15.75$ & $100.00 \pm 10.90$ & $100.00 \pm 8.10$ \\
\hline
\end{tabular}

Table 5-4: Tabulation of the monosaccharide analyses completed on each of the fractionated samples. The fractionated samples include SMP<10kDa, SMP10-30kDa, and SMP $>30 k D a$. Hexoses and HexNAcs were determined following TFA and $\mathrm{HCl}$ digestion, respectively. Shown are the means \pm the standard deviation of 4 experiments. The top section represents the mass of sugar in $100 \mu \mathrm{g}$ protein of the fractionated sample. The middle section depicts the data scaled to reflect its contribution to the ensemble as determined by A280 (p. 133). 
In the top portion of Table 5-4 the MSA results are presented as $\mu \mathrm{g}$ sugar/ $100 \mu \mathrm{g}$ protein of that fraction. This depiction of the results therefore reflects the extent of protein glycosylation. The SMP $<10 \mathrm{kDa}$ fraction, which was shown to be inactive in the crystallisation assay (p. 130 and 131), is only slightly glycosylated (24.88 \pm $3.60 \mu \mathrm{g} / 100 \mu \mathrm{g}$ protein) relative to the higher MW fractions. The morphologically active fraction SMP10-30kDa is the most heavily glycosylated fraction with a 1 to 1.6 protein to glycan mass ratio. Both the SMP10-30kDa and the SMP>30kDa fractions display a conserved GIcNAc to GalNAc ratio of 2 to 1 . This may indicate that there are glycans of similar structure across both active fractions.

In the middle section of Table 5-4 the results have been scaled to reflect the mass of sugar contributed by each fraction to the SMP ensemble. For example, the relative proportion of the $10-30 \mathrm{kDa}$ fraction was determined to be $30.3 \pm 3.6 \mathrm{wt} \%$ of the protein from A280 measurements (p. 133). We therefore multiplied the results in the top section of Table 5-4 ( $\mu \mathrm{g}$ sugar/ $100 \mu \mathrm{g}$ protein itself) by its relative protein contribution to the ensemble. From this data manipulation we observe that the SMP10-30kDa fraction contributes only slightly more sugar than the SMP>30kDa fraction $(49.59 \pm 7.00$ and $36.32 \pm 2.90 \mu \mathrm{g}$ sugar/100 $\mu \mathrm{g}$ protein, respectively). This representation of the data also demonstrates that the mass of each monosaccharide is within uncertainty for all monosaccharides, except galactose, for the two active fractions. In the SMP10-30kDa fraction the mass of galactose is significantly higher. Combining the total values we observe that 92.50 $\pm 7.64 \mu \mathrm{g}$ sugar $/ 100 \mu \mathrm{g}$ protein SMP has been accounted for. As this is within uncertainty of the mass of sugar determined for the ensemble $(103.5 \pm 10.7 \mu \mathrm{g}$ sugar/100 $\mu$ g protein SMP) we can conclude that the experimental methods are reliable.

In the lowest section of Table 5-4 the MSA results are presented as a mol\% to reflect the proportion of each monosaccharide by number. From a comparison of the MSA profiles in these units we observe that the proportion of galactose is significantly higher in the morphologically-active fraction (SMP10-30kDa) compared to the nucleating fraction $(\mathrm{SMP}>30 \mathrm{kDa})$. The observation that this 
monosaccharide is singularly enhanced relative to the other monosaccharides may indicate the presence of galactose homopolymers. Sulfated versions of these glycans, the carrageenans, ${ }^{[15]}$ have been shown to affect solution properties such as viscosity which could affect crystal growth. There are, however, other structurebased interpretations of these MSA results. For example, the 1:1:2 ratio of galactose to GalNAc to GIcNAc may indicate that there are keratan sulfate oligomers (Gal-GlcNAc dimer repeats) and HexNAc polymers (GalNAc-GIcNAc dimer repeats) within the SMP10-30kDa fraction.

All N-glycans contain mannose within their pentasaccharide core. As each of the fractionated samples contains a small amount of mannose they all have the potential to display $\mathrm{N}$-glycosylation. We are therefore unable to make any speculation about the crystallisation activity of the N-glycans in the SMP sample from this analysis.

\subsubsection{Malachite Green Assay}

In chapter 4 (p. 100) we observed that the SMP ensemble is $2.40 \pm 0.61$ protein wt\% phosphate. From the AAA of the fractionated samples (p. 135) we demonstrated that all fractions have the potential to hold phosphate modification through the presence of serine in the protein backbone. Using the malachite green standard curve depicted in chapter 4 (p. 100) we determined the distribution of phosphate across the MW fractions. The results of this analysis are presented in Table 5-5.

\begin{tabular}{|l|c|c|c|}
\hline \multicolumn{1}{|c|}{ Sample } & $\begin{array}{c}\mu \mathrm{PO}_{4}{ }^{3-} / 100 \mu \mathrm{g} \\
\text { Protein }\end{array}$ & $\begin{array}{c}\mu \mathrm{PO}_{4}{ }^{3-} / 100 \mu \mathrm{g} \\
\text { protein SMP }\end{array}$ & $\begin{array}{c}\text { Proportion of } \mathrm{PO}_{4}{ }^{3-} \\
\text { of SMP by mass }\end{array}$ \\
\hline SMP $<10 k D a$ & $0.23 \pm 0.06$ & $0.06 \pm 0.02$ & $0.03 \pm 0.01$ \\
\hline $\begin{array}{l}\text { SMP10- } \\
\text { 30kDa }\end{array}$ & $5.22 \pm 1.33$ & $1.58 \pm 0.46$ & $0.88 \pm 0.22$ \\
\hline SMP>30kDa & $0.37 \pm 0.09$ & $0.16 \pm 0.04$ & $0.09 \pm 0.02$ \\
\hline \multicolumn{1}{|c|}{ Total } & NA & $1.80 \pm 0.46$ & $1.00 \pm 0.22$ \\
\hline
\end{tabular}

Table 5-5: Results for the malachite green assay of the SMP fractionated samples. Shown are the means \pm the standard deviation of 4 experiments. In column 2 the results represent the mass of phosphate within $100 \mu \mathrm{g}$ protein of that fraction. Column 3 shows the results scaled according to how much each fraction contributes to the SMP ensemble as determined by A280 measurements (p. 133). 
In column 2 of Table 5-5 the results are presented in units which reflect the degree of phosphorylation within that fraction. From this depiction we can see that the SMP10-30kDa fraction is approximately 20 times more phosphorylated in comparison to the other two fractions. In column 3 we have scaled each of the fractions relative to their abundance in SMP, for example, SMP>30kDa represents $43.2 \pm 1.5 \mathrm{wt} \%$ of the protein as determined by $A 280$ measurements (p. 133). The total mass of phosphate following this conversion shows that SMP is $1.80 \pm 0.46$ protein wt\% phosphate. This result adds validity to the experimental methods adopted as it is within uncertainty of the phosphate content of SMP at $2.40 \pm 0.61$ protein wt\% phosphate.

In column 4 we have calculated the proportion of total phosphate in each fraction. From this depiction we have shown that $88 \pm 22 \%$ of the phosphate in SMP is within the SMP10-30kDa fraction. This result may indicate a structure-function relationship between the phosphate moiety and the morphological activity. Previous investigations ${ }^{[16,17]}$ which focussed on the role of the phosphate PTM have shown that the phosphate moiety inhibits calcium carbonate growth. If this is also the case in the SMP system then we would expect to see a decrease in morphological features which result from inhibition following the removal of the phosphate residues. This is tested using the crystallisation assay in chapter 6 ( $p$. 186) following the selective removal of phosphate (SMPDePO and SMPDePTM, p. 181). Livingston et al. $^{[18]}$ showed that the genome of Strongylocentrotus purpuratus encodes for secreted phosphated calcium-binding proteins. If we demonstrate a connection between the phosphate and the morphological activity then we may have identified the morphologically-active species within the SMP ensemble.

\subsubsection{SDS-PAGE}

SDS-PAGE was used to analyse each of the SMP fractions. The three different stains used to reveal the migration profile were: silver stain (protein, Figure 5-2), Alcian blue pH 1 (sulfates, Figure 5-3), and Stains-All (calcium-binding, Figure 5-3). 


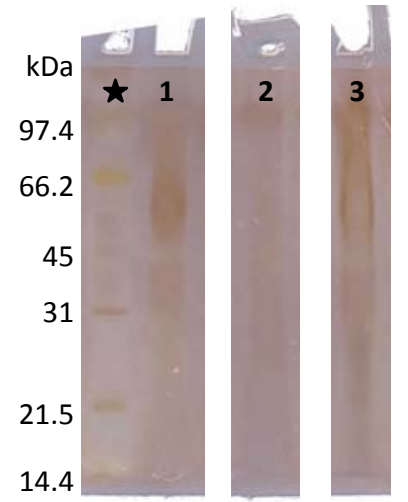

Figure 5-2: Scan of a silver stained SDS-PAGE gel $(12 \%)$ of SMP (lane 1$),$ SMP $<30 \mathrm{kDa}$ (lane 2), and SMP $>30 k D a$ (lane 3). Relative molecular weights as determined by electrophoresis of standards are indicated (black star).

A silver stained gel was only completed for the samples SMP $<30 \mathrm{kDa}$ and SMP>30kDa. The SMP<10kDa and SMP10-30kDa samples were not analysed by this technique as the macromolecules within SMP below $20 \mathrm{kDa}$ do not stain with silver (p. 111). From this analysis (Figure 5-2) it appears that the fractionation procedure has been successful. The SMP $<30 \mathrm{kDa}$ sample does not show any sign of stained features whereas the SMP $>30 \mathrm{kDa}$ sample has a strong staining feature at 40-70 kDa.
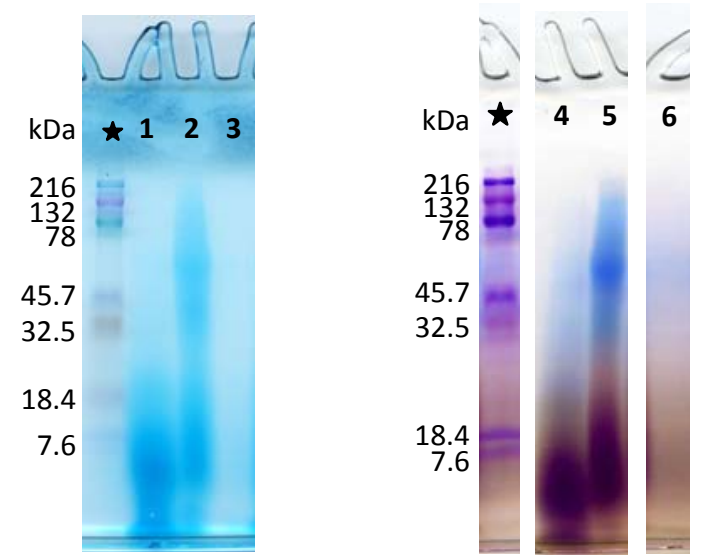

Figure 5-3: Scans of Alcian blue pH 1 (lanes 1 to 3) and Stains-All (lanes 4 to 6) stained 10-20\% gradient SDS-PAGE gels of: SMP10-30kDa (lanes 1 and 4), SMP>30kDa (lanes 2 and 5), and SMP $<10 k D a$ (lanes 3 and 6), respectively. Relative molecular weights as determined by electrophoresis of standards are indicated (black star). 
In Figure 5-3 are the results obtained from electrophoresis of the various fractionated samples using both the Alcian blue $\mathrm{pH} 1$ (left) and Stains-All (right) stains. From these SDS-PAGE results it appears that the MW of the macromolecules included within each of the fractions may not be within the MWs assigned to that fraction. For example, the SMP>30kDa sample (lanes 2 and 5) should not contain species with MWs below $30 \mathrm{kDa}$. However, as we can see there is material within this fraction which has migrated to the elution front with a relative MW less than $\sim 7 \mathrm{kDa}$. In addition, the SMP10-30kDa sample (lanes 1 and 4) should have no material with MWs greater than $30 \mathrm{kDa}$. However, in lane 4 there is arguably material which stains up to $\sim 216 \mathrm{kDa}$. These results demonstrate that SMP is therefore non-standard in terms of either; its SDS-PAGE migration, or its apparent size which affects fractionation across the spin-filter.

For the SMP10-30kDa and SMP>30kDa samples there should be no material below 10 and $30 \mathrm{kDa}$, respectively. Even though we observe staining below these thresholds for both of these samples it does not necessarily indicate inefficient fractionation based on MW. The issue could be that the extensive posttranslational modification of the SMP macromolecules is interfering with their migration relative to the $\mathrm{MW}$ protein standards. In an ideal SDS-PAGE characterisation experiment the analyte is unravelled and coated in negatively charged SDS molecules, where the number of SDS molecules is proportional to the size of the protein. The extent of SDS-PAGE migration is therefore based on both charge and size. ${ }^{[19]}$ Deviations from this ideal scenario leading to anomalous MW data occur when dealing with species which are heavily glycosylated and/or charged which influences their interaction with SDS and therefore the electric field. ${ }^{[20]}$ In this situation species tend to migrate according to their intrinsic negative charge, as opposed to their true $\mathrm{MW} .^{[20,21]}$ The charged moieties which have a profound effect on SDS-PAGE migration include sulfation and sialic acid. ${ }^{[22,}$ ${ }^{23]}$ In chapter 4 (p. 123) we showed that SMP includes a variety of species which can affect SDS-PAGE migration, such as glycans, sialic acid, and sulfates. Each of these PTMs render assignment of MW based on SDS-PAGE mobility prone to 
error. ${ }^{[21]}$ An example from the biomineralisation literature which demonstrates this, where the observed MW was lower than the true MW, was published by Marin et al. ${ }^{[24]}$ Mucoperlin migrates at $55 \mathrm{kDa}$ while having a deduced mass of 66.7 kDa. One of the explanations proffered for the anomalous migration was the presence of interfering PTMs. The lack of staining for the SMP $<10 \mathrm{kDa}$ sample and the observation of staining to the elution front for the two heavier MW samples supports this non-standard SDS-PAGE migration based explanation. That is, there is material which did not pass through the $10 \mathrm{kDa}$ MWCO spin-filter which migrates to the elution front.

For the SMP10-30kDa sample there should be no staining at MWs greater than $30 \mathrm{kDa}$. However, we observe in the Stains-All stained gel (lane 6) there is a faint blue colouration up to the range limit of the gel at $\sim 216 \mathrm{kDa}$. This anomaly in the SDS-PAGE MW profile is in contrast to the previous one discussed, as in this instance the MW appears greater than the true value. This property of a biomineral extract has been observed previously. For example, Morse et al. ${ }^{[19]}$ showed that the $8 \mathrm{kDa}$ protein AP8 migrates at $14 \mathrm{kDa}$ on SDS-PAGE. Another example is E7 which migrates at $17 \mathrm{kDa}$ on SDS-PAGE while the actual mass is $11 \mathrm{kDa} .{ }^{[25]}$ The source of this MW discrepancy was attributed to arguments previously discussed, for example, anomalous SDS binding. In these cases the source of the SDS repulsion was the acidic amino acids. Again, as there is an abundance of acidity (sulfates and carboxylates) throughout the SMP ensemble this mechanism of migration interference may also be applicable in this context.

In an attempt to determine the MW profile of SMP using alternative methods $\mathrm{Dr}$ Ian Simms at Industrial Research Ltd kindly ran an HPLC column of SMP versus a series of standards (Figure 5-4). The results of this experiment demonstrate the influence that chemical structure can have on relative migration. As SMP is approximately one to one protein to sugar both protein and sugar standards were run to calibrate the elution time relative to $\mathrm{MW}$. This MW standardisation clearly demonstrates that the elution time is strongly influenced by chemical structure. We observed that bovine serum albumin (red trace), a common protein standard 
with a MW of $67 \mathrm{kDa}$, elutes at approximately $30 \mathrm{kDa}$ relative to the sugar-based Pullulan standards.

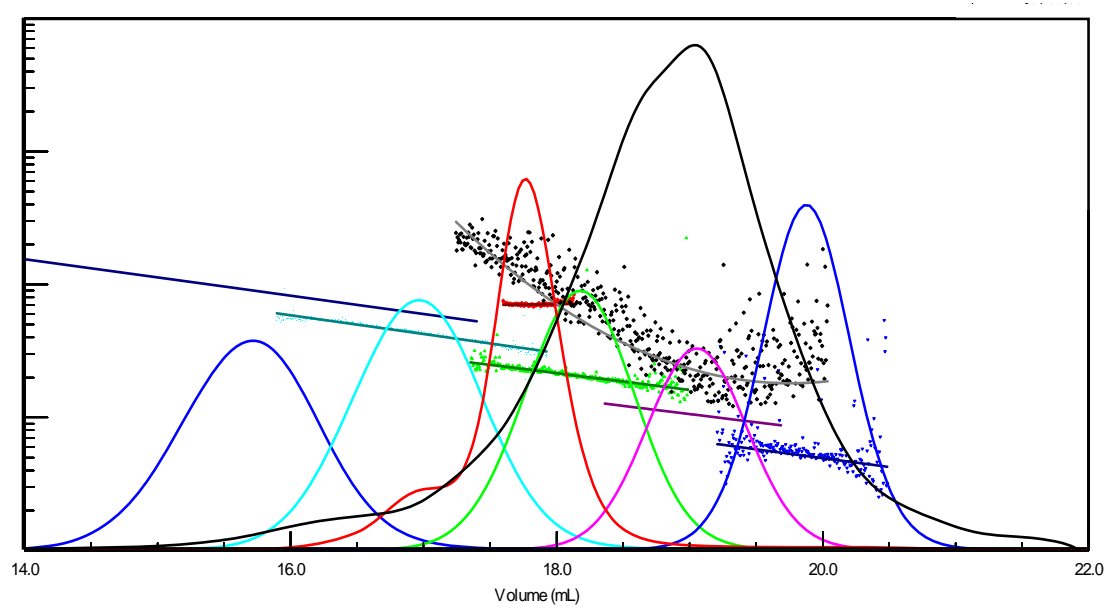

Figure 5-4: Overlay trace of SMP (black line) and a series of Pullulan standards monitored using refractive index following elution through a size-exclusion HPLC column. Assignment of peaks from left to right: $100 \mathrm{kDa}$ (blue), $48 \mathrm{kDa}$ (light blue), $24 \mathrm{kDa}$ (green), $12 \mathrm{kDa}$ (pink), and $6 \mathrm{kDa}$ (blue). All of these were detected using refractive index. Bovine serum albumin (67kDa, red trace) was detected measuring A280. These data were kindly collected by Dr lan Simms at Industrial Research Ltd.

We have now outlined how post-translational modification can lead to erroneous MW data and have therefore rationalised the observed SDS-PAGE data for the various SMP fractions. However, an alternative interpretation of the data would be that the SDS-PAGE migration is accurate and therefore the MW of the species within each of the fractions is not as limited to the MW range as defined by the spin-filter MWCO. The spin-filter membranes are made of a porous material. From the size of the pores an estimate is made as to the MW of proteins which will not pass through the pores, that is, estimating the MWCO of the spin-filter. This calculation is based on proteins of standard shape and charge. Therefore, the more that a protein deviates from standard, the less reliable the spin-filter MWCO parameter is. As SMP is not standard, due to the abundance of post-translational modification, the actual MW of the species which are retained by the spin-filter is unknown.

Despite the anomalous SDS-PAGE migration and/or the MW discrepancy for the SMP10-30kDa and SMP>30kDa samples, the use of these filters reliably returned 
the same subsets of macromolecules. This was demonstrated by the various analytical techniques and the reproducible crystallisation results.

The SMP $>30 \mathrm{kDa}$ sample (lane 5) stains blue at MWs greater than $30 \mathrm{kDa}$ following treatment with Stains-All. This blue staining may be linked to calcium-binding functionality and/or a heavily polyanionic structure. ${ }^{[19]}$ This colour development may therefore be linked to the activity associated with this fraction as it has been demonstrated previously that polyanionic structures can promote calcite nucleation. ${ }^{[26]}$ However, it does not follow that an intense blue colour under Stains-All demonstrates an ability to affect crystal growth, as in the case of calmodulin. ${ }^{[19]}$ The anionic species within the SMP $>30 \mathrm{kDa}$ sample which may be influencing the nucleation process include; acidic amino acids, phosphate, sialic acid, and sulfate. In chapter 6 we determine which of these species are involved in both the nucleating function and the morphological activity.

\subsection{Chapter Five Fracti OnATEd SMP Summary}

In chapter 4 we observed, using SDS-PAGE analysis, that there were apparently distinct species within the SMP ensemble above and below $30 \mathrm{kDa}$. Following on from this we fractionated SMP across a series of MWCO spin-filters and isolated three fractions, namely SMP $<10 \mathrm{kDa}$, SMP10-30kDa, and SMP $>30 \mathrm{kDa}$. Using these samples as additives in our in vitro crystallisation assay we demonstrated that the morphological and nucleating functions of the complete ensemble were contained within the SMP10-30kDa and SMP>30kDa fractions, respectively. In addition, we observed that $\mathrm{SMP}<10 \mathrm{kDa}$ does not interfere with crystal growth in vitro. This result overall demonstrates that the functional capabilities of the SMP ensemble are controlled by a limited variety of species. As we isolated an ensemble of species $(\mathrm{SMP}>30 \mathrm{kDa}$ ) which have the ability to induce nucleation it appears that there are many macromolecules within the sea urchin spine which are able to induce nucleation. This result, that there are many nucleators within the SMP ensemble, supports the hypothesis that sea urchin spines are constructed from aligned coalesced nanobricks. 
The actual MWs of the species contained within the various fractions were unable to be determined. This issue arises as a consequence of the atypical nature of the macromolecules within the SMP ensemble as they include significant amounts of PTM and charge. These modifications render MW assignment based on the MWCO of the spin-filter and SDS-PAGE analysis complicated.

Analysis of the distribution of phosphate throughout the SMP ensemble (Table 5-5) showed that $88 \pm 22$ wt\% of the phosphate is contained within the morphologically active fraction (SMP10-30kDa). This chemical architecture may therefore be involved in the morphological activity associated with this fraction. From the AAA of SMP $>30 \mathrm{kDa}$ we noted that there was a relatively low proportion of Asx indicating that the blue staining under Stains-All is probably encoded via post-translational modification. 


\subsection{References}

[1] R. A. Metzler, I. W. Kim, K. Delak, J. S. Evans, D. Zhou, E. Beniash, F. Wilt, M. Abrecht, J. W. Chiou, J. H. Guo, S. N. Coppersmith, P. U. P. A. Gilbert, Langmuir 2008, 24, 2680.

[2] F. Marin, G. Luquet, B. Marie, D. Medakovic, Current Topics in Developmental Biology, Vol 80 2008, 80, 209.

[3] B. Marie, G. Luquet, L. Bedouet, C. Milet, N. Guichard, D. Medakovic, F. Marin, Chembiochem 2008, 9, 2515.

[4] A. Matsushiro, T. Miyashita, H. Miyamoto, K. Morimoto, B. Tonomura, A. Tanaka, K. Sato, Mar Biotechnol (NY) 2003, 5, 37.

[5] F. C. Meldrum, H. Col’^Ifen, Chemical Reviews 2008, 108, 4332.

[6] A. K. Y. Oaki, T. Miura, H. Imai,, Advanced Functional Materials 2006, 16, 1633.

[7] J. L. Arias, A. Neira-Carrillo, J. I. Arias, C. Escobar, M. Bodero, M. David, M. S. Fernandez, Journal of Materials Chemistry 2004, 14, 2154.

[8] J. C. Marxen, M. Hammer, T. Gehrke, W. Becker, Biological Bulletin 1998, 194, 231.

[9] F. Nudelman, B. A. Gotliv, L. Addadi, S. Weiner, J Struct Biol 2006, 153, 176.

[10] M. A. Crenshaw, H. Ristedt, The histochemical localization of reactive groups in septal nacre from Nautilus pompilius. In: The Mechanisms of Mineralization in the Invertebrates and Plants., University of South Carolina Press, Colombia, 1976.

[11] J. Seto, Y. Zhang, P. Hamilton, F. Wilt, Journal of Structural Biology 2004, 148, 123.

[12] M. C. Farachcarson, D. D. Carson, J. L. Collier, W. J. Lennarz, H. R. Park, G. C. Wright, Journal of Cell Biology 1989, 109, 1289.

[13] Martin F. Brown, Jacqueline S. Partin, Christopher E. Killian, William J. Lennarz, Development Growth \& Differentiation 1995, 37, 69.

[14] Martina Michenfelder, Germaine Fu, Camille Lawrence, James C. Weaver, Brandon A. Wustman, Laura Taranto, John Spencer Evans, Daniel E. Morse, Biopolymers 2003, 70, 522.

[15] V. L. Campo, D. F. Kawano, D. B. d. Silva Jr, I. Carvalho, Carbohydrate Polymers 2009, 77, 167.

[16] B. A. Halloran, J. E. Donachy, Comparative Biochemistry and Physiology BBiochemistry \& Molecular Biology 1995, 111, 221. 
[17] T. Samata, D. Ikeda, A. Kajikawa, H. Sato, C. Nogawa, D. Yamada, R. Yamazaki, T. Akiyama, Febs Journal 2008, 275, 2977.

[18] B. T. Livingston, C. E. Killian, F. Wilt, A. Cameron, M. J. Landrum, O. Ermolaeva, V. Sapojnikov, D. R. Maglott, A. M. Buchanan, C. A. Ettensohn, Developmental Biology 2006, 300, 335.

[19] G. Fu, S. Valiyaveettil, B. Wopenka, D. E. Morse, Biomacromolecules 2005, 6, 1289.

[20] B. J. Van Klinken, A. W. Einerhand, H. A. Buller, J. Dekker, Anal Biochem 1998, 265, 103.

[21] K. M. A. J. Tytgat, D. M. Swallow, B. J. W. Vanklinken, H. A. Buller, A. W. C. Einerhand, J. Dekker, Biochemical Journal 1995, 310, 1053.

[22] J. Dekker, P. H. Aelmans, G. J. Strous, Biochem J 1991, 277 ( Pt 2), 423.

[23] W. M. O. Vanbeurdenlamers, R. Speebrand, J. Dekker, G. J. Strous, Biochimica Et Biophysica Acta 1989, 990, 232.

[24] F. Marin, P. Corstjens, B. de Gaulejac, E. de Vrind-De Jong, P. Westbroek, J Biol Chem 2000, 275, 20667.

[25] D. J. Armstrong, A. Roman, Biochemical and Biophysical Research Communications 1993, 192, 1380.

[26] F. C. Meldrum, International Materials Reviews 2003, 48, 187. 


\section{CHAPTER 6 : RESULTS AND DI SCUSSI ON SPECI FI C DI GESTI ON OF SMP}

In the previous chapter it was shown that the two crystallisation properties of morphology and nucleation are controlled by species which are distinctly separate by MW. That is, the species which control morphological activity were contained in the SMP10-30kDa fraction and the species within the SMP>30kDa fraction induces nucleation. The aim of this thesis was to better understand the chemical structures which contribute to these in vitro crystallisation observables. In order to achieve this we selectively cleaved the SMP chemical assemblage and tested the function of the dissected products in the crystallisation assay. The chemical moieties removed include: $\mathrm{N}$-glycans (p. 149), sialic acids (SMPDeSia, p. 170), sulfates (SMPDeSO, p.170), phosphates (SMPDePO, p. 181), the complete glycone (SMPDeGly, p. 149), and SMP removed of all post-translational modification (SMPDePTM, p. 181). In the preparation of these digests the $\mathrm{N}$ - and O-glycans were isolated and the structures of the neutral glycone determined. From this analysis we addressed the comments that the composition and structure of biomineral-associated glycans warrant further exploration, ${ }^{[1]}$ including those occluded within the spines of sea urchin. ${ }^{[2]}$

\subsection{GLYCOSYLATION}

From a MSA (p. 106) and HPLC (p. 109) of SMP we demonstrated that there is substantial protein glycosylation. There are two types of protein glycosylation; Nand O-glycosylation. MacKenzie et al. ${ }^{[3]}$ suggested, analysing a sample equivalent to SMP, that the N-glycans hold the morphological activity of the ensemble. We were therefore interested in testing the function of SMP, using the in vitro assay, with the N-glycans removed. Using the enzyme PNGase $\mathrm{F}$ we could selectively cleave this post-translational modification. Therefore the products following treatment of SMP with PNGase F were SMP with the N-glycans removed (SMPDeNg) and the N-glycans. 
As glycosylation represents over $50 \mathrm{wt} \%$ (p. 123) of the SMP ensemble we were also interested in liberating the O-glycans and assessing their contribution, in isolation, to the activity of SMP. We used reductive $\beta$-elimination to cleave the O-glycans from SMPDeN-g. Finally, as a complement to these samples we used acid hydrolysis to completely deglycosylate the SMP ensemble while leaving the protein intact (SMPDeGly).

\subsubsection{AMI No ACID ANALYSIS}

An AAA was completed on SMPDeGly to test the selectivity of the deglycosylation reaction, that is, to test whether there was unwanted proteolysis as a consequence of the acid digestion. The results from this analysis are presented in Table 6-1. As can be seen the majority of the amino acids are similar to that of the native ensemble. We can therefore conclude that the deglycosylation reaction did not lead to significant proteolysis.

\begin{tabular}{|l|c|c|}
\hline \multirow{2}{*}{ Amino Acid } & SMPDeGly & SMP \\
\cline { 2 - 3 } & \multicolumn{2}{|c|}{ mol $\%$} \\
\hline Asx & $14.5 \pm 0.4$ & $13.6 \pm 0.4$ \\
\hline Serine & $6.0 \pm 0.4$ & $6.8 \pm 0.5$ \\
\hline Glx & $8.6 \pm 0.2$ & $9.4 \pm 0.3$ \\
\hline Glycine & $26.7 \pm 1.8$ & $24.8 \pm 1.5$ \\
\hline Histidine & $0.4 \pm 0.0$ & $0.8 \pm 0.1$ \\
\hline Arginine & $1.0 \pm 0.2$ & $3.0 \pm 0.7$ \\
\hline Threonine & $4.6 \pm 0.7$ & $5.3 \pm 0.8$ \\
\hline Alanine & $13.5 \pm 1.0$ & $12.5 \pm 0.9$ \\
\hline Proline & $6.3 \pm 0.6$ & $7.5 \pm 0.7$ \\
\hline Tyrosine & $2.2 \pm 0.2$ & $1.5 \pm 0.1$ \\
\hline Valine & $2.6 \pm 0.4$ & $3.2 \pm 0.5$ \\
\hline Methionine & $3.6 \pm 0.9$ & $1.7 \pm 0.5$ \\
\hline Lysine & $0.3 \pm 0.1$ & $0.6 \pm 0.2$ \\
\hline Isoleucine & $2.1 \pm 0.1$ & $2.5 \pm 0.2$ \\
\hline Leucine & $2.2 \pm 0.2$ & $2.6 \pm 0.3$ \\
\hline Phenylalanine & $5.5 \pm 0.6$ & $4.6 \pm 0.6$ \\
\hline \multicolumn{1}{|c|}{ Total } & $100.0 \pm 2.6$ & $100.0 \pm 2.5$ \\
\hline
\end{tabular}

Table 6-1: The results obtained following AAA of SMPDeGly and SMP (included for comparison). The tests for cysteine, tryptophan, or any unusual amino acids, were not completed. Shown are the means \pm the standard deviation of 2 experiments. Asx and Glx represent; Asp and Asn, and Glu and Gln, respectively. These data were collected by the Australian Proteome Analysis Facility. 


\subsubsection{MONOSACCHARI DE ANALYSIS}

Monosaccharide analyses of the isolated N-glycans, SMPDeN-g, and SMPDeGly were completed. From this type of analysis we were able to determine the relative quantities of the $\mathrm{N}$ - and O-glycans, as well as their monosaccharide profiles. This is the first time that the $\mathrm{N}$ - and $\mathrm{O}$-glycones have been quantified and profiled for the OM extracted from the spines of any sea urchin species. The results of these investigations are presented in Table 6-2. For the completely deglycosylated sample, SMPDeGly, we used MSA to monitor the efficacy of the deglycosylation reaction. These results are presented in Table 6-3.

\begin{tabular}{|l|c|c|c|}
\hline \multicolumn{1}{|c|}{ Sugar } & $\begin{array}{c}\mu \mathrm{g} / 100 \mu \mathrm{g} \text { protein } \\
\text { SMP }\end{array}$ & mol\% & $\begin{array}{c}\text { wt\% of SMP } \\
\text { glycone }\end{array}$ \\
\hline Fucose & $0.1 \pm 0.1$ & $0.8 \pm 0.0$ & $1.0 \pm 0.0$ \\
\hline Mannose & $2.4 \pm 0.9$ & $23.8 \pm 9.5$ & $103.6 \pm 112.2$ \\
\hline Galactose & $0.1 \pm 0.0$ & $-0.2 \pm 0.0$ & $0.5 \pm 0.3$ \\
\hline GlcNAc & $9.8 \pm 1.5$ & $49.7 \pm 2.3$ & $21.9 \pm 14.6$ \\
\hline GalNAc & $5.1 \pm 0.6$ & $25.8 \pm 0.6$ & $19.4 \pm 9.7$ \\
\hline \multicolumn{1}{|c|}{ Total } & $17.5 \pm 1.9$ & $100.0 \pm 9.8$ & $17.0 \pm 1.9$ \\
\hline \multicolumn{4}{|c|}{ O-glycone } \\
\hline Fucose & $8.3 \pm 0.3$ & $11.3 \pm 0.4$ & $72.0 \pm 41.9$ \\
\hline Mannose & $0.8 \pm 0.3$ & $1.0 \pm 0.4$ & $34.7 \pm 38.5$ \\
\hline Galactose & $11.6 \pm 1.0$ & $14.4 \pm 1.1$ & $62.9 \pm 37.4$ \\
\hline GlcNAc & $38.6 \pm 1.9$ & $44.7 \pm 2.2$ & $86.4 \pm 48.3$ \\
\hline GalNAc & $20.7 \pm 0.5$ & $25.6 \pm 0.6$ & $78.2 \pm 31.5$ \\
\hline \multicolumn{1}{|c|}{ Total } & $80.0 \pm 2.2$ & $100.0 \pm 2.6$ & $77.3 \pm 2.2$ \\
\hline
\end{tabular}

Table 6-2: Monosaccharide analyses of the SMP N- and O-glycones. Shown are the means \pm the standard deviation of 4 experiments. In column 2 the results depict the mass of each sugar relative to $100 \mu \mathrm{g}$ protein SMP. In column 4 the mass of each sugar has been compared to the mass of that monosaccharide present in the total ensemble (p. 106). The hexoses and HexNAcs were determined from TFA and $\mathrm{HCl}$ digestion, respectively.

Collectively, the mass of the $\mathrm{N}$ - and O-glycans (column 2) is $97.5 \pm 2.9 \mu \mathrm{g} / 100 \mu \mathrm{g}$ protein. This result is within uncertainty of the MSA of SMP $(103.5 \pm 10.7 \mu \mathrm{g} / 100$ $\mu \mathrm{g}$ protein, p. 106). Therefore glycan liberation, fractionation, and quantification procedures are valid. From the total mass detected for each glycone $(17.5 \pm 1.9$ and $80.0 \pm 2.2 \mu \mathrm{g} / 100 \mu \mathrm{g}$ protein for the $\mathrm{N}$ - and O-glycans, respectively) we have demonstrated that the ratio by mass of $\mathrm{N}$ - to O-glycosylation is approximately one to four. As SMP is just over half sugar $(54.0 \pm 5.3 \mathrm{wt} \%$, p. 123$)$ it therefore follows 
that O-glycosylation constitutes just under half of total mass of the SMP ensemble ( $\sim 4$ wt\%). This result of the ratio of $\mathrm{N}$ - to O-glycosylation is similar to that of Albeck et al. ${ }^{[2]}$ who analysed to OM within the spines of Paracentrotus lividus. Using ${ }^{1} \mathrm{H}$ NMR they showed that there was approximately a one to three ratio of $\mathrm{N}$ to O-glycosylation. These ratios between the $\mathrm{N}$ - and O-glycans are indicative of macromolecules such as keratan sulfate proteoglycans and mucins.

In column 3 of Table 6-2 each glycone is depicted as a mol\%, therefore demonstrating the molar ratio of each monosaccharide within each glycone. From this analysis we can see that the N-glycone is comprised of GlcNAc, GaINAc, and mannose; with the HexNAc monomers comprising $75.5 \pm 9.8 \mathrm{~mol} \%$. As all $\mathrm{N}$-glycans have mannose incorporated into the core structure this result strongly suggests that there are N-glycan HexNAc oligomers. However, we did not test the isolated N-glycans for sialic acid and as we observed in chapter 4 (p. 123) $7.6 \pm 2.2$ ensemble wt\% consists of sialic acid. Indeed sialic acid has been shown to be present within the $\mathrm{N}$-glycone of the MSP130 glycoprotein. ${ }^{[4]}$ While the predominance of the HexNAc sugars is maintained for the O-glycone $(70.3 \pm 2.3$ mol\%) the diversity of monosaccharides is greater including galactose (14.4 \pm 1.1 mol\%) and fucose (11.3 \pm 0.4 mol\%). Therefore no structural elucidation can be determined for the O-glycans from this data alone. However, the MSA profile of the O-glycans is characteristic of mucin-like glycans ${ }^{[5,6]}$ with an abundance of GlcNAc, GalNAc, and galactose; and small amounts of mannose, fucose and sialic acid. It is also interesting that both glycones are predominantly comprised of HexNAc sugars (>70 mol\%) and a conserved ratio of these HexNAc monosaccharides of two to one GIcNAc to GalNAc for both glycones. This ratio was also observed in chapter 5 for the fractionated samples (p. 136). Conservation of this ratio suggests that there are structural constraints. We therefore believe that there are HexNAc oligomers which contain both GIcNAc and GaINAc.

To determine the relative contribution by mass of each glycan type to the overall glycosylation of SMP we manipulated the data in column 2. We converted each of the results in column 2 to a wt\% relative to the mass of each monosaccharide in 
SMP, as determined by the MSA of SMP in chapter 4 (р. 106). Therefore, for a particular monosaccharide the $\mathrm{N}$ - and O-glycone percentages in column 4 should ideally add to 100 wt\%. For example, we can see that all of the GalNAc has been accounted with $19.4 \pm 9.7 \mathrm{wt} \%$ in the $\mathrm{N}$-glycone and the remaining $78.2 \pm 31.5 \mathrm{wt} \%$ included as O-glycosylation.

From this depiction of the data we can see that the PNGase $\mathrm{F}$ liberation of the $\mathrm{N}$ glycans has gone to completion. Mannose is present in all N-glycans as it is a component of the characteristic core structure. In column 4 we see that $103.6 \pm$ 112.2 wt\% of the mannose can be accounted for within the $\mathrm{N}$-glycan liberated material alone, compared to $34.7 \pm 38.5 \mathrm{wt} \%$ in the O-glycan sample. Being able to isolate the $\mathrm{N}$-glycone directly provides an ideal scenario to assess the role of the $\mathrm{N}$-glycans in vitro. In a typical PNGase F digestion the glycoprotein analyte is prepared for deglycosylation with the use of detergent and/or proteases to render the N-glycans accessible to the PNGase $\mathrm{F}$. This is because the release of $\mathrm{N}$-glycans from native glycoproteins is typically inefficient due to steric constraints. ${ }^{[7,8]}$ From this MSA we have demonstrated that the $\mathrm{N}$-glycone can be successfully liberated without destruction of the remaining O-glycoprotein enabling this species to also be analysed. The successful treatment of SMP with PNGase F here is in contrast to Albeck et al. ${ }^{[2]}$ who found that the OM extracted from the spines of Paracentrotus lividus was resistant to PNGase F. As the liberation of N-glycans in this context has gone to near completion we do not believe that steric hindrance is an issue, in spite of the heavy $\mathrm{O}$-glycosylation. This result demonstrates that the $\mathrm{N}$-glycans within SMP are spatially removed from the O-glycosylation. This trait is common of mucin-like glycosylation.

To assess the effectiveness of the deglycosylation reaction a MSA of SMPDeGly was completed. The results of this analysis are presented in Table 6-3. Only an $\mathrm{HCl}$ digestion was used in this analysis to liberate the monosaccharides, that is, we were only interested in monitoring the quantity of the HexNAcs. It has been well established $^{[9]}$ that glycosidic bonds involving hexoses are more susceptible to acid hydrolysis. In contrast, glycosidic bonds involving HexNAcs are more resistant to 
acid hydrolysis, requiring $\mathrm{HCl}$ to digest the associated glycosidic linkages. We therefore assumed that if the majority of the HexNAcs had been removed the more facile hexoses would also have been liberated.

\begin{tabular}{|l|c|c|}
\hline \multicolumn{1}{|c|}{ Sugar } & $\begin{array}{c}\mu \mathrm{g} / 100 \mu \mathrm{g} \text { protein } \\
\text { SMP }\end{array}$ & wt\% of SMP glycone \\
\hline Glucose & $1.4 \pm 0.5$ & $88.9 \pm 66.4$ \\
\hline GalNAC & $3.8 \pm 1.4$ & $17.2 \pm 12.7$ \\
\hline
\end{tabular}

Table 6-3: Tabulation of the results obtained following monosaccharide analysis of SMPDeGly. Shown are the means \pm the standard deviation of 4 experiments. The hexoses and HexNAcs were determined from an $\mathrm{HCl}$ digestion only.

There were only two monosaccharides detected in the MSA of SMPDeGly; glucose and GalNAc. The observation that $88.9 \pm 66.4$ wt\% of the glucose persisted through the deglycosylation reaction was surprising given that all of the GlcNAc, and the majority of the GaINAc ( $82.8 \pm 12.7$ wt\%), had been successfully removed. We therefore believe that glucose was introduced through sample contamination, potentially from paper fragments in the laboratory. For this reason glucose was omitted from all MSA results presented in this thesis.

The observation of GalNAc in small quantities is consistent with a successful deglycosylation. The monosaccharide which is involved in the linking of the protein and glycan chain is reported as being more resistant to TFMS hydrolysis. ${ }^{[0]}$ For example, the deglycosylation reaction is unable to remove the core sugar (GIcNAc) of asparagine-linked N-glycans. ${ }^{[11]}$ This monosaccharide was not detected in the MSA of SMPDeGly which reflects the proportionally low levels of N-glycosylation. The most common core structure of O-glycosylation involves linkage between either serine or threonine and GalNAc. We observed 2.0 \pm 0.6 GalNAc residues per 100 amino acids for SMPDeGly. Detection of this sugar demonstrates the predominance of O-glycosylation.

\subsubsection{Malachite Green Assay}

The malachite green assay was used to monitor the phosphate content of SMPDeN-g and SMPDeGly. The decision to analyse these samples by this method was made because it was straightforward to monitor the amount of sample using 
A280 measurements. Based on this, the ratio of phosphate was more accurately determined. The results of this malachite green assay analysis are presented in Table 5-5.

\begin{tabular}{|l|c|c|}
\hline \multicolumn{1}{|c|}{ Sample } & $\begin{array}{c}\mu \mathrm{PO}_{4}{ }^{3-} / 100 \mu \mathrm{g} \\
\mathrm{SMP} \text { protein }\end{array}$ & $\begin{array}{c}\mu \mathrm{g} \mathrm{PO}{ }_{4}{ }^{3-} / 100 \mu \mathrm{g} \\
\mathrm{SMP} \text { ensemble }\end{array}$ \\
\hline SMP & $2.40 \pm 0.61$ & $1.08 \pm 0.44$ \\
\hline SMPDeN-g & $3.20 \pm 0.81$ & $1.44 \pm 0.58$ \\
\hline SMPDeGly & $3.20 \pm 0.81$ & $1.44 \pm 0.58$ \\
\hline
\end{tabular}

Table 6-4: The phosphate content of SMPDeN-g and SMPDeGly as determined using the malachite green assay. Shown are the means \pm the standard deviation of 4 experiments. SMP is included for comparison.

The phosphate content of both deglycosylation samples were identical $(1.44 \pm 0.58$ $\mu \mathrm{g} \mathrm{PO}_{4}{ }^{3-} / 100 \mu \mathrm{g}$ SMP ensemble), and within uncertainty of the phosphate content of native SMP (1.08 $\pm 0.44 \mu \mathrm{g} \mathrm{PO}{ }_{4}^{3-} / 100 \mu \mathrm{g}$ SMP ensemble). That is, removal of the glycans has not affected the mass of phosphate. We can therefore conclude that all phosphates are protein bound and SMPDeGly still bares the full phosphate complement. This result is consistent with the investigation by Karamanos et al. ${ }^{[12]}$ who observed no phosphorylation of glycans attached to SPI or SPII. This result demonstrates for the first time that the phosphate associated with the acidic OM within the spines of any sea urchin species is protein bound. Phosphoserine has been recognised as a means for incorporation of phosphate into a biomineral extract. ${ }^{[13,14]}$ In chapter 5 we demonstrated that the phosphate is predominantly associated with the SMP10-30kDa fraction (p. 138) and from the AAA (p. 135) that this fraction includes serine (5.6 $\pm 0.2 \mathrm{~mol} \%)$. This may therefore be the mechanism of phosphate incorporation into the protein backbone of SMP.

\subsubsection{SDS-PAGE}

In Figure 6-1 are scans of the silver stained SDS-PAGE gels of SMPDeN-g SMPDeGly. For SMPDeN-g (lane 2) we observe a mass reduction in comparison to SMP (lane 1) of the most profoundly stained material (at $\sim 45$ to $65 \mathrm{kDa}$ ). This result is consistent with the report of Mackenzie et al. ${ }^{[3]}$ who completed a similar analysis of SMP. We have therefore confirmed that there are $\mathrm{N}$-glycans associated with these heavier 
MW species. This result is consistent with both the MSA results (chapter 5, p. 136) which showed there are mannose residues associated with the SMP>30kDa material, and our running hypothesis that this stained feature at $\sim 40$ to $70 \mathrm{kDa}$ includes SM30 which has been shown to be $\mathrm{N}$-glycosylated. ${ }^{[15,16]}$ As protein glycosylation encodes for heterogeneity, deglycosylation often leads to SDS-PAGE band sharpening. We do not observe this following the liberation of the N-glycans. There are numerous reasons why this band sharpening may not apply in the context of SMP, for example, the protein backbone is acidic (p. 102) which leads to electrophoretic smearing. ${ }^{[17]}$

Killian et al. ${ }^{[15]}$ noted that the SDS-PAGE MW of SM30 (46 and $49 \mathrm{kDa}$ ) did not match the calculated mass of $30.6 \mathrm{kDa}$. In an attempt to determine the cause for this MW discrepancy they completed experiments to remove both $\mathrm{N}$ - and O-glycosylation. From this analysis they showed that there was $3.5 \mathrm{kDa}$ of $\mathrm{N}$ glycosylation and no O-glycosylation, leaving $~ 13 \mathrm{kDa}$ of unexplained mass. ${ }^{[15]}$ As SMP appears to include numerous macromolecules with MWs similar to SM30 we cannot verify whether there is a 3 to $4 \mathrm{kDa}$ decrease in the mass of the species within SMP following treatment with PNGase F.
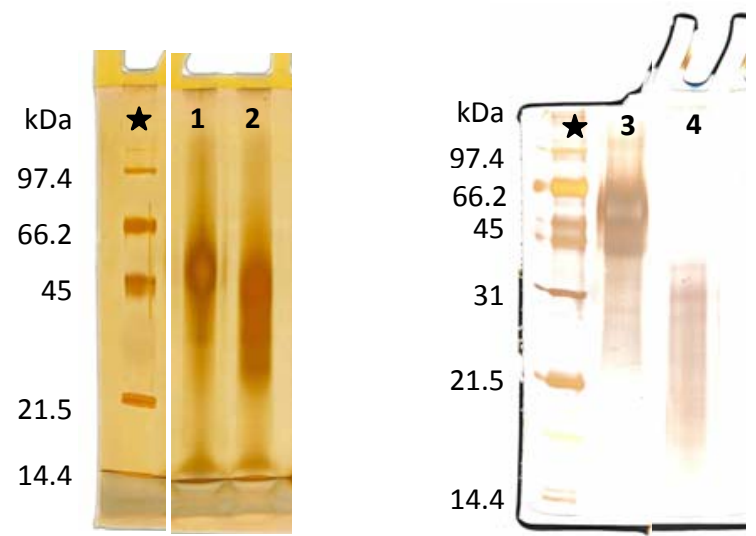

Figure 6-1: Scans of silver stained SDS-PAGE gels (12\%) of SMP (lanes 1 and 3), SMPDeN-g (lane 2), and SMPDeGly (lane 4). Relative molecular weights as determined by electrophoresis of standards are indicated (black star).

While Killian et al. ${ }^{[15]}$ had the foresight to test for glycosylation, from our analysis of SMP we believe that the unaccounted for mass is O-glycosylation. Firstly, the 
MW of SMPDeGly (lane 4) is $31 \mathrm{kDa}$, the mass of deglycosylated SM30. That is, glycosylation accounts for the additional $\sim 16.5 \mathrm{kDa}$. Killian et al. ${ }^{[15]}$ observed no Oglycosylation, which is in stark contrast to the abundance of O-glycosylation for SMP. We believe that the reason they did not observe a decrease in MW following borohydride reduction is that the concentration of base $(\mathrm{NaOH})$ used was too low (5 mM). Typical preparations use $1 \mathrm{M} \mathrm{NaOH}$ (p. 76). We determined the ratio of $\mathrm{N}$ to O-glycosylation for SMP to be 1 to 4 (p. 136). This ratio matches the ratio of $\mathrm{N}$ glycans (3.5 kDa) to unexplained mass ( $16.5 \mathrm{kDa}$ ) for SM30 as determined by Killian et al. ${ }^{[15]}$

In Figure 6-2 are scanned images of the Alcian blue $\mathrm{pH} 1$ stained gels of the deglycosylation products SMPDeN-g (lane 2) and SMPDeGly (lane 3). There is only a slight difference, a decrease in the band at $\sim 50 \mathrm{kDa}$, between the staining profiles of SMP (lane 1) and SMPDeN-g. This would appear to indicate that the Nglycans associated with these species are sulfated. Killian et al. ${ }^{[15]}$ showed that there are conserved sulfated $\mathrm{N}$-glycans across a variety of species within this $\mathrm{MW}$ range. However, the decrease in intensity may also be rationalised by the changed migration of the SMPDeN-g sample as observed on the silver stained gel irrespective of whether the $\mathrm{N}$-glycans are sulfated or not.

We observe no staining of SMPDeGly under Alcian blue stain. As the TFMS deglycosylation protocol used does not liberate sulfates bound to protein ${ }^{[11]}$ we can conclude that all of the sulfates within SMP are housed on the glycan framework. This is the first time that this has been reported for an OM extracted from any sea urchin based mineral.

Sulfation of the glycans occluded in sea urchin mineralised tissues was inferred by Albeck et al. ${ }^{[2]}$ (Paracentrotus lividus) using infrared spectroscopy and demonstrated by Karamanos et al. ${ }^{[12,18]}$ (Sphaerechinus granularis) using colorimetric assays. Sulfates have been shown to be incorporated into the OM of other biomineral systems via the carbohydrate framework. ${ }^{[1,19-21]}$ Numerous roles have been attributed to the sulfated glycans, including ion and water entrapment 
and viscosity modification. ${ }^{[22]}$ The function of this glycan sulfation was tested through the removal of sulfate (SMPDeSO) and is reported later this chapter ( $p$. 179 and 180).

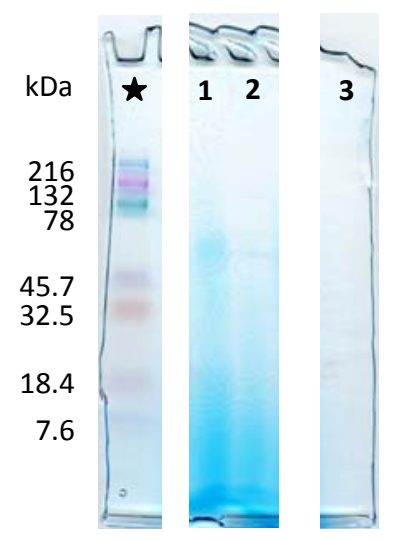

Figure 6-2: Scans of Alcian blue $(\mathrm{pH} 1)$ stained SDS-PAGE gels (10-20\%) of SMP (lane 1), SMPDeN-g (lane 2), and SMPDeGly (lane 3). Relative molecular weights as determined by electrophoresis of standards are indicated (black star).

In Figure 6-3 are the Stains-All stained SDS-PAGE gels of SMPDeN-g (lane 2) and SMPDeGly (lane 3). Following removal of the $\mathrm{N}$-glycans we observed a slight change in the staining profile at $\sim 50 \mathrm{kDa}$ in comparison to SMP (lane 1). As with the Alcian blue stained gel this may reflect the decrease in mass of the heavier MW species following the removal of the $\mathrm{N}$-glycans. Another explanation is that the calcium-binding $\mathrm{N}$-glycans shown to be associated with $\mathrm{SM} 30^{[4,15,16]}$ have been removed.

The blue-stained feature at electrophoretic MWs >30 kDa has been altered following the removal of the $\mathrm{N}$-glycans but is not removed. As there is persistent calcium-binding functionality we can conclude that the mediation of this function is not limited to N-glycosylation. This observation is consistent with Farach-Carsen et al. ${ }^{[4]}$ who showed that masking the N-glycan functionality of MSP130, through complex formation with the mAb1223 antibody, did not remove the ability to bind calcium. 


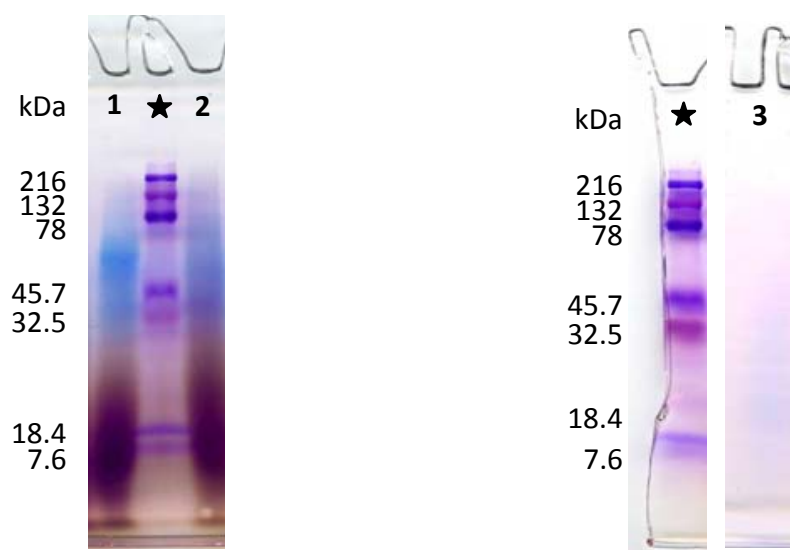

Figure 6-3: Scans of Stains-All stained SDS-PAGE gels (10-20\%) of SMP (lane 1), SMPDeN-g (lane 2), and SMPDeGly (lane 3). Relative molecular weights as determined by electrophoresis of standards are indicated (black star).

The Stains-All stained gel of SMPDeGly (Figure 6-3) shows that the brown colour has been completely removed and there remains only a faint blue colour which is consistent with the MW range revealed by the silver stain of this sample (p. 156). This result indicates that the brown colour below $30 \mathrm{kDa}$ and the majority of the calcium-binding functionality are carbohydrate encoded. This is consistent with the AAA results (p. 102) which showed that calcium-binding amino acids Asx and Glx are poorly represented in SMP.

Calcium-binding proteins appear blue under Stains-All stain. ${ }^{[23]}$ The persistence of blue colour development for SMPDeGly indicates that these phosphoproteins may bind calcium. As discussed earlier Livingston et al. ${ }^{[24]}$ reported that, based on genomic analysis, there may be calcium-binding phosphoproteins within the spines of Strongylocentrotus purpuratus. SMPDeGly includes phosphoproteins which appear to have calcium-binding ability.

\subsubsection{LINKAgE ANALYSIS}

In the MSA we determined the type and quantity that each monosaccharide contributes to the SMP glycone. A linkage analysis determines how these monomer units are joined together, that is, which sugar ring hydroxyl groups are involved in glycosidic bonding to adjacent monomers to form the glycan chain. 
Signal assignment in a linkage analysis is made based on the gas chromatograph retention time, in combination with the MS fragmentation pattern.

From this analysis we only observed one low intensity signal in the chromatogram. This signal was diagnostic of 1,4-linked HexNAcs. This result is consistent with both the HexNAc oligomers and keratan sulfate glycan structures being present within the SMP glycone. As demonstrated by the Alcian blue stained SDS-PAGE gel of SMPDeGly (p. 158) all sulfate groups within SMP are housed within the glycan framework. Due to the lack of signals in the linkage analysis we have determined that the vast majority of the SMP glycone is charged. This is the first time that it has been shown across the acidic OM extracted from any sea urchin mineralised tissue.

As discussed in chapter 2 (p. 47) the analyte preparation procedure adopted in this work involves: intact glycan release, permethylation, purification, hydrolysis into monomer units, and derivatisation for GC-MS analysis. In the purification step of the linkage analysis (following permethylation) charged species, including sulfated glycans, are discarded in the aqueous waste material. This loss of the charged glycans was limited to the glycan structural analyses, including this linkage analysis and the glycan profiling.

\subsubsection{Glycan Profiling}

In the previous section we showed that the majority of the SMP glycone is charged. As preparation of the glycans for the glycan profiling was similar to the linkage analysis the structures presented in Figure 6-4 and Figure 6-5 are for the neutral glycans only. Based on the absence of $\mathrm{N}$-glycan core structures in the Oglycan samples we can conclude that the removal of the $\mathrm{N}$-glycans went to completion. This is because the reaction conditions used to liberate the O-glycans is unselective, liberating all remaining glycosylation. This demonstration that the $\mathrm{N}$-glycans were completely removed using PNGase $\mathrm{F}$ is consistent with the results of the MSA (p. 151). Based on the observed masses of the O-glycan structures we have demonstrated that they were indeed attached to protein structures as 
opposed to being occluded as an independent polymer. This is consistent with the HPLC data which showed that the protein and glycans are covalently linked. The structures were determined from the MSMS fragmentation patterns. In the left hand column of Figure 6-4 (high hexose structures) the arrangement of the terminal hexoses (empty circles) was inferred. The observation that there are sialic acid residues attached to the glycans indicates that the method used to isolate SMP was sufficiently mild as sialic acid is particularly susceptible to acid hydrolysis. ${ }^{[7]}$ The results presented are the first structure determination for any glycan extracted from any sea urchin mineral.

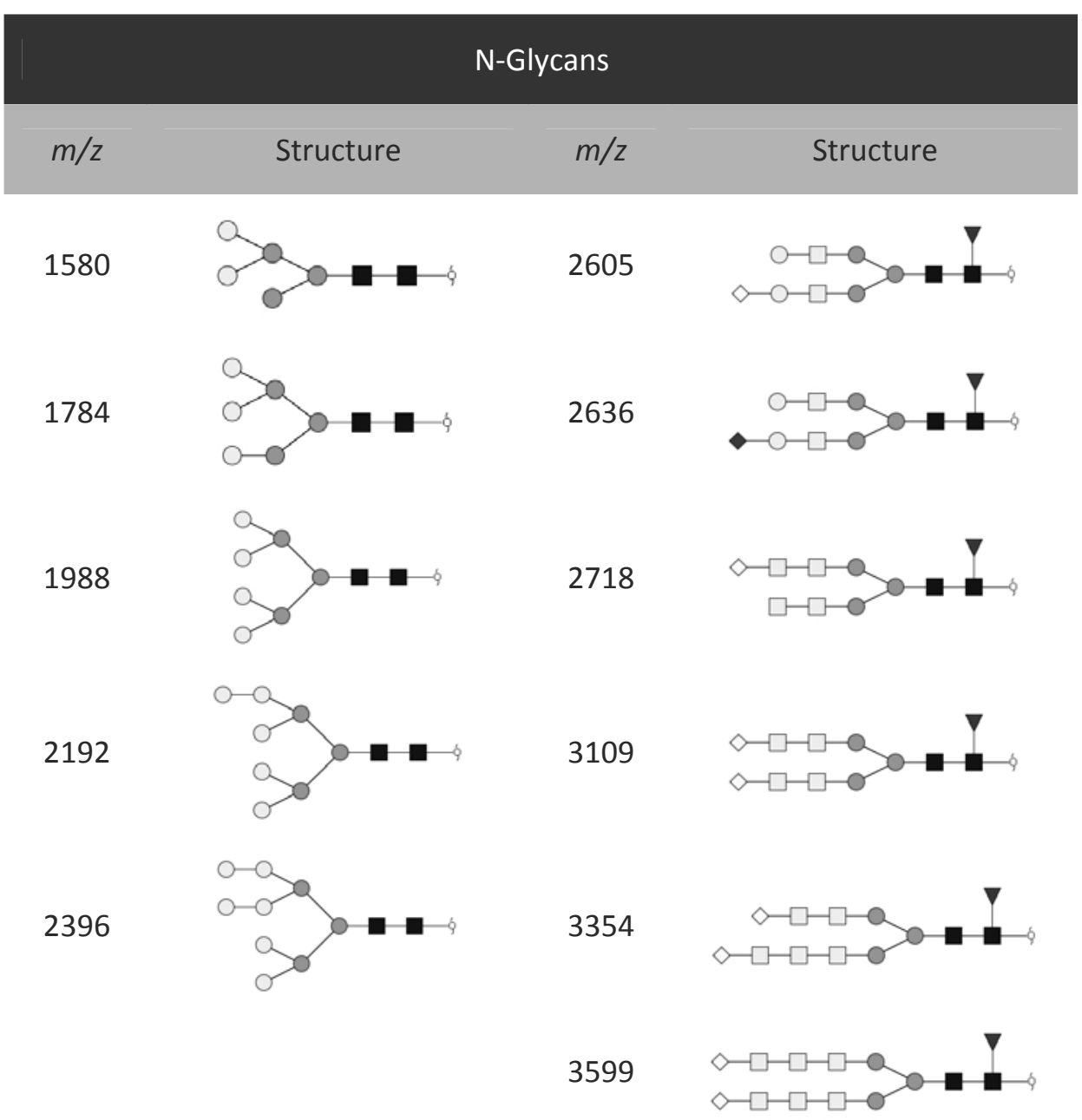

Figure 6-4: Structures of the neutral N-glycans of SMP. Light gray squares represent HexNAcs, black squares GlcNAc, circles hexoses, dark gray circles mannose, dark gray triangles fucose, light gray diamonds $\mathrm{N}$-glycolylneuraminic, and dark gray diamond $\mathrm{N}$-acetylneuraminic acid. Results were collected as part of the GlycoTRIC programme, Dell Laboratory, Imperial College of London. 


\section{O-Glycans}

\begin{tabular}{|c|c|c|c|c|}
\hline$m / z$ & Structure & $m / z$ & Structure & $m / z$ \\
\hline
\end{tabular}

575

820

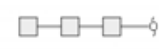

1065

믐ㅁㅇ

1310

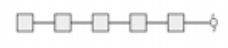

1556

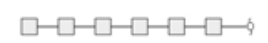

1947

1702

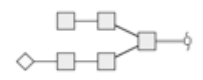

1025

779

925

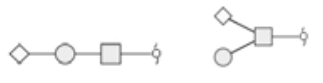

1457
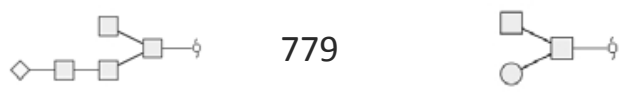

1801

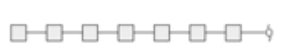

2192

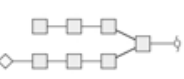

1270

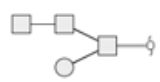

2046

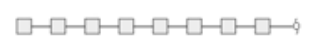

2438

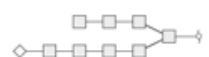

1661

1416
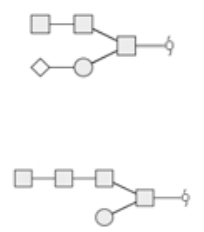

2292

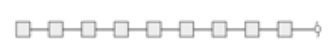

2683

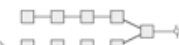

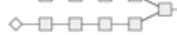

1515

2537

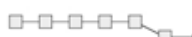

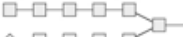

$\sim \square-\square-a-0$

1760

2782

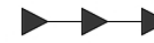

2005
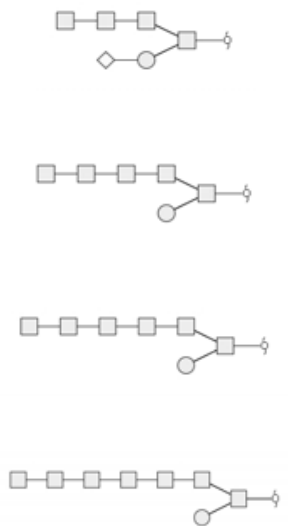

Figure 6-5: Structures of the neutral O-glycans of SMP. Squares represent HexNAcs, circles hexoses, dark gray triangles fucose, and diamonds $\mathrm{N}$-glycolylneuraminic acid. Results were collected as part of the GlycoTRIC programme, Dell Laboratory, Imperial College of London.

From this analysis we can see that there are four general structural groupings; high-hexose (Figure 6-4, left column), fucose oligomers (fucan-like) (Figure 6-5, $m / z$ 591), HexNAc oligomers (Figure 6-4 and Figure 6-5), and alternating hexoseHexNAc chains (Figure 6-4, top right). We would expect the high-hexose structures 
to be high-mannose structures as this is a prolific $\mathrm{N}$-glycan structure. These structures are presumably not the source of either in vitro crystallisation function, or the mAb1223 epitope, as they are such a common N-glycan motif.

Fucans are a class of polysaccharide involving sulfated fucose monomers. The trisaccharide found here was not reduced indicating that it was not liberated from a protein. This class of molecule has been found in marine algae and invertebrates, such as the sea urchin. Structural investigations of the fucans in sea urchin demonstrated simple structures including trisaccharide repeats. As far as we are aware this is the first time fucan oligomers have been shown to be present within mineralised tissues. Little is known about the biological role of most fucans although they have been implicated in structural applications. ${ }^{[25]}$ The observation that this glycan structure is present within SMP may account for the relatively high abundance of fucose $(11.5 \pm 2.9 \mu \mathrm{g} / 100 \mu \mathrm{g}$ protein SMP, p. 106).

In the MSA analysis of the N-glycans (p. 151) we determined that the N-glycans are $75.5 \pm 2.9$ mol\% HexNAcs and $23.8 \pm 0.8$ mol\% mannose. From this glycan profiling we observe high-mannose structures which further constrains the structural diversity of the remaining HexNAcs to HexNAc oligomers. We therefore conclude that the N-glycone is comprised of sulfated HexNAc oligomers. This addition of negative charge to these sugar species is in contrast to the chitin of molluscs.

From this glycan profile analysis we have shown that the echinoderm has adopted a chitin analogue and incorporated it into the mineral via covalent linkage to an integral protein. Chitin is incorporated in many biomineral structures as a polysaccharide. In the aragonitic layer of mollusc shells it presents as a highly ordered polymer scaffold external to the mineral. In this context the chitin facilitates mineral construction in numerous ways, ${ }^{[21,26-28]}$ for example, orientating crystal growth. ${ }^{[28,29]}$ In contrast, in the calcitic layer of the mollusc shell, such as Atrina rigida, ${ }^{[30]}$ the chitin is intracrystalline, as we have demonstrated here. While the incorporation of HexNAc structures into the calcite mineral phase is conserved there are distinct differences. For example, as we have demonstrated here the 
glycans are occluded as glycoproteins (the $\mathrm{m} / \mathrm{z}$ value indicating that they were liberated from protein, Figure 6-4 and Figure 6-5), and they are sulfated (Figure 6-2).

Ameye et al. ${ }^{[31]}$ speculated that the GlcNAc repeat N-glycans may be involved in the stabilisation of ACC as the proteins bearing this chemical functionality were preferentially located in the inner region of the spines. Testing the validity of this assertion is beyond the functional capability of our in vitro crystallisation assay. There are however numerous other potential roles. For example, HexNAc chains are particularly resistant to acid hydrolysis ${ }^{[9]}$ and the by-product of calcium carbonate formation is acid (p. 2) which leads to mineral dissolution. This functional capability may be enhanced through the incorporation of sulfation. The controlled removal of the acid by-product has not been accounted for, with Miyamoto et al. ${ }^{[32]}$ suggesting that there may be proton pumps within the protein architecture of nacrein. There was however no experimental evidence to support this. An alternative hypothesis is that the HexNAc chains are involved in the mechanical properties of the mineral, as calcite has susceptible (104) cleavage planes. ${ }^{[33]}$ Indeed, it has been shown that crystals grown in the presence of the sea urchin Paracentrotus lividus mineral extracts lead to conchoidal fracture properties in synthetic crystals. ${ }^{[34]}$ This suggestion is supported by the observation that chitin is also incorporated into the mineral phase in the prisms of mollusc shells. As these are also made of calcite they exhibit the same structural liability.

\subsubsection{Crystallisation}

The function of the N- and O-glycans, SMPDeN-g, and SMPDeGly was tested using the in vitro crystallisation assay to test the relative contribution of the glycan products to the properties of nucleation and morphology. The results of this analysis are presented in Table 5-1 and Figure 6-6. This is the first time that sea urchin derived O-glycans and completely deglycosylated protein have been used as additives in the in vitro crystallisation assay. 
The numbers of crystals grown in the presence of both sets of isolated glycans are within the bounds of the blank and significantly less than the number grown in the presence of SMP. This indicates that the isolated glycans are not able to realise the nucleating capacity of SMP. The number of crystals grown in the presence of the deglycosylated additive, SMPDeGly, is significantly lower than the blank. This indicates that the phosphoproteins inhibit crystal growth. Overall, this analysis of the protein and glycone components has demonstrated that the glycans and protein are jointly sufficient and individually insufficient. That is, no one chemical component of the SMP can produce the nucleating capability of SMP.

\begin{tabular}{|l|c|}
\hline \multicolumn{1}{|c|}{ Sample } & $\begin{array}{c}\text { Nucleation density } \\
\text { (crystals/mm }\end{array}$ \\
\hline Blank & $14 \pm 7$ \\
\hline SMP & $87 \pm 41$ \\
\hline N-glycans & $10 \pm 2$ \\
\hline O-glycans & $6 \pm 1$ \\
\hline SMPDeN-g & $45 \pm 19$ \\
\hline SMPDeGly & $1 \pm 1$ \\
\hline
\end{tabular}

Table 6-5: The number of crystals grown in the presence of the various glycan derivatives. Shown are the means \pm the standard deviation of 4 experiments for the glycan derivative samples. SMP and blank results are included for comparison.

The role of the $\mathrm{N}$-glycans in the nucleating capability is not entirely clear. The number of crystals grown in the presence of the SMPDeN-g while within the bounds of uncertainty of the number grown in the presence of SMP is lower. We can therefore only conclude that if the $\mathrm{N}$-glycans are indeed contributing to the nucleating capability of SMP then the influence is slight.

We were able to probe the role of the attached O-glycans by comparing the nucleation densities of SMPDeN-g and SMPDeGly. From the results provided in Table 5-1 we can see that there are significantly fewer crystals grown in the presence of SMPDeGly as compared to SMPDeN-g. This indicates that the proteinassociated O-glycans have a dramatic influence on the ability to induce crystal formation. As mentioned, however, the isolated O-glycans are unable to replicate this nucleating property in isolation of the protein. This observation of a species 
having the ability to nucleate when fixed, and inhibiting when liberated in solution has been observed and reported previously. ${ }^{[35]}$

The observation that neither of the isolated glycones is able to bring about an increase in the number of crystals indicates that the nucleation is not induced by individual sugar chains. This may imply that either the spatial arrangement of the chains is vital or that the protein and glycans co-operate to bring about the observed nucleation. In terms of the spatial arrangement of the glycan chains it has been stated that conformational stability of glycans probably occurs, and therefore the function can be encoded, when saccharides are bound in near vicinity to the protein core through intermolecular contacts of two or more aligned chain segments. ${ }^{[2,36]}$ Under the co-operation model the sulfated glycans induce an ionotropic effect ${ }^{[37]}$ in the vicinity of an ordered protein carboxylate domain which leads to controlled nucleation. This model also has been postulated in the context of biomineralisation. ${ }^{[38]}$

Understanding the structural aspects that lead to nucleation is complicated and beyond the experimental evidence collected here. Structural elements which have been shown to be present within the SMP assemblage and may be involved in the nucleating capacity of SMP include the acidic carboxylate, phosphate, and sulfate functionalities. In the following two sections of this chapter we assess the relative contributions of these species to effect nucleation.

In Figure 6-6 are example SEM images depicting crystals grown in the presence of the various glycosylation additives: SMPDeN-g (row A), N-glycans (row B), Oglycans (row C), and SMPDeGly (rows D and E). The morphology of the crystals grown in the presence of the SMPDeN-g (row A) are indistinguishable from those grown in the presence of SMP (p. 121). This demonstrates that the $\mathrm{N}$-glycans are not required to realise the morphological role of SMP within the confines of our in vitro assay. This result is in contrast to MacKenzie et al. ${ }^{[3]}$ who observed crystals with no discernable order grown in the presence of SMPDeN-g. 
From these experiments we observe that both liberated glycan fractions are distinctly morphologically active (rows B and C). The monosaccharide (p. 151) and glycan profile (p. 161 and 162) analyses both indicated that the $\mathrm{N}$ - and O-glycan ensembles include sulfated HexNAc sugars. In spite of these similarities their morphological activities are significantly different.

From the morphology of the crystals grown in the presence of the liberated $\mathrm{N}$ - and O-glycans (rows B and C) we have shown that neither component is able to produce crystal morphologies equivalent to those grown in the presence of SMP. This result is in contrast to MacKenzie et al. ${ }^{[3]}$ who completed an equivalent experiment using SMP N-glycans. They suggested that the morphological activity of the N-glycans was effectively similar to SMP.

The crystallisation experiments using the glycans as additives were competed at $\sim 30 \mu \mathrm{g}$ protein/mL equivalent. That is, as neither of these samples contains protein we used a concentration of sugar which was equivalent to its relative abundance in SMP. Therefore, the actual concentration of additive (sugar) in the $\mathrm{N}$-glycan and O-glycan experiments were $7.9 \pm 1.4$ and $36 \pm 1.8 \mu \mathrm{g} / \mathrm{mL}$ (MSA, Table 6-2, column 2 ), respectively. The morphological activity of the $\mathrm{N}$-glycans is remarkably pronounced given its relatively low concentration, that is, they are morphologically potent. The morphology of the crystals is also remarkably ordered. This is in contrast to the results of Albeck et al. ${ }^{[2]}$ who observed that the $\mathrm{N}$-glycans isolated from Paracentrotus lividus interacted with growing calcite in a non-specific manner. 

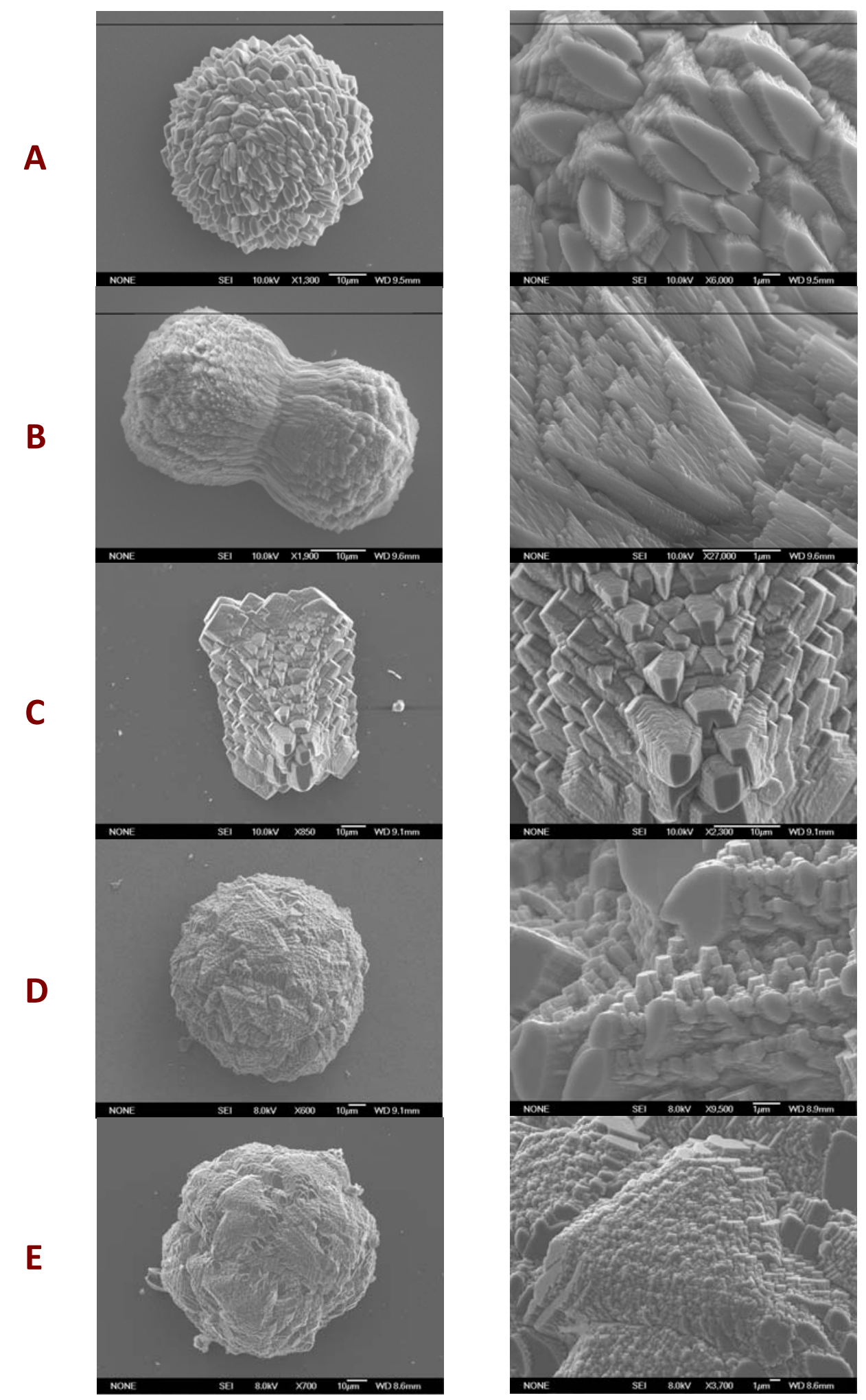

Figure 6-6: SEM images showing the morphology of $\mathrm{CaCO}_{3}$ crystals grown in the presence of SMPDeN-g (row A), N-glycans (row B), O-glycans (row C), and SMPDeGly (rows D and E).

In Figure 6-6 there are two rows of images presented to explain the deglycosylated SMP data. In row $D$ the deglycosylated phosphoprotein has the chemical capacity 
to produce crystal morphologies which are indistinguishable from those grown in the presence of SMP. This is a significant and surprising result given the abundance of sugar, which is morphologically potent, in the morphologically active SMP10$30 \mathrm{kDa}$ fraction (p. 136). To assess the relative contributions of the protein and the phosphate we treated SMPDeGly with a phosphatase and tested the morphological activity of SMP completely removed of post-translational modifications (SMPDePTM, p. 186).

These SMP-like crystals were, however, accompanied by crystals which did not resemble the morphology of SMP crystals. An SEM image depicting an example of the alternate morphology is depicted in row E. From these two results it appears that the protein holds sufficient chemical machinery to produce an influence similar to the native ensemble. However, the glycans also contribute indicating the subtle chemical construction necessary for reproducibility. The glycan chains which appear to be included within the SMP machinery, including HexNAc structures, carrageenans and/or keratan sulfate all have the ability to affect local solution properties such as viscosity or ion flux.

From this experiment it appears that the sugars, while not morphologically necessary, perform important regulatory functions such as the modulation of bicarbonate ions which results in a change in morphological activity. The scope of these functions is difficult to monitor as there are numerous functions which are outside the scope of our assay, such as the stabilisation of ACC and the control of crystal orientation. Consistent with our analysis of SMP, Marie et al. ${ }^{[1]}$ observed a change in the morphological activity of the OM extracted from the aragonitic layer of Unio pictorum following the removal of the saccharide moiety.

Another limitation of our experimental procedure is that we have removed the macromolecules from their fixed native environment. In doing so, we have potentially changed their activity. For example, we have shown that the activity of the glycans switches from nucleating to not following liberation from their fixed state attached to the protein. Glycans which are in close proximity can exert 
conformational stability on one another ${ }^{[36]}$ and may therefore present an ordered tailored template to influence crystal growth. Isolated glycans may, in contrast, be susceptible to the conformational demands of the growing crystal. ${ }^{[3]}$ It is quite a simple concept that the isolated glycans probably have modified properties as compared to their activity attached to the protein. However, this phenomenon also applies on a larger architectural scale. Crenshaw, Ristedt, ${ }^{[39]}$ and Nudelman ${ }^{[40]}$ demonstrated the intricacies of spatial arrangement in vivo with their investigations on the interlamellar matrices of the cephalopod Nautilus pompilius. Four regions were identified under a single crystal mollusc tablet. The regions they identified were: a central spot rich in carboxylates, a central ring-shaped area rich in sulfates, an area between the central nucleation region and the imprint periphery containing carboxylates, and the intertabular matrix rich in carboxylates and sulfates. So while our in vitro assay indicates that the sulfated glycans exert little influence on crystal morphology in vitro they may be a vital component of a larger in vivo architecture.

\subsection{ACI DIC GLYCOSYLATI ON}

We have established that there is a significant amount of sialic acid (ferric-orcinol assay, p. 123) in the SMP glycone. We have also shown that the abundant sulfate is exclusively glycan-based, with the vast majority of the glycone being charged. Functionally we observed that these acidic glycans are not absolutely necessary to realise the morphological activity of SMP (SMPDeGly, p. 168). However, they are completely necessary for the nucleating activity of SMP to be realised, in the context of our in vitro crystallisation assay. This observation is consistent with the literature for other biomineral systems as it has been shown that acidic glycans have the ability to induce nucleation. ${ }^{[41]}$ To test the dependence of the nucleating function on the sialic acids and sulfates we used chemical methods, based on glycobiological techniques, to selectively remove them. This included treatment of SMP with acetic acid to remove the sialic acids (SMPDeSia) and with methanolic $\mathrm{HCl}$ to remove the sulfates (SMPDeSO). To better assess the role of sulfation we prepared a series of samples, from partially desulfated through to completely 
desulfated. The samples prepared were: SMPDeSO3hr, SMPDeSO5hr, SMPDeSO7hr, and SMPDeSO9hr; where the numeral represents the time in hours that the sample was incubated in acid.

\subsubsection{AMI NO ACID ANALYSIS}

To ensure that the acid digestion had not inadvertently digested proteinaceous material we completed an AAA of the SMPDeSO9hr sample. Being the sample which was incubated for the longest time in acid it was assumed that if this sample had not undergone any proteolysis then the other desulfated samples would also be unaffected. The results of this AAA are presented in Table 6-6. From the consistency of the amino acid ratios for the methanolic $\mathrm{HCl}$ treated sample (SMPDeSO9hr) and the native SMP we have demonstrated that the desulfation reaction does not lead to significant proteolysis. The SMPDeSia sample was not analysed by this method due to limited resources.

\begin{tabular}{|l|c|c|}
\hline \multirow{2}{*}{ Amino Acid } & SMPDeSO9hr & SMP \\
\cline { 2 - 3 } & \multicolumn{2}{|c|}{ mol\% } \\
\hline Asx & $14.5 \pm 0.4$ & $13.6 \pm 0.4$ \\
\hline Serine & $5.8 \pm 0.4$ & $6.8 \pm 0.5$ \\
\hline Glx & $9.6 \pm 0.3$ & $9.4 \pm 0.3$ \\
\hline Glycine & $24.6 \pm 1.6$ & $24.8 \pm 1.5$ \\
\hline Histidine & $0.6 \pm 0.0$ & $0.8 \pm 0.1$ \\
\hline Arginine & $1.3 \pm 0.3$ & $3.0 \pm 0.7$ \\
\hline Threonine & $5.0 \pm 0.7$ & $5.3 \pm 0.8$ \\
\hline Alanine & $13.7 \pm 1.0$ & $12.5 \pm 0.9$ \\
\hline Proline & $7.0 \pm 0.7$ & $7.5 \pm 0.7$ \\
\hline Tyrosine & $2.0 \pm 0.2$ & $1.5 \pm 0.1$ \\
\hline Valine & $2.9 \pm 0.5$ & $3.2 \pm 0.5$ \\
\hline Methionine & $3.5 \pm 0.9$ & $1.7 \pm 0.5$ \\
\hline Lysine & $0.6 \pm 0.2$ & $0.6 \pm 0.2$ \\
\hline Isoleucine & $2.2 \pm 0.1$ & $2.5 \pm 0.2$ \\
\hline Leucine & $2.6 \pm 0.2$ & $2.6 \pm 0.3$ \\
\hline Phenylalanine & $4.5 \pm 0.5$ & $4.6 \pm 0.6$ \\
\hline \multicolumn{1}{|c|}{ Total } & $100.0 \pm 2.6$ & $100.0 \pm 2.5$ \\
\hline
\end{tabular}

Table 6-6: The AAA results obtained for SMPDeSO9hr. SMP is included as a comparison. Shown are the means \pm the standard deviation of 2 experiments. Asx and Glx represent aspartic acid and asparagine, and glutamic acid and glutamine, respectively. Cysteine, tryptophan, and the unusual amino acids were not tested for. These data were collected by the Australian Proteome Analysis Facility (APAF). 


\subsubsection{MONOSACCHARI DE ANALYSIS}

Monosaccharide analyses were completed on SMPDeSia and the SMPDeSO series to test whether there had been any unwanted glycan digestion as glycosyl bonds are susceptible to acid hydrolysis. We also completed analysis of SMPDeSia and the desulfated series using the ferric-orcinol assay. For SMPDeSia this was to test the efficacy of the sialic acid removal. For the desulfated series it was to assess whether sialic acid, which is particularly susceptible to acid hydrolysis, had been inadvertently removed. The results of these analyses are presented in Table 6-7 (SMPDeSia) and Table 6-8 (SMPDeSO). In these monosaccharide analyses we only completed accurate tests for the quantities of hexoses, that is, following TFA digestion. This was because the hexose glycosidic bonds are more susceptible to acid than the HexNAc glycosidic bonds. ${ }^{[9]}$ To quantify the extent of deglycosylation we compared the monosaccharide analyses for SMPDeSia and SMPDeSO to the monosaccharide profile of SMP following TFA digestion. As the TFA digestion does not liberate the full HexNAc complement we corrected these proportions by adding in the HexNAcs which are not liberated following TFA digestion of SMP, that is, the more stable $\mathrm{HCl}$ contingent.

\begin{tabular}{|c|c|c|}
\hline Sugar & $\begin{array}{c}\mu \mathrm{g} / 100 \mu \mathrm{g} \text { protein } \\
\text { SMP }\end{array}$ & $\begin{array}{l}\text { Remaining wt } \% \\
\text { compared to SMP }\end{array}$ \\
\hline Fucose & $8.1 \pm 0.7$ & $70.0 \pm 23.9$ \\
\hline Mannose & $1.1 \pm 0.2$ & $47.2 \pm 27.4$ \\
\hline Galactose & $9.7 \pm 1.2$ & $52.2 \pm 16.2$ \\
\hline GlcNAc & $5.9 \pm 0.4$ & $80.7 \pm 23.1$ \\
\hline GalNAc & $4.3 \pm 0.7$ & $77.1 \pm 18.9$ \\
\hline Total & $29.0 \pm 1.6$ & NA \\
\hline \multicolumn{3}{|c|}{ Ferric-orcinol assay } \\
\hline Sialic acid & $1.03 \pm 0.28$ & $5.0 \pm 4.0$ \\
\hline
\end{tabular}

Table 6-7: The monosaccharide distribution of SMPDeSia. Shown are the means \pm the standard deviation of 4 experiments. The hexoses and HexNAcs were quantified following TFA hydrolysis. The sialic acid content was determined using the ferric-orcinol assay. In column 2 are the masses for each monosaccharide relative to protein mass. In column 3 the mass in column 2 is compared to the mass of each monosaccharide as determined for native SMP (p. 106). 


\begin{tabular}{|l|c|c|}
\hline \multicolumn{1}{|c|}{ Sugar } & $\begin{array}{c}\mu \mathrm{g} / 100 \mu \mathrm{g} \text { protein } \\
\text { SMP }\end{array}$ & $\begin{array}{c}\text { Remaining wt\% } \\
\text { compared to SMP }\end{array}$ \\
\hline Fucose & $3.9 \pm 0.4$ & $33.6 \pm 21.5$ \\
\hline Mannose & $1.1 \pm 0.2$ & $47.9 \pm 42.0$ \\
\hline Galactose & $10.6 \pm 1.4$ & $57.5 \pm 34.9$ \\
\hline GlcNAc & $9.4 \pm 0.7$ & $88.5 \pm 25.4$ \\
\hline GalNAc & $5.4 \pm 0.9$ & $79.6 \pm 19.5$ \\
\hline \multicolumn{1}{|c|}{ Total } & $30.4 \pm 1.9$ & $\mathrm{NA}$ \\
\hline \multicolumn{3}{|c|}{ Ferric-orcinol assay } \\
\hline Sialic acid & $10.88 \pm 2.99$ & $57.3 \pm 40.2$ \\
\hline
\end{tabular}

Table 6-8: The averaged MSA results from the series of desulfated samples. Shown are the means \pm the standard deviation of 4 experiments. The hexoses and HexNAcs were quantified following TFA hydrolysis. The sialic acid content was determined using the ferric-orcinol assay. In column 2 are the masses for each monosaccharide relative to protein mass. In column 3 the mass in column 2 is compared to the mass of each monosaccharide as determined for native SMP (p. 106).

Depicted in column 3, Table 6-7 and Table 6-8, are the results of the MSA as a wt\% of each monosaccharide in SMP. Therefore, in Table 6-7 (SMPDeSia) we can see that for sialic acid (bottom row) only $5.0 \pm 4.0 \mathrm{wt} \%$ of the sialic acid content of SMP remains. That is $95.0 \pm 4.0$ wt\% has been removed. This result indicates that the sialic acid removal has been successful. For the other monosaccharides in Table 6-7 a result of $100 \mathrm{wt} \%$ would indicate that the acid digestion is selective and the full complement of that monosaccharide remains. As this is not the case we have demonstrated that the removal of the sialic acid has led to unwanted glycan loss. From the data in column 3, Table 6-7, we determined that on average only $65.4 \pm$ $23.1 \mathrm{wt} \%$ of the standard monosaccharides remain. As the glycone appears to be heavily sulfated we have presumably removed a significant amount of sulfate in the sialic acid removal.

In Table 6-8 is a similar analysis of the SMPDeSO samples. These results were averaged across all SMPDeSO incubation times. From the associated uncertainty we can see that there was no additional sugar loss with increasing incubation time. In column 3 we observe that for the sugars masses determined using MSA that a significant mass of the glycone has been removed (38.6 \pm 21.7 wt\%). In addition, we have shown that the desulfation was not selective as $42.7 \pm 40.2 \mathrm{wt} \%$ of the sialic acid has been removed. 
From these sugar analyses we have demonstrated that the two acid digestions are not selective. The hydrolysis of sialic acid has removed some sulfate and the desulfation has digested some sialic acid. Both reactions removed approximately one third of the glycone. Due to this cross-reactivity the data collected is more convoluted and therefore assertions based on structure-function relationships are less tenable.

\subsubsection{Malachite Green Assay}

From the malachite green analysis of SMPDeGly (p. 155) we demonstrated that the phosphate is directly bound to the protein. We would therefore expect that reactions leading to monosaccharide removal would not affect the phosphate levels. In Table 6-9 are the phosphate contents of the neutralised glycan samples. This analysis demonstrates that the phosphate levels for all of the treated samples are within uncertainty of SMP. These results support the conclusion that the protein has not been inadvertently digested in the glycan neutralisation reactions (AAA, SMPDeSO9hr, p. 171).

\begin{tabular}{|l|c|}
\hline \multicolumn{1}{|c|}{ Sample } & $\begin{array}{c}\mu \mathrm{g} \mathrm{PO}_{4}{ }^{3-} / 100 \mu \mathrm{g} \\
\mathrm{SMP} \text { protein }\end{array}$ \\
\hline SMP & $2.40 \pm 0.61$ \\
\hline SMPDeSia & $3.20 \pm 0.81$ \\
\hline SMPDeSO $\mathrm{hr}$ & $3.04 \pm 0.77$ \\
\hline SMPDeSO $7 \mathrm{hr}$ & $4.07 \pm 1.03$ \\
\hline SMPDeSO9hr & $3.68 \pm 0.93$ \\
\hline
\end{tabular}

Table 6-9: Phosphate content of the various glycan neutralised samples, as determined using the malachite green assay. Shown are the means \pm the standard deviation of 4 experiments. SMP is included for comparison.

\subsubsection{SDS-PAGE}

In Figure 6-7 are images of the Alcian blue $\mathrm{pH} 1$ stained gels of the various neutralised glycan samples. Using this stain we could monitor the effectiveness of the desulfation reaction. For the SMPDeSO series (lanes 3 to 6 ) the extent of sulfation decreases with increasing incubation time until the staining is negligible, indicating that the desulfation has gone to near completion. For the SMPDeSia sample we observe a slight decrease in the intensity of staining throughout the 
ensemble compared to SMP. This observation is consistent with the MSA analysis (p. 172) which showed that $34.6 \pm 23.1 \mathrm{wt} \%$ of the non-sialic acid monosaccharides are removed which are presumably sulfated (p. 159).
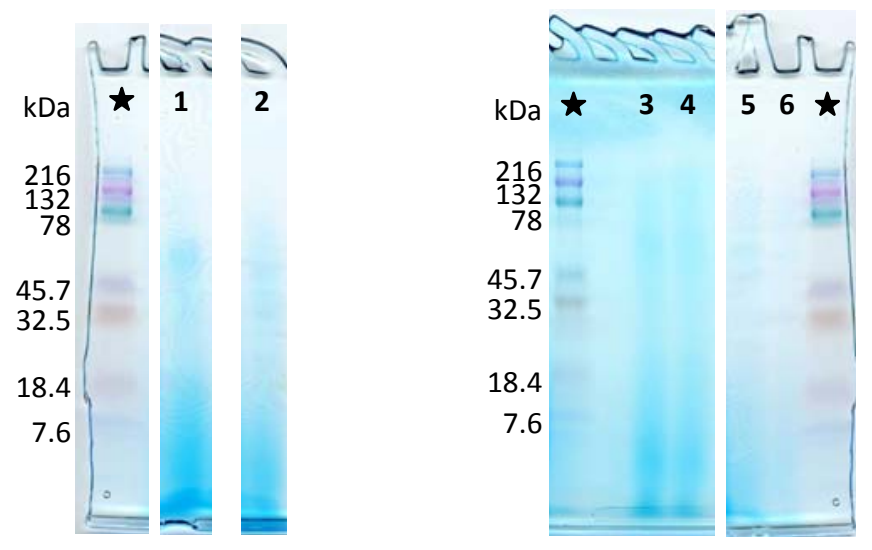

Figure 6-7: Scans of the Alcian blue ( $\mathrm{pH} 1)$ stained SDS-PAGE gels (10-20\%) of SMP (lane 1), SMPDeSia (lane 2), and SMPDeSO3, 5, 7, and 9hr (lanes 3 to 6, respectively). Relative molecular weights as determined by electrophoresis of standards are indicated (black star).

In Figure 6-8 are the silver stained SDS-PAGE gels of SMPDeSia (lane 2), SMPDeSO7hr, and SMPDeSO9hr (lanes 4 and 5, respectively). Neither of the glycan neutralisation reactions appears to have significantly hydrolysed these samples as both still stain strongly at MWs greater than $40 \mathrm{kDa}$. The SMPDeSia sample has a much broader MW staining range in comparison to SMP (lane 1) indicating an increase in susceptibility to the silver stain and/or hydrolysis by-products. For the SMPDeSO7hr and $9 \mathrm{hr}$ samples we observe an increase in the MW. This observation adds validity to our assertions in chapter 5 relating to the anomalous migration profiles of the fractionated samples (p. 140). In this argument we stated that charge can interfere with MW assignments relative to standards. Here we observe an increase in relative $\mathrm{MW}$ following the removal of negatively charged chemical functionality.

This silver stain result is very promising in terms of the overall analysis. The motivation to remove the sialic acid and sulfate groups was to test their role in the nucleating ability of SMP, as these chemical functionalities have been shown to be involved in other systems. As demonstrated in chapter 5 the nucleating activity is confined to the $>30 \mathrm{kDa} \mathrm{MW}$ species. As we have observed from the silver stained 
gels that the acidic digestions have not caused a substantial decrease in the mass of the heavier MW species we infer that the protein and sugar primary structures of these most relevant species, are still predominantly intact.

From the structural analyses including AAA, MSA, and the malachite green assay, we have shown that no other chemical moiety is affected with increased incubation time. From the Alcian blue analysis (Figure 6-7) we demonstrated that the extent of sulfation decrease across the desulfation series. We have therefore successfully synthesised a series where the only apparent variable is the degree of glycan acidity.
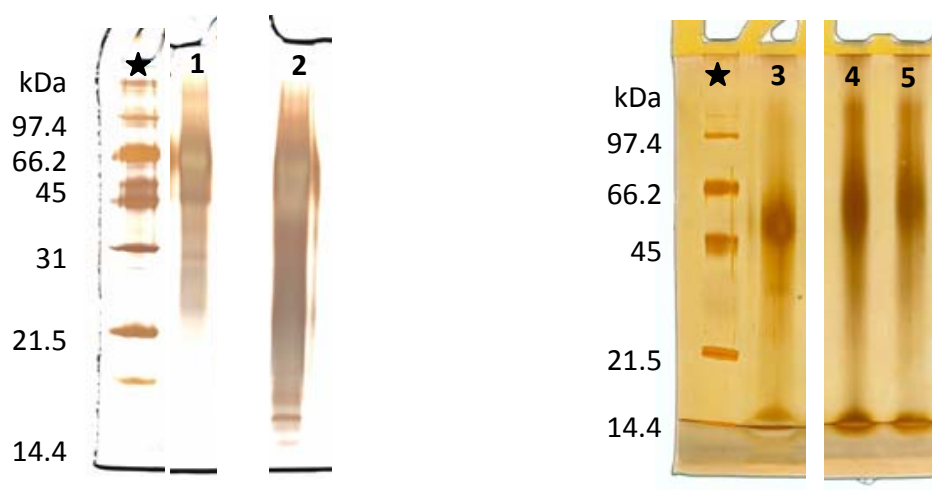

Figure 6-8: Scans of silver stain SDS-PAGE gels (12\%) of SMP (lanes 1 and 3), SMPDeSia (lane 2), SMPDeSO7hr (lane 4), and SMPDeSO9hr (lane 5). Relative molecular weights as determined by electrophoresis of standards are indicated (black star).

In Figure 6-9 are scans of the Stains-All stained SDS-PAGE gels of SMPDeSia (lane 2) and the SMPDeSO series (lanes 3 to 6 ). We see a substantial change in the colour profile for all of the glycan neutralised samples in comparison to SMP (lane 1). It is difficult to deconvolute the source of this profile staining change. This is because there has been sialic acid, sulfate, and monosaccharides removed under both acid digestion regimes. However, some conclusions can still be made.

For SMPDeSia and the SMPDeSO series we observed a decrease in the intensity of the blue staining at MWs greater than $30 \mathrm{kDa}$. A loss of calcium-binding functionality following the removal of glycan acidity has been previously observed. ${ }^{[42]}$ In addition, we observe a decrease in the intensity of the red colour 
below $30 \mathrm{kDa}$ for all samples. For the SMPDeSO series we observe that as the incubation time increases the red colour near the elution front diminishes until it is completely removed. This may indicate a direct relationship between glycan acidity and the Stains-All red colour development. We have therefore shown that the glycan based acidity is involved in the development of both colours.
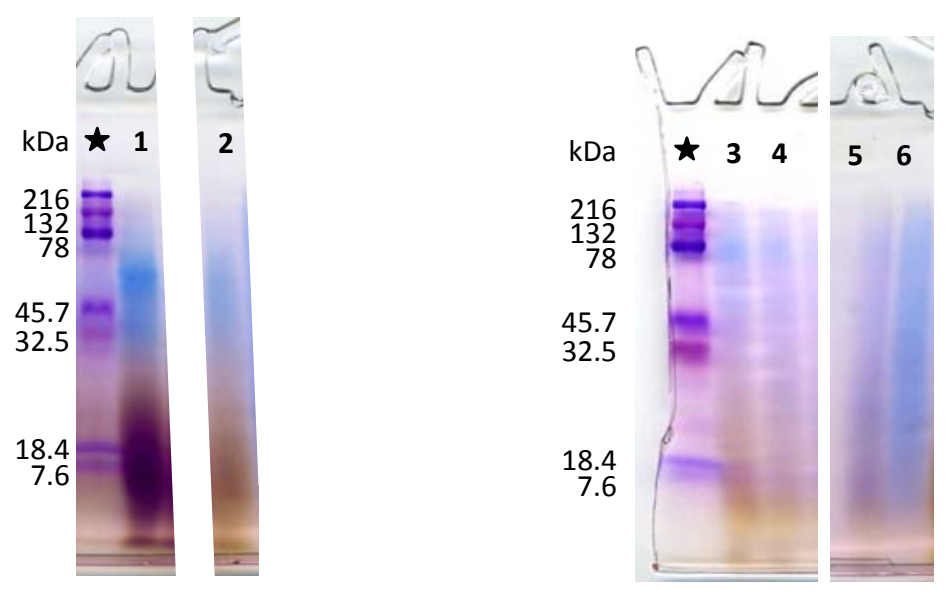

Figure 6-9: Scans of Stains-All stained SDS-PAGE gels (10-20\%) of SMP (lane 1) and SMPDeSia (lane 2), and SMPDeSO3, 5, 7, and 9hr (lanes 3 to 6, respectively). Relative molecular weights as determined by electrophoresis of standards are indicated (black star).

Following the removal of the majority of the sulfate (SMPDeSO9hr) we reveal an underlying, previously masked, blue colour throughout the MW range of the gel from below $8 \mathrm{kDa}$ to approximately $216 \mathrm{kDa}$. This blue colouration is significantly greater compared to the Stains-All profile of SMPDeGly (p. 159). We can therefore conclude that this blue colouration reflects glycan-based calcium-binding. The functional groups remaining and therefore the potential candidates include residual acidic functionality or $\mathrm{N}$-acetyl groups (HexNAcs). As the extent of blue colour does not appear to decrease across the SMPDeSO series it would appear that the glycan acidity is not the source of this calcium-binding functionality. We therefore suspect that the desulfated HexNAc oligomers are involved. Indeed it has been demonstrated in the literature that chitin substrates have the ability to bind cations. ${ }^{[43]}$ Due to limited resources we were unable to follow this potentially significant lead. 


\subsubsection{Crystallisation}

In Table 6-10 is a summary of the number of crystals grown in the presence of SMPDeSia and the desulfated samples. For SMPDeSia we observe a distinct decrease in the number of crystals grown in comparison to the nucleation density when SMP is used as an additive. It is not surprising that the nucleation density decreased following the removal of the sialic acid. Using the periodic acid-Schiff base stain (p. 114) we showed that this chemical moiety is predominantly associated with the macromolecules which induce nucleation, that is, with MWs greater than $30 \mathrm{kDa}$.

For the desulfated samples we observe that the ability to induce nucleation is only lost after a 7 hour incubation time in methanolic $\mathrm{HCl}$. Explicitly, the SMPDeSO3hr and $5 \mathrm{hr}$ samples both have nucleation densities within the bounds of the SMP sample. In contrast, the SMPDeSO7hr and $9 \mathrm{hr}$ samples both have nucleation densities which are significantly reduced in comparison to SMP and are within the bounds of the blank sample. Deconvolution of the structural significance of this result in terms of the sialic acid and sulfate functionality is not possible as neither of the chemical digestion protocols were chemically discrete. However, a dependence specifically on the acidic groups is demonstrated by the switching from nucleator to not within the SMPDeSO series where the only variable is glycan acidity.

The involvement of the glycans on the nucleation capacity was initially demonstrated by the deglycosylated sample SMPDeGly (p. 165) which is unable to facilitate nucleation. The low numbers of crystals grown in the presence of the liberated acidic glycans (p. 165), however, demonstrated that the chemical construction required to induce nucleation is greater than the acidic glycans. A structure-function relationship between acidic glycans and nucleation has been reported previously. ${ }^{[41,44,45]}$ Sulfated glycans are believed to facilitate nucleation via induction of an ionotropic effect, that is, to attract positive ions to the nucleation site. $^{[46]}$ 


\begin{tabular}{|l|c|}
\hline \multicolumn{1}{|c|}{ Sample } & $\begin{array}{c}\text { Nucleation density } \\
\text { (crystals/mm }\end{array}$ \\
\hline Blank & $14 \pm 7$ \\
\hline SMP & $87 \pm 41$ \\
\hline SMPDeSia & $14 \pm 8$ \\
\hline SMPDeSO3hr & $83 \pm 19$ \\
\hline SMPDeSO5hr & $101 \pm 8$ \\
\hline SMPDeSO7hr & $17 \pm 15$ \\
\hline SMPDeSO9hr & $15 \pm 6$ \\
\hline
\end{tabular}

Table 6-10: The nucleation density (crystals $/ \mathrm{mm}^{2}$ ) of the various SMP glycan neutralised samples. Shown are the means \pm the standard deviation of 4 experiments for the glycan neutralised samples. The blank and SMP sample results are included for comparison.

The role of the N-glycans on MSP130 has been linked to the ability to deposit the calcium carbonate spicule. ${ }^{[4,47]}$ This ability to deposit calcium has been attributed to the ability to sequester calcium ions via the acidic carbohydrate moiety mediated through either the sialic acids and/or the sulfate residues. Making the assumption that deposition in vivo translates to nucleating proficiency in vitro the results obtained here are consistent with the literature.

In Figure 6-10 are examples of SEM images of crystals grown in the presence of the various desulfation samples; SMPDeSO3, 5, 7, and 9hr. From this analysis we observed that there is no change in the crystal morphology with increasing desulfation of the glycans. This indicates that the sulfates are not necessary to realise the morphological activity of SMP. This result is consistent with the SMPDeGly results which showed that the glycans, and therefore the sulfates as they are attached to the glycans, are not necessary to reproduce the morphological effect of the complete ensemble (p. 168).

The morphology of the crystals grown in the presence of SMPDeGly varied in that some were equivalent to SMP and others were not (p. 168). We therefore believe that while the glycans are not necessary to realise the morphological affect of SMP they may be involved in morphology regulation. The crystals grown in the presence of SMPDeSO9hr were equivalent to those grown in the presence of SMP. As the chemical difference between SMPDeGly and SMPDeSO9hr includes the 
calcium-binding HexNAc glycans, these structures may be involved in this regulating function.

A

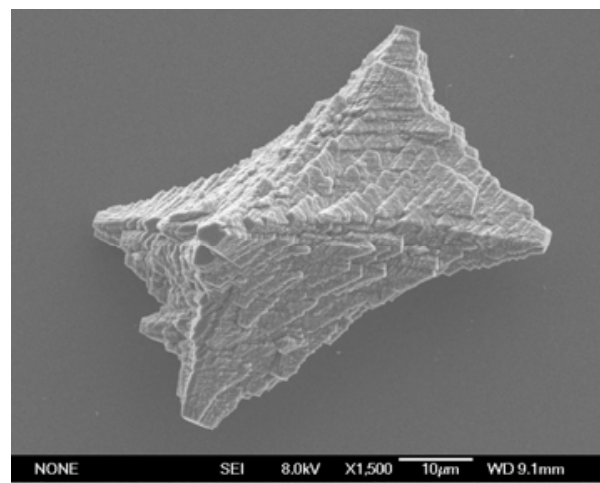

B

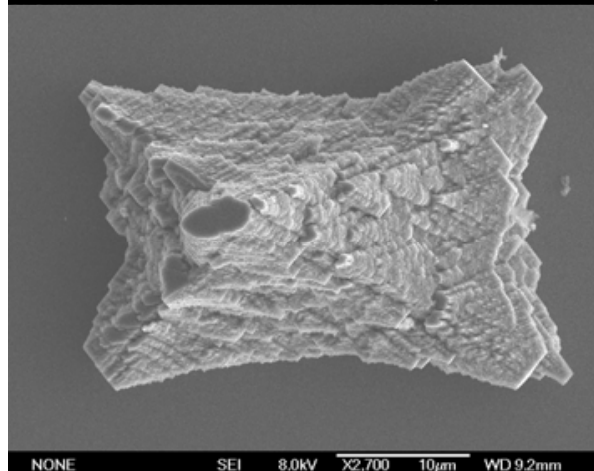

C
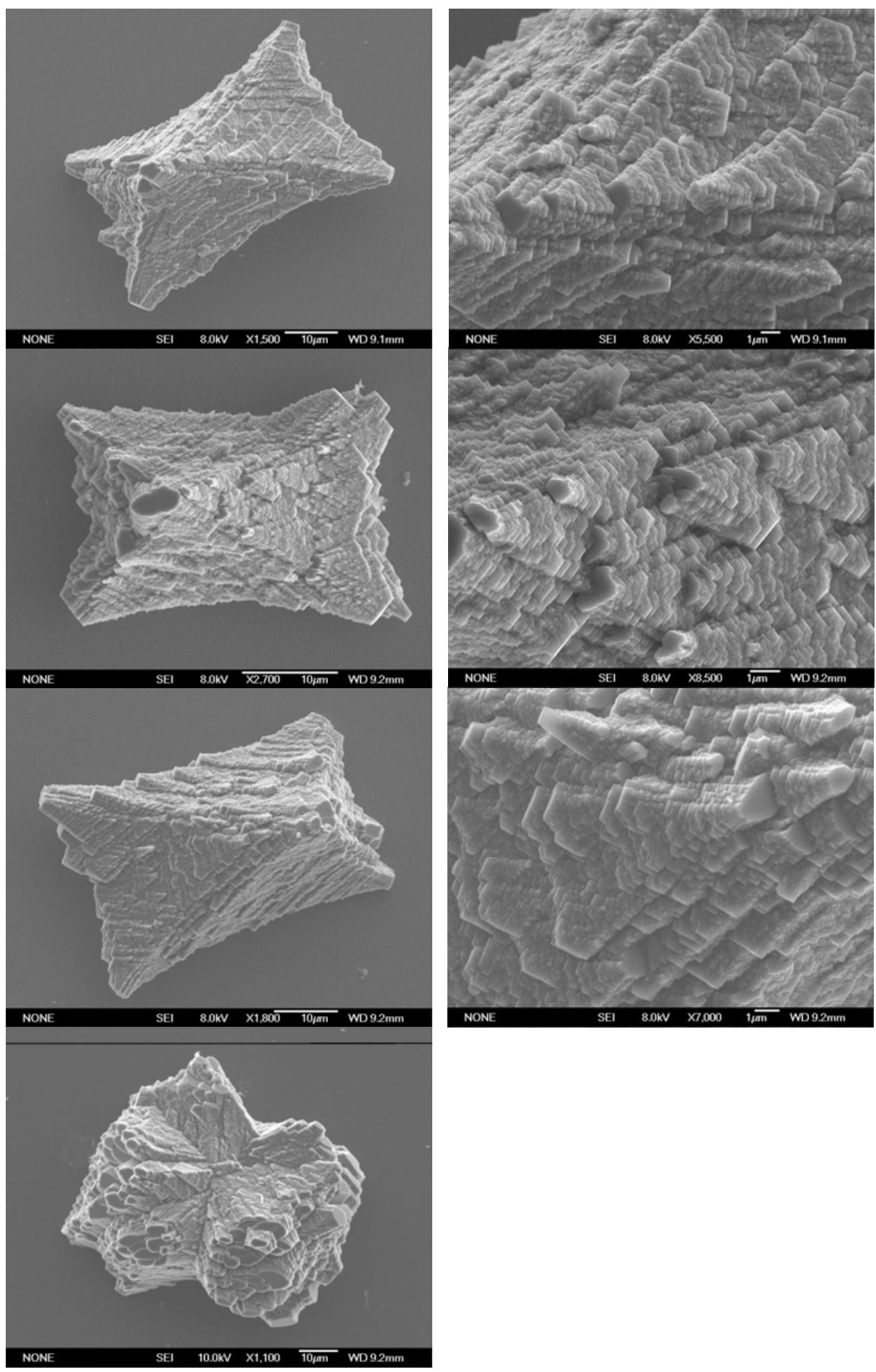

\section{NONE}

Figure 6-10 SEM images showing morphology of $\mathrm{CaCO}_{3}$ crystals grown in the presence of SMPDeSO3, 5, 7, and 9hr (rows A to D, respectively). 
The conclusion that the morphological activity of SMP is not dependent on the glycans is further substantiated by analysis of crystal morphologies produced using SMPDeSia as an additive (Figure 6-11). Following acetic acid treatment, which removed $95.0 \pm 4.0 \mathrm{wt} \%$ of the sialic acid, the calcium carbonate crystals grown are indistinguishable from those grown using SMP as an additive.
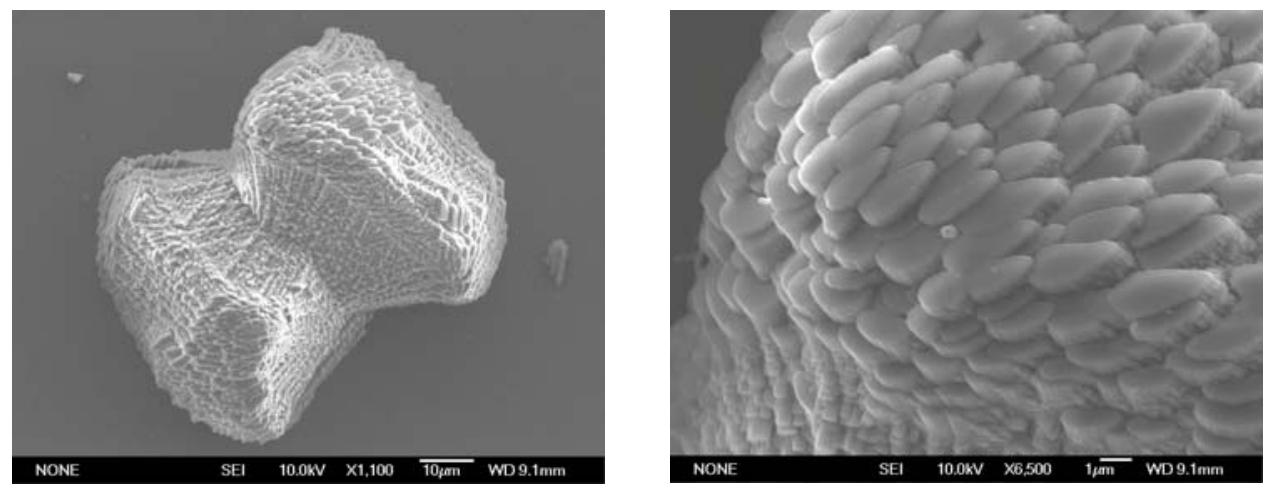

Figure 6-11: SEM images demonstrating morphology of $\mathrm{CaCO}_{3}$ crystals grown in the presence of SMPDeSia.

\subsection{Phosphate}

Phosphoproteins have been shown to be occluded in biomineral tissues. Selective removal of the phosphate can influence the ability of the macromolecule to interact with calcium carbonate. ${ }^{[13,14]}$ Using the malachite green assay on the fractionated samples (p. 138) we observed that $85 \pm 75$ wt\% of the phosphate content of SMP is located in the morphologically active fraction, SMP10-30kDa, and $10 \pm 8$ wt\% is associated with the nucleating fraction SMP>30kDa. From the malachite green analysis of SMPDeGly (p. 155) we observed that the phosphate is bound to the protein, presumably via serine residues as has been shown for other biomineral systems. ${ }^{[13,48,49]}$ To test whether the phosphate in SMP contributes to the morphological or nucleating activity we prepared two samples; SMPDePO and SMPDePTM. SMPDePO was prepared by direct incubation of SMP with the phosphatase. SMPDePTM involved treatment of SMPDeGly with a phosphatase. We were interested in removing the phosphate from the SMPDeGly sample as this species was shown to contain the complete morphological activity of SMP (p. 121) while only having two chemical types; protein and phosphate. 


\subsubsection{Malachite Green Assay}

The malachite green assay was used to assess the efficacy of the dephosphorylation reactions and purification procedure, which involved spinning the lysate across a $3 \mathrm{kDa}$ spin-filter. The results of this analysis are presented in Table 6-11.

In the first two rows of Table 6-11 are the phosphate quantities for SMP and SMPDePO (SMPDePO>3kDa). While the mass of phosphate for these two samples are within the bounds of uncertainty we believe that a significant amount of phosphate has indeed been removed from the phosphatase-treated sample. The results in the next two rows depict the phosphate content of SMPDePO<3kDa and $\mathrm{SMP}<3 \mathrm{kDa}$. If indeed no phosphate was liberated from SMP then we would expect the phosphate content of the dephosphorylation eluant for these two samples to be equivalent. However, as rows 3 and 4 demonstrate the phosphate content of SMPDePO<3kDa was significantly higher $\left(2.01 \pm 0.51 \mu \mathrm{g} \mathrm{PO}_{4}{ }^{3-} / 100 \mu \mathrm{g}\right.$ protein SMP) than $\mathrm{SMP}<3 \mathrm{kDa}$ at $0.06 \pm 0.02 \mu \mathrm{g} \mathrm{PO}{ }_{4}^{3-} / 100 \mu \mathrm{g}$ protein SMP. These results demonstrate that the dephosphorylation of SMP was partially successful. This conclusion was supported by the change in the 2D SDS-PAGE data following treatment of SMP with phosphatase (Figure 6-15, gels A and B).

\begin{tabular}{|l|c|}
\hline \multicolumn{1}{|c|}{ Sample } & $\begin{array}{c}\mu \mathrm{PO}_{4}{ }^{3-} / 100 \mu \mathrm{g} \\
\mathrm{SMP}^{\prime} \text { protein }\end{array}$ \\
\hline SMP & $2.40 \pm 0.61$ \\
\hline SMPDePO $>3 \mathrm{kDa}$ & $1.77 \pm 0.45$ \\
\hline SMPDePO $<3 \mathrm{kDa}$ & $2.01 \pm 0.51$ \\
\hline SMP<3kDa & $0.06 \pm 0.02$ \\
\hline SMPDePTM & $0.08 \pm 0.02$ \\
\hline
\end{tabular}

Table 6-11: The phosphate content of SMPDePO (SMPDePO>3kDa) and SMPDePTM as determined using the malachite green assay. Shown are the means \pm the standard deviation of 4 experiments. $\mathrm{SMP}, \mathrm{SMPDePO}<3 \mathrm{kDa}$, and $\mathrm{SMP}<3 \mathrm{kDa}$ are included for comparison.

To quantify the extent of dephosphorylation the following procedure was used. The mass of phosphate that remained attached to the protein (SMPDePO $>3 \mathrm{kDa}$ ) was divided by the mass of phosphate in the experimental system 
(SMPDePO >3kDa + SMPDePO<3kDa). We therefore conclude that $52.4 \pm 51.8 \mathrm{wt} \%$ of the phosphate was removed by enzymatic digestion of SMP.

To test the efficiency of the dephosphorylation reaction we digested the phosphoprotein casein in parallel. This digestion went to completion. We therefore suggest that the inefficiency of the digestion was due to steric constraints, presumably glycosylation. This assertion is consistent with the structural data (malachite green assay, p. 138; MSA, p. 136) which showed that the phosphate containing species (SMP10-30kDa) are also the most heavily glycosylated. We therefore suggest that there are macromolecules within the SMP ensemble which display both of these PTMs, that is, we have glycosylated phosphoproteins in SMP. This speculation is supported by the malachite green assay results for SMPDePTM (Table 6-11). We observe that when the glycosylation is present the dephosphorylation reaction only removes $52.4 \pm 51.8 \mathrm{wt} \%$ of the phosphate, however, following deglycosylation the efficacy of the dephosphorylation reaction of SMPDeGly increases to $96.7 \pm 48.3$ phosphate wt\%.

\subsubsection{SDS-PAGE}

In Figure 6-12 are scans of the SDS-PAGE gels following electrophoretic analysis of the dephosphorylation products. From the three SDS-PAGE stains; silver, Alcian blue, and Stains-All we could not observe any significant difference between the profiles of SMPDePO (lanes 2, 4, and 6) and SMP (lanes 1, 3, and 5). These results were to be expected. The silver stain most profoundly reveals species within SMP which have a MW from approximately 40 to $70 \mathrm{kDa}$. In chapter 5 we demonstrated that the proteins with MWs $>30 \mathrm{kDa}$ only present a small amount of phosphate $(0.16 \pm 0.04$ ensemble wt\%). It therefore follows that we would not expect a significant mass shift following partial dephosphorylation. Using the Alcian blue stain we observed no change, which was to be expected as we demonstrated in chapter 2 (p.44) that this stain is selective for sulfate. There are two apparent components to the Stains-All profile of SMP; a blue region above $30 \mathrm{kDa}$ and a red region below. Given that the majority of the phosphate within SMP is in the $<30 \mathrm{kDa}$ range (91 $\pm 78 \mathrm{wt} \%$ ) we would have expected that any change would be 
apparent in the red region. As we do not observe this we conclude that the red region does not reveal phosphorylation. This is consistent with the assignment of the red colour being due to the acidic glycans (p. 177).
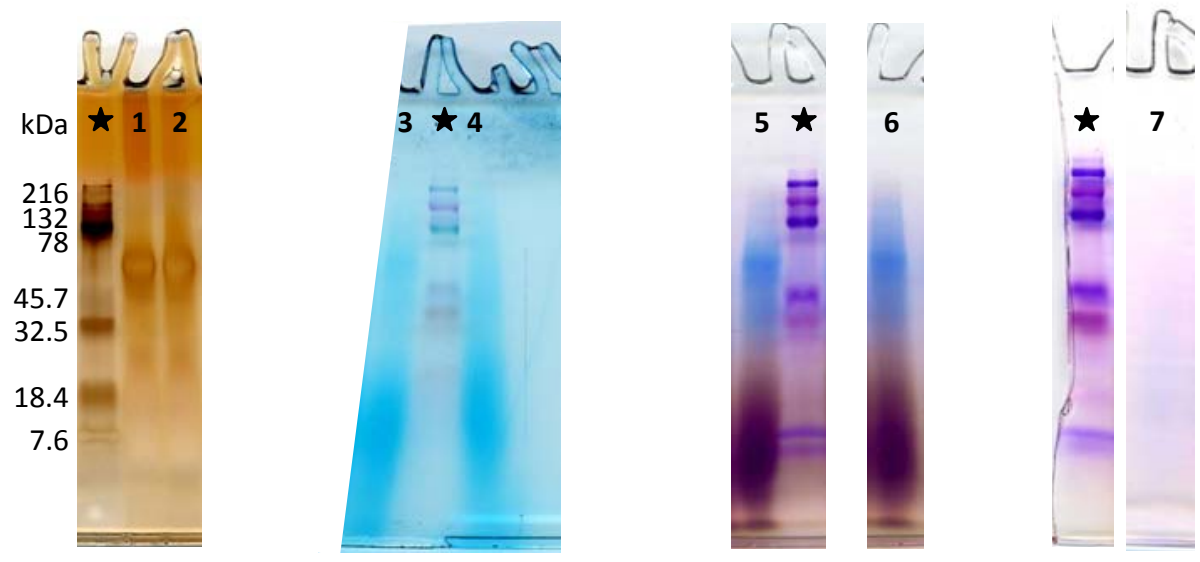

Figure 6-12: Scans of SDS-PAGE gels (10-20\%) of SMPDePO and SMPDePTM. Lanes 1 and 2: silver stained SMP and SMPDePO, respectively. Lanes 3 and 4: Alcian blue $(\mathrm{pH} 1)$ stained SMP and SMPDePO, respectively. Lanes 5 and 6: Stains-All stained SMP and SMPDePO, respectively. Lane 7: Stains-All stained SMPDePTM. Relative molecular weights as determined by electrophoresis of standards are indicated (black star) with MWs indicated on the left.

Due to the limited amount of SMPDePTM only the Stains-All dye was used to visualise this sample on SDS-PAGE (lane 7). The staining profile, while faint, appears to be similar to that of SMPDeGly (p. 159). This result indicates that the blue staining observed for SMPDeGly is not of phosphate origin. We therefore conclude that the calcium-binding activity of SMPDeGly and SMPDePTM is mediated by the acidic amino acids. So while aspartic and glutamic acid are poorly represented in the sea urchin system, as stated by Addadi et al., ${ }^{[50]}$ they do have the ability to bind calcium.

\subsubsection{CRYSTALLISATI ON}

The nucleation densities using the dephosphorylation products (SMPDePO and SMPDePTM) as additives are presented in Table 6-12. The nucleation densities of SMP and SMPDePO are within uncertainty indicating that the phosphatase accessible phosphates do not have a role in the nucleation functionality of SMP in vitro. This result is not surprising given the low abundance of phosphate in the SMP $>30 k D a$ sample $(0.16 \pm 0.04$ ensemble wt\%). There was, however, the 
possibility that phosphate was involved in this functionality as published by Samata et al. ${ }^{[14]}$ The nucleation densities of SMPDeGly ( $1 \pm 1$ crystals $/ \mathrm{mm}^{2}$, p. 165) and SMPDePTM ( $2 \pm 1$ crystals/mm², Table 6-12) also support the conclusion that the phosphates are not involved in the nucleating function of SMP. The only chemical difference between these two samples is that SMPDeGly still exhibits the full phosphate contingent.

\begin{tabular}{|l|c|}
\hline \multicolumn{1}{|c|}{ Sample } & $\begin{array}{c}\text { Nucleation density } \\
\text { (crystals } / \mathrm{mm}^{2} \text { ) }\end{array}$ \\
\hline Blank & $14 \pm 7$ \\
\hline SMP & $87 \pm 41$ \\
\hline SMPDePO & $79 \pm 5$ \\
\hline SMPDePTM & $2 \pm 1$ \\
\hline
\end{tabular}

Table 6-12: The nucleation density (crystals $/ \mathrm{mm}^{2}$ ) of the dephosphorylated samples SMPDePO and SMPDePTM. Shown are the means \pm the standard deviation of 4 experiments for the dephosphorylated samples. SMP and blank results are included for comparison.

In Figure 6-13 are example SEM images demonstrating the morphology of crystals grown in the presence of SMPDePO (row A), SMPDePTM (row C), and SMP (rows B and D) for comparison. Using SMPDePO as an additive resulted in crystals which closely resembled those grown in the presence of native SMP (row B). This would imply that the phosphatase accessible phosphates do not influence crystal morphology in vitro. This result demonstrates that the role of these phosphates is beyond the scope of in vitro crystallisation assay as they do not affect either of the crystallisation variables. Potential roles therefore include, for example, crystal orientation and polymorph selection. 

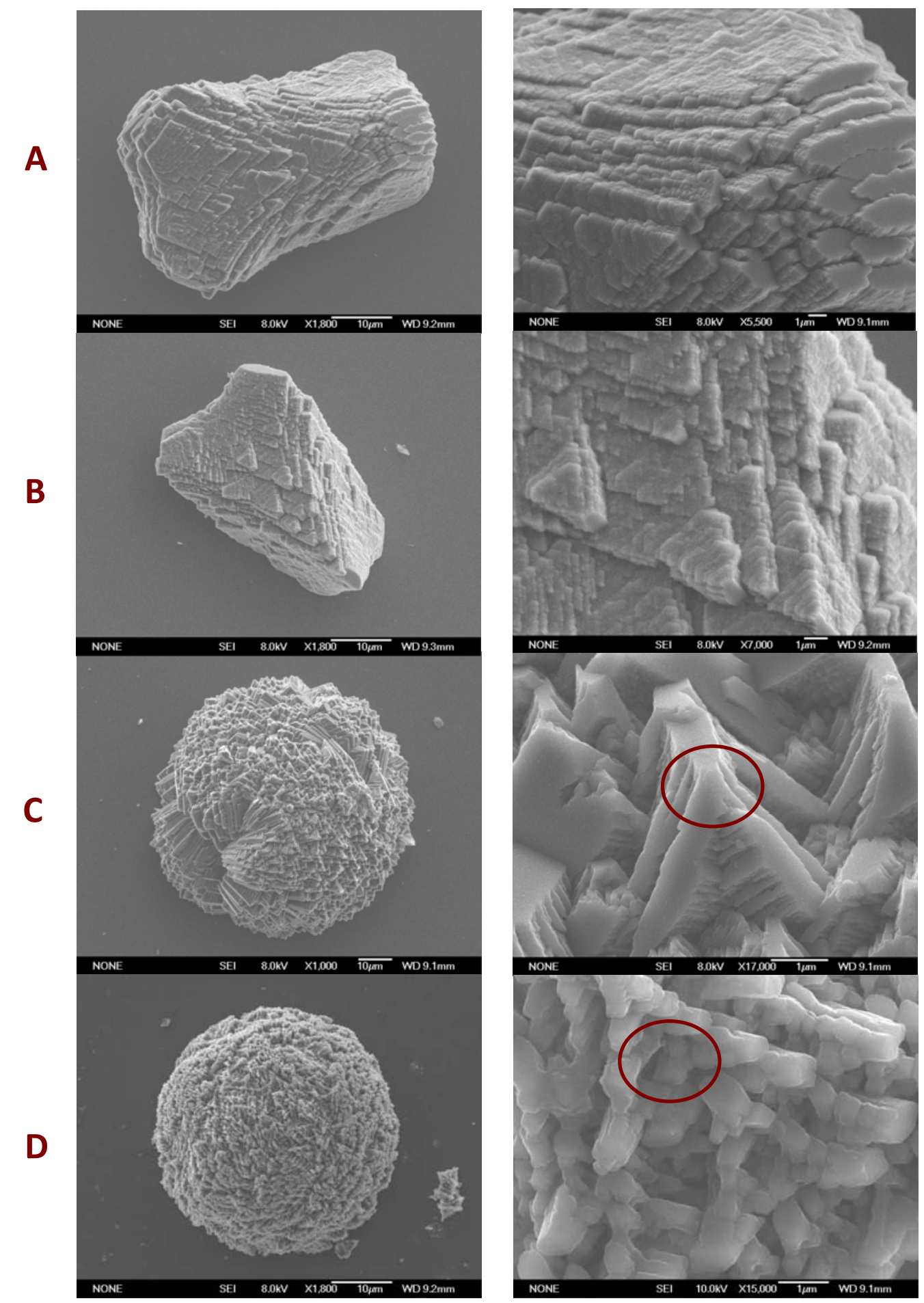

Figure 6-13: $\mathrm{SEM}$ images showing the morphology of $\mathrm{CaCO}_{3}$ crystals grown in the presence of SMPDePO (row A) and SMPDePTM (row C). The morphology of crystals grown in the presence of $S M P$ is included for comparison (rows $B$ and $D$ ).

The crystals grown in the presence of SMPDePTM (row C) show a distinct change in the morphological activity as compared to SMP (row D) and therefore also 
SMPDeGly (p. 168). The change in activity, which cannot be explicitly characterised as we are unable to identify a crystallographic axis, is highlighted in Figure 6-13 with red circles (rows $C$ and $D$ ). From this analysis we have demonstrated that the phosphates, which are rendered phosphatase accessible following the removal of the glycans, fulfill a specific morphological role in SMP.

Phosphate-mediated morphological activity has been reported previously. For example, phosphonate has been shown to have an inhibitory effect on calcite growth as a small molecule ${ }^{[51]}$ and phosphate is a common functional component of $\mathrm{CaCO}_{3}$ inhibitors. ${ }^{[49]}$ The mechanism of interaction through phosphate with the growing crystal remains, however, unknown. ${ }^{[13]}$

From this analysis we have demonstrated that the morphologically active species are phosphorylated. This chemical modification is probably in close proximity of glycosylation as the morphologically active phosphate is sterically sheltered from phosphate. This spatial arrangement of these PTMs would suggest that their functional objectives are co-aligned. One of the unexplained phenomena of biomineralisation is how the organism removes the acidic by-product of the calcium carbonate precipitation reaction (p. 2) away from the site of precipitation. In the work by Miyamoto et al. ${ }^{[32]}$ they speculated that there may be proton pumps within the organic architecture, which have as yet, not been found. Here we proffer that the glycosylation which surrounds the phosphorylated morphological active site may regulate ion flux including, for example, dissipation of the acid by-product. Livingston et al. ${ }^{[24]}$ speculated that there are calciumbinding phosphoproteins within the mineralised tissues of sea urchin. We therefore speculate that these calcium-binding phosphoproteins may be glycosylated and morphologically active within the SMP ensemble.

The morphological activity of SMP which has been treated to remove all PTMs detected (SMPDePTM) still has the chemical functionality to significantly affect the morphology of crystals grown in vitro. As far as we are aware the only chemical structures within SMPDePTM are amino acids. We therefore conclude that the 
acidic amino acids within the peptide backbone are also directly involved in the morphological activity of SMP.

From this in vitro assay we observed that the partial dephosphorylation had no observable affect on activity whereas complete dephosphorylation had a much more pronounced effect. This same relationship has been observed by Borbas et al. $^{[13]}$ who showed that there was a correlation between the degree of phosphorylation and the in vitro function.

It was interesting to note that the morphology of the crystals grown in the presence of SMPDePTM (Figure 6-13, row C) closely match the morphology of the crystals grown in the presence of the soluble OM extracted from the nacreous layer of Haliotis iris (Figure 6-14). Characterisation of the molluscan PTMs showed that these macromolecules are only negligibly post-translationally modified. We have therefore shown that the protein portion of SMP, removed of extensive posttranslational modification, influences crystal morphology in a similar fashion to this protein-based molluscan extract. This result was similar to that of Albeck et al. ${ }^{[2,52]}$ who showed that the organic matrices extracted from the mollusc Atrina rigida and sea urchin Paracentrotus lividus interacted with the same calcite faces following deglycosylation.
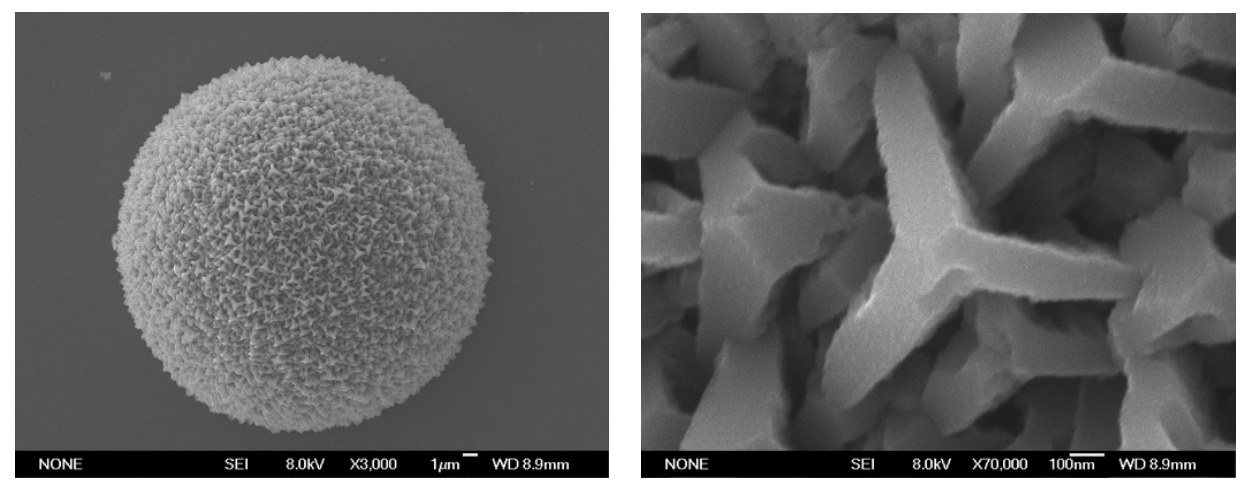

Figure 6-14: SEM images of calcium carbonate crystals grown in the presence of the soluble OM extracted from the nacreous layer of Haliotis iris. These images were kindly provided by Catherine Davis. 


\subsection{D SDS-PAGE Of SPECI fic Digesti ON PRODUCTS}

In chapter 4 (p. 118) we analysed SMP using 2D electrophoresis under a variety of stains. To better appreciate the relationship between PTM and pl we completed 2D electrophoresis on a few of the digested species investigated in this chapter including; SMPDePO, SMPDeSO, and SMPDeGly. The results of this analysis are presented in Figure 6-15.

From a comparison of gels A (SMP) and C (SMPDePO) we observe that the only change following dephosphorylation is that the dark brown spots have shifted to more neutral pl values, as indicated by the blue rectangles. This result indicates that these species are phosphorylated, and that the phosphate residues influence the $\mathrm{pl}$ of these macromolecules. The other spots on gels $\mathrm{A}$ and $\mathrm{C}$ (orange polygons) have not moved indicating that if they are phosphorylated it is not phosphatase accessible. In gel D (SMPDeGly) the spots in the blue rectangle have not shifted in comparison to SMP indicating that they are not glycosylated. This observation demonstrates that the phosphates removed following incubation of SMP with phosphatase (SMPDePO, gel B) were not glycosylated.

In chapter 4 we suggested that the spot indicated by the red arrow (gel A) includes the SM30 isoforms. This assignment was based on the MW ( 50 kDa), the pl ( 4.0), and the Alcian blue and Stains-All stained 2D gels (p. 118) demonstrating that it is sulfated and can bind calcium. As SM30 is not phosphorylated the observation that this spot was unaffected by the phosphatase digestion is consistent with this assignment. 

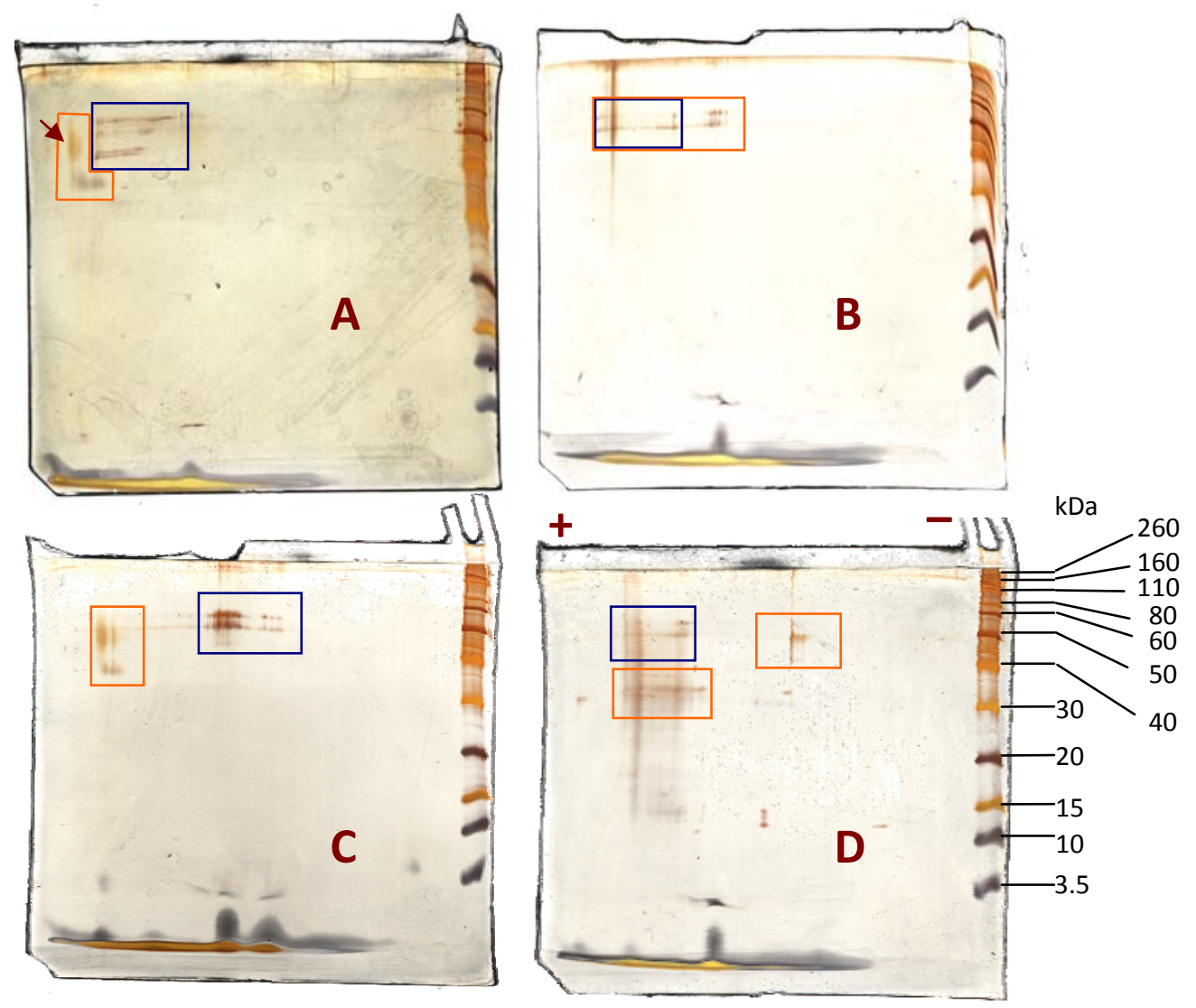

Figure 6-15: Scanned images of silver stained 2D SDS-PAGE gels of SMP (gel A), SMPDeSO (gel B), SMPDePO (gel C), and SMPDeGly (gel D). The first dimension was a non-equilibrium gradient gel using Immobiline with a $\mathrm{pH}$ range of 3 to 10 . The second dimension was a SDS-PAGE gel (12\%). Molecular weights $(\mathrm{kDa})$ were determined relative to $\mathrm{MW}$ standards as indicated on gel $\mathrm{D}$. The direction of the applied electric field is represented by the charge symbols above gel $\mathrm{D}$. The boxed features are discussed in the text.

The features marked by the orange polygon in gel A (SMP) are no longer apparent following desulfation (gel B) indicating that they are sulfated. This conclusion is consistent with the observation that the spot indicated by the red arrow (gel A) stained under Alcian blue at $\mathrm{pH} 1$ (p. 118). In contrast, the phosphorylated species in the blue rectangle in gel A have not moved on desulfation (gel B). This indicates that these species are not sulfated.

The macromolecules which are within the orange polygon in gel A move towards neutrality following desulfation and are within the orange rectangle in gel $\mathrm{B}$. This assignment was based on two observations. Firstly, in the 1D silver stained gel of SMPDeSO we observed an increase in the relative MW upon desulfation. Secondly, 
the phenomenon of sulfated glycans having a dramatic affect on pl has been reported previously by Marie et al. ${ }^{[1,21]}$

The spots within the orange polygon in gel A (SMP) represent macromolecules which are sulfated. As we determined that the sulfate within SMP is glycan-based (p. 158), we can conclude that these species must also be glycosylated. We would therefore expect them to have moved in the 2D SDS-PAGE gel of SMPDeGly (gel D). We believe that the species marked by the orange polygon in gel $\mathrm{A}$ are within the orange rectangle in gel $D$. The rationale for this is as follows. In gel B we observed that the removal of sulfate resulted in $\mathrm{pl}$ shift toward neutrality and therefore if the glycans were removed so was the sulfate. In the 1D gel of SMPDeGly we observed a reduction in mass to $\sim 31 \mathrm{kDa}$. Based on this $\mathrm{pl}$ and MW data we encapsulated the spots which include the deglycosylated desulfated species. This result indicates that the SM30 isoforms are within the spines of Evechinus chloroticus as it has been shown that the pl of SM30 without PTM is 5.94. ${ }^{[53]}$

From this analysis we have demonstrated that the post-translational modification architectures, including phosphorylation and sulfation, have a dramatic affect on the $\mathrm{pl}$ of the SMP macromolecules. The phenomenon of sulfated glycans having a dramatic affect on $\mathrm{pl}$ has been reported previously by Marie et al. ${ }^{[1,21]}$ who analysed the OM occluded within the aragonitic layer of Unio pictorum. Another similarity between SMP and their OM was that they both display relatively low levels of acidic amino acids, as demonstrated by AAA. We have therefore shown that this encoding of acidity via the glycan framework occurs across species. In addition, it is worth noting that the OM analysed by Marie et al. was sourced from aragonite whereas SMP was extracted from calcite. This therefore demonstrates that the incorporation of acidity via the glycan framework is not exclusive to aragonite minerals. 


\subsection{Chapter Si X: Selecti Ve Digesti on Summary}

There is a $\sim 13 \mathrm{kDa}$ difference between the accounted for MW and the SDS-PAGE MW of SM30. ${ }^{[15]}$ From our analysis of SMP we believe that O-glycosylation accounts for this discrepancy. Analysis of deglycosylated SMP showed that the heaviest species has a MW of $31 \mathrm{kDa}$, the predicted mass of SM30 based on genomic data. Glycosylation therefore accounts for $\sim 16 \mathrm{kDa}$ of mass. Killian et al. showed that $\mathrm{N}$-glycosylation accounts for 3 to $4 \mathrm{kDa}$ of this. Therefore $\mathrm{O}$ glycosylation accounts for the remaining mass. In their report Killian et al. tested for O-glycosylation, however, the method they used to liberate the O-glycans was too mild at $5 \mathrm{mM} \mathrm{NaOH}$. Our argument that the remaining $13 \mathrm{kDa}$ involves $\mathrm{O}$ glycosylation is further supported by the MSA of the SMP glycosylation samples which showed that the ratio of $\mathrm{N}$ - to O-glycosylation is approximately one to four.

From linkage analysis of the glycans we found that there are 1,4-linked HexNAcs within the SMP glycone. This result is consistent with both the HexNAc and keratan sulfate glycan structures. The presence of HexNAc N- and O-glycans within SMP was confirmed using glycan profiling techniques. From the relative abundance of the various monosaccharides we inferred that there are mucin-like, keratan sulfate, and/or carrageenan structures within the SMP glycone.

Direct treatment of SMP with PNGase F successfully liberated the N-glycone, as demonstrated by the MSA and glycan profile analysis of the isolated $\mathrm{N}$ - and $\mathrm{O}$-glycans. The efficiency of this digestion suggests that the $\mathrm{N}$ - and O-glycans are spatially removed which is typical of mucin-like glycosylation. ${ }^{[6]}$ We also observed that the ratio of protein to sugar was one to one, and $\mathrm{N}$ - to O-glycosylation was approximately one to four. Both of these ratios also indicate the presence of macromolecules such as mucins and proteoglycans.

From the limited diversity of the MSA the N-glycan structures are limited to high mannose and HexNAc oligomers. In the literature it has been reported that there are conserved $\mathrm{N}$-glycan based epitopes within a variety of species within the spicules of Strongylocentrotus purpuratus. ${ }^{[16]}$ We therefore suggest that the 
structure of these epitopes include HexNAc recognition as the high mannose Nglycans are prolific. The sialic acid content of these N-glycans was, however, not determined.

Using SDS-PAGE analysis we have shown that the sulfates are glycan based and from colorimetric methods the phosphate is protein based. These results were confirmed by 2D SDS-PAGE analysis, which also showed that these PTMs have a significant effect on the $\mathrm{pl}$ of the macromolecules. From the linkage analysis and glycan profiling experiments we also showed that the majority of the SMP glycone is charged.

From crystallisation experiments using the SMPDeN-g we showed that the $\mathrm{N}$-glycans are not required for either the morphological or nucleating functions in vitro. We did observe, however, that the isolated $\mathrm{N}$-glycans are morphologically potent which may demonstrate that they serve an important role in vivo.

From analysis of various digestion products we have demonstrated that the molecular architecture required to bring about the nucleating function within the SMP ensemble is complex. We have shown that the glycans and protein are jointly sufficient to bring about the nucleating capacity of SMP. In addition, removal of the glycan acidity leads to a significant decrease in the nucleation density. This glycan neutralisation did not, however, have any affect on the morphology of crystals grown in the presence of SMP. This was not surprising as we have demonstrated that the deglycosylated protein in and of itself is able to generate crystals which are indistinguishable to those grown in the presence of SMP. Given this, it was also shown that there were many crystals grown in the presence of SMPDeGly which did not match the morphology of those grown in the presence of SMP. We therefore conclude that, while the glycans are not necessary, they perform a regulatory role to increase crystal morphology standardisation.

Based on the various chemical analyses conducted we believe that there are active glycan architectures within the SMP ensemble. These include: HexNAc oligomers, mucin-like, keratan sulfate, and/or carrageenan structures. These types of 
oligomers have the ability to affect solution characteristics, such as viscosity and ion transport including relevant ions such as protons and bicarbonate ions. Here we proffer that the glycosylation which surrounds the phosphorylated morphological active site may regulate ion flux including, for example, dissipation of the acid by-product. In this work we have also demonstrated that there are glycans, presumably HexNAc oligomers, which have the ability to bind calcium. This has not been demonstrated previously in the context of biomineralisation and is significant.

We have identified that the phosphate moiety contributes to the morphological activity of SMP. Not all phosphates are involved, however, only those rendered accessible following SMP deglycosylation. We therefore believe that the morphologically active species may be the secreted calcium-binding phosphoproteins, found from genomic analysis of Strongylocentrotus purpuratus. ${ }^{[24]}$

Comparison of the morphology of crystals grown in the presence of SMPDePTM and the proteins extracted from the nacreous layer of Haliotis iris demonstrated that these samples influence crystal morphology in a similar fashion. This result appears to indicate that the protein portions of these two extracts are similar. 


\subsection{References}

[1] B. Marie, G. Luquet, J. P. P. De Barros, N. Guichard, S. Morel, G. Alcaraz, L. Bollache, F. Marin, Febs Journal 2007, 274, 2933.

[2] S. Albeck, S. Weiner, L. Addadi, Chemistry--A European Journal 1996, 2, 278.

[3] C. R. MacKenzie, S. M. Wilbanks, K. M. McGrath, Journal of Materials Chemistry 2004, 14, 1238.

[4] M. C. Farachcarson, D. D. Carson, J. L. Collier, W. J. Lennarz, H. R. Park, G. C. Wright, Journal of Cell Biology 1989, 109, 1289.

[5] J. F. Forstner, G. G. Forstner, Physiology of the Gastrointestinal Tract, 3rd ed., Raven, New York, 1994.

[6] G. J. Strous, J. Dekker, Crit Rev Biochem Mol Biol 1992, 27, 57.

[7] M. Fukuda, ed;, A. Kobata, ed, Glycobiology : a practical approach, Oxford University Press, Oxford, 1993.

[8] W. J. H. Lennarz, G. W., Methods in Enzymology 1994, 230.

[9] H. Takemoto, S. Hase, T. Ikenaka, Analytical Biochemistry 1985, 145, 245.

[10] A. S. B. Edge, C. R. Faltynek, L. Hof, L. E. Reichert, P. Weber, Analytical Biochemistry 1981, 118, 131.

[11] A. S. B. Edge, Biochem. J. 2003, 376, 339.

[12] N. K. Karamanos, A. Manouras, S. Anagnostides, E. Makatsori, T. Tsegenidis, C. A. Antonopoulos, Biochimie 1996, 78, 171.

[13] A. P. W. Jill E. Borbas, C. Steven Sikes,, Journal of Experimental Zoology 1991, 258, 1.

[14] T. Samata, D. Ikeda, A. Kajikawa, H. Sato, C. Nogawa, D. Yamada, R. Yamazaki, T. Akiyama, Febs Journal 2008, 275, 2977.

[15] C. E. Killian, F. H. Wilt, J. Biol. Chem. 1996, 271, 9150.

[16] Martin F. Brown, Jacqueline S. Partin, Christopher E. Killian, William J. Lennarz, Development Growth \& Differentiation 1995, 37, 69.

[17] B.-A. Gotliv, L. Addadi, S. Weiner, Chembiochem : a European journal of chemical biology 2003, 4, 522. 
[18] A. Manouras, N. K. Karamanos, T. Tsegenidis, C. A. Antonopoulos, Comparative Biochemistry and Physiology, Part B: Biochemistry \& Molecular Biology 1991, 99B, 119.

[19] Ravindra.Mh, Ravindra.Mh, Acta Histochemica 1974, 48, 26.

[20] K. Simkiss, Comparative Biochemistry and Physiology 1965, 16, 427.

[21] B. Marie, G. Luquet, L. Bedouet, C. Milet, N. Guichard, D. Medakovic, F. Marin, Chembiochem 2008, 9, 2515.

[22] F. Marin, P. Corstjens, B. de Gaulejac, E. de Vrind-De Jong, P. Westbroek, J Biol Chem 2000, 275, 20667.

[23] J. C. Marxen, W. Becker, Comp Biochem Physiol B Biochem Mol Biol 2000, 127, 235.

[24] B. T. Livingston, C. E. Killian, F. Wilt, A. Cameron, M. J. Landrum, O. Ermolaeva, V. Sapojnikov, D. R. Maglott, A. M. Buchanan, C. A. Ettensohn, Developmental Biology 2006, 300, 335.

[25] O. Berteau, B. Mulloy, Glycobiology 2003, 13, 29 R.

[26] S. Weiner, W. Traub, Febs Letters 1980, 111, 311.

[27] S. Weiner, Y. Talmon, W. Traub, International Journal of Biological Macromolecules 1983, 5, 325.

[28] Y. Levi-Kalisman, G. Falini, L. Addadi, S. Weiner, Journal of Structural Biology 2001, $135,8$.

[29] S. Weiner, W. Traub, Philosophical Transactions of the Royal Society of London, Series B: Biological Sciences 1984, 304, 425.

[30] F. Nudelman, H. H. Chen, H. A. Goldberg, S. Weiner, L. Addadi, Faraday Discuss 2007, 136, 9.

[31] L. Ameye, G. De Becker, C. Killian, F. Wilt, R. Kemps, S. Kuypers, P. Dubois, Journal of Structural Biology 2001, 134, 56.

[32] H. Miyamoto, T. Miyashita, M. Okushima, S. Nakano, T. Morita, A. Matsushiro, Proceedings of the National Academy of Sciences of the United States of America 1996, 93, 9657.

[33] S. Weiner, L. Addadi, Journal of Materials Chemistry 1997, 7, 689.

[34] A. Berman, L. Addadi, S. Weiner, Nature 1988, 331, 546.

[35] A. P. Wheeler, J. W. George, C. A. Evans, Science 1981, 212, 1397.

[36] D. A. Rees, E. J. Welsh, Angewandte Chemie-International Edition 1977, 16, 214.

[37] H. Thiele, A. Awad, J Biomed Mater Res 1969, 3, 431. 
[38] L. Addadi, J. Moradian, E. Shay, N. G. Maroudas, S. Weiner, Proc Natl Acad Sci U S A 1987, 84, 2732.

[39] M. A. Crenshaw, H. Ristedt, The histochemical localization of reactive groups in septal nacre from Nautilus pompilius. In: The Mechanisms of Mineralization in the Invertebrates and Plants., University of South Carolina Press, Colombia, 1976.

[40] F. Nudelman, B. A. Gotliv, L. Addadi, S. Weiner, J Struct Biol 2006, 153, 176.

[41] J. L. Arias, M. S. Fernandez, Chemical Reviews 2008, 108, 4475.

[42] L. E. King, M. Morrison, Analytical Biochemistry 1976, 71, 223.

[43] M. A. Robinson-Lora, R. A. Brennan, Bioresource Technology 2009, 100, 5063.

[44] J. L. Arias, A. Neira-Carrillo, J. I. Arias, C. Escobar, M. Bodero, M. David, M. S. Fernandez, Journal of Materials Chemistry 2004, 14, 2154.

[45] S. Kinoshita, H. Saiga, Experimental Cell Research 1979, 123, 229.

[46] F. C. Meldrum, International Materials Reviews 2003, 48, 187.

[47] J. Anstrom, J. Chin, D. Leaf, A. Parks, R. Raff, Development 1987, 101, 255.

[48] A. P. Wheeler, K. W. Rusenko, D. M. Swift, C. S. Sikes, Marine Biology 1988, 98, 71.

[49] D. Hay, S. Schluckebier, E. Moreno, Calcified Tissue International 1986, 39, 151.

[50] L. Adaddi, S. Weiner, Angew. Chem. Int. Ed. Engl. 1992, 31, 153.

[51] M. M. Reddy, G. H. Nancollas, Desalination 1973, 12, 61.

[52] S. Albeck, L. Addadi, S. Weiner, Connective Tissue Research 1996, 35, 365.

[53] Fred H. Wilt, Christopher E. Killian, Brian T. Livingston, Differentiation 2003, 71, 237. 


\section{CHAPTER 7 : CONCLUSIONS}

In this thesis we have investigated the in vitro structure-function relationships of an acidic OM extracted from within the spines of the sea urchin Evechinus chloroticus. The motivation was to map the structure-function relationships in vitro, focussing on the PTMs, and translate the principles learnt into strategies towards programmable crystal growth. We were also interested in assessing the functional relevance of PTM so as to put in context the functional analyses completed on cloned proteins which do not bare the in vivo PTMs.

Using a series of analytical methods we have shown that the SMP ensemble is heavily post-translationally modified including glycosylation, sulfation, and phosphorylation. To better understand how these modifications are structurally incorporated into the ensemble and the various functions they fulfill we manipulated the SMP ensemble in a variety of ways. These manipulations included fractionation and selective digestion of the ensemble. A deeper understanding of the roles fulfilled by PTM was achieved by testing the ability of the various SMP fractions to affect calcium carbonate growth in vitro. This was in terms of the ability to initiate crystal growth and affect crystal shape. A summary of the results obtained is outlined.

From the MSA of SMP we demonstrated that glycosylation accounts for $54.0 \pm 5.3$ $w t \%$ of the ensemble. From the co-elution of both the protein and sugar and the observed masses of isolated glycans we have shown that this glycosylation is protein-bound. Following selective and complete liberation of the $\mathrm{N}$-glycans it was determined that O-glycosylation accounts for $80.0 \pm 2.2 \mathrm{wt} \%$ of the glycone.

From a linkage analysis of the isolated $\mathrm{N}$ - and O-glycones we have shown that the majority of the SMP glycone is charged. As sialic acid includes carboxylate functionality, and is reasonably abundant (7.6 \pm 3.4 ensemble wt\%), it will contribute to this property. However, analysis of the completely deglycosylated sample (SMPDeGly) revealed that the abundant sulfation is exclusively housed on the glycan framework. 
Using glycan profiling techniques we have shown that there are HexNAc structures within both the $\mathrm{N}$ - and $\mathrm{O}$-glycones. With the HexNAc monomers accounting for over $70 \mathrm{~mol} \%$ of the glycan monomers the potential dominance of this structural motif within the glycan framework was demonstrated. From a comparison of the Stains-All stained SDS-PAGE gels of desulfated SMP and deglycosylated SMP it appears that the HexNAc oligomers are able to bind calcium which is relevant in the context of controlling calcium carbonate growth.

The glycan structures are not limited, however, to HexNAc structures. This was demonstrated by the observation that galactose represents $14.4 \pm 1.1 \mathrm{~mol} \%$ of the SMP glycone. This observation raises the possibility that there are other significant glycan structures. The suggested structures include either mucin-like or keratan sulfate which have HexNAc-galactose dimers; or galactose homopolymers. These sulfated O-glycan structures are suggested as they are consistent with the MSA results. These assignments were supported by the observation of anomalous SDSPAGE migration, as was observed for the fractionated samples.

Fractionation of SMP showed that the species which have the ability to affect crystal morphology in vitro were within the SMP10-30kDa fraction. Following the removal of the glycans we demonstrated that the glycans participate in, but are not necessary to realise this morphological function. From the preparation of a sample stripped of all PTMs we have shown that some of the phosphate moieties are involved in the SMP morphological machinery. The activity of the phosphate was, however, relatively minor. We have therefore shown that assessing the morphological function of a cloned protein in the absence of PTM may be valid. In conjunction with the genomic analysis of Strongylocentrotus purpuratus by Wilt et al. ${ }^{[1]}$ we suspect that the calcium-binding phosphoproteins are the morphologically active species.

It was determined that the heaviest macromolecules (SMP>30kDa) have the functional capacity to induce nucleation. The observation of many macromolecules which have the ability to induce nucleation supports the mesocrystal mechanism 
of spine formation. The ability to induce nucleation was lost, however, following the removal of the SMP glycans. In order to determine the glycan structural features which participate in the nucleating function we completed a variety of chemical digestions to remove the glycan based acidic groups. From this analysis we have shown that the sialic acid and sulfate groups are involved in the nucleating function. As we demonstrated a positive correlation between the extent of sulfation and the ability to nucleate this may be via an ionotropic effect. As we observed sulfates in the non-nucleating fractions we can conclude that the presence of sulfates does not imply the ability to nucleate. The isolated acidic glycans themselves are unable to effect nucleation as use of these oligomers as an additive did not increase in the number of crystals grown over a blank experiment. Therefore, either the spatial arrangement of the glycans is important, or the protein is directly involved. We have shown that the protein and acidic glycans are individually insufficient but jointly sufficient to promote nucleation.

It appears that there may be two general mechanisms of encoding the abundant acidic moieties into a biomineral associated OM. This can either be via the protein backbone, included as aspartic and/or glutamic acid; or through modification of the glycan framework with sulfate and/or sialic acid functionality. In the former case the protein may exhibit very little PTM, and in the later case the protein is relatively neutral. Albeck et al. ${ }^{[2]}$ showed that the OM occluded within the calcitic prisms of Atrina rigida is protein based ( $1 \pm 1$ sugar residues/100 amino acids) and acidic $(74.7 \mathrm{~mol} \% \mathrm{Asx}+\mathrm{Glx})$. In contrast Marie et al. $^{[3]}$ showed that the OM extracted from the aragonitic layer of the Unio pictorum included highly acidic glycans attached to relatively neutral proteins ( 24 mol\% Asx + Glx). This result of relatively neutral proteins modified with acid glycans is aligned with what we observe for SMP $(24 \pm 0.5 \mathrm{~mol} \% \mathrm{Asx}+\mathrm{Glx})$. These results demonstrate that the organisation of acidic functionality within the OMs is not limited to either molluscs or sea urchin, nor is it exclusive to either aragonite or calcite. Albeck et al. ${ }^{[2]}$ showed that the OM extracted from the spines of Paracentrotus lividus adopts a heavily glycosylated/low protein acidity strategy. As these results are consistent 
with ours we may have shown that this OM organisation may be the prevalent strategy adopted by sea urchins.

Despite the different chemical strategies to incorporate the acidic functionality into the $\mathrm{OM}$ we have shown that the protein portions produce crystal morphologies which are indistinguishable. This was demonstrated by comparison of crystals grown in the presence of SMP removed of all post-translational modification and the proteins extracted from the aragonitic layer of Haliotis iris.

From SDS-PAGE analysis it appears that SM30 is within the spines of Evechinus chloroticus. This is interesting as this species has also been shown to be prevalent in other sea urchin species including Lytechinus pictus, Lytechinus variegatus, and Strongylocentrotus purpuratus. ${ }^{[4]}$ From our analysis of the PTMs within SMP we have shown for the first time that O-glycosylation accounts for the $\sim 13 \mathrm{kDa}$ discrepancy between the mass of the protein and the migratory mass on SDSPAGE. ${ }^{[5]}$ As we suspect that $\mathrm{SM} 30$ is within the SMP>30kDa fraction it may therefore be involved in the nucleating function associated with this fraction.

Using 2D SDS-PAGE we have shown that both the sulfates and phosphates affect the pl of SMP macromolecules.

\subsection{FUTURE DIRECTIONS}

The method adopted to complete the glycan profile experiment was developed for neutral glycans. At the time that we completed the experiments we were unaware that the majority of the SMP glycone is charged. The structures that comprise the complete glycone therefore remain elusive. The mucin-like/keratan sulfate/carrageenan structural assignment was therefore based on indirect analyses, such as MSA. There have been methods developed to directly determine the structure of charged glycans. For example, using Hakamori permethylation to derivatise the glycans for MS analysis allows for the collection of charged structural information. Alternatively, the glycans could be desulfated prior to using the method adopted in this thesis. It would be interesting to determine the 
detailed structure of the HexNAc glycans. As we observed for the fractionated samples and the liberated glycans there was a conserved two to one relationship of GlcNAc to GalNAc which may have functional implications.

Using the in vitro crystallisation assay we enumerated the number of crystals grown and related this to the ability of the organic additive to promote nucleation. We would have liked to support this connection using alternative experimental methods. For example, the in vitro assay developed by Wheeler et al. ${ }^{[6]}$ which measures the rate of crystal precipitation.

Another experimental method we would have liked to employ in the characterisation of the SMP ensemble is the carbonic anhydrase assay. ${ }^{[7]}$ Marie et al. ${ }^{[8]}$ used this assay to demonstrate carbonic anhydrase activity within the soluble matrix extracted from the shell of Unio pictorum. It would have been interesting to observe whether this functionality is; within the SMP ensemble, primarily located within either the morphologically-active or nucleating fractions, and whether the efficacy involves PTM support.

Analysis of the protein structures within SMP could reveal useful information. As there is extensive PTM of the SMP macromolecules there are experimental complications associated with methods developed for MS analysis of proteins. For example, the PTMs inhibit protease access to the protein backbone. In addition, structural assignment is complicated due to the variety of chemical moieties, removing the possibility of current software interpretation. Having generated methods to successfully remove all of the PTMs the protein component should be available for thorough analysis.

We have shown that the chemical architecture which leads to nucleation is relatively complicated. Translating the general information obtained into strategies for programmable growth is beyond the knowledge acquired in this work. We did observe that there are HexNAc glycans which appear to be able to bind calcium. It would be interesting to pursue work which focuses on the use of fixed HexNAc oligomers and its sulfated equivalent. Other glycans which may be 
present within the SMP glycone include mucin-like and/or keratan sulfate structures. As these species are able to modulate flux of relevant ions, incorporating this type of chemical functionality could improve control over crystal growth in vitro. 


\subsection{References}

[1] B. T. Livingston, C. E. Killian, F. Wilt, A. Cameron, M. J. Landrum, O. Ermolaeva, V. Sapojnikov, D. R. Maglott, A. M. Buchanan, C. A. Ettensohn, Developmental Biology 2006, 300, 335.

[2] S. Albeck, S. Weiner, L. Addadi, Chemistry--A European Journal 1996, 2, 278.

[3] B. Marie, G. Luquet, J. P. P. De Barros, N. Guichard, S. Morel, G. Alcaraz, L. Bollache, F. Marin, Febs Journal 2007, 274, 2933.

[4] Martin F. Brown, Jacqueline S. Partin, Christopher E. Killian, William J. Lennarz, Development Growth \& Differentiation 1995, 37, 69.

[5] C. E. Killian, F. H. Wilt, J. Biol. Chem. 1996, 271, 9150.

[6] A. P. Wheeler, J. W. George, C. A. Evans, Science 1981, 212, 1397.

[7] T. H. Maren, Physiol. Rev. 1967, 47, 595.

[8] B. Marie, G. Luquet, L. Bedouet, C. Milet, N. Guichard, D. Medakovic, F. Marin, Chembiochem 2008, 9, 2515. 
